\author{
Universidade de São Paulo \\ Instituto de Física
}

\title{
Estudo e Caracterização Física de Cerâmicas Indígenas Brasileiras
}

\author{
Jessica Fleury Curado
}

Orientador: Prof. Dr. Nemitala Added

Tese de doutorado apresentada ao Instituto de Física para a obtenção

do título de Doutor em Ciências

\section{Comissão Examinadora}

Prof. Dr. Nemitala Added (IF-USP)

Profa. Dra. Elisabeth Mateus Yoshimura (IF-USP)

Prof. Dr. Nilberto Heder Medina(IF-USP)

Prof. Dr. Carlos Roberto Appoloni (UEL)

Profa. Dra. Fabíola Andrea Silva (MAE-USP) 
"Ix é xa purauk $\mathrm{h}$ rundí acaiú pucuçáua rupí ahé $\mathrm{r}$ c ... ...Cuhíre umbáua ãna; ix c r rí, mahar c xa meh quáu In çupé, quahá "livro" upé, "instrumento" omungaturú arãma raíra itá ian r tãma çuíuára, ocenõi arãma aitá Tupána, iuíre murak çupé."

"Eu trabalhei durante quatro anos nele... ...Agora já acabou; eu estou alegre, porque eu posso dar a ti, neste livro, um instrumento para defender os filhos de nossa terra, para chamá-los para Deus e o trabalho". 
Dedicado à minha família, fonte de todo o meu conhecimento para a vida 


\section{Agradecimentos}

Ao Professor Nemitala Added, por sua orientação neste trabalho e em todos os outros, desde a iniciação científica. Agradeço imensamente por seus ensinamentos, por sua dedicação, paciência e por sempre acreditar e confiar em meu trabalho.

À Professora Márcia de Almeida Rizzutto pela grande amizade, confiança e conselhos que contribuíram para o meu crescimento profissional e pessoal.

Ao professor Manfredo Harry Tabacniks pela amizade, pelas discussões sobre física e pelos conhecimentos transmitidos.

Aos arqueólogos Professora Fabíola Andrea Silva e Eduardo Bespalez por me mostrarem a beleza da arqueologia, pelas informações e pela grande confiança.

Ao Professor José Luis Ruvalcaba-Sil por me aceitar em seu laboratório, por sua confiança em meu trabalho e por me deixar fascinada pelo estudo de objetos do patrimônio cultural arqueológico.

Às pessoas que me ajudaram nos laboratórios e nas diversas fases do trabalho: à Karim López Guzmán e Francisco Jaimes Beristain pelo apoio durante as medidas no Laboratório Peletron da UNAM; à Marcel Dupret Lopes Barbosa e Marcos Rodrigues Antônio pelo apoio nos períodos de experimento no Laboratório LAMFI da USP; à Martha Aldred pelo auxílio nos experimentos no Laboratório de Dosimetria da USP.

Aos meus pais, José Carlos e Maria, e aos meus irmãos, Paulo e Rebeca, que sempre me apoiaram e incentivaram, principalmente nos momentos "nervosos" durante a tese. Seus conselhos foram indispensáveis para a conquista de meus objetivos.

Às grandes amigas Adriana e Suene pelas horas de conversa, pela ajuda e apoio em todas as horas.

Aos meus grandes amigos "los chicos del cubo" Ulises, Kilian e Éder, pela grande amizade e por fazerem eu me sentir em casa, mesmo a quilômetros de meus país.

A todos os amigos e colegas que de alguma forma colaboraram para a realização deste trabalho.

À CAPES pelo suporte técnico e financeiro. 


\section{Resumo}

O presente trabalho tem por objetivo caracterizar e identificar a natureza de recursos cerâmicos brasileiros utilizando métodos físicos não destrutivos. O estudo está inserido na área interdisciplinar da Arqueometria e envolve a participação de pesquisadores do Museu de Arqueologia e Etnografia da Universidade de São Paulo (MAE-USP). As amostras analisadas são de grande interesse arqueológico, pois foram coletadas em uma região do Pantanal sul-matogrossense que possui um complexo processo de ocupação envolvendo diversas tradições culturais, entre as quais a tradição Guarani e a tradição Pantanal. Os fragmentos cerâmicos foram caracterizados através das técnicas de Emissão de Raios X Induzido por Partícula (PIXE) e Fluorescência de Raios X (XRF) para a determinação da composição da matriz da pasta cerâmica e através da técnica de Radiografia Computadorizada para a investigação da estrutura interna das peças. A técnica PIXE permitiu uma caracterização dos elementos majoritários encontrados na matriz cerâmica $(Z<26)$, usados na previsão do valor da densidade da matriz. A técnica XRF foi utilizada para determinar as concentrações elementares com destaque para os elementos minoritários $(Z>26$, wt\% $<5 \%)$ presentes na pasta cerâmica. Essas técnicas, quando associadas a métodos de análise estatísticos permitiram um melhor entendimento do conjunto de amostras. Os resultados encontrados apontam uma clara diferença na composição elementar das amostras encontradas nos diferentes sítios arqueológicos e pertencentes às diferentes tradições. Com a aplicação da técnica de Radiografia as amostras foram separadas de acordo com a presença de tempero em sua estrutura e através da análise das imagens radiográficas foi determinada a densidade dos fragmentos. Neste trabalho foi possível estabelecer uma relação entre os fragmentos cerâmicos estudados às suas tradições, assim como aos sítios arqueológicos nos quais foram coletados. 


\begin{abstract}
The present work aims to characterize and identify the nature of Brazilian ceramics using non-destructive physical methods. The study is inserted in the interdisciplinary area of the Archaeometry and involves the participation of researchers from the Museum of Archaeology and Ethnography of the University of São Paulo (MAE-USP). The analyzed samples are of great archaeological interest, as they have been collected in a region of Pantanal in the state of Mato Grosso do sul with a complex settlement process that involves different cultural traditions like the Guarani tradition and the tradition Pantanal. The ceramic fragments were characterized through the techniques of X-ray Emission Particle-Induced (PIXE) and X-Ray Fluorescence (XRF) to determine the composition of the matrix of the ceramic paste and using the technique of Computed Radiography for the investigation of internal structure of the sherds. PIXE technique allowed a characterization of majoritarian elements found in ceramic matrix $(Z<26)$ and was used in the prediction of the density of the paste. XRF technique was used to determine the elemental concentration with emphasis on the minority elements $(Z>26$, wt $\%<5 \%$ ) presents in ceramic paste. These techniques, when associated with statistical methods of analysis allow a better understanding of the sample set. The results show a clear difference in the elemental composition of the samples found in different archaeological sites and from different cultural traditions. By applying the technique of X-ray samples were separated according to the presence of temper in its structure and through images was obtained the density of fragments. In this work it was possible to establish a link between the studied ceramic fragments to their traditions, as well as the archaeological sites in which they were collected.
\end{abstract}




\section{Índice}

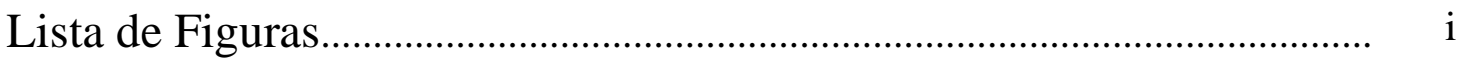

Lista de Tabelas..................................................................................... xi

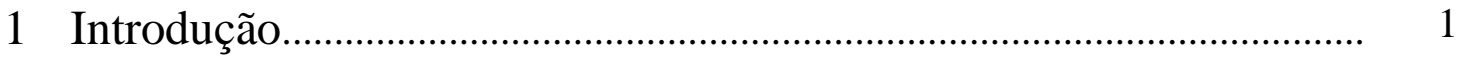

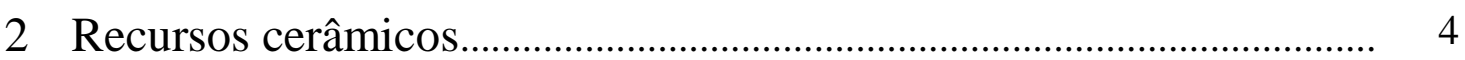

2.1 Produção de cerâmica................................................................................... 5

2.2 Tradição Pantanal...................................................................................... 7

2.3 Tradição Guarani................................................................................. 8

2.4 Estudos arqueométricos dos recursos cerâmicos....................................... 8

3 Território Indígena Aldeia Lalima............................................................ 10

3.1 Trajetória da ocupação regional........................................................... 12

3.2 Pesquisas arqueológicas na Aldeia Lalima............................................. 13

3.3 Sítio Córrego Lalima/Sede (MS-MI-01)_................................................. 16

3.4 Sítio Asa do Pote (MS-MI-06).............................................................. 17

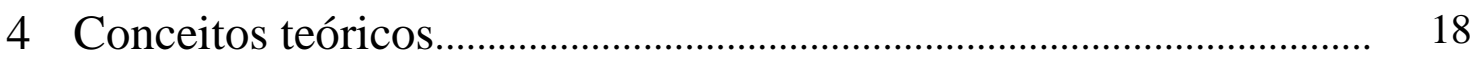

$4.1 \quad$ Natureza dos raios X.................................................................. 18

4.2 Produção e emissão de raios X.................................................................. 19

$4.3 \quad$ Propriedades dos raios X.................................................................. 22

4.4 Emissão de raios X induzida por partícula (PIXE)................................... 24

4.5 Fluorescência de raios X (XRF)........................................................... 27

4.6 Técnica de radiografia...................................................................... 28 


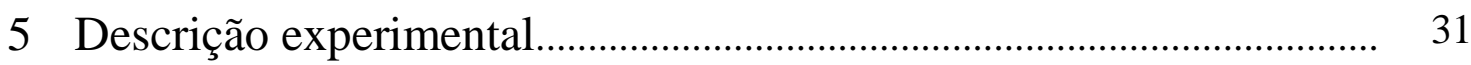

5.1 Amostras analisadas........................................................................ 31

5.2 Laboratório LAMFI............................................................................. 32

5.3 Laboratório de Dosimetria......................................................................... 35

5.4 Laboratório de Caracterização de Bens Culturais (LABENS).................. 37

$5.5 \quad$ Laboratório Peletron (UNAM) ................................................................. 38

6 Análise estatística multivariada.................................................................... 40

6.1 Análise de Componentes Principais......................................................... 41

6.2 Análise de Agrupamentos....................................................................... 45

7 Resultados e Análise de dados experimentais....................................... 50

7.1 Emissão de raios X induzida por partícula (PIXE)................................. 50

$7.2 \quad$ Fluorescência de raios X (XRF)................................................................ 67

7.3 Técnica de radiografia.......................................................................... 102

8 Considerações finais............................................................................. 140

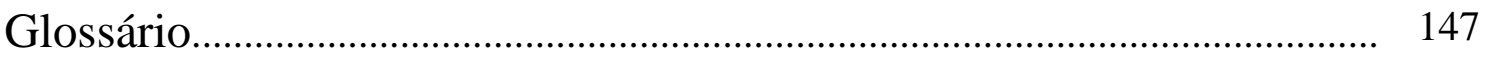

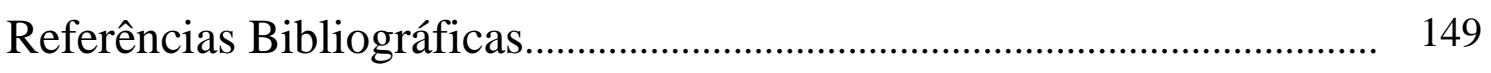

Catálogo de peças...................................................................................... 152 


\section{Lista de Figuras}

Figura $1 \quad$ Mapa de localização do território indígena Lalima. 10

Figura 2 Mapa de localização dos sítios arqueológicos encontrados no 15 território indígena Lalima.

Figura 3 Exemplo de distribuição do espectro de raios X contínuo, em função 19 da tensão, da corrente e do material do ânodo do tubo de raios $X$.

Figura 4 Espectro de emissão de raios X característicos em função da energia 20 (a) e do comprimento de onda (b) dos fótons. Fonte: Apostila Laboratório FNC 315 IFUSP

Figura 5 Diagrama de níveis de energia de raios $X$ apresentando as principais 21 séries e transições permitidas.

Figura 6 Linha de feixe externo dedicada a estudos de arqueometria no 34 laboratório LAMFI-USP. (Foto J.F.Curado)

Figura 7 Tubo de raios $X$ Philips $M G 450$ presente no Laboratório de 36 Dosimetria-IFUSP utilizado neste estudo. (Foto Lab. Dosimetria)

Figura $8 \quad$ Montagem do equipamento semiportátil de XRF pertencente ao 37 laboratório LABENS-PoliUSP. (Foto A.C.Neiva)

Figura 9 Detalhe da linha de pesquisa de feixe externo no Laboratório 38 Peletron - UNAM. (Foto: Peletron-UNAM)

Figura 10 Sistema portátil de XRF (SANDRA) pertencente ao laboratório 39 Peletron-UNAM. (Foto: J.F.Curado)

Figura 11 Exemplo de curva Scree plot, utilizada na análise de componentes 43 principais. Este gráfico de exemplo corresponde à análise feita por XRF nos fragmentos apresentados neste estudo.

Figura 12 Exemplo de Círculo de correlação utilizado na análise de 44 componentes principais. Este gráfico de exemplo corresponde à análise feita por XRF nos fragmentos apresentados neste estudo.

Figura 13 Exemplo de dendrograma obtido através da análise de 49 agrupamentos. (Fonte: software STATISTIC). Na figura podemos observar cortes (linhas vermelhas) que indicam a formação de subgrupos de acordo com a distância de dissimilaridade. 
Figura 14 Arranjo experimental utilizado no primeiro experimento PIXE 51 (LAMFI). Na imagem estão indicados: 1.Saída do feixe; 2.Folha de $A u ; 3$.Detector voltado à folha de Au; 4. Detector voltado à amostra. A peça apresentada é de origem etnográfica proveniente da aldeia Lalima.

Figura 15 Espectro de raios X típico obtido para a amostra de cerâmica 52 Etnográfica através da técnica PIXE obtidos no laboratório LAMFIIFUSP ( $1^{\circ}$ experimento).

Figura 16 Resultados obtidos para a concentração elementar dos fragmentos analisados Como exemplos são apresentados dois elementos majoritários (Si e $\mathrm{Fe}$ ) e dois elementos minoritários (Zn e S). As incertezas correspondem a valores entre $1 \%$ e $5 \%$ para os elementos majoritários e entre $10 \%$ e $20 \%$ para os elementos minoritários e traços. As incertezas foram calculadas através da propagação de erros.

Figura 17 Gráficos de Concentração elementar versus Amostras para os 55 elementos Si, Fe, K e Ca. As incertezas para os elementos (majoritários) variam entre 5 e $10 \%$ e foram calculadas através de propagação de erros.

Figura 18 Gráficos de Concentração elementar versus Amostras para os 56 elementos Al, Ti e Mn. As incertezas para os elementos (majoritários) variam entre 5 e $10 \%$ e foram calculadas através de propagação de erros.

Figura 19 Dendrograma obtido para o conjunto de 34 amostras estudadas 57 através da técnica PIXE no Laboratório LAMFI (2ºxperimento). Como parâmetros para a realização dos cálculos foram utilizados todos os elementos. Os fragmentos pertencentes à cultura Guarani estão destacados em cor verde e os fragmentos pertencentes à cultura Pantanal estão em cor preta.

Figura 20 Espectros típicos obtidos pela técnica PIXE para o fragmento 59 cerâmico MI1-1906, obtidos no laboratório Peletron-UNAM. A. Espectro obtido pelo detector Si-Pin dedicado aos elementos com $\mathrm{Z} \preceq 6$; B. Espectro obtido pelo detector LEGe dedicado aos elementos com $\mathrm{Z} \geq 26$. 
Figura 21 Gráficos de Área normalizada versus Amostras para os elementos Si 60 e Fe. A diferenciação em cores corresponde aos sítios arqueológicos. As incertezas para os elementos Si e Fe variam entre $1 \%$ e $2 \%$ dos valores.

Figura 22 Gráficos de Área normalizada versus Amostras para os elementos Zn e Pb. A diferenciação em cores corresponde aos sítios arqueológicos. As incertezas para os elementos $\mathrm{Zn}$ e $\mathrm{Pb}$ variam entre $5 \%$ e $10 \%$ dos valores.

Figura 23 Gráficos de Área normalizada versus Amostras para os elementos Si e Pb. A diferenciação em cores corresponde às tradições às quais os fragmentos pertencem. As incertezas para o elemento Si corresponde à $2 \%$ dos valores e as incertezas para o elemento Pb correspondem à $10 \%$ dos valores.

Figura 24 Gráficos de área normalizada obtidos através da técnica PIXE no 63 laboratório Peletron-UNAM. A diferenciação em cores corresponde aos sítios arqueológicos. A. Gráfico "Al versus Pb”; B. Gráfico "Si versus Fe".

Figura 25 Gráficos de área normalizada obtidos através da técnica PIXE no 64 laboratório Peletron-UNAM. A diferenciação em cores corresponde às tradições. A. Gráfico "Al versus Pb"; B. Gráfico "Zn versus $K$ ”.

Figura 26 Dendrograma obtido para conjunto de 32 fragmentos cerâmicos analisados com a técnica PIXE no Laboratório Peletron-UNAM. A linha vermelha indica uma distância de dissimilaridade de valor 100. A separação é obtida quando analisado com relação aos sítios arqueológicos indicados em cores, a cor vermelha representa o sítio Sede/Córrego Lalima e a cor preta representa o Sítio Asa do Pote.

Figura 27 Análise PCA obtida para conjunto de 32 fragmentos cerâmicos analisados com a técnica PIXE no Laboratório Peletron-UNAM. A separação é obtida quando analisado com relação aos sítios arqueológicos, estando estes indicados em cores, a cor vermelha representa o sítio Sede/Córrego Lalima (MI1) e a cor azul representa o sítio Asa do Pote. 
Figura 28 Espectro típico obtido pela técnica XRF para o fragmento cerâmico MI1-1906 no laboratório Peletron-UNAM com a utilização do sistema SANDRA.O pico de Molibdênio é proveniente do tudo de raios $X$.

Figura 29 Gráficos de Concentração elementar versus Amostras para os elementos Al e Mn. Os itens em cor cinza pertencem ao Sítio Sede (MI1) e os em cor vermelha pertencem ao Sítio Asa do Pote (MI6). As incertezas correspondem a $30 \%$ do valor do Al e a $10 \%$ do valor do $M n$.

Figura 30 Gráficos de Concentração elementar versus Amostras para os 70 elementos Zn e Zr. Os itens em cor cinza pertencem ao Sítio Sede (MI1) e os em cor vermelha pertencem ao Sítio Asa do Pote (MI6). As incertezas correspondem a $20 \%$ do valor do $\mathrm{Zn}$ e a $13 \%$ do valor do $\mathrm{Zr}$.

Figura 31 Gráficos de Concentração elementar versus Amostras para os elementos $\mathrm{Zn}$ e Zr. Os itens em cor verde correspondem aos fragmentos Guarani e os em cor cinza aos fragmentos Pantanal. As incertezas correspondem a $30 \%$ do valor do Al e a $10 \%$ do valor do $M n$.

Figura 32 Gráficos de Concentração elementar versus Amostras para os 71 elementos $\mathrm{Zn}$ e Zr. Os itens em cor verde correspondem aos fragmentos Guarani e os em cor cinza aos fragmentos Pantanal. As incertezas correspondem a $20 \%$ do valor do Zn e a $13 \%$ do valor do $Z r$.

Figura 33 Espectro típico obtido pela técnica XRF para o fragmento cerâmico 73 MI1-1906 no Instituto de Física da USP.

Figura 34 Gráfico de Desvio relativo versus Amostras para os elementos K, Ca, 76 $\mathrm{Ti}, \mathrm{Cr}, \mathrm{Mn}$. As incertezas correspondem a cerca de $40 \%$ do valor para o Ca e variam entre $15 \%$ e $25 \%$ para os demais elementos.

Figura 35 Gráfico de Desvio relativo versus Amostras para os elementos Fe, 77 $\mathrm{Ni}, \mathrm{Cu}, \mathrm{Zn}$ e $\mathrm{Pb}$. As incertezas correspondem a cerca de $10 \%$ do valor para o $\mathrm{Fe}$, cerca de $40 \%$ para o Cu e variam entre $15 \%$ e $25 \%$ para os demais elementos. 
Figura 36 Gráfico de Desvio relativo versus Amostras para os elementos $\mathrm{Br}, 78$ $\mathrm{Rb}, \mathrm{Sr}, \mathrm{Y}$ e Zr. As incertezas correspondem a cerca de $60 \%$ do valor para o Y e variam entre $15 \%$ e $25 \%$ para os demais elementos.

Figura 37 Gráficos dos Desvios relativos dos elementos $\mathrm{Zr}$ versus Fe obtidos 80 pela técnica XRF para o conjunto de 112 fragmentos cerâmicos. A. Apresenta o conjunto total; $B$. Apresenta detalhe em região onde não há uma separação entre os grupos.

Figura 38 Dendrograma obtido utilizando os 15 elementos determinados através da técnica XRF As linhas em vermelho indicam diferentes níveis de dissimilaridade entre os elementos presentes na pasta cerâmica.

Figura 39 Dendrograma obtido utilizando como parâmetro todos os elementos determinados através da técnica XRF. Os fragmentos são apresentados através de cores de acordo com sua classificação. As linhas vermelhas indicam diferentes níveis de dissimilaridade nos quais há formação de subgrupos.

Figura 40 Dendrograma obtido utilizando como parâmetro todos os elementos determinados através da técnica XRF. Os fragmentos pertencentes ao sítio Asa do pote estão destacados em cor vermelha e os pertencentes ao sítio Sede/Córrego Lalima estão em cor preta.

Figura 41 Dendrograma obtido utilizando como parâmetro os elementos $K, C a, 84$ Ti, $\mathrm{Cr}, \mathrm{Ni}, \mathrm{Zn}, \mathrm{Rb}$, Sr e Zr determinados através da técnica XRF. Os fragmentos pertencentes ao sítio Asa do pote estão destacados em cor vermelha e os pertencentes ao sítio Sede/Córrego Lalima estão em cor preta.

Figura 42 Dendrograma obtido utilizando como parâmetros todos os elementos determinados através da técnica XRF. Os fragmentos apresentados em cor verde pertencem à tradição Guarani e os apresentados em cor preta pertencem à tradição Pantanal.

Figura 43 Dendrograma obtido utilizando como parâmetros os elementos Ti, 86 $\mathrm{Cr}, \mathrm{Zn}, \mathrm{Rb}, \mathrm{Sr}$ e $\mathrm{Zr}$ determinados através da técnica XRF. Os fragmentos apresentados em cor verde pertencem à tradição Guarani e os apresentados em cor preta pertencem à tradição Pantanal. 
Figura 44 Dendrograma obtido utilizando como parâmetros os elementos $C r, \quad 86$ $R b$, Sr e Zr determinados através da técnica XRF. Os fragmentos apresentados em cor verde pertencem à tradição Guarani e os apresentados em cor preta pertencem à tradição Pantanal.

Figura 45 Dendrograma obtido utilizando todos os elementos determinados através da técnica XRF. Os fragmentos apresentados em cor verde pertencem à tradição Guarani e os apresentados em cor preta pertencem à tradição Pantanal.

Figura 46 Dendrograma obtido utilizando os elementos $\mathrm{Fe}, \mathrm{Rb}, \mathrm{Sr}$ e $\mathrm{Zr} 88$ determinados através da técnica XRF. Os fragmentos apresentados em cor verde pertencem à tradição Guarani e os apresentados em cor preta pertencem à tradição Pantanal.

Figura 47 Dendrograma obtido utilizando todos os elementos determinados 89 através da técnica XRF. Os fragmentos apresentados em cor verde pertencem à tradição Guarani e os apresentados em cor preta pertencem à tradição Pantanal.

Figura 48 Dendrograma obtido utilizando os elementos $\mathrm{Fe}, \mathrm{Mn}, \mathrm{Sr}$ e Cr 90 determinados através da técnica XRF. Os fragmentos apresentados em cor verde pertencem à tradição Guarani e os apresentados em cor preta pertencem à tradição Pantanal.

Figura 49 Gráfico onde são apresentadas as porcentagens relativas aos fatores 91 utilizados na análise de PCA para os dados obtidos através da análise XRF.

Figura 50 Figura obtida através da análise PCA aplicada aos elementos 92 encontrados pela técnica XRF.

Figura 51 Figura obtida através da análise PCA aplicada aos dados obtidos por XRF em 112 fragmentos e utilizando como variáveis todos os elementos determinados. As peças estão indicadas de acordo com sua classificação.

Figura 52 Figura obtida através da análise PCA aplicada aos dados obtidos 94 por XRF em 112 fragmentos e utilizando como variáveis todos os elementos determinados. Os fragmentos indicados em cor vermelha pertencem ao sítio Asa do Pote e os fragmentos indicados em cor azul pertencem aio sítio Sede/Córrego Lalima. 
Figura 53 Figura obtida através da análise PCA aplicada aos dados obtidos por XRF em 112 fragmentos e utilizando como variáveis os elementos $\mathrm{K}, \mathrm{Ti}, \mathrm{Cr}, \mathrm{Zn}, \mathrm{Rb}$, Sr e Zr. Os fragmentos indicados em cor vermelha pertencem ao sítio Asa do Pote e os fragmentos indicados em cor azul pertencem aio sítio Sede/Córrego Lalima.

Figura 54 Figura obtida através da análise PCA aplicada aos dados obtidos por XRF em 112 fragmentos e utilizando como variáveis todos os elementos determinados. Os fragmentos indicados em cor verde pertencem à tradição Guarani e os indicados em cor preta pertencem à tradição Pantanal.

Figura 55 Figura obtida através da análise PCA aplicada aos dados obtidos 97 por XRF em 112 fragmentos e utilizando como variáveis os elementos $\mathrm{K}, \mathrm{Ti}, \mathrm{Zn}, \mathrm{Pb}, \mathrm{Rb}$, Sr e Zr. Os fragmentos indicados em cor verde pertencem à tradição Guarani e os indicados em cor preta pertencem à tradição Pantanal.

Figura 56 Figura obtida através da análise PCA aplicada aos dados obtidos por XRF em 88 fragmentos encontrados no sítio Sede/Córrego Lalima e utilizando como variáveis todos os elementos determinados. Os fragmentos indicados em cor verde pertencem à tradição Guarani e os indicados em cor preta pertencem à tradição Pantanal.

Figura 57 Figura obtida através da análise PCA aplicada aos dados obtidos por XRF em 88 fragmentos encontrados no sítio Sede/Córrego Lalima e utilizando como variáveis os elementos $\mathrm{Fe}, \mathrm{Pb}, \mathrm{Sr}$ e $\mathrm{Zr}$. Os fragmentos indicados em cor verde pertencem à tradição Guarani e os indicados em cor preta pertencem à tradição Pantanal.

Figura 58 Figura obtida através da análise PCA aplicada aos dados obtidos 100 por XRF em 24 fragmentos encontrados no sítio Asa do Pote e utilizando como variáveis todos os elementos determinados. Os fragmentos indicados em cor verde pertencem à tradição Guarani e os indicados em cor preta pertencem à tradição Pantanal. 
Figura 59 Figura obtida através da análise PCA aplicada aos dados obtidos por XRF em 24 fragmentos encontrados no sítio Asa do Pote e utilizando como variáveis os elementos $\mathrm{Fe}, \mathrm{Mn}, \mathrm{Sr}$ e Cr. Os fragmentos indicados em cor verde pertencem à tradição Guarani e os indicados em cor preta pertencem à tradição Pantanal.

Figura 60 Imagem de fragmentos cerâmicos obtida através de radiografia 103 convencional e posteriormente digitalizada. As condições de irradiação são dadas por $50 \mathrm{kV}$ de tensão aplicada, corrente de 15 mA e um tempo de exposição de 5 minutos.

Figura 61 Imagem obtida através de radiografia computadorizada para o 105 estudo de fragmentos cerâmicos. Chapa 1. Na imagem está indicado o padrão de Alumínio (Al) utilizado neste estudo.

Figura 62 Gráficos obtidos utilizando o programa ImageTool em imagem de 106 padrão de Al obtida através de radiografia computadorizada Chapa 1. A. Imagem radiográfica do padrão d Al; B. Gráfico do perfil do tom de cinza do padrão de Al; C. Gráfico de área em função da contagem obtida para cada espessura do padrão de Al.

Figura 63 Gráfico de espessura versus tom de cinza obtidos da imagem do 107 padrão de Al para as seis chapas radiográficas adquiridas.

Figura 64 Imagem para o padrão de Al obtida nas diferentes chapas, antes e 107 depois da normalização.

Figura 65 Gráficos obtidos utilizando o programa ImageTool nas imagens de 108 fragmentos cerâmicos obtida através de radiografia computadorizada. A. Fragmento MI1-1038 (Pantanal/com tempero); B. Fragmento MI1-990 (Pantanal/pouco tempero); C. Fragmento MI6-154 (Guarani/sem tempero).

Figura 66 Exemplo de classificação de peças de acordo com a presença de 110 tempero. A. Fragmento MI6-167, não possui tempero; B. Fragmento MI1-1012 possui pouco tempero; C. Fragmento MI1-1038 possui tempero.

Figura 67 Gráfico relacionando posição do pico, desvio e a presença de 110 tempero para as imagens obtidas através de radiografia computadorizada. 
Figura 68 Gráfico relacionando centróide do pico com a espessura média de cada fragmento e a presença de tempero para s imagens obtidas através de radiografia computadorizada.

Figura 69 Gráfico centróide versus espessura de cada fragmento e materiais com densidades conhecidas (Alumínio, Massa de modelar e Teflon). Estão indicados os valores obtidos para a densidade dos fragmentos através do método de Arquimedes.

Figura 70 Gráfico comparativo entre as densidades para os fragmentos 121 cerâmicos, obtidas pela técnica PIXE e pelo método de Arquimedes.

Figura 71 Espectro de emissão de tubo de raios $X$ Phillips para uma tensão 122 aplicada de 73 kV. Fonte: R.A.Terini, 1999 [33].

Figura 72 Imagem radiográfica obtida para materiais conhecidos com 123 espessuras vareáveis entre $0,2 \mathrm{~cm}$ e $1,0 \mathrm{~cm}$. Na imagem são apresentados os materiais Alumínio, Massa de modelar, Teflon e Polytec.

Figura 73 Gráfico relacionando centróide do pico (tom de cinza) com a 123 espessura de cada segmento de diferentes materiais radiografados: Alumínio, Massa de modelar, Teflon e Polytec.

Figura 74 Gráfico $(\mu / \rho)$ versus $Z$ para uma energia de 30keV.Dados fornecidos 126 pelo NIST.

Figura 75 Representação esquemática da variação da intensidade do feixe de 128 raio $X$ ao interagir com os materiais (amostra e filme radiográfico).

Figura 76 Gráfico taxa de transmissão versus espessura para diferentes 130 materiais para nas energias de radiação $30 \mathrm{keV}$ e $50 \mathrm{keV}$.

Figura 77 Gráfico de taxa de transmissão versus tom de cinza para diferentes materiais em uma energia de radiação de $30 \mathrm{keV}$.

Figura 78 Gráfico de Taxa de transmissão versus Tom de cinza para o elemento 132 alumínio em uma energia de radiação de $30 \mathrm{keV}$.

Figura 79 Gráfico comparativo entre as densidades para os fragmentos 136 cerâmicos, obtidas pelo método de Arquimedes e pela técnica de radiografia.

Figura 80 Imagens radiográficas de fragmentos pertencentes à tradição 137 Pantanal, com espessuras semelhantes e temperos diferentes. A.MI1959; B. MI1-985. 
Figura 81 Gráfico comparativo entre as densidades para os fragmentos 138 cerâmicos, obtidas pelas técnicas PIXE e de radiografia.

Figura 82 Gráfico de densidade versus amostra. As amostras indicadas pela 139 cor vermelha pertencem ao sítio Sede/Córrego Lalima (MI1) e as indicadas pela cor preta pertencem ao sítio Asa do Pote (MI6).

Figura 83 Gráfico de densidade versus amostra. As amostras indicadas pela 139 cor verde pertencem à tradição Guarani e as indicadas pela cor preta pertencem à tradição Pantanal. 


\section{Lista de Tabelas}

Tabela 1 Sítios arqueológicos encontrados no território indígena Lalima e as correspondentes tradições tecnológicas observadas.

Tabela 2 Valores aplicados ao tubo de raios-X na técnica de radiografia.

Tabela 3 Amostras analisadas. As peças MII são arqueológicas provenientes do Sítio Sede da Aldeia Lalima.

Tabela 4 Amostras de cerâmicas brasileiras arqueológicas analisadas no 54 segundo experimento utilizando a técnica PIXE no laboratório LAMFI.

Tabela 5 Amostras de cerâmicas brasileiras arqueológicas analisadas utilizando a técnica PIXE no laboratório Peletron/UNAM.

Tabela 6 Amostras de cerâmicas brasileiras arqueológicas analisadas utilizando a técnica XRF.

Tabela $7 \quad$ Valores médios de área relativa para os elementos encontrados nas quatro combinações de sítio e tradição cultural.

Tabela $8 \quad$ Valores de concentrações elementares normalizados obtidos para o fragmento MI1-162.

Tabela 9 Valores das médias de concentrações elementares normalizados através de transformação obtidos para as quatro combinações de sítio e tradição cultural.

Tabela 10 Valores de densidade obtidos para objetos padrões de composições conhecidas.

Tabela 11 Valores de densidade e outras características obtidas para os fragmentos cerâmicos estudados. A incerteza da espessura é dada por 0,05cm, a incerteza da massa é dada por 0,1g e a incerteza da densidade foi determinada através de cálculos de propagação.

Tabela 12 Valores de densidade e outras características obtidas para os fragmentos cerâmicos estudados. A incerteza da espessura é dada por 0,05cm, a incerteza da massa é dada por 0,1g e a incerteza da densidade foi determinada através de cálculos de propagação.

Tabela 13 Principais compostos presentes na composição do solo e nos fragmentos cerâmicos estudados.

Tabela 14 Cálculos realizados para cálculo de massa molar normalizada. 
Tabela 15 Valores de densidade determinados utilizando a técnica PIXE.

Tabela 16 Valores de densidade obtidos utilizando a técnica PIXE e o método de Arquimedes.

Tabela 17 Valores de coeficiente de absorção de massa ( $\mu / \rho)$ a uma energia de $30 \mathrm{keV}$.

Tabela 18 Valores calculados para $Z_{\text {eff }}$ e $(\mu / \rho)(30 \mathrm{keV})$ de diferentes materiais.

Tabela 19 Comparação entre os valores obtidos para $(\mu / \rho)$ a uma energia de $30 \mathrm{keV}$.

Tabela 20 Valores de taxa de transmissão de raios-X para diferentes materiais e espessuras para uma energia de $50 \mathrm{keV}$.

Tabela 21 Valores de taxa de transmissão de raios-X para diferentes materiais e espessuras para uma energia de $30 \mathrm{keV}$.

Tabela 22 Valores de taxa de transmissão obtidos para os fragmentos 133 cerâmicos em uma energia de $30 \mathrm{keV}$.

Tabela 23 Valores de Densidade obtidos para os fragmentos cerâmicos 134 utilizando a técnica de radiografia.

Tabela 24 Tabela comparativa entre as densidades obtidas por diferentes 135 métodos. 


\section{Capítulo 1}

\section{Introdução}

Atualmente, a linha que separa a arte e os estudos científicos é tênue e permeável. Pesquisadores de diferentes áreas criam cada vez mais um espaço interdisciplinar, desenvolvendo uma linguagem e objetivos em comum para facilitar o entendimento da história e da evolução do ser humano. Longe do enfoque exclusivamente humanista, as técnicas de caracterização proporcionam uma avaliação do estado da obra e permitem um conhecimento mais profundo da mesma.

Arqueometria é o ramo de pesquisa interdisciplinar que emprega métodos científicos (técnicas de caracterização e análise) ao estudo do patrimônio cultural e arqueologia, permitindo obter informações sobre o desenvolvimento humano. A arqueometria propõe uma investigação experimental com maior enfoque na estrutura e na composição elementar do material proporcionando informações mais detalhadas sobre o processo de manufatura e sobre a origem do item [1].

Um dos temas importantes abordados pela arqueometria é o estudo de recursos cerâmicos. Por ser um dos materiais mais estáveis e abundantes, a cerâmica tornou-se uma das principais fontes de informações do contexto histórico e arqueológico de diferentes civilizações.

Estudos usando experimentos químicos e físicos tornam possível determinar diversas características de grande interesse tais como a composição do material empregado em sua fabricação, técnica de manufatura empregada e até mesmo a idade dos objetos estudados. 
Dentre os diferentes métodos físicos aplicáveis podemos citar as técnicas de Feixes Iônicos (Ion Beam Analysis - IBA ${ }^{[1]}$ ), que utilizam a interação dos materiais com feixes de íons acelerados e também as técnicas que utilizam a interação da radiação com a matéria.

Entre os aspectos diferenciadores é válido ressaltar que muitas dessas técnicas são multielementares, permitindo a identificação e quantificação de diversos elementos presentes na amostra através de uma única medida, sem provocar danos durante as medidas. Um aspecto de destaque é que essas técnicas são consideradas não destrutivas, podendo ser aplicadas sem a necessidade de realizar uma amostragem do objeto a ser estudado. Outro fator importante é a realização das análises em condições atmosféricas naturais sem a utilização de câmaras de vácuo que limitam o tamanho e as características da amostra analisada.

Essas técnicas fornecem informações através de diferentes fenômenos físicos que permitem obter importantes informações sobre os materiais tais como a composição elementar, a posição estratigráfica (presença de camadas) e a presença de estruturas internas. Entre as técnicas IBA pode-se destacar a técnica "Particle Induced X-Ray Emission" (PIXE) ${ }^{[2]}$ [2] e entre as técnicas que utilizam radiação podem ser citados o método "X-Ray Fluorescence" $(\mathrm{XRF})^{[3]}$ [3] e a técnica de imagem radiológica [4]. As técnicas aqui mencionadas são amplamente aplicadas em estudos na área de arqueometria e em objetos de bens culturais, proporcionando importantes pesquisas e resultados.

O presente trabalho tem por objetivo caracterizar e identificar a natureza de recursos cerâmicos arqueológicos brasileiros, provenientes de uma região do pantanal sulmatogrossense utilizando métodos físicos não destrutivos na tentativa de criar um banco de dados.

As amostras utilizadas neste estudo foram gentilmente cedidas pelo Museu de Arqueologia e Etnologia da USP sob a supervisão da Professora Fabíola Andrea Silva. As amostras consistem em fragmentos cerâmicos encontrados em dois sítios arqueológicos existentes na Aldeia Lalima, localizada próximo ao município de Miranda no estado do Mato Grosso do Sul. De acordo com informações arqueológicas, os fragmentos estudados correspondem à parte da parede de vasilhas de uso doméstico pertencentes a duas tradições indígenas distintas, tradição Guarani e tradição Pantanal. 
Através do estudo foi estabelecida uma base de dados contendo informações a respeito da composição elementar de materiais provenientes dos diferentes sítios arqueológicos e culturas indígenas. E ao mesmo tempo, foi possível obter informações sobre a tecnologia empregada na confecção dos bens culturais cerâmicos estudados.

Para a realização desse estudo foram aplicadas diferentes técnicas de caracterização tais como "Particle Induced X-Ray Emission" (PIXE) "X-Ray Fluorescence" (XRF), e a técnica Radiológica.

As técnicas PIXE e XRF permitem a determinação e a análise de elementos estudando as propriedades dos raios $\mathrm{X}$ característicos emitidos pelas amostras dentro das limitações dos métodos.

Com a utilização da técnica radiológica é possível determinar e quantificar os materiais adicionados na argila (tempero ${ }^{[4]}$ ), além de proporcionar uma melhor análise visual das peças.

Para a análise dos resultados obtidos pelas técnicas foram aplicados métodos estatísticos para verificar as similaridades entre os diferentes grupos de fragmentos.

Os Capítulos 2 e 3 são dedicados à descrição das características e generalidades a respeito dos recursos cerâmicos e aspectos gerais dos sítios arqueológicos nos quais foram encontrados os fragmentos e cerâmicas e suas tradições culturais.

Nos Capítulos 4 e 5 são apresentados, respectivamente, os princípios teóricos das técnicas experimentais utilizadas e o procedimento experimental. No Capítulo 6 são descritos os métodos de análise estatística aplicados no estudo dos fragmentos.

No Capítulo 7 são apresentados e discutidos os resultados obtidos através das técnicas experimentais e da análise estatística. E, por fim, no Capítulo 8 são apresentadas as conclusões e considerações finais. 


\section{Capítulo 2}

\section{Recursos cerâmicos}

A cerâmica é o primeiro material sintético criado pela sociedade humana e é de enorme importância desde a época pré-histórica, com a produção de utensílios de uso diário e cerimoniais, até a época moderna, onde a cerâmica é empregada na fabricação de objetos de decoração, no ramo industrial, na indústria aéreo-espacial e até mesmo em aplicações médicas.

O termo "cerâmica" tem origem Grega keramos, traduzido como "material queimado" ou "louça de barro", sendo relacionado com a arte ou processo de fazer artigos úteis ou ornamentais de argila, moldando-os e queimando-os a alta temperatura. A cerâmica é a combinação perfeita dos quatro elementos fundamentais considerados pelos gregos: terra, água, ar e fogo. É formada por terra, moldada com água, seca pelo ar e consolidada ao fogo.

A fabricação de cerâmica é uma técnica muito antiga, sendo que os primeiros indícios de sua produção são do período Paleolítico Superior (40000-10000 $\mathrm{AP}^{[5]}$ ) e sua utilização foi difundida rapidamente [5], sendo atualmente uma grande fonte de informações sobre diferentes culturas, épocas e civilizações.

A produção da cerâmica é realizada com a utilização de argilas como matériaprima. As argilas são silicatos de alumínio com diferentes graus de hidratação e quantidades de impurezas sendo sua fórmula básica $\mathrm{Al}_{2} \mathrm{O}_{3} 2 \mathrm{SiO}_{2} 2 \mathrm{H}_{2} \mathrm{O}$. São formadas por partículas finas com água intersticial tendo dessa maneira uma característica de plasticidade, ou seja, pode ser moldada através da aplicação de forças mecânicas. Com a retirada da água existente no material, através de um processo de secagem ou de queima, o produto resultante perde sua plasticidade, sendo conhecido como cerâmica, conservando a forma imposta ao objeto. [6] 


\subsection{Produção de cerâmica}

A argila está presente em grande parte da superfície terrestre. Suas fontes podem ser encontradas a céu aberto, em minas subterrâneas ou jazidas. Cada local de extração dessa matéria-prima possui características particulares que influenciam diretamente as propriedades e composições da cerâmica.

A técnica de produção do material cerâmico passa por diferentes processos, cujas escolhas podem interferir nas características resultantes do objeto final, sejam características estruturais, morfológicas ou composicionais.

Inicialmente é feita a escolha da argila. Quando retirada da natureza, geralmente contém diversas impurezas, orgânicas ou inorgânicas, e na grande maioria das vezes são necessários processos manuais para a sua homogeneização. Para cada categoria da produção cerâmica, a produção das massas argilosas, denominada pasta, pode necessitar de acréscimo ou retirada de elementos em sua composição, de acordo com sua aplicação. Nesse processo, podem ser adicionados elementos não-plásticos, denominados temperos, cuja adição modifica algumas propriedades da matéria durante e após o processo de queima.

Após a seleção e preparação da matéria-prima, a peça será confeccionada, utilizando-se de uma ou várias técnicas, de acordo com a tradição cultural ou com a funcionalidade do objeto produzido. É nesta etapa também onde se iniciam os tratamentos e acabamentos dados às superfícies dos objetos, nem sempre com a finalidade decorativa. Podem ser feitas aplicações plásticas, que modificam a superfície, e a aplicação de pinturas. Nessa fase, também é possível a aplicação de um "banho" empregando outra argila diluída, com textura ou coloração diferente.

A última fase de preparação dos objetos é a de queima do material e é considerada a mais delicada em todo o processo de manufatura. Com o controle da queima é possível atribuir diferentes atributos ao material fabricado, obtendo características desejáveis em termos de coloração, durabilidade ou estética. 
Através da escolha e da realização de cada um dos procedimentos na manufatura, cada peça poderá ter características exclusivas dependentes da tecnologia empregada.

A cerâmica é produzida tradicionalmente por muitos povos indígenas, principalmente os que habitam regiões de florestas. Cada povo tem uma técnica diferente para transformar o barro em peças utilitárias ou cerimoniais com uma diversidade de formas, texturas, cores e usos. Tradicionalmente, a produção da cerâmica, entre os povos indígenas que vivem no Brasil, é totalmente manual.

No Brasil, os índios representam uma parcela pequena, porém importante da população brasileira $(0,4 \%)$ [6] que precisa ser resguardada como um dos tesouros étnicos brasileiros. Devido à grande extensão do território brasileiro, existem diversas "nações indígenas" com costumes e culturas próprios. O povoamento irregular deste território fez com que diferentes regiões do país existam uma grande variedade de objetos cerâmicos com atributos e características composicionais específicas.

Sendo a segunda maior região do Brasil, a região centro oeste possui uma grande riqueza cultural e arqueológica. Nesta região se encontra a maior planície inundável do planeta, o Pantanal, considerado um dos últimos santuários ecológicos existentes. Devido às suas características naturais, a região pantaneira mostrou-se ideal para abrigar diversas comunidades indígenas durante séculos. Sua pré-história teve início com o estabelecimento de grupos de pescadores-caçadores-coletores, seguido pelo desenvolvimento do cultivo e pela ocupação de grupos ceramistas pertencentes a diferentes tradições culturais.

Entre estas tradições culturais ceramistas podemos citar a tradição Pantanal e a tradição Guarani. 


\subsection{Tradição Pantanal}

A tradição Pantanal é a tradição mais antiga identificada na região. Datações feitas por radiocarbono sugerem sua formação entre 3000 e 2000 AP [7]. Do ponto de vista tecnológico, essa tradição é caracterizada pela confecção de vasilhas de uso doméstico, utilizadas para servir e armazenar alimentos sólidos e líquidos. Tais vasilhas são de tamanho pequeno, cuja altura raramente ultrapassa $30 \mathrm{~cm}$ e em formato de meia esfera, sendo menos freqüente os formatos esféricos e com pescoço, os chamados jarros e moringas.

A manufatura é acordelada, ou seja, com a utilização de roletes de argila sobrepostos e o tempero é geralmente formado por cacos moídos, sendo rara a presença de cacos de conchas trituradas [8]. Outros objetos foram encontrados tais como cachimbos e rodas de fuso que indicam o uso de fumo e algodão, sugerindo a prática de técnicas de cultivo destes produtos.

Uma característica de destaque desta tradição, em relação a outras que ocorrem na América do Sul, é a variação existente nos tipos de decoração plástica, em especial na dos corrugados, que são pequenas marcas e ondulações na superfície do objeto, ainda que a maior parte dos cacos apresente uma decoração alisada. Na decoração, também está presente, em grande quantidade, a utilização de engobo ${ }^{[6]}$ vermelho.

Dentro deste contexto, a tradição Pantanal ainda pode ser subdividida em dois grupos, a fase Pantanal, cujas cerâmicas são associadas a aterros, e a fase Jacadigo.

Os estudos arqueológicos sugerem que na formação da Tradição Pantanal houve influência cultural das diferentes sociedades que habitavam a área juntamente com o estabelecimento de populações provenientes de outras regiões $[9,10]$. 


\subsection{Tradição Guarani}

A tradição ceramista Guarani está diretamente associada aos grupos linguísticos Guarani, originários na região amazônica. Diferentes objetos pertencentes a esta tradição foram encontrados em uma grande extensão do território brasileiro em uma faixa cronológica entre 2000 e 1000 AP.

Os materiais arqueológicos da tradição Guarani encontrados são formados principalmente por fragmentos de vasilhas cerâmicas, vestígios líticos ${ }^{[7]}$ e enterramentos em urnas funerárias.

A produção cerâmica desses grupos é caracterizada pela grande diversidade de técnicas de manufatura e aplicações. Os objetos podem ser de uso doméstico, cerimoniais (ex. urnas funerárias) ou ornamentais (ex. contas de colares).

Apesar das variações, as vasilhas cerâmicas apresentam características estilísticas típicas e peculiares. Dentre esses objetos, existem várias classificações com relações aos tamanhos, formas e função específica. Também são diversificadas as técnicas de manufatura e de decoração dos objetos. A produção das peças pode ser modelada, acordelada moldada ou torneada. A pasta, por sua vez, pode apresentar diferentes temperos e em diferentes graus. Os acabamentos superficiais podem apresentar pinturas ou decorações plásticas, em inúmeras expressões decorativas [11].

\subsection{Estudos arqueométricos dos recursos cerâmicos}

No estudo de sociedades culturais, o aparecimento de cerâmica pode ser utilizado como marcador cronológico para diferentes níveis de uma escavação arqueológica e a sua distribuição pode indicar uma rota de comércio, relações de amizades ou trocas entre diferentes localidades. Este recurso cerâmico também pode fornecer informações sobre a antiga tecnologia empregada e sobre o comportamento humano da época, informações que são de grande interesse para arqueólogos e historiadores. 
Em geral, a produção de cerâmica está associada a populações fixas, em especial às populações que realizam a atividade de agricultura [12,13]. No estudo de recursos cerâmicos é comum obter informações e interpretá-las através de investigações observacionais, a partir de características externas às peças, tais como forma, utilização (uso diário, ritualístico ou funerário), estilo decorativo entre outros.

A arqueometria propõe uma investigação experimental com maior enfoque na estrutura e na composição elementar do material proporcionando maiores informações sobre o processo de manufatura e sobre a origem do item. Através de experimentos químicos e físicos é possível determinar características de grande interesse tais como a presença de tempero, a idade e a temperatura de queima do objeto.

Um exemplo destes experimentos é a análise elementar da cerâmica que permite distinguir diferentes grupos e fontes de argila empregada na fabricação. Isto devido ao fato de que os produtos cerâmicos incorporam elementos ambientais característicos da sua região de origem, possuindo desta forma diferentes composições elementares. A determinação dos elementos da matriz e dos elementos traços fornece informações suficientes para caracterizar e determinar a origem da argila. Elementos traços são considerados os elementos que possuem concentração inferior a $1000 \mathrm{ppm}^{[8]}$ ou $0,1 \%$ da composição.

O estudo elementar também fornece informações sobre a tecnologia empregada na manufatura, pois cada tipo de argila reage de maneira diferente aos processos de fabricação, incluindo o processo de queima, podendo interferir na oxidação dos elementos presentes na composição da argila.

Outra estratégia para estudar a cerâmica é determinar o perfil em profundidade dos elementos presentes nas amostras. Com esse estudo, é possível determinar as diferenças entre o corpo cerâmico e a superfície, observando a presença de aditivos ou a difusão de determinados elementos na cerâmica.

Em um estudo de arqueometria, voltado a materiais cerâmicos, deve-se correlacionar diferentes técnicas onde seja permitido explorar a peça em diferentes pontos de vista, sejam observacionais, estruturais ou analíticos. Dessa forma, se faz necessária a combinação de técnicas que possibilitem analisar esses fatores independentemente. 


\section{Capítulo 3}

\section{Território Indígena Aldeia Lalima}

O território indígena Aldeia Lalima encontra-se no município de Miranda, no centro-oeste de Mato Grosso do Sul. É localizado entre o curso médio do rio Miranda e o córrego Barreiro, sendo cortado pelo córrego do Lima. O território da Aldeia possui pouco mais de 3.000ha e faz fronteira com as Fazendas Santa Rosa e Vargem Grande em uma área cedida pelo INCRA ${ }^{[9]}$ e está situado a $50 \mathrm{~km}$ do perímetro urbano de Miranda e sua localização é dada pela coordenada UTM 21K 0574403/7725693 ${ }^{[10]}$.

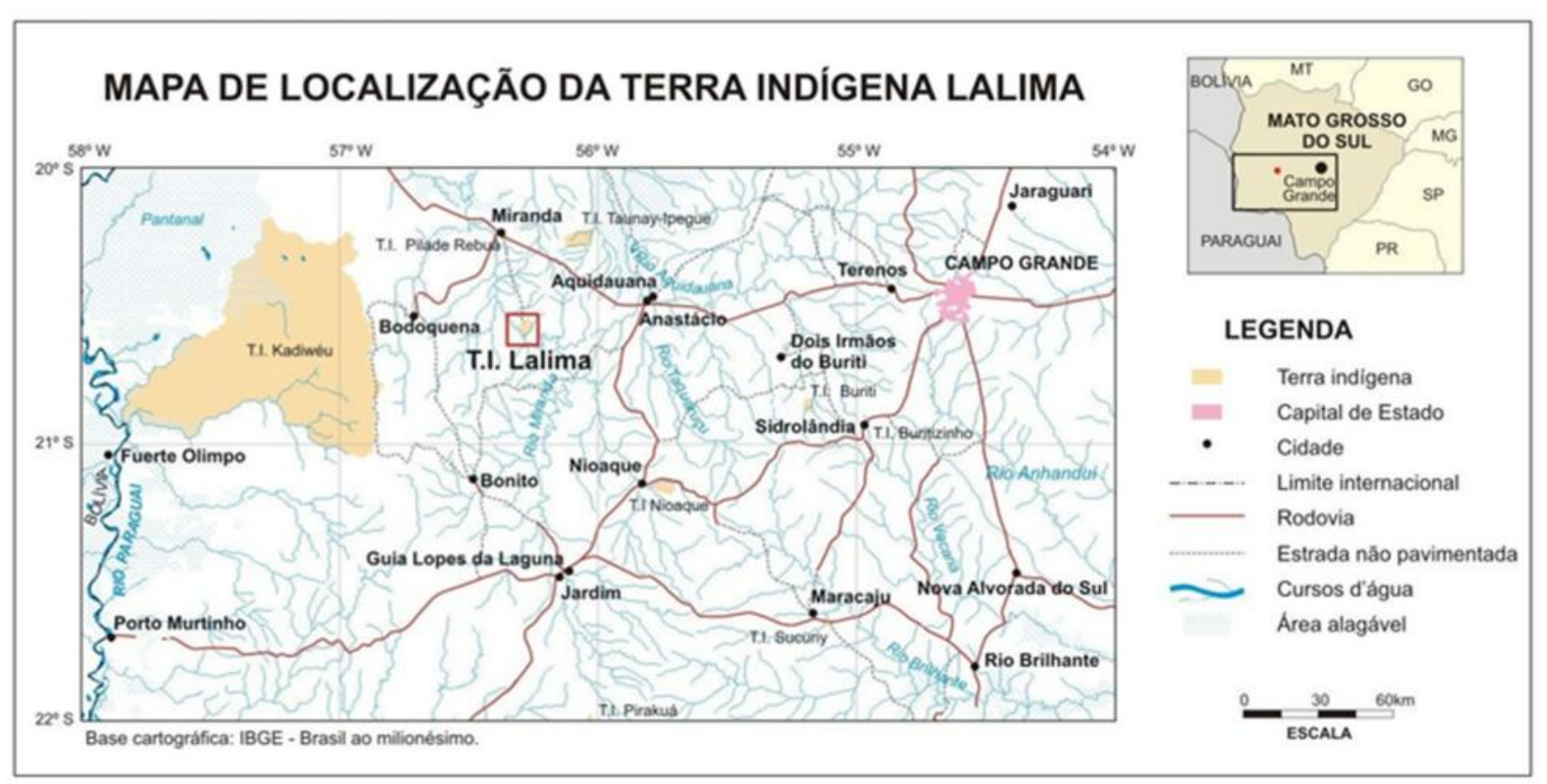

Figura 1. Mapa de localização do território indígena Lalima. 
O Posto Indígena Lalima foi fundado em 1907 pelo Serviço de Proteção aos Índios (SPI) e foi formado por diferentes grupos étnicos devido à política indigenista do início do século XX, que impunha o confinamento das populações indígenas em reservas. Descendentes étnicos Kinikinao, Laiana e Terena foram convocados a ocupar o território juntamente com os Guaikurú que habitavam a região desde o século XIX [14]. A aldeia é considerada território Terena, porque a maioria dos habitantes assim se identifica.

Com uma população de cerca de 1300 habitantes, o território possui seis núcleos populacionais, sendo o principal o núcleo Sede. Todas estas localidades estão conectadas por ruas, estradas e trilhas diversas. Em sua estrutura, a Aldeia possui duas escolas, dois postos de saúde, energia elétrica, água encanada e entre outras facilidades de caráter público. As casas são construídas principalmente com madeiras, bambu e sapé, embora também existam casas de madeira e alvenaria. São circundadas por roças e quintais utilizados para o cultivo de pomares e plantas medicinais, assim como para a criação de animais domésticos. As habitações formam pequenos núcleos que abrigam famílias aparentadas.

A principal ocupação dos habitantes é a chamada changa, um trabalho braçal assim como o boia fria, prestando serviços nas fazendas e nas usinas sucroalcooleiras da região. Alguns habitantes acabam assumindo os serviços para o funcionamento da comunidade e alguns poucos exercem trabalhos que exigem maior capacitação, tais como: enfermeiros ou professores. Muitas famílias vivem da agricultura, cuja produção é vendida no município de Miranda.

A organização política da comunidade é formada pelo chefe de posto, pelo cacique, pelo vice-cacique e pelo conselho tribal. O chefe de posto é um funcionário público, porém sua nomeação depende de sua aceitação por parte do cacique, do vice e do conselho. Em Lalima, o chefe de posto é originário da própria aldeia, sendo descendentes de índios Kinikinao e Terena. O cacique e o vice são eleitos pela comunidade, porém o conselho é escolhido pelos membros prestigiosos e anciões da aldeia, assim como pelo cacique e seu vice. 


\subsection{Trajetória da ocupação regional}

O contexto arqueológico e histórico da ocupação indígena regional da Aldeia Lalima sugere que a área da aldeia pode apresentar materiais arqueológicos relacionados com populações culturalmente diversas, que teriam se estabelecido na região ao longo dos séculos.

Apesar de algumas controvérsias, as pesquisas arqueológicas apontam que a ocupação indígena na região começou no final do período pleistocênico, cerca de 10000 AP, com o surgimento de grupos paleoíndios nas áreas de refúgios ecológicos em torno do Pantanal sul-mato-grossense, áreas propícias para populações caçadoras-coletoras. Porém, pesquisas arqueológicas indicam que o Pantanal se tornou totalmente ocupado a partir de 3000 anos atrás através do desenvolvimento de populações indígenas construtoras de aterros [15]. O aumento destes aterros e o surgimento da cerâmica, denominada Tradição Pantanal, datada entre 2.800 e 800 AP, são os principais correlatos destes processos [16].

Com as condições ambientais favoráveis, essa região atraiu diversas populações de diferentes regiões do país. Entre essas populações, encontraram-se pequenas aldeias de populações indígenas de tradição ceramista Guarani que cultivavam a terra e reproduziram na área seu típico padrão de assentamento e exploração de recursos. No estado do Mato Grosso do Sul, a ocupação Guarani foi datada entre 1300 e 300 AP [8].

O processo de colonização, tanto espanhol como português, trouxe a queda da cultura indígena na região de Miranda. Os colonizadores espanhóis, após esgotarem a mão de obra indígena na região de Assunção, no Paraguai, tentaram dominar a região de Mato Grosso do Sul com a fundação da cidade de Santiago de Xerez em 1593 [17]. Pelo lado português, aumentaram as missões jesuítas e a expansão bandeirante para obter a conquista do interior do país, transformando as populações indígenas em mão de obra escrava. 
Após o período de colonização e o abandono da região tanto pelos Guaranis como pelos espanhóis, a região de Miranda voltou a ser ocupada por populações indígenas tais como Mbayá e os Terenas. Porém, durante todo o século XVIII e grande parte do século XIX houve grandes disputas territoriais entre indígenas e colonizadores. Após vencer a resistência indígena, os portugueses se estabeleceram definitivamente na região de Miranda. As populações indígenas remanescentes formaram um grande contingente de mão-de-obra que foi explorada nas fazendas criadas na região. No início do século $\mathrm{XX}$, os descendentes étnicos em Miranda, formados principalmente por índios Terena, foram liberados do cativeiro nas colônias de fazenda e transferidos para reservas indígenas sob a responsabilidade do antigo $\mathrm{SPI}^{[11]}$.

\subsection{Pesquisas arqueológicas na Aldeia Lalima}

As pesquisas arqueológicas realizadas na região da Aldeia Lalima foram realizadas seguindo os procedimentos metodológicos de levantamento de superfícies e de coletas. $\mathrm{O}$ levantamento de superfície foi realizado com o objetivo de localizar e registrar os sítios arqueológicos relacionados com a história da ocupação indígena regional em Lalima [14]. Os pesquisadores responsáveis pela pesquisa na Aldeia Lalima são a Profa. Fabíola Andrea Silva e o pesquisador Eduardo Bespalez.

A localização dos sítios foi feita através da vistoria baseada nos dados bibliográficos existentes e nas informações orais fornecidas pelos atuais habitantes da comunidade. As coletas foram realizadas com o objetivo de se obter um conjunto de materiais e dados arqueológicos, tais como extensão, tipo e estado de conservação do sítio. As coletas foram realizadas em duas etapas, em superfície e em subsuperfície.

Em superfície, foram feitas coletas assistemáticas, ou seja, recolhendo e registrando os objetos sem a utilização de técnicas especiais em uma área previamente setorizada, e coletas sistemáticas juntamente com um taqueômetro ${ }^{[12]}$, em áreas também préselecionadas. As coletas em subsuperfície foram feitas de maneira sistemática com a escavação de furos de sondagem e de poços testes em áreas setorizadas. 
Durantes as pesquisas de campo no território foram encontrados 13 sítios arqueológicos e 7 ocorrências, todos contendo materiais cerâmicos e a céu aberto. Destes, 11 sítios e 4 ocorrências foram localizados no território indígena Lalima e os demais foram encontrados nas fazendas vizinhas.

Nos sítios arqueológicos existentes no território indígena foram encontrados fragmentos cerâmicos pertencentes a diferentes tradições: Guarani, Pantanal e Etnohistórico. Os sítios arqueológicos e as tradições existentes são apresentados na Figura 2 e na Tabela 1.

Tabela 1. Sítios arqueológicos encontrados no território indígena Lalima e as correspondentes tradições tecnológicas observadas.

\begin{tabular}{ccc}
\hline \hline Sítio Arqueológico & Sigla & Tradição tecnológica \\
\hline \hline Córrego Lalima / Sede & MS-MI-01 & Guarani e Pantanal \\
\hline José Rondon de Souza & MS-MI-02 & Pantanal \\
\hline Tapera do Limpão & MS-MI-03 & Pantanal \\
\hline Tapera do Gino & MS-MI-04 & Etno-histórico, Guarani e Pantanal \\
\hline Tapera da Mata do Urumbeva & MS-MI-05 & Etno-histórico \\
\hline Asa do Pote & MS-MI-06 & Guarani e Pantanal \\
\hline Campina & MS-MI-07 & Guarani \\
\hline Manuel de Souza Neto & MS-MI-08 & Pantanal \\
\hline Tapera do Pirizal & MS-MI-09 & Etno-histórico \\
\hline Sítio Potrero & MS-MI-10 & Pantanal \\
\hline Anita Vieira & MS-MI-11 & Guarani \\
\hline Hélio Correia & MS-MI-12 & Guarani \\
\hline Tapera do Agápto & MS-MI-13 & Etno-histórico \\
\hline \hline
\end{tabular}




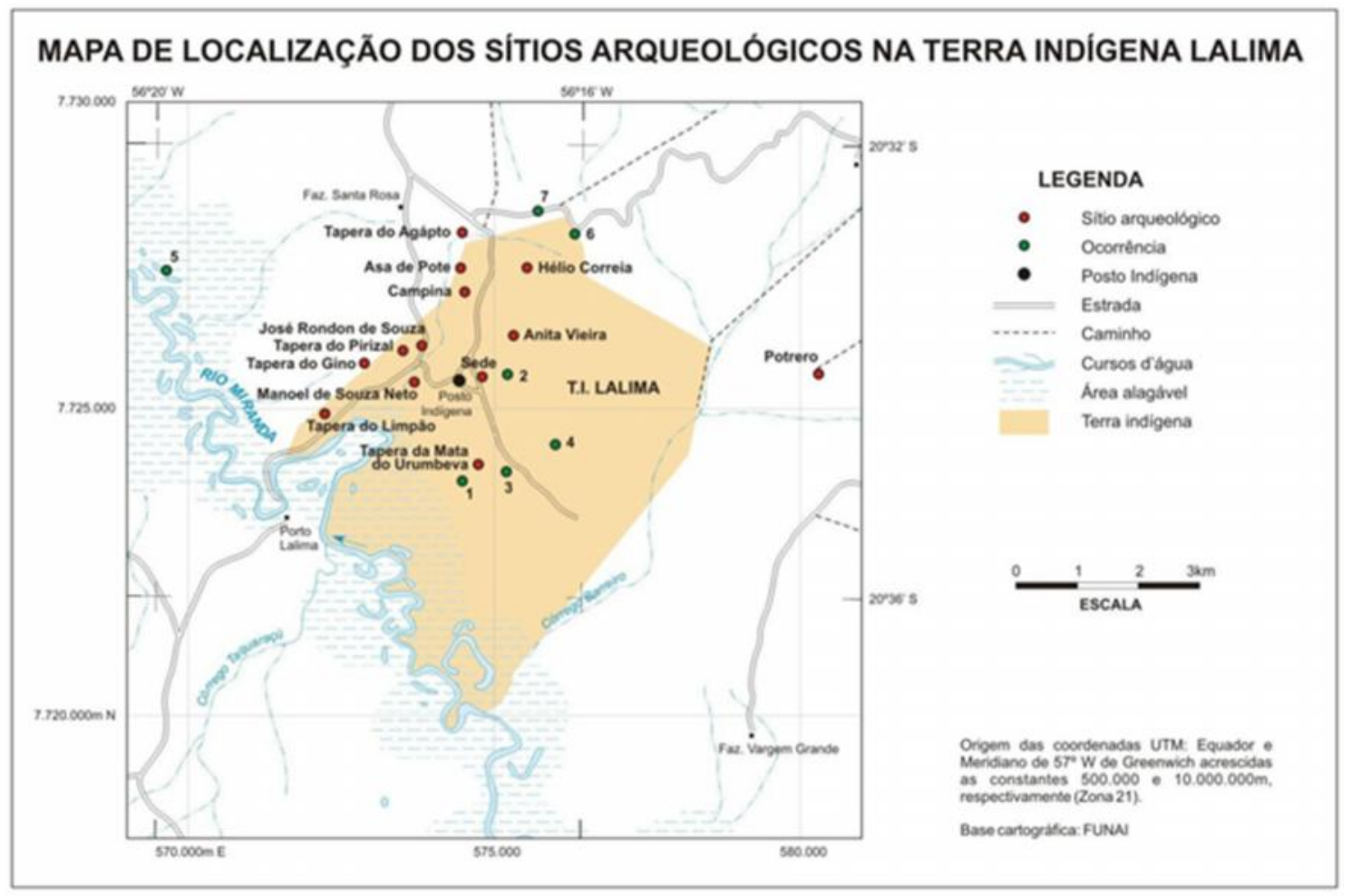

Figura 2. Mapa de localização dos sítios arqueológicos encontrados no território indígena Lalima.

No presente trabalho, foram estudados e analisados conjuntos de fragmentos cerâmicos encontrados nos sítios arqueológicos de Córrego Lalima / Sede (MS-MI-01) e Asa do Pote (MS-MI-06). A seguir encontra-se uma apresentação resumida destes sítios. 


\subsection{Sítio Córrego Lalima / Sede (MS-MI-01)}

O sítio Córrego Lalima se encontra em uma suave colina rodeada por nascentes e cursos flúvio-pluviais localizado próximo ao centro do território indígena. Nesta área também se localiza a sede da comunidade indígena atual.

O terreno do local encontra-se perturbado e remexido devido às diversas benfeitorias estruturais existentes tais como escolas, estradas e postos da FUNAI $^{[13]}$ e FUNASA $^{[14]}$. Estão presentes também as habitações indígenas e as diversas obras de manutenção tais como escavações, aterros, terraplanagens e práticas cotidianas, tais como: limpeza, criação de animais e agricultura. Em algumas áreas foram encontrados restos de materiais industrializados, tais como: metal, plástico, tecido e vidro, juntamente com o material arqueológico.

Para realizar as escavações, o sítio foi separado em quatro setores. Os setores 1 e 3 são constituídos basicamente por materiais de origem Guarani, e o setor 2 apresenta materiais de origem na tradição Pantanal e o setor 4 apresenta materiais das duas tradições.

Os materiais arqueológicos encontrados são principalmente fragmentos de vasilhas cerâmicas das tradições Guarani e Pantanal e encontram-se espalhados por toda a superfície do terreno, incluindo as áreas com construções tais como estradas, ao redor das casas, campo de futebol, nas roças e lixeiras. Nas escavações foram encontrados ao todo 2.461 objetos, onde 2.357 são fragmentos cerâmicos, 49 de origem líticas, 42 orgânicos, 11 louças e 2 amostras de carvão.

Entre os fragmentos cerâmicos encontram-se uma grande variedade de bordas, bases e, em maior quantidade, paredes de vasilhas. Os materiais foram analisados com relação à espessura dos fragmentos e, no caso das bordas, com relação ao diâmetro da vasilha. Com relação ao acabamento de superfície dos fragmentos, foram encontradas peças com tratamento cromático e, em sua maioria, peças com tratamentos plásticos, tais como corrugados, ungulados, polidos e outros. 


\subsection{Sítio Asa do Pote (MS-MI-06)}

O sítio Asa do Pote se encontra em uma encosta suave próximo a uma nascente fluvial que foi transformada em um açude. Localizado ao extremo norte do território indígena, próximo a entrada da aldeia, é o segundo local mais povoado de Lalima.

Parte da área está recoberta por mata e o restante apresenta domicílios, roçados, pastos, currais e estradas. Novamente o terreno do local se encontra perturbado devido às estruturas habitacionais.

Os materiais arqueológicos encontrados foram coletados de maneira sistemática, sendo encontrados 394 objetos arqueológicos, onde 365 correspondem a fragmentos de vasilhas cerâmicas, 14 de origem líticas, 2 orgânicos e 9 amostras de carvão. Para realizar as escavações, o sítio foi separado em dois setores. O setor 1 é constituído basicamente por materiais de origem Guarani, e o setor 2 apresenta materiais de origem na tradição Pantanal.

Assim como no sítio Córrego Lalima, no sítio Asa do Pote, os fragmentos cerâmicos apresentam uma grande variedade de bordas, bases e em maior quantidade, paredes de vasilhas. Os materiais foram analisados com relação à espessura dos fragmentos e no caso das bordas, com relação ao diâmetro da vasilha. Com relação ao acabamento de superfície dos fragmentos, foram encontradas peças com tratamento cromático e em maioria, peças com tratamentos plásticos, tais como corrugados, ungulados, polidos e outros. 


\section{Capítulo 4}

\section{Conceitos teóricos}

Nesse capitulo serão descritos os principais conceitos das técnicas experimentais utilizadas na caracterização dos fragmentos cerâmicos neste estudo. As técnicas utilizadas foram Emissão de Raios X induzidos por Partículas (PIXE - Particle Induced X-ray Emission), Fluorescência de Raios X (XRF - X-Ray Fluorescence) e a Técnica de Radiografia.

Inicialmente será apresentada uma introdução ao fenômeno de produção de raios $\mathrm{X}$ e sua interação com a matéria.

\subsection{Natureza dos Raios X}

Raios X, assim chamado por seu descobridor Wilhelm Röentgen devido a sua natureza até então desconhecida, são radiações eletromagnéticas com comprimento de onda entre 100 a $0,1 \AA$ e cuja energia varia entre $10^{3}$ e $10^{5}$ eV [18].

Os raios $\mathrm{X}$ propagam-se com a velocidade da luz e, por serem ondas eletromagnéticas, estão sujeitas à diversos fenômenos tais como refração, reflexão, difração, polarização e interferência. 


\subsection{Produção e emissão de Raios X}

Os raios $\mathrm{X}$ podem ser produzidos por bombardeamento dos materiais por partículas carregadas (elétron, próton, alfa), por bombardeamento de radiação (raios X e raios gama) ou por um tubo de raios $\mathrm{X}$.

Os raios X são produzidos um alvo (metálico) é bombardeado por elétrons, acelerados por uma grande diferença de potencial. Na produção de raios $\mathrm{X}$ estão envolvidos dois processos fundamentais [19].

O primeiro é chamado Bremsstralung ou radiação de fretamento, onde um fóton de raio $\mathrm{X}$ é criado pela desaceleração do elétron pelos átomos do alvo. $\mathrm{O}$ espectro do raio $\mathrm{X}$ de fretamento é contínuo, podendo assumir qualquer energia entre valores próximos a zero até o um valor máximo de energia. Essa energia máxima independe do material que constitui o alvo, dependendo somente da diferença de potencial na qual os elétrons são submetidos.

Em um tubo de raios $X$, o espectro contínuo depende da tensão e da corrente aplicadas ao tubo e do material que forma o ânodo. Quando a tensão do tubo aumenta, os comprimentos de onda mínimos diminuem e a intensidade dos raios $\mathrm{X}$ aumenta sendo proporcional à corrente aplicada ao tubo, como apresentado na Figura 3.

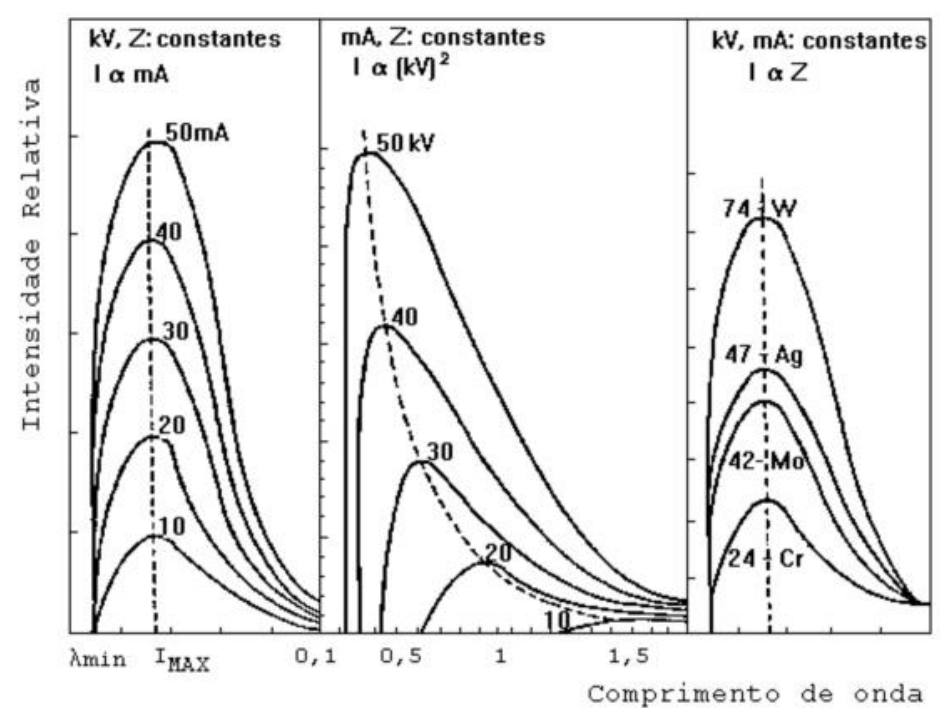

Figura 3. Exemplo de distribuição do espectro de raios $X$ contínuo, em função da tensão, da corrente e do material do ânodo do tubo de raios $X$. 
$\mathrm{O}$ segundo processo é a obtenção dos chamados raios $\mathrm{X}$ característicos. Ao interagir com a matéria, as partículas ou as emissões de onda podem produzir uma excitação nos átomos presentes no alvo e emitir raios $\mathrm{X}$ de energias específicas, as chamadas linhas características. O espectro de linhas características consiste em uma série de linhas discretas e específicas para cada elemento químico, como apresentado na Figura 4.
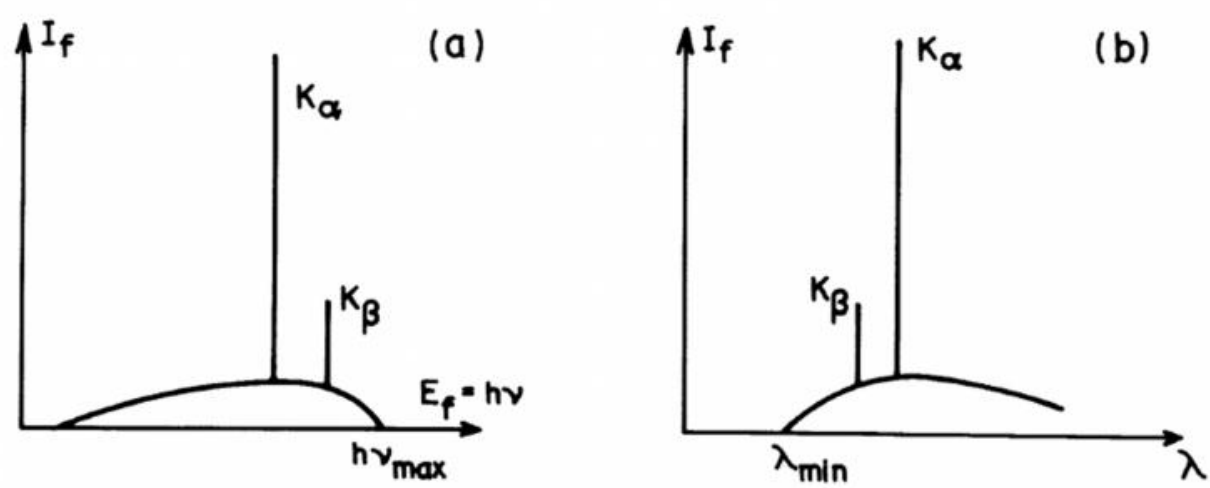

Figura 4. Espectro de emissão de raios $X$ característicos em função da energia (a) e do comprimento de onda (b) dos fótons. Fonte: Apostila Laboratório FNC 315 IFUSP

Ao bombardear uma amostra com um feixe (partículas ou raios $\mathrm{X}$ ) com energia suficientemente alta, as camadas eletrônicas mais internas $(\mathrm{K} \mathrm{e} \mathrm{L)} \mathrm{dos} \mathrm{átomos} \mathrm{da} \mathrm{amostra}$ poderão ser ionizadas. As vacâncias produzidas serão espontaneamente preenchidas por elétrons das camadas mais externas acompanhadas por uma emissão de raios $\mathrm{X}$ característicos do átomo. Transições ocorridas para a camada mais interna, a camada $\mathrm{K}$, são denominados raios $\mathrm{X}$ da série $\mathrm{K}$, transições para a camada $\mathrm{L}$ são os raios $\mathrm{X}$ da série $\mathrm{L} \mathrm{e}$ assim por diante. Cada linha em determinada série recebe um índice conforme a sua transição. Este índice é dado por letras gregas, desta forma a linha mais intensa da série K, é denominada $K_{\alpha}$, a segunda mais intensa é denominada $K_{\beta}$, assim por diante. Para as demais linhas e séries de acordo com a notação de Siegbahn [20]. 
A Figura 5 mostra um diagrama esquemático de níveis atômicos em que as principais séries e transições permitidas pela regra de seleção quântica são apresentadas.
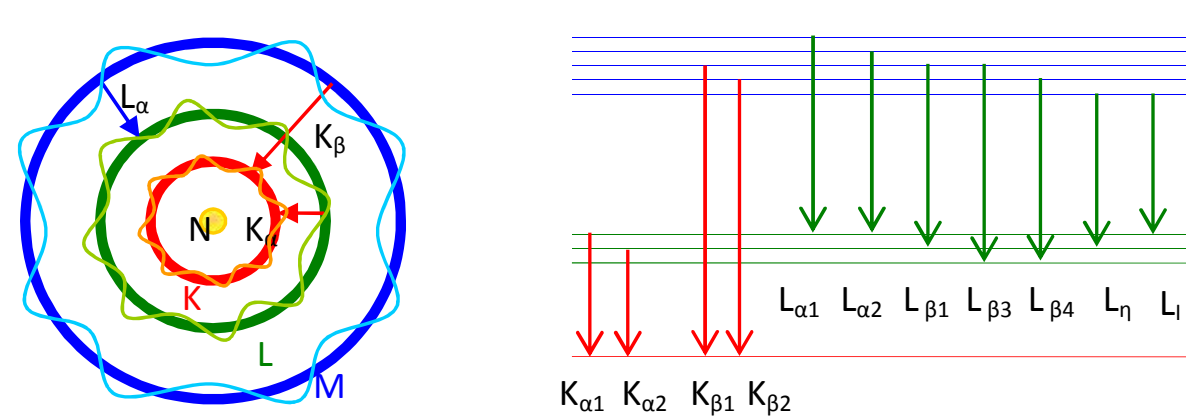

$\mathrm{M}$

$(3 s, 3 p, 3 d)$

$\mathrm{L}$

$(2 s, 2 p)$

Figura 5. Diagrama de níveis de energia de raios $X$ apresentando as principais séries $e$ transições permitidas.

Utilizando esse processo e por meio da análise em energia dos raios $\mathrm{X}$ característicos detectados é possível determinar os elementos presentes em uma amostra, pois cada energia é típica de determinada transição dos átomos de cada elemento. A energia dos picos leva à identificação dos elementos presentes na amostra (análise qualitativa), enquanto que a intensidade do pico permite determinar a concentração relativa ou absoluta (semiquantitativa ou análise quantitativa).

A análise elementar típica é realizada para os elementos da tabela periódica compreendidos entre o Alumínio e o Urânio com a obtenção de um único espectro. Os raios $\mathrm{X}$ dos elementos mais leves do que Alumínio não são usualmente observados devido a sua baixa energia, pois não atingem o detector devido à absorção na janela do detector ou no ambiente onde se encontra a amostra. Para a análise de elementos minoritários, como por exemplo, a análise de objetos cerâmicos, pode-se utilizar um filtro de atenuação de raios $\mathrm{X}$ nas energias dos elementos majoritários com $\mathrm{Z}$ mais baixo alcançando uma maior sensibilidade, pois estes filtros causarão uma atenuação nos elementos mais leves, mas permitirão a análise dos elementos acima da borda de absorção do filtro. 


\subsection{Propriedades dos Raios X}

Os raios $\mathrm{X}$, por serem ondas eletromagnéticas, estão sujeitos à diversos fenômenos e podem causar diversos efeitos. Entre os efeitos, podemos citar: o efeito fluorescente, que ocorre quando os raios X excitam algumas substâncias e fazem com que estas emitam luz; o efeito ionizante, causando movimento de elétrons (gases), dando como resultado partículas eletricamente carregadas e o efeito biológico, causando mudanças nas células dos tecidos dos seres vivos, podendo geram mutações, inflamações ou até mesmo a morte do tecido.

Por sua vez os raios $X$ também podem sofrer efeitos de atenuação e de absorção por um material. Esse efeito ocorre quando um feixe de raios $\mathrm{X}$ passa através da matéria transferindo parte ou toda sua energia por meio de inúmeras interações com os átomos do material.

O grau de atenuação do feixe depende da composição, da densidade e da espessura do material, além da energia da radiação. Esse processo obedece à lei exponencial [21,22] dada por:

$$
I_{x}=I_{0} e^{-\mu(E) x}
$$

onde $I_{0}$ é a intensidade do feixe de raios $\mathrm{X}$ incidente, $I_{x}$ é a intensidade a uma profundidade $x$ e $\mu$ é o coeficiente de atenuação linear. 
Porém, a definição mais usual é definida utilizando a densidade do material absorvedor, seguindo a equação:

$$
\mathrm{I}_{\mathrm{x}}=\mathrm{I}_{0} \mathrm{e}^{-(\mu / \rho) \rho \mathrm{x}}
$$

onde $(\mu / \rho)$ é o coeficiente de absorção de massa, $\rho$ é a densidade do material e x é a espessura do material.

A curva de absorção de massa pode apresentar variações de acordo com o comprimento de onda, possuindo descontinuidades abruptas chamadas de barreiras de absorção. Estas descontinuidades se produzem quando a energia dos fótons tem um valor suficiente para conseguir ionizar camadas adicionais dos átomos absorvedores. Em consequência, as chamadas bordas $\mathrm{K}, \mathrm{L}, \mathrm{M}$, etc. dos espectros de absorção correspondem às energias de ionização das respectivas camadas eletrônicas. Fótons com energia menor que a energia de ionização das diversas camadas podem eventualmente excitar átomos promovendo transições eletrônicas a níveis de energia superiores desocupados. 


\subsection{Emissão de Raios X induzida por Partícula (PIXE)}

O método de análise PIXE [20] é uma técnica elementar poderosa e não destrutiva utilizada para a análise de amostras de diversas áreas como biologia, geologia, arqueologia e no auxílio na conservação e restauração de obras de arte e bens do patrimônio histórico cultural. Sua aplicação ajuda na identificação e quantificação de elementos, podendo fornecer respostas a perguntas a respeito da procedência, da idade e da autenticidade da amostra.

A técnica PIXE permite a caracterização elementar do material, baseando-se no fenômeno de emissão do espectro de raios $\mathrm{X}$ característicos. A excitação dos elementos presentes no material é feita a partir do bombardeamento com feixe de partículas, tais como próton e partículas alfas.

$\mathrm{Na}$ análise PIXE de um filme fino, o número de raios $\mathrm{X}$ detectados $N_{i}$, para um determinado elemento, é determinado por:

$$
N_{i}=\frac{\Omega}{4 \pi} \varepsilon_{i} \frac{N_{0}}{A_{n}} \frac{Q}{q e \cos \alpha} \sigma_{i}\left(E_{0}\right) \rho_{n} l
$$

onde $Q$ é a carga total incidente, é o ângulo sólido subentendido pelo detector, $\sigma_{i}$ é a seção de choque de produção de raios $\mathrm{X}$ característicos para tal elemento, $\varepsilon_{i}$ é a eficiência do detector, $q$ é o estado de carga da partícula incidente, $e$ é a carga do elétron e $\rho_{n} l$ é a espessura da amostra. 
Esta equação pode ser reduzida:

$$
N_{i}=r_{i} Q\left(\rho_{n} l\right)
$$

onde $r_{i}$ é denominado fator de resposta do arranjo experimental dado por:

$$
r_{i}=\frac{\Omega}{4 \pi} \varepsilon_{i} \frac{N_{0}}{A_{n}} \frac{\sigma_{i}\left(E_{0}\right)}{q e \cos \alpha}
$$

Para realizar a análise de alvos grossos, é necessário utilizar um fator de correção que leva em conta a perda de energia dentro da matéria, determinado a partir dos fatores de rendimento de alvos finos. No nosso caso, este fator de correção foi determinado pelo do programa computacional CLARA [23].

Desta forma a concentração elementar de uma dada amostra é calculada por:

$$
\left(\rho_{n} l\right)=\frac{N_{i}}{r_{i} Q f}
$$

onde $N_{i}$ corresponde a área de cada elemento e $f$ é o fator de correção para alvos grossos calculando para as condições experimentais utilizadas e também levando em consideração a composição da amostra analisada.

Para a análise de alvos espessos também é possível determinar a concentração através da utilização de padrões referenciados. Esses padrões, que devem ter as características composicionais semelhantes, auxiliam na determinação do fator resposta do arranjo experimental. Essa análise também minimiza o efeito da carga incidente sobre as amostras. 
Uma análise qualitativa dos resultados pode ser feita normalizando os valores obtidos para a área de um elemento no espectro, formado pelo número de raios $\mathrm{X}$ detectados $N_{i}$, pela área total do espectro, procedimento que também minimiza o efeito da carga incidente sobre as amostras.

A técnica PIXE é extensamente aplicada em estudos e análise de objetos de arte e arqueologia por duas principais razões: inicialmente a técnica é reconhecida como não destrutiva, fato necessário em estudos de objetos de valor, onde é inviável a tomada de amostras dos objetos em questão bem como imprimir marcas referentes ao estudo. A segunda razão é a facilidade de utilizar a técnica em uma linha de feixe externo, ou seja, em medidas realizadas em ar ou em outra atmosfera controlada, permitindo a análise de objetos grandes ou frágeis, incompatíveis com um ambiente a vácuo e sem a necessidade de amostragem.

Quando aplicada ao estudo particular de objetos cerâmicos, a caracterização elementar pode direcionar a análise para enfoques distintos de acordo com o objetivo. $\mathrm{O}$ estudo pode ser dirigido à análise da pasta com a determinação de seus elementos majoritários (matriz) e elementos minoritários (traços). Esse estudo, como exemplo, está diretamente associado à identificação de proveniência e à correlação de objetos pertencentes a um mesmo grupo. Também é possível direcionar o estudo à superfície das peças cerâmicas, permitindo a identificação de possíveis pigmentos ou tratamentos realizados na superfície da peça. Outra possibilidade é vincular o estudo ao entendimento da tecnologia de manufatura aplicada na confecção do objeto. 


\subsection{Fluorescência de Raios X (XRF)}

O método de análise XRF [24] é uma técnica multielementar não destrutiva, também aplicada na análise de amostras de diversas áreas, incluindo a área de arqueometria. A técnica XRF fornece informações sobre a composição elementar da amostra por meio da análise dos raios $\mathrm{X}$ característicos emitidos após a irradiação com um feixe de fótons continuo e monocromático, ou seja, com sua energia bem definida. É um método, assim como PIXE, baseado no fenômeno de produção de raios X característicos.

A principal diferença entre os métodos está no projétil incidente nos átomos da amostra para provocar a emissão da radiação. Em XRF utiliza-se um feixe de raios X enquanto em PIXE utilizam-se partículas aceleradas, sendo o processo de excitação dos átomos do alvo o mesmo. Porém essa alteração do projétil causa algumas mudanças significativas nos resultados obtidos relacionados com a energia do feixe e profundidade atingida [25].

No método XRF há uma limitação na identificação dos elementos presentes na amostra estudada, pois serão excitados somente elementos com energia de ligação menor do que a energia dos raios $\mathrm{X}$ que constituem o feixe da análise. Essa energia do feixe de análise depende basicamente da tensão aplicada ao ânodo do tubo de raios $\mathrm{X}$ utilizado.

Para realizar a identificação dos elementos presentes nas amostras é necessário fazer uma medida de calibração utilizando padrões de composições conhecidas. Essas curvas são utilizadas nos processos de qualificação e quantificação elementar das amostras.

Em arqueometria, a técnica XRF tem sido amplamente aplicada devido a algumas facilidades: inicialmente por ser uma técnica não destrutiva não havendo a necessidade de amostragem e em seguida por não deixar impressões de uso na peça. Outras vantagens são a rápida aquisição de medidas com uso de equipamentos portáteis para a aplicação da técnica, permitindo desta forma a realização de medidas in situ [26]. 


\subsection{Técnica de Radiografia}

Há cerca de duzentos anos, no início do século XIX, o homem conseguiu produzir as primeiras imagens utilizando uma película fotossensível quando exposta a luz, o que chamamos de fotografia. Neste mesmo século, em novembro de 1895, o físico Wilhelm Röentgen descobriu que os denominados raios $\mathrm{X}$ também podem formar imagens em películas e com uma característica especial: atravessar corpos opacos. Esta propriedade foi imediatamente usada pelos curiosos, cientistas e principalmente profissionais da área de medicina. Os primeiros responsáveis pela utilização e divulgação da nova técnica eram em sua maioria fotógrafos sem qualquer ligação com a medicina, tornando suas imagens muito populares. Anos mais tarde, em 1910, a radiologia foi profissionalizada criando-se medidas de segurança obrigatórias impondo à radiologia um caráter técnico e cientifico [27].

Atualmente a aplicação da técnica de radiografia é amplamente utilizada tanto na área de medicina, quanto na indústria e em pesquisas acadêmicas na área de arqueometria devido à sua característica de identificar estruturas internas de objetos e corpos [28].

$\mathrm{Na}$ técnica de radiologia podem ser utilizados diferentes tipos de radiações eletromagnéticas, sendo mais comumente utilizada a radiação de raios $\mathrm{X}$.

A radiação é geralmente produzida por tubos de raios $\mathrm{X}$ ou por fontes radioativas, tais como ${ }^{60} \mathrm{Co}$ e ${ }^{192} \mathrm{Ir}$. Em especial, nos tubos de produção de raios X, é possível controlar a tensão e a corrente aplicada, parâmetros que variam conforme o objetivo e o material a ser estudado. A alteração na corrente modifica a taxa de produção de raios X, o que influencia no tempo de exposição à radiação. Já a alteração na tensão aplicada ocasiona uma mudança no espectro de energia dos raios $\mathrm{X}$ produzidos, alterando o poder de penetração na matéria. 
$\mathrm{Na}$ técnica de radiografia convencional, a detenção dos raios $\mathrm{X}$ é feita com a utilização de um filme semelhante ao fotográfico. Esse filme é composto por uma base de plástico (poliéster) ou de acetato de celulose que serve de suporte à emulsão gelatinosa composta por sais de brometo de prata $(\mathrm{AgBr})$ ou de iodeto de prata $(\mathrm{AgI})$. Quando sensibilizado por um fóton de rios-X ou pela luz visível, o cátion de prata se torna neutro se transformando num metal $(\mathrm{AgO})$ de coloração escura. A região não sensibilizada mantém uma coloração transparente após um processo químico de revelação. A sensibilização do filme depende das características do objeto o qual se radiografa variando de acordo com as densidades das diversas estruturas que foram atravessadas pela radiação, com maior ou menor absorção destes raios X [29].

Com o aprimoramento da técnica radiológica, foram sendo identificando algumas desvantagens da radiografia convencional, tais como a alta dose de radiação aplicada e o tempo de exposição, a variação na qualidade da imagem obtida, a utilização de produtos químicos tóxicos, entre outros. Procurando minimizar estes fatores, a radiologia foi associada a sistemas computacionais para as diversas etapas da técnica, como para a aquisição, transferência, armazenamento ou simplesmente para o tratamento das imagens obtidas.

A aquisição de uma imagem radiológica digital pode ser feita de duas maneiras, a primeira utilizando os mesmos equipamentos da radiografia convencional, porém substituindo o chassi com filme de Ag por um chassi formado por placas de fósforo, a chamada radiografia computadorizada $(\mathrm{CR})^{[15]}$ e a segunda utilizando os mesmos equipamentos da radiografia convencional, porém substituindo o chassi por uma placa de circuitos sensíveis aos raios $\mathrm{X}$, ou seja, um detector digital, diretamente ligado a um microcomputador, a chamada radiografia digital (DR $)^{[16]}$. 
Na radiografia computadorizada, as imagens geradas são reconstituídas a partir da transformação de pulsos elétricos em dígitos formando uma imagem digital. Esta é apresentada em uma tela de computador ou filme radiológico na forma de uma matriz. $\mathrm{Na}$ intersecção das linhas com as colunas forma-se a unidade básica da imagem digital, o píxel (picture element). Para que a imagem digital possa ser interpretada como a imagem de um objeto com uma determinada estrutura, os dígitos de cada píxel da imagem são convertidos em tons de cinza numa escala proporcional aos seus valores, no nosso caso 8 bits correspondendo a uma escala de 256 tons de cinza.

Em estudos de arte e arqueologia, a técnica de radiação vem sido empregada em diversos materiais como papel, tecidos, cerâmicas, metais, pinturas e inclusive em corpos, devido ao fato da técnica possibilitar a observação de estruturas e características internas sem danificar o objeto.

Em especial, quando aplicada ao estudo de objetos cerâmicos, a técnica de radiografia permite uma melhor visualização da peça como um todo. Inicialmente é possível observar algumas características do corpo da peça como a existência ou não de fraturas, sejam internas ou externas e a presença de algum tipo de restauro realizado no objeto. Com uma observação mais apurada, é possível caracterizar a pasta cerâmica utilizada, em especial com relação à presença e tipos de temperos utilizados, densidade e porosidade, além de permitir a obtenção de informações sobre a tecnologia empregada na manufatura das peças $[30,31]$. 


\section{Capítulo 5}

\section{Descrição experimental}

Nesse capítulo serão descritos os laboratórios e os equipamentos utilizados nesse estudo.

Inicialmente será apresentada uma descrição das amostras analisadas e em seguida uma descrição resumida dos laboratórios. Os laboratórios utilizados para a realização das técnicas foram o laboratório $\mathrm{LAMFI}^{[17]}$ e o Laboratório de Dosimetria, localizados no Instituto de Física da Universidade de São Paulo, o equipamento XRF pertencente ao laboratório LABENS $^{[18]}$ da Escola Politécnica da Universidade de São Paulo e o Laboratório Peletron, localizado no Instituto de Física da Universidad Autónoma do México.

\subsection{Amostras analisadas}

Os fragmentos cerâmicos utilizados neste estudo foram gentilmente cedidos pelo Museu de Arqueologia e Etnologia da USP sob a supervisão da Professora Fabíola Andrea Silva

Os materiais foram coletados na aldeia indígena Lalima, no município de Miranda, no estado do Mato Grosso do Sul. As peças analisadas foram encontradas em dois sítios arqueológicos diferentes, o Sítio Sede/Córrego Lalima (MI1) e no Sítio Asa de pote (MI6), sítios localizados com uma distância aproximadamente de $3 \mathrm{~km}$ entre eles. De acordo com informações arqueológicas referentes ao estilo das peças, os fragmentos pertencem a duas tradições indígenas, à tradição Guarani e à tradição Pantanal. Ao todo foram emprestados 148 fragmentos arqueológicos. O registro fotográfico dos fragmentos analisados estão apresentados no Catálogo de Peças. 
A Professora Fabíola é reconhecida como fiel depositária das peças através da portaria $\mathrm{N}^{\mathrm{o}} 39$ de 9 de fevereiro de 2007 (Diário Oficial da União) pelo Instituto do Patrimônio Histórico e Artístico Nacional (IPHAN).

\subsection{Laboratório de Análise de Materiais por Feixes Iônicos}

No Laboratório de Análise de Materiais por Feixes Iônicos (LAMFI) foram realizadas análises com a técnica PIXE. As análises foram realizadas juntamente com a montagem e desenvolvimento da linha de feixe externo projetada para atender também a análises em arqueometria e em bens culturais.

O laboratório é constituído por um acelerador eletrostático tipo Pelletron - Tandem, modelo 5SDH, com "stripper" gasoso $\left(\mathrm{N}_{2}\right)$ para troca de carga do feixe construído pela NEC, National Electrostatic Corporation - EUA, que pode alcançar até 1,7MV de tensão no terminal. Para a produção dos feixes são utilizadas duas fontes de íons, a Alphatross de rádio frequência que possui câmara de troca de carga com vapor de rubídio, usualmente utilizado para a obtenção de feixe de partículas $\alpha$, e uma fonte do tipo SNICS (Source of Negative Ions by Cesium Sputtering) utilizada para a criação de vários feixes iônicos de vários elementos, no nosso caso, tipicamente prótons [32]. Variando a tensão no terminal é possível obter feixes com uma grande gama de energias para utilização em experimentos de retroespalhamento, PIXE, implantação iônica e física nuclear. O feixe, por sua vez, é defletido para uma das quatro estações de análise do laboratório.

A estação de análise PIXE é utilizada em experimentos onde é permitido o estudo em amostras que possam ser montadas em vácuo. A câmara contém um porta-amostras linear parcialmente automatizado e controles de posicionamento XY manuais e externos. Nesse sistema, utiliza-se de dois detectores de raios-X tipo $\mathrm{Si}(\mathrm{Li})$ [33] associados à eletrônica de controle e aquisição. 
A estação de Multiuso, normalmente utilizada para medidas com a técnica de Espectrometria por retroespalhamento de Rutherford (RBS), permite a montagem de uma adaptação para feixe externo onde a linha termina em uma saída com uma janela fina de kapton $(25$ ou $8 \mu \mathrm{m})$ pelo qual o feixe de íons é extraído para a atmosfera, possibilitando que o feixe, depois de atravessar uma pequena faixa de ar, atinja o objeto que será analisado.

A terceira linha de análise é dedicada à utilização da técnica denominada MALDIAMS (Matrix Assisted LaserDesorption Ionization - Accelerator Mass Spectrometry), utilizada para realizar espectrometria de massa em alta energia e identificar moléculas com massa superior a $10^{5}$ u.m.a com resolução de poucas unidades. O sistema é formado por uma fonte de íons acoplada ao acelerador e é uma parceria do LAMFI com o Laboratório de instrumentação e Partículas da USP (LIP).

A quarta linha de feixe é dedicada a análises com a utilização de feixe externo, destinada à análise de objetos incompatíveis com o ambiente em vácuo. O início de sua montagem deu-se no ano de 2008 e no mesmo ano iniciaram-se experimentos de caráter provisório para regulagem e calibração da mesma. No ano de 2009 e 2010, a linha recebeu os últimos itens permanentes, tais como um conjunto de lentes de focalização e uma saída para o feixe externo fixa. A linha possui dois detectores de raios-X tipo Si-Pin. Também podem ser acoplados ao sistema um detector de raios $\gamma$, um detector de barreira para RBS e um detector de luminescência.

Neste estudo, foram realizadas algumas medidas de caracterização utilizando a técnica PIXE, no laboratório LAMFI. Inicialmente utilizou-se a câmara Multiuso com a adaptação realizada para o feixe externo e posteriormente foi utilizada a linha própria do feixe externo dedicada a estudos em arqueometria. 
Nos experimentos, utilizou-se um feixe de ${ }^{+} \mathrm{H}$ com energia de 2,6 MeV, antes da janela de saída do feixe correspondendo a uma energia de $1,8 \mathrm{MeV}$ na amostra, que incidiu perpendicularmente à mesma. Para a determinação da carga que atinge a amostra, utilizouse uma fina folha de ouro localizada entre a saída do feixe e a amostra, cuja distância foi de $5,0(2) \mathrm{cm}$. Para obtenção dos espectros foram utilizados dois detectores de raios $\mathrm{X}$ do tipo Si-Pin, sendo um direcionado à amostra e o outro direcionado à folha de ouro, para a obtenção da carga incidida sobre a amostra.

Para certificar a calibração do sistema e utilizar como referência para as análises quantitativas, foi utilizada uma amostra de SRM8704 NIST ${ }^{[19]}$ "Buffalo River Sediment" [34] como material referenciado. O certificado do padrão referenciado encontra-se em anexo.

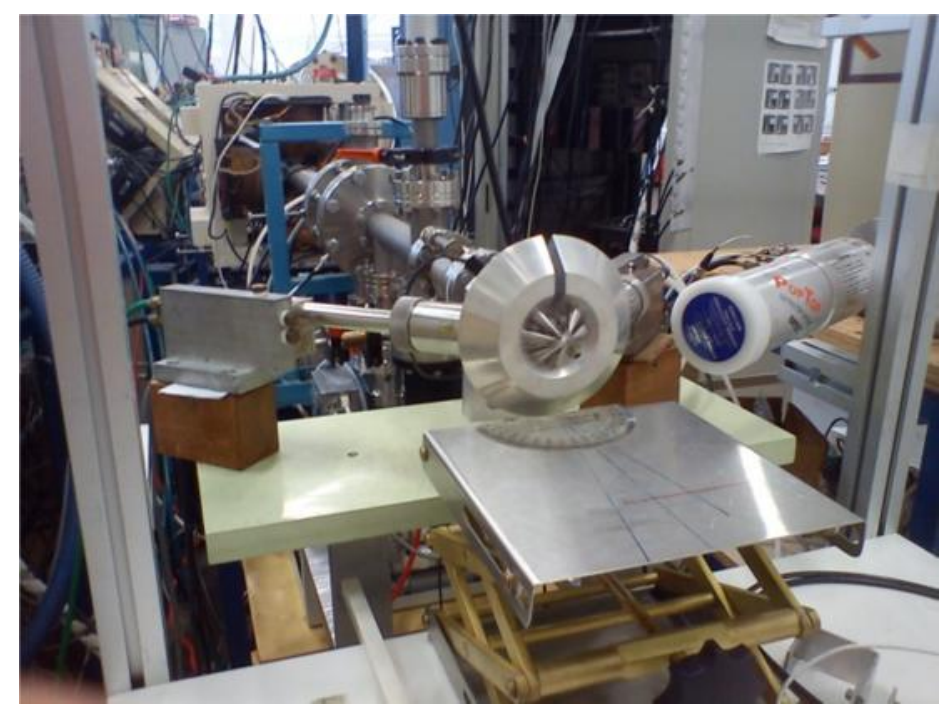

Figura 6. Linha de feixe externo dedicada a estudos de arqueometria no laboratório LAMFI-USP. (Foto J.F.Curado) 


\subsection{Laboratório de Dosimetria}

No laboratório de Dosimetria do IFUSP foram realizadas análises com a técnica de radiografia. As irradiações foram feitas em duas etapas: inicialmente utilizando a técnica de radiografia tradicional e em seguida utilizando a técnica de radiografia computadorizada.

O laboratório possui quatro salas para irradiação e uma sala para o armazenamento de fontes radioativas de baixa atividade. Todas as salas foram devidamente dimensionadas e construídas de modo a oferecer condições de operação dentro das normas vigentes de Proteção Radiológica. A primeira sala possui em operação duas fontes de radiação, uma de Cobalto-60 e um tubo de raios $\mathrm{X}$ usados principalmente em pesquisa. Em duas outras salas estão instaladas uma fonte de Césio-137 e uma fonte de Cobalto-60. A quarta sala, projetada especialmente para irradiações com nêutrons dispõe de fontes de AmerícioBerílio (AmBe).

O laboratório também possui, entre outros equipamentos, um sistema de digitalização de multi-aplicações CR 30-X da Agfa Health Care utilizado para aplicações radiológicas. O equipamento utiliza o software NX que é uma ferramenta de controle de qualidade e identificação de imagens e o software de processamento de imagens MUSICA2, ambos da Agfa [34].

Neste estudo, foi utilizado o tubo de raios X Philips MG450 presente no laboratório para a obtenção das imagens radiográficas. O tubo possui um intervalo de tensão variável de $20-420 \mathrm{kV}$ e um intervalo de corrente variável de 0-15 mA. O equipamento possui um filtro inerente de 2,2 $\mathrm{mm}$ de Berílio e um anodo em ângulo de 22 graus. 


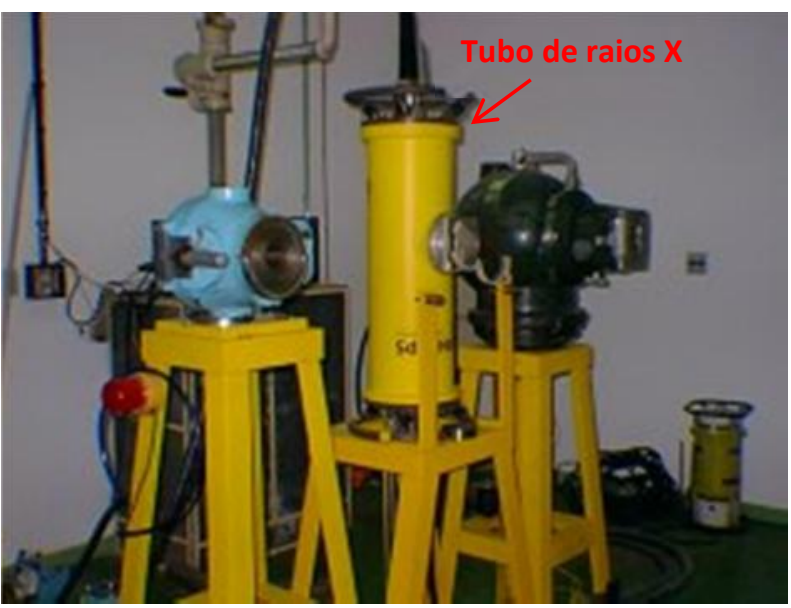

Figura 7. Tubo de raios X Philips MG450 presente no Laboratório de Dosimetria-IFUSP utilizado neste estudo. (Foto Lab. Dosimetria)

A tensão e a corrente aplicada no tubo foram alteradas conforme a metodologia empregada e as espessuras das peças radiografadas. Os valores estão apresentados na Tabela 2.

Tabela 2. Valores aplicados ao tubo de raios-X na técnica de radiografia.

\begin{tabular}{cccccc}
\hline \hline Técnica de radiografia & $\begin{array}{c}\text { Tensão } \\
\text { aplicada } \\
(\mathrm{kV})\end{array}$ & $\begin{array}{c}\text { Corrente } \\
\text { aplicada } \\
(\mathrm{mA})\end{array}$ & $\begin{array}{c}\text { Tempo de } \\
\text { radiação }(\mathrm{s})\end{array}$ & $\begin{array}{c}\text { Distância } \\
(\mathrm{m})\end{array}$ & $\begin{array}{c}\text { Espessura da } \\
\text { Peça }(\mathrm{cm})\end{array}$ \\
\hline \hline Convencional & $50-120$ & 15 & $60-300$ & $3,5(1)$ & $0,4(1)-3,0(1)$ \\
\hline Computadorizada & 50 & 3 & 10 & $3,5(1)$ & $0,4(1)-1,0(1)$ \\
\hline Computadorizada & 50 & 3 & 13 & $3,5(1)$ & $>1,0(1)$ \\
\hline \hline
\end{tabular}




\subsection{Laboratório de caracterização de bens culturais (LABENS)}

O Laboratório de caracterização de bens culturais, localizado na Escola Politécnica da USP, possui como equipamento de pesquisa principal um sistema semiportátil para a realização de espectrometria de Fluorescência de raios X.

O sistema é formado por um tubo de raios-X com ânodo de $\mathrm{W}$ e utiliza um detector resfriado a água SI-PIN Amptek de resolução 150eV@Mn K $\alpha$. A área irradiada na amostra corresponde a um círculo com cerca de $4 \mathrm{~mm}$ de raio. A distância entre a amostra e a saída do tubo de raios-X foi de $1,0 \mathrm{~cm}$ e a mesma distância foi usada entre a amostra e o detector.

As condições de trabalho foram $55 \mathrm{kV}$ e $0,5 \mathrm{~mA}$ e o tempo de aquisição dos espectros de raios-X foi de 600 s. Para certificar a calibração do sistema e utilizar como referência para as análises quantitativas, foi utilizado novamente amostras de SRM8704 NIST "Buffalo River Sediment" como material referenciado para a realização da calibração e quantificação das amostras.

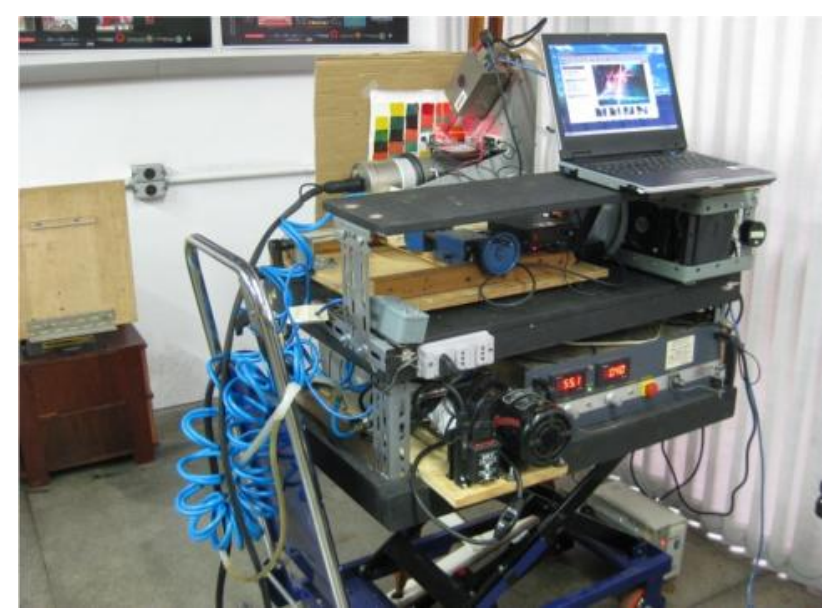

Figura 8. Montagem do equipamento semiportátil de XRF pertencente ao laboratório LABENS-PoliUSP. (Foto A.C.Neiva) 


\subsection{Laboratório Peletron - UNAM}

O laboratório Peletron, localizado na Universidad Autónoma de México (UNAM), foi utilizado para a realização de medidas com as técnicas PIXE e XRF.

O laboratório possui um acelerador eletrostático tipo Pelletron - Tandem, modelo 9SDH-2 construído pela NEC, National Electrostatic Corporation - EUA, podendo obter até $3 \mathrm{MV}$ de tensão no terminal. Possui duas fontes de íons, sendo uma de rádio frequência (Alphatross), com câmara de troca de carga com vapor de rubídio e a outra do tipo SNICS (Source of Negative Ions by Cesium Sputtering).

O laboratório tem como enfoque em suas pesquisas a ciência básica, modificação de materiais e a análise de materiais. Para tanto existem quatro linhas montadas dedicadas a diferentes áreas sendo astrofísica nuclear, implantação iônica, raios X e uma linha de feixe externo, utilizada em estudos em objetos de arte e arqueologia.

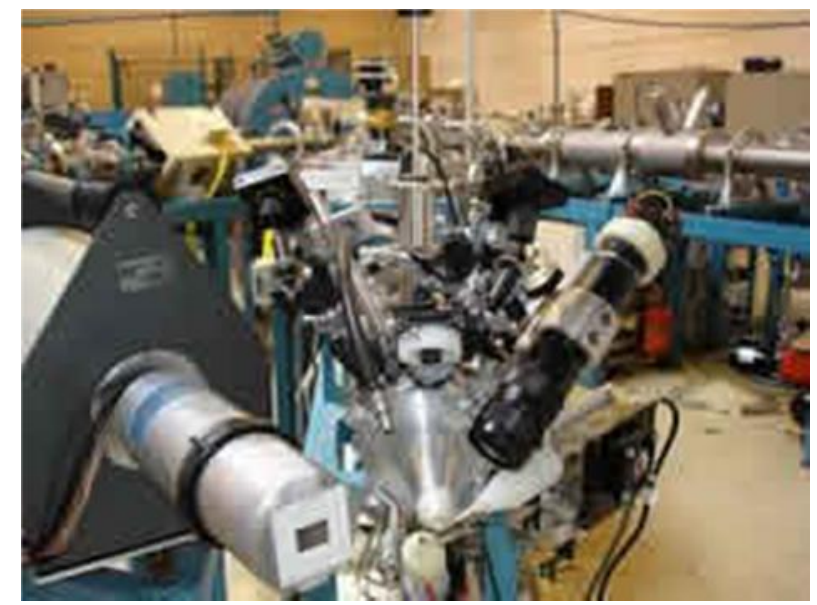

Figura 9. Detalhe da linha de pesquisa de feixe externo no Laboratório Peletron - UNAM. (Foto: Peletron-UNAM) 
O laboratório também possui um sistema portátil de XRF, utilizado em análises arqueométricas in situ (SANDRA - Sistema de Analisis No Destructivo por Rayos X) [35]. O sistema é composto por um tubo raios X de Molibdênio (Mo) e um detector Si-Pin.

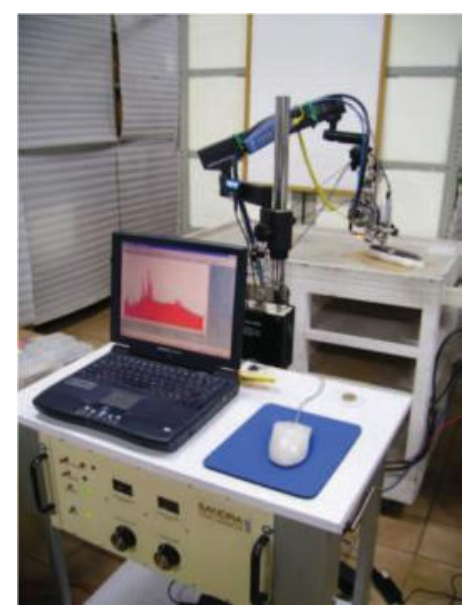

Figura 10. Sistema portátil de XRF (SANDRA) pertencente ao laboratório PeletronUNAM. (Foto: J.F.Curado)

Um pequeno conjunto de 32 amostras foi analisado utilizando a técnica PIXE com feixe externo. Dois detectores foram usados para a detecção dos raios-X, um detector SiPin para os elementos leves e um detector LEGe $^{[20]}[36]$ com um absorvedor de $150 \mu \mathrm{m}$ de Al para os elementos pesados. Entre a saída do detector Si-Pin e a amostra existe um fluxo de He constante utilizado para minimizar a presença do elemento Argônio presente no ar. A energia do feixe de próton com 1,5 mm de diâmetro foi de $3 \mathrm{MeV}$ antes da saída do feixe e o tempo de irradiação foi de $300 \mathrm{~s}$.

Foram realizadas medidas utilizando a técnica XRF com o sistema SANDRA utilizando uma energia de $45 \mathrm{keV}$ com uma corrente de $0,30 \mathrm{~mA}$ e com um tempo de irradiação de $120 \mathrm{~s}$.

Em ambas as técnicas os materiais de referência SRM 2704 NIST "Buffalo River Sediment", SRM2710 NIST "Montana Soil” também foram analisados para a calibração e medidas de concentração. 


\section{Capítulo 6}

\section{Análise estatística multivariada}

A estatística multivariada consiste em um conjunto de métodos estatísticos que permite a análise simultânea de medidas múltiplas para cada indivíduo ou objeto em análise, ou seja, qualquer método que permita a análise simultânea de duas ou mais variáveis pode ser considerado como multivariado.

Existem vários métodos de análise multivariada com finalidades bem diversas entre si e podem ser classificados em dois grupos. O primeiro grupo constitui em técnicas exploratórias de simplificação da estrutura de variabilidade dos dados, tais como as técnicas de análise de componentes principais e análise de agrupamento entre outras. $\mathrm{O}$ segundo constitui em técnicas de inferência estatística tais como testes de hipóteses e análises de variância [37, 38].

De maneira geral, os métodos multivariados tem o objetivo de simplificar e facilitar a interpretação dos casos estudados por meio do cálculo de índices ou gráficos que sintetizem as informações gerais.

Historicamente, essas técnicas foram inicialmente aplicadas em áreas das ciências humanas, porém sua utilização foi expandida às diversas áreas do conhecimento humano. Atualmente, os diversos métodos de análise multivariados são realizados com o auxílio computacional baseados em fundamentos teóricos. 


\subsection{Análise de Componentes Principais}

A análise de componentes principais, também chamada de $\mathrm{PCA}^{[21]}$ [39], é um método de análise estatística multivariada e tem como objetivo determinar em um conjunto de variáveis a existência de subconjuntos coerentes relativamente independentes uns dos outros. De maneira resumida, é uma técnica de classificação que determina as relações existentes entre os diversos casos a serem estudados e suas variáveis.

Essa técnica utiliza um inter-relacionamento entre as variáveis de modo que estas possam ser escritas em termos de um grupo de menores elementos denominados fatores. Os fatores explicam a variância das variáveis através das correlações entre as variáveis utilizadas em determinado estudo.

Para realizar uma análise de componentes principais necessitamos dos dados de $\mathrm{p}$ variáveis para $\mathrm{n}$ indivíduos. Utilizando estas informações, calculamos uma matriz de covariância.

Suponhamos um conjunto de amostras de tamanho n com p variáveis. Agrupando as informações de todas as amostras podemos gerar uma matriz $\mathrm{n} x \mathrm{p}$ dada por:

$$
\mathrm{X}_{\mathrm{n} x \mathrm{p}}=\left[\begin{array}{cccc}
X_{11} & X_{21} & \ldots & X_{p 1} \\
X_{12} & X_{22} & \ldots & X_{p 2} \\
\vdots & \vdots & \vdots & \vdots \\
X_{1 n} & X_{2 n} & \ldots & X_{p n}
\end{array}\right]
$$

$O$ vetor de médias $\mu$ é estimado pelita vetor de médias amostrais $\overline{\mathrm{X}}$ definido por:

$$
X=\left[\begin{array}{c}
-1 \\
1 \\
2 \\
-1 \\
-1
\end{array}\right]
$$

onde $\bar{X}_{\iota}$ é a média amostral, $\mathrm{i}=1,2, \ldots, \mathrm{p}$. 
A matriz de covariâncias amostrais $S_{p x p}$ é definida por:

$$
S_{p x p}=\left[\begin{array}{cccc}
S_{11} & S_{12} & \ldots & S_{1 p} \\
S_{21} & S_{22} & \ldots & S_{2 p} \\
\vdots & \vdots & \vdots & \vdots \\
S_{p 1} & S_{p 2} & \ldots & S_{p p}
\end{array}\right]
$$

sendo $S_{i j}=S_{j i}, j \neq i$, onde a variância amostral da i-ésima variável $S_{i i}$ é definida por:

$$
S_{i i}=\frac{\sum_{l=1}^{n}\left(X_{i l}-\bar{X}_{i}\right)^{2}}{n-1}
$$

e a covariância amostral entre a i-ésima e j-ésima variáveis é definida por

$$
\mathrm{S}_{\mathrm{ij}}=\frac{\sum_{l=1}^{n}\left(X_{i l}-\bar{X}_{i}\right)\left(X_{j l}-\bar{X}_{j}\right)}{n-1}
$$

Na matriz de covariâncias podemos determinar seus autovalores e seus respectivos autovetores normalizados, denotados por $\mathrm{e}_{\mathrm{i}}=\left(\mathrm{e}_{\mathrm{i} 1} \mathrm{e}_{\mathrm{i} 2 \ldots} \ldots \mathrm{e}_{\mathrm{ip}}\right)$.

Podemos definir o vetor $\mathrm{Y}$ como sendo a combinação linear entre as variáveis aleatórias do vetor $\mathrm{X}$ e os autovetores da matriz de covariância. A j-ésima componente principal da matriz $S_{p x p}, j=1,2, \ldots, p$ é definida como:

$$
Y_{j}=e_{j 1} X_{1}+e_{j 2} X_{2}+\cdots+e_{j p} X_{p}
$$


Para classificar e destacar as relações entre as variáveis e os casos estudados, a técnica PCA recorre a recursos gráficos. As variáveis e os casos são graficados em um espaço bidimensional gerados pelas componentes principais. Estes gráficos podem ser associados às variáveis ou aos casos.

Uma das curvas de interesse é o método gráfico Scree plot ${ }^{[22]}$ (Figura 11), que representa a porcentagem de variação relacionando a componente na ordenada e os autovalores (Eigenvalue), em ordem decrescente na abscissa. Se a curva se estabilizar com relação aos autovalores, podemos restringir a análise somente nas componentes principais com autovalores superiores à estabilização. Na Figura 11, como exemplo, ao analisarmos os valores obtidos para cada componente, podemos observar que as três primeiras explicam aproximadamente $60 \%$ da variabilidade total dos dados, havendo uma diminuição na variação (estabilização) a partir da quarta componente. As demais componentes possuem uma baixa taxa de explicação, não sendo necessário incluí-las nas análises.

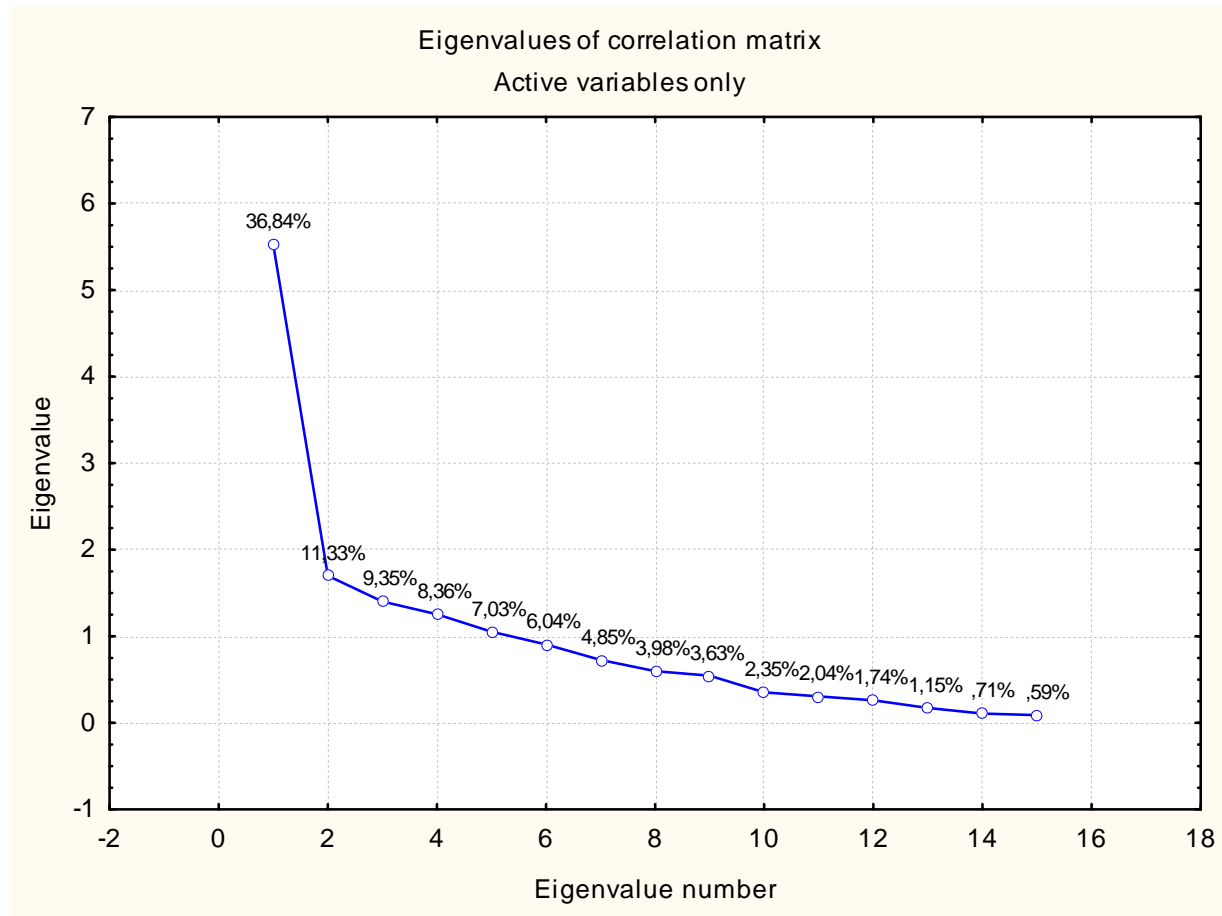

Figura 11. Exemplo de curva Scree plot, utilizada na análise de componentes principais. Este gráfico de exemplo corresponde à análise feita por XRF nos fragmentos apresentados neste estudo. 
Outro aspecto que podemos analisar é o gráfico associado às variáveis do estudo. As variáveis são representadas em um círculo denominado circulo de correlação cujos eixos são formados pelos fatores da componente principal. Para analisar a figura devemos levar em consideração as projeções dos pontos nos eixos. Este gráfico auxilia na classificação dos casos em diferentes conjuntos de acordo com suas coordenadas correspondentes nos eixos. A análise das proximidades ou oposições entre variáveis é feita em termos de correlações.

Como podemos observar, na Figura 12, algumas variáveis estão sobrepostas umas às outras. Isso mostra que essas possuem a mesma representatividade no gráfico. Outro fato importante, é que algumas variáveis estão bem próximas ao círculo unitário. Isso mostra que estas possuem uma maior contribuição, em relação às variáveis que estão mais afastadas. Como exemplo, podemos observar os elementos $\mathrm{Ca}$ e $\mathrm{Cu}$ que são fortemente correlacionadas entre si, mas independentes dos elementos $\mathrm{Cr}$ e Zr. Neste exemplo também é possível observar uma correlação negativa forte entre os elementos $\mathrm{Zr}$ e Y, que são apresentados em direções opostas.

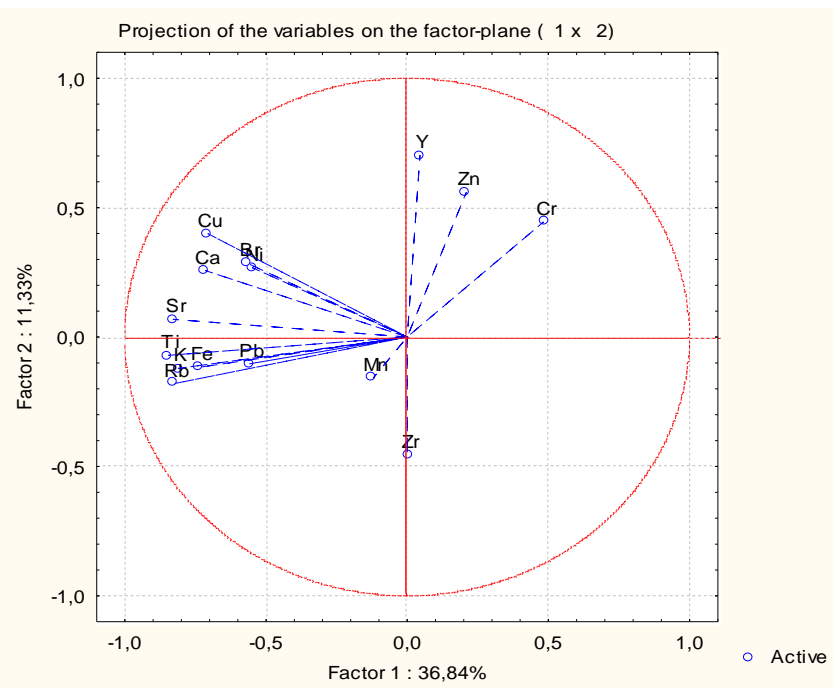

Figura 12. Exemplo de Círculo de correlação utilizado na análise de componentes principais. Este gráfico de exemplo corresponde à análise feita por XRF nos fragmentos apresentados neste estudo. 


\subsection{Análise de Agrupamentos}

A análise de agrupamentos, também conhecida como análise de conglomerados ou análise de cluster, é um método de análise estatística multivariada e tem como objetivo separar populações ou conjuntos de amostras em grupos, de maneira que os elementos pertencentes ao mesmo grupo possuam similaridades entre si, considerando algumas características pré-determinadas [40].

Em outras palavras, a análise de agrupamentos é uma coleção de algoritmos que classificam elementos que são aplicados em conjuntos nos quais não se possui uma hipótese a priori sobre a estrutura ou comportamento dos dados.

A análise de agrupamento envolve algumas decisões subjetivas, como qual a técnica a mais conveniente, conforme as circunstâncias. Existem várias técnicas, porém deve-se decidir qual é a mais adequada para determinado propósito, uma vez que diferentes técnicas podem levar a diferentes soluções.

Estas técnicas supõem inicialmente a existência de $\mathrm{n}$ elementos do conjunto. A cada etapa, os elementos vão sendo agrupados, reduzindo o número de conglomerados.

A cada estágio do procedimento os grupos são comparados por meio de uma medida de dissimilaridade. Essas medidas indicam as distâncias entre os elementos do conjunto avaliando se dois pontos estão próximos, e, portanto, se podem fazer parte de um mesmo grupo, ou não. Nas medidas de dissimilaridade, quanto menor os valores obtidos mais similares serão os elementos que estão sendo tratados. 
Existem várias medidas que podem ser utilizadas como distâncias entre elementos, entre as quais podemos citar: a distância euclidiana, a distância euclidiana quadrada e a distância euclidiana padronizada, a distância de Minkowski, distância Mahalanobis, distância de Chebychev, entre outras [37].

A distância Euclidiana, o tipo mais comumente escolhido para o cálculo das distâncias, é definida como a distância geométrica entre dois elementos (i e j) para todas as variáveis (v) no espaço multidimensional. É calculada como:

$$
d_{i j}=\sqrt{\sum_{1}^{v}\left(x_{i}-x_{j}\right)^{2}}
$$

No presente trabalho, as análises foram realizadas utilizando a distância Euclidiana quadrada que atribui um peso progressivo aos elementos mais afastados. É calculada como:

$$
d_{i j}{ }^{2}=\sum_{1}^{v}\left(x_{i}-x_{j}\right)^{2}
$$

Outro fator a ser definido na aplicação das técnicas de análise multivariada é a escolha do método estatístico a ser utilizado. 
Estes métodos estatísticos podem ser classificados de duas maneiras:

- As técnicas não-hierárquicas, ou técnicas por particionamento, utilizadas quando se utiliza um número de grupos pré-estabelecidos.

- $\quad$ As técnicas denominadas hierárquicas, utilizadas em análises exploratórias para a identificação do número de agrupamentos possíveis. Estas consistem em realizar uma sequência de sucessivos agrupamentos ou sucessivas divisões de elementos, em que os elementos são agregados ou desagregados, podendo ainda ser chamadas de aglomerativas e divisivas. Nestas técnicas, os resultados são apresentados em um diagrama bidimensional denominado dendrograma cujas ligações representam agrupamentos. Se selecionarmos no dendrograma um determinado nível de distância, obteremos uma classificação dos números de grupos existentes nesse nível e dos elementos em cada grupo.

Nas técnicas hierárquicas, os métodos mais comuns de agrupamento são: ligação simples, ligação completa, dos centróides, da mediana, das médias das distâncias e da soma de erros quadráticos ou variância (método Ward).

O método de ligação simples, também conhecido como método do elemento mais próximo ou Neighbourhoods, é considerado o método mais simples, sendo de uso geral e de rápida aplicação. Uma de suas características é não exigir que o número de agrupamentos seja fixado a priori. Neste caso, a distância entre os grupos é definida como sendo a distância entre os objetos mais parecidos destes grupos. O resultado apresenta grupos mais longos quando comparado a outros métodos e seus dendrogramas são pouco informativos, devido à informação dos elementos intermediários que não são evidentes. 
Em razão da sua simplicidade, esse método apresenta grande desvantagem. $\mathrm{O}$ fato de reunir um objeto ao elemento "mais próximo" do grupo já formado faz com que os objetos intermediários entre os grupos sejam rapidamente aglomerados a esses. Ocorre, então, um encadeamento de objetos que dificulta a separação dos grupos.

O método de ligação completa, também conhecido por método do elemento mais distante (utilizado nas análises presentes neste trabalho), é um dos métodos de maior aplicação em análise de agrupamento e também não é necessária a fixação do número de agrupamentos. A distância entre dois grupos é definida pelos objetos de cada grupo que estão mais distantes. Ou seja, formam-se todos os pares com um membro de cada grupo. A distância entre os grupos é definida pelo par que possuir maior distância. Os resultados deste método apresentam grupos compactos e não é indicado se os dados apresentarem um agrupamento cadenciado. Este método elimina o problema da cadeia ou corrente prolongada existente no método de ligação simples. Em decorrência disso, as chances de se obter grupos mais equilibrados e menos dissimilares aumentam, obtendo grupos mais compactos.

Utilizando a matriz de proximidade entre as amostras, podemos construir um diagrama denominado dendrograma. $\mathrm{O}$ dendrograma pode ser apresentado verticalmente ou horizontalmente. A Figura 13 apresenta um dendrograma vertical, que tem indicado em seu eixo vertical as distâncias de dissimilaridade entre as amostras e seu eixo horizontal apresenta as amostras estudadas na ordem em que são agrupadas.

A interpretação de um dendrograma de amostras é feito de maneira intuitiva, onde duas amostras próximas devem ter também valores semelhantes para as variáveis medidas. Dessa forma, quanto maior a proximidade entre as medidas relativas às amostras, maior a similaridade entre elas. Já na medida de dissimilaridade, quanto maior for o valor observado, menos parecidos serão os objetos de estudo. $\mathrm{O}$ dendrograma hierarquiza esta similaridade de modo que podemos ter uma visão bidimensional da similaridade ou dissimilaridade de todo o conjunto de amostras utilizado no estudo. Quando o dendrograma construído é das variáveis, a similaridade entre duas variáveis aponta forte correlação entre estas variáveis do conjunto de dados estudado. 
Um corte no dendrograma a qualquer nível de aglomeração produz uma classificação em subgrupos. Estes subgrupos estão associados a um determinado grau de dissimilaridade. Na figura 13 é apresentado um exemplo do programa STATISTICA[41]. O eixo horizontal indica os casos (amostras) analisados, o eixo y indica a distância normalizada entre os casos. Se observarmos nesse dendrograma os cortes indicados pelas linhas em vermelho, o primeiro corte mostra uma distância de dissimilaridade de valor 40, formando neste caso três subgrupos. Neste mesmo exemplo, um corte na distância dissimilaridade de valor 100, forma dois subgrupos completamente distintos.

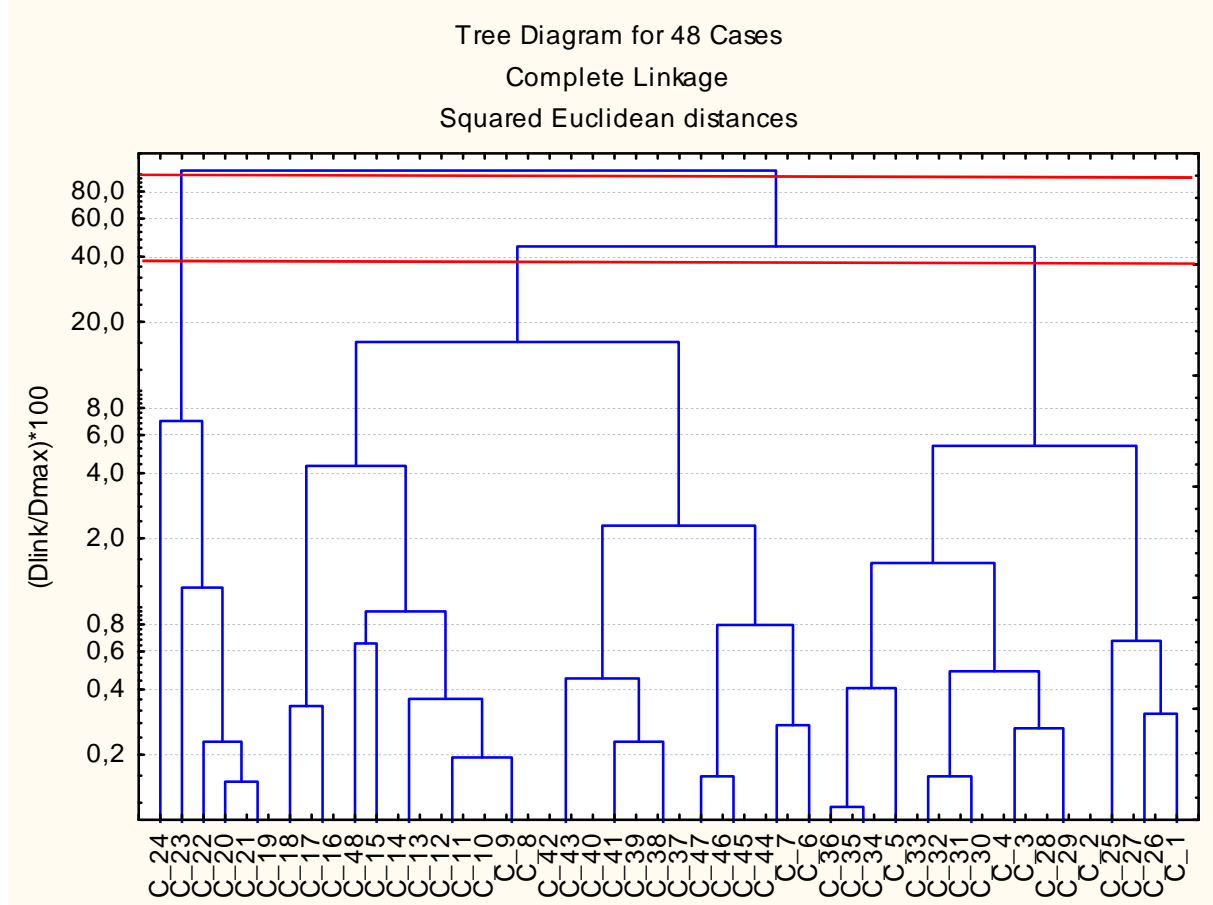

Figura 13. Exemplo de dendrograma obtido através da análise de agrupamentos. (Fonte: software STATISTIC). Na figura podemos observar cortes (linhas vermelhas) que indicam a formação de subgrupos de acordo com a distância de dissimilaridade. 


\section{Capítulo 7}

\section{Resultados e Análise de dados experimentais}

Neste capítulo serão apresentados os resultados experimentais obtidos e as análises realizadas pelas diferentes técnicas empregadas.

\subsection{Emissão de Raios X induzida por Partícula (PIXE)}

A utilização da técnica PIXE permitiu a identificação e a quantificação elementar da pasta dos fragmentos cerâmicos estudados. As medidas experimentais foram realizadas nos laboratórios LAMFI-IFUSP e Peletron-UNAM.

O primeiro experimento realizado no laboratório LAMFI foi de caráter preliminar utilizando uma adaptação para a extração de um feixe externa na linha de Multiuso. Neste período foram feitos diversos testes em cerâmicas modernas sem valor cultural. Estes testes serviram para avaliar as condições experimentais tais como corrente, tempo de irradiação dos fragmentos e verificar o limite de detecção para os diferentes elementos.

Em seguida aos testes, foram analisados oito fragmentos cerâmicos, sendo sete de origem arqueológica encontrados no Sítio Sede/Córrego Lalima e um de origem etnográfica $^{[23]}$ proveniente da mesma região. Foram realizados três ou quatro pontos de irradiação por peça, sendo ao menos um ponto na parte anterior, posterior e lateral de cada peça. As amostras analisadas nesse período estão apresentadas na Tabela 3 e o arranjo experimental usado é mostrado na Figura 14. 


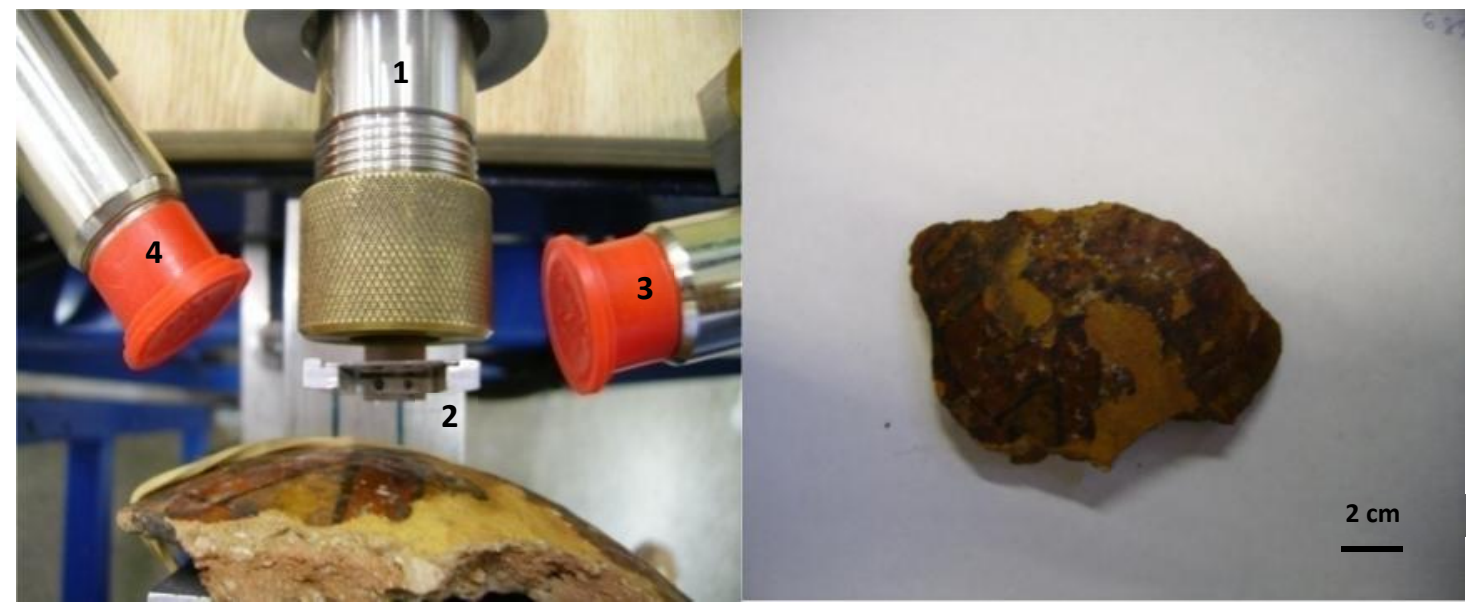

Figura 14. Arranjo experimental utilizado no primeiro experimento PIXE (LAMFI). Na imagem estão indicados: 1.Saída do feixe; 2.Folha de Au; 3.Detector voltado à folha de Au; 4. Detector voltado à amostra. A peça apresentada é de origem etnográfica proveniente da aldeia Lalima.

Nesse arranjo experimental, o feixe é extraído através de uma janela de Kapton de $25 \mu \mathrm{m}$. Após a saída, o feixe atravessa uma folha de Au com $100 \mu \mathrm{g} / \mathrm{cm}^{2}$ que é utilizada para a verificação da carga depositada na amostra. A detecção dos raios X característicos dos elementos nas amostras e dos raios $\mathrm{X}$ característicos da folha de Au são feitas por dois detectores Si-Pin.

Tabela 3. Amostras analisadas. As peças MII são arqueológicas provenientes do Sítio Sede da Aldeia Lalima.

\begin{tabular}{ll}
\hline \hline Amostra & Posição/Característica \\
\hline \hline Etnográfica & $\begin{array}{l}\text { Anterior - Pigmento vermelho } \\
\text { Anterior - Pigmento amarelo } \\
\text { Posterior, Lateral }\end{array}$ \\
\hline MI1-21 & Posterior, Anterior, Lateral \\
\hline MI1-50 & $\begin{array}{l}\text { Anterior - Pigmento Vermelho } \\
\text { Posterior, Lateral }\end{array}$ \\
\hline MI1-88 & Posterior, Anterior, Lateral \\
\hline MI1-24 & $\begin{array}{l}\text { Posterior claro/escuro } \\
\text { Anterior, Lateral }\end{array}$ \\
\hline MI1-23 & Posterior, Anterior, Lateral \\
\hline MI1-45 & $\begin{array}{l}\text { Anterior - Pigmento Vermelho } \\
\text { Posterior, Lateral }\end{array}$ \\
\hline MI1-144 & Posterior, Anterior, Lateral \\
\hline \hline
\end{tabular}


Para realizar as irradiações foi utilizado um feixe de prótons com energia de 1,8 $\mathrm{MeV}$ na amostra, uma corrente de $50 \mathrm{nA}$ e 20 minutos de irradiação por ponto. Um espectro de raios X típico obtido está apresentado na Figura 15.

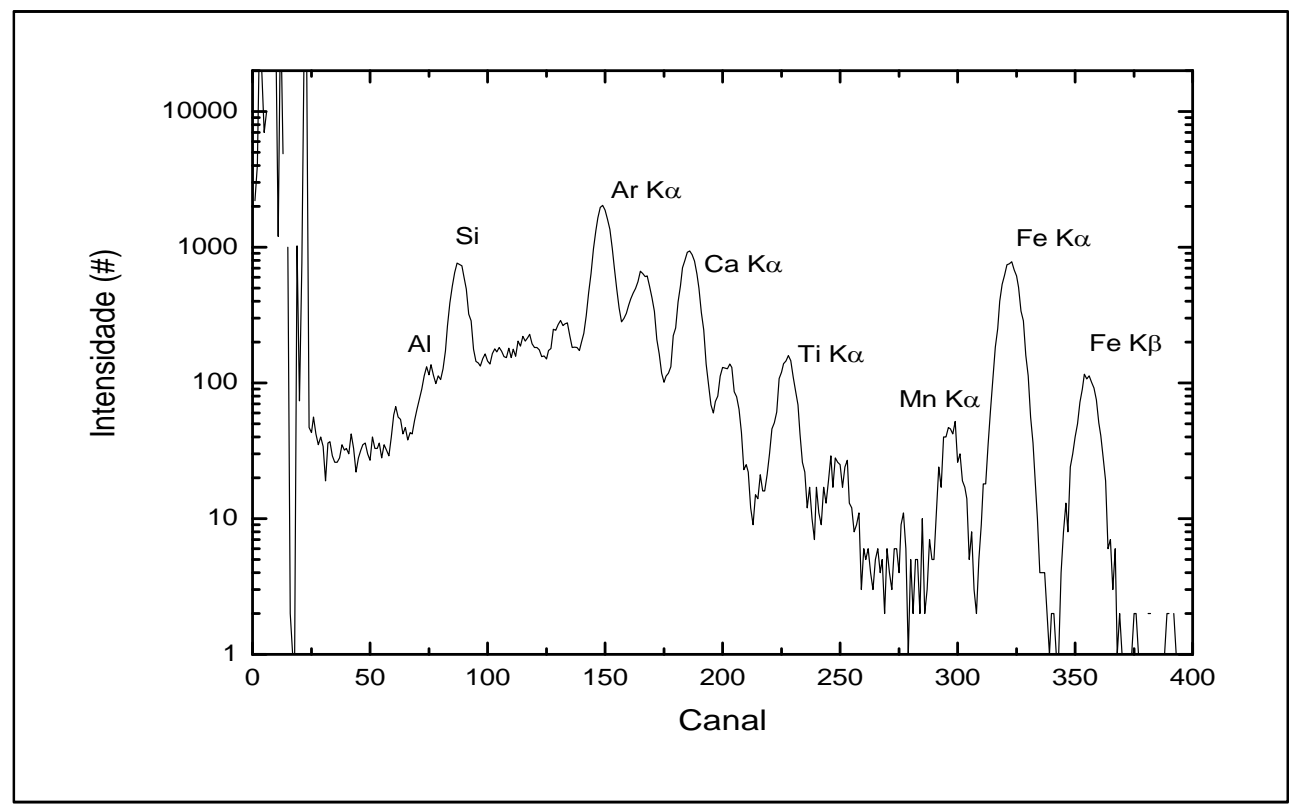

Figura 15. Espectro de raios X típico obtido para a amostra de cerâmica Etnográfica através da técnica PIXE obtidos no laboratório LAMFI-IFUSP ( $1^{\circ}$ experimento).

Nos espectros, os picos referentes às transições da camada $\mathrm{K}$ dos elementos presentes na cerâmica podem ser observados. As áreas destes picos estão diretamente relacionadas com o número de raios $\mathrm{X}$ emitidos por determinado elemento, sendo proporcional ao número de átomos desse elemento na amostra. Os picos de raios $\mathrm{X}$ estão relacionados com as diferentes transições entre as camadas eletrônicas dos átomos presentes na amostra.

Utilizando a área correspondente a cada pico é possível determinar a concentração relativa de cada elemento presente na amostra utilizando como normalização a soma das áreas obtidas para cada espectro. Esta normalização é feita para minimizar o efeito da diferença de carga incidente sobre cada amostra. 
Para a obtenção da área dos picos, utilizou-se o programa WinQXAS (Quantitative X-Ray Analysis System) [42] utilizado na análise quantitativa de raios X. O pacote computacional QXAS, desenvolvido e distribuído pela IAEA (International Atomic Energy Agency) avalia o espectro ajustando a altura e a largura dos picos, descontando também a contribuição do fundo estatístico presente no espectro de raios X.

Ao todo foram analisados 15 elementos, entre matriz e elementos traços. Os elementos majoritários (com massa > 5\%) observados são $\mathrm{Si}, \mathrm{K}, \mathrm{Ca}, \mathrm{Ti}$ e $\mathrm{Fe}$ e os minoritários são $\mathrm{Al}, \mathrm{S}, \mathrm{Cl}, \mathrm{V}, \mathrm{Cr}, \mathrm{Mn}, \mathrm{Ni}, \mathrm{Cu}, \mathrm{Zn}$ e Ba. Algumas diferenças significativas nas concentrações elementares foram notadas entre as amostras, em especial nos elementos metálicos. Alguns elementos estão apresentados na Figura 16. As incertezas destes resultados foram calculadas através da propagação de erros e correspondem a valores entre 1\% e 5\% para os elementos majoritários e entre $10 \%$ e $20 \%$ para os elementos minoritários e traços.

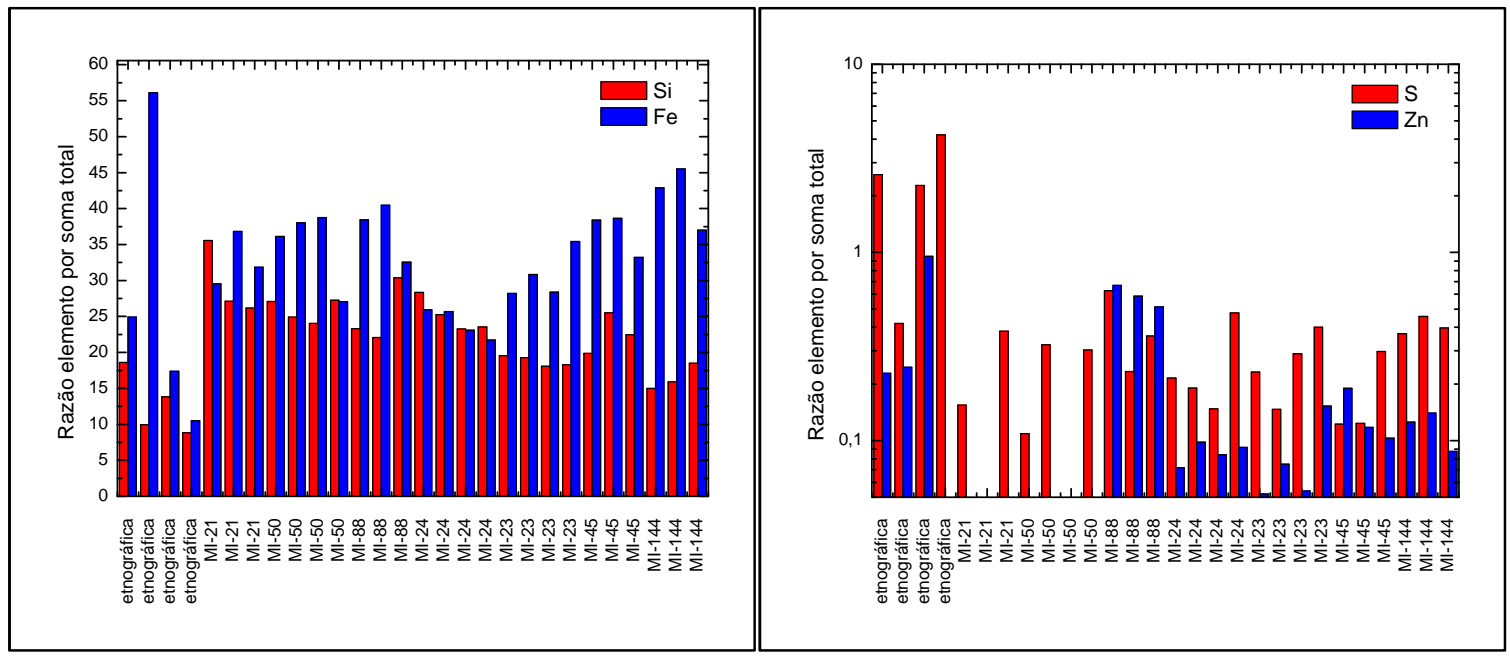

Figura 16. Resultados obtidos para a concentração elementar dos fragmentos analisados Como exemplos são apresentados dois elementos majoritários (Si e Fe) e dois elementos minoritários (Zn e S). As incertezas correspondem a valores entre 1\% e 5\% para os elementos majoritários e entre $10 \%$ e $20 \%$ para os elementos minoritários e traços. As incertezas foram calculadas através da propagação de erros.

De acordo com os valores encontrados, podemos apontar algumas diferenças entre a peça etnográfica e as demais, e algumas diferenças entre os objetos arqueológicos, especialmente com relação aos elementos metálicos, tais como o Zn. Porém, por serem análises preliminares, não se pode obter nenhuma conclusão desta primeira medida experimental. 
O segundo período de tomada de dados foi realizado utilizando a nova canalização montada para feixe externo no laboratório LAMFI. A linha foi utilizada sem as últimas melhorias, tais como quadrupolo eletrostático para uma melhor focalização do feixe, limitando desta forma a obtenção de corrente (menores do que $1 \mathrm{nA}$ ), o que inviabilizou a medida de elementos mais pesados $(Z>26)$. Desta forma, a análise foi restringida aos elementos majoritários presentes nas amostras, em especial Si e Fe. Nesse período foram analisadas 34 amostras, sendo 17 originárias do Sítio Sede (9 Guarani e 8 Pantanal) e 17 do Sítio Asa de Pote (6 Guarani e 11 Pantanal), apresentadas na Tabela 4. O material de referência NIST 2704 foi utilizado para a calibração e para as análises quantitativas. O padrão referenciado é necessário nos casos em que as amostras analisadas são consideradas alvos espessos, ou seja, quando o feixe incidente para dentro da amostra.

Tabela 4. Amostras de cerâmicas brasileiras arqueológicas analisadas no segundo experimento utilizando a técnica PIXE no laboratório LAMFI.

\begin{tabular}{ccc}
\hline \hline Amostra & Sítio & Tradição \\
\hline \hline MI1-163 & Sede & Guarani \\
\hline MI1-168 & Sede & Guarani \\
\hline MI1-182 & Sede & Guarani \\
\hline MI1-296 & Sede & Guarani \\
\hline MI1-962 & Sede & Pantanal \\
\hline MI1-965 & Sede & Pantanal \\
\hline MI1-973 & Sede & Pantanal \\
\hline MI1-974 & Sede & Pantanal \\
\hline MI1-985 & Sede & Pantanal \\
\hline MI1-1017 & Sede & Pantanal \\
\hline MI1-1026 & Sede & Pantanal \\
\hline MI1-1035 & Sede & Pantanal \\
\hline MI1-1900 & Sede & Guarani \\
\hline MI1-1901 & Sede & Guarani \\
\hline MI1-1906 & Sede & Guarani \\
\hline MI1-1909 & Sede & Guarani \\
\hline MI1-1912 & Sede & Guarani \\
\hline \hline
\end{tabular}

\begin{tabular}{ccc}
\hline \hline Amostra & Sítio & Tradição \\
\hline \hline MI6-3 & Asa do Pote & Pantanal \\
\hline MI6-15 & Asa do Pote & Pantanal \\
\hline MI6-18 & Asa do Pote & Pantanal \\
\hline MI6-36 & Asa do Pote & Pantanal \\
\hline MI6-50 & Asa do Pote & Pantanal \\
\hline MI6-59 & Asa do Pote & Pantanal \\
\hline MI6-80 & Asa do Pote & Pantanal \\
\hline MI6-81 & Asa do Pote & Pantanal \\
\hline MI6-86 & Asa do Pote & Guarani \\
\hline MI6-132 & Asa do Pote & Guarani \\
\hline MI6-139 & Asa do Pote & Pantanal \\
\hline MI6-150 & Asa do Pote & Guarani \\
\hline MI6-154 & Asa do Pote & Guarani \\
\hline MI6-160 & Asa do Pote & Guarani \\
\hline MI6-167 & Asa do Pote & Guarani \\
\hline MI6-374 & Asa do Pote & Pantanal \\
\hline MI6-389 & Asa do Pote & Pantanal \\
\hline \hline
\end{tabular}


No experimento utilizou-se um feixe de prótons com energia de 2,4 $\mathrm{MeV}$ antes da janela de saída do feixe correspondendo a uma energia de 1,8 MeV, com uma corrente de 0,2 nA e com 10 minutos de tempo de irradiação em cada ponto. Foram irradiados 3 pontos por peça, sendo um ponto em cada superfície plana do fragmento (anterior e posterior) e um na região lateral da peça, sempre na região da pasta da peça. Para realizar a análise dos espectros e a obtenção das áreas correspondentes a cada elemento foi utilizado o programa WinQXAS.

Ao todo foram observados 7 elementos pertencentes à matriz das amostras. Os elementos observados foram $\mathrm{Al}, \mathrm{Si}, \mathrm{K}, \mathrm{Ca}, \mathrm{Ti}, \mathrm{Mn}$ e Fe. Nas Figuras 17 e 18 são apresentados os valores de concentração elementar obtida. Os valores foram determinados com a utilização do padrão referenciado e correspondem às medidas realizadas na região lateral dos fragmentos. As incertezas para os elementos (majoritários) variam entre 5 e $10 \%$ e foram calculadas através de propagação de erros.

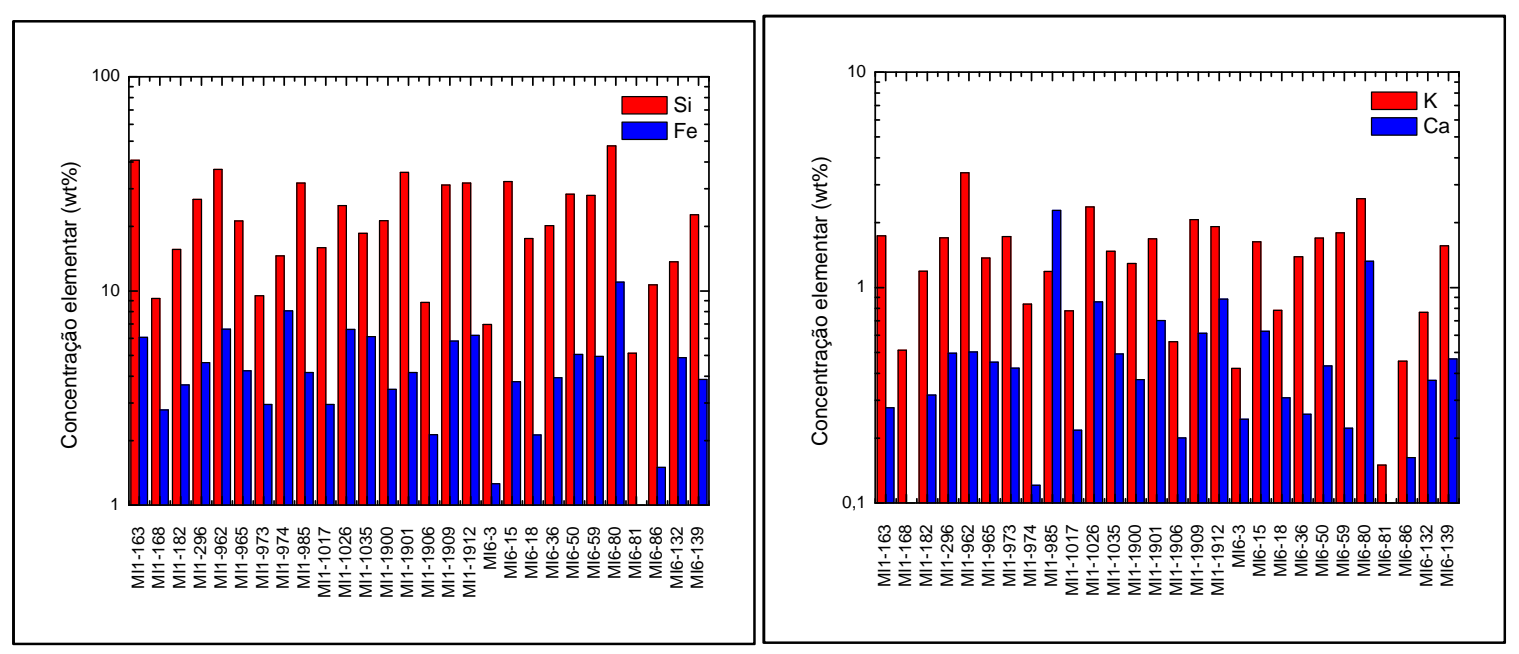

Figura 17. Gráficos de Concentração elementar versus Amostras para os elementos $\mathrm{Si}, \mathrm{Fe}, \mathrm{Ke} \mathrm{Ca}$. As incertezas para os elementos (majoritários) variam entre 5 e $10 \%$ e foram calculadas através de propagação de erros. 


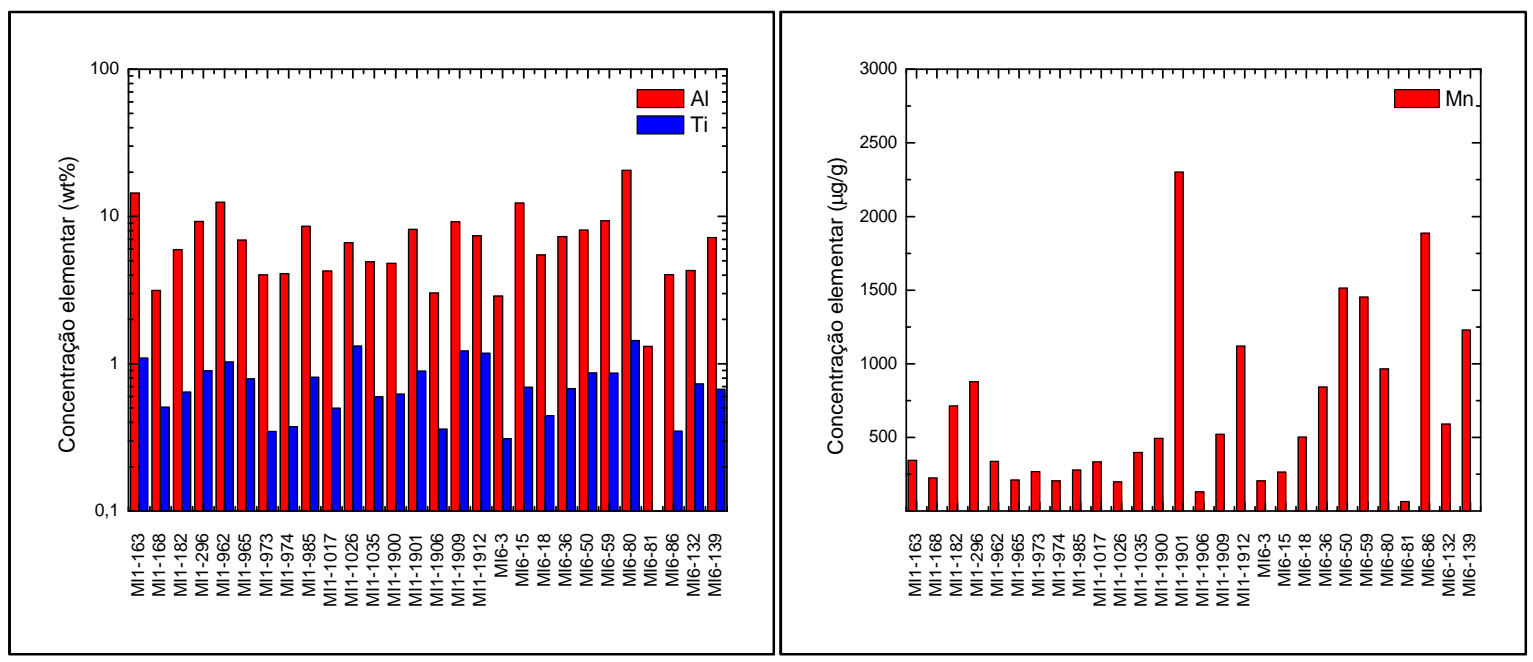

Figura 18. Gráficos de Concentração elementar versus Amostras para os elementos Al, Ti e Mn. As incertezas para os elementos (majoritários) variam entre 5 e $10 \%$ e foram calculadas através de propagação de erros.

Em uma análise inicial, nestes resultados não é possível apontar nenhuma diferença relevante, seja com relação ao sítio arqueológico ou com relação à cultura estudada. Em todos os elementos existem amostras discrepantes das demais, estes casos deverão ser analisados separadamente. Os resultados obtidos para o elemento Mn apontam uma pequena variação de concentração nos fragmentos pertencentes à cultura Guarani, encontrados no sítio Asa do Pote.

Aplicando as técnicas de análise multivariada, não é possível obter nenhum agrupamento seja com relação ao sítio arqueológico ou em relação à cultura a qual pertencem os fragmentos. Os gráficos e valores obtidos se apresentam de maneira dispersa e sem coerência. 


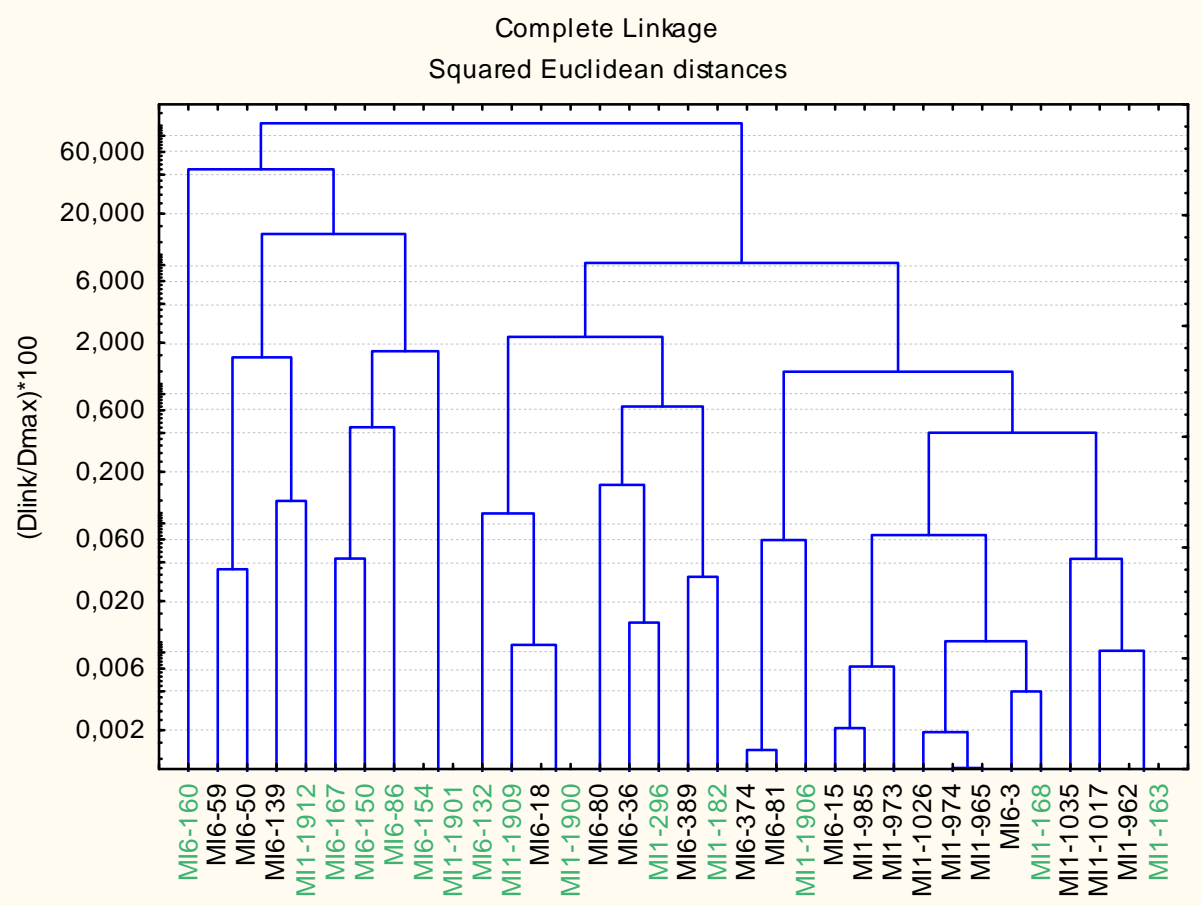

Figura 19. Dendrograma obtido para o conjunto de 34 amostras estudadas através da técnica PIXE no Laboratório LAMFI ( $2^{\circ}$ experimento). Como parâmetros para a realização dos cálculos, foram utilizados todos os elementos. Os fragmentos pertencentes à cultura Guarani estão destacados em cor verde e os fragmentos pertencentes à cultura Pantanal estão em cor preta.

Um terceiro experimento utilizando a técnica PIXE foi realizado no laboratório Peletron localizado no Instituto de Física da Universidad Autônoma de México, utilizando a linha dedicada a análises arqueométricas com a utilização de um feixe externo.

Neste estudo foi analisada a pasta de 32 fragmentos cerâmicos, apresentados na Tabela 5. Dois detectores foram usados para a detecção dos raios X, um detector Si-Pin com um fluxo de He para os elementos leves e um detector LEGe com um absorvedor de $150 \mu \mathrm{m}$ de Al para os elementos pesados. A energia do feixe de prótons com 1,5 mm de diâmetro foi de $3 \mathrm{MeV}$ antes da saída do feixe, correspondendo a uma energia de 2,6 MeV na amostra e o tempo de irradiação foi de 5 minutos. Materiais de referência NIST (SRM 2704, 2710, 2711) também foram analisados para a calibração e medidas de concentração. 
Tabela 5. Amostras de cerâmicas brasileiras arqueológicas analisadas utilizando a técnica PIXE no laboratório Peletron/UNAM.

\begin{tabular}{ccc}
\hline \hline Amostra & Sítio & Tradição \\
\hline \hline MI6-160 & Asa do Pote & Guarani \\
\hline MI6-374 & Asa do Pote & Pantanal \\
\hline MI6-50 & Asa do Pote & Pantanal \\
\hline MI6-36 & Asa do Pote & Pantanal \\
\hline MI6-15 & Asa do Pote & Pantanal \\
\hline MI6-80 & Asa do Pote & Pantanal \\
\hline MI6-3 & Asa do Pote & Pantanal \\
\hline MI6-139 & Asa do Pote & Pantanal \\
\hline MI6-150 & Asa do Pote & Guarani \\
\hline MI6-59 & Asa do Pote & Pantanal \\
\hline MI6-167 & Asa do Pote & Guarani \\
\hline MI6-154 & Asa do Pote & Guarani \\
\hline MI6-86 & Asa do Pote & Guarani \\
\hline MI6-132 & Asa do Pote & Guarani \\
\hline MI6-18 & Asa do Pote & Pantanal \\
\hline MI6-128 & Asa do Pote & Guarani \\
\hline \hline
\end{tabular}

\begin{tabular}{ccc}
\hline \hline Amostra & Sítio & Tradição \\
\hline \hline MI6-81 & Asa do Pote & Pantanal \\
\hline MI6-389 & Asa do Pote & Pantanal \\
\hline MI1-1906 & Sede & Guarani \\
\hline MI1-1901 & Sede & Guarani \\
\hline MI1-1925 & Sede & Guarani \\
\hline MI1-1902 & Sede & Guarani \\
\hline MI1-295 & Sede & Guarani \\
\hline MI1-1017 & Sede & Pantanal \\
\hline MI1-965 & Sede & Pantanal \\
\hline MI1-1035 & Sede & Pantanal \\
\hline MI1-985 & Sede & Pantanal \\
\hline MI1-974 & Sede & Pantanal \\
\hline MI1-973 & Sede & Pantanal \\
\hline MI1-11 & Sede & Guarani \\
\hline MI1-976 & Sede & Pantanal \\
\hline MI1-1900 & Sede & Guarani \\
\hline \hline
\end{tabular}

Um espectro típico obtido pela técnica é apresentado na Figura 20, correspondendo ao espectro adquirido para o fragmento MI1-1906. Na Figura 20A é apresentado o espectro obtido pelo detector Si-Pin dedicado aos elementos com menor $\mathrm{Z}$ (Z ک 6 ). A Figura 20B apresenta o espectro obtido pelo detector LEGe dedicado aos elementos com maior $Z(Z \geq 26)$. Em ambos os espectros são indicados alguns elementos que se destacam. Para a obtenção das áreas relativas aos picos de todos os elementos presente no espectro foi utilizado o programa WinQXAS. 

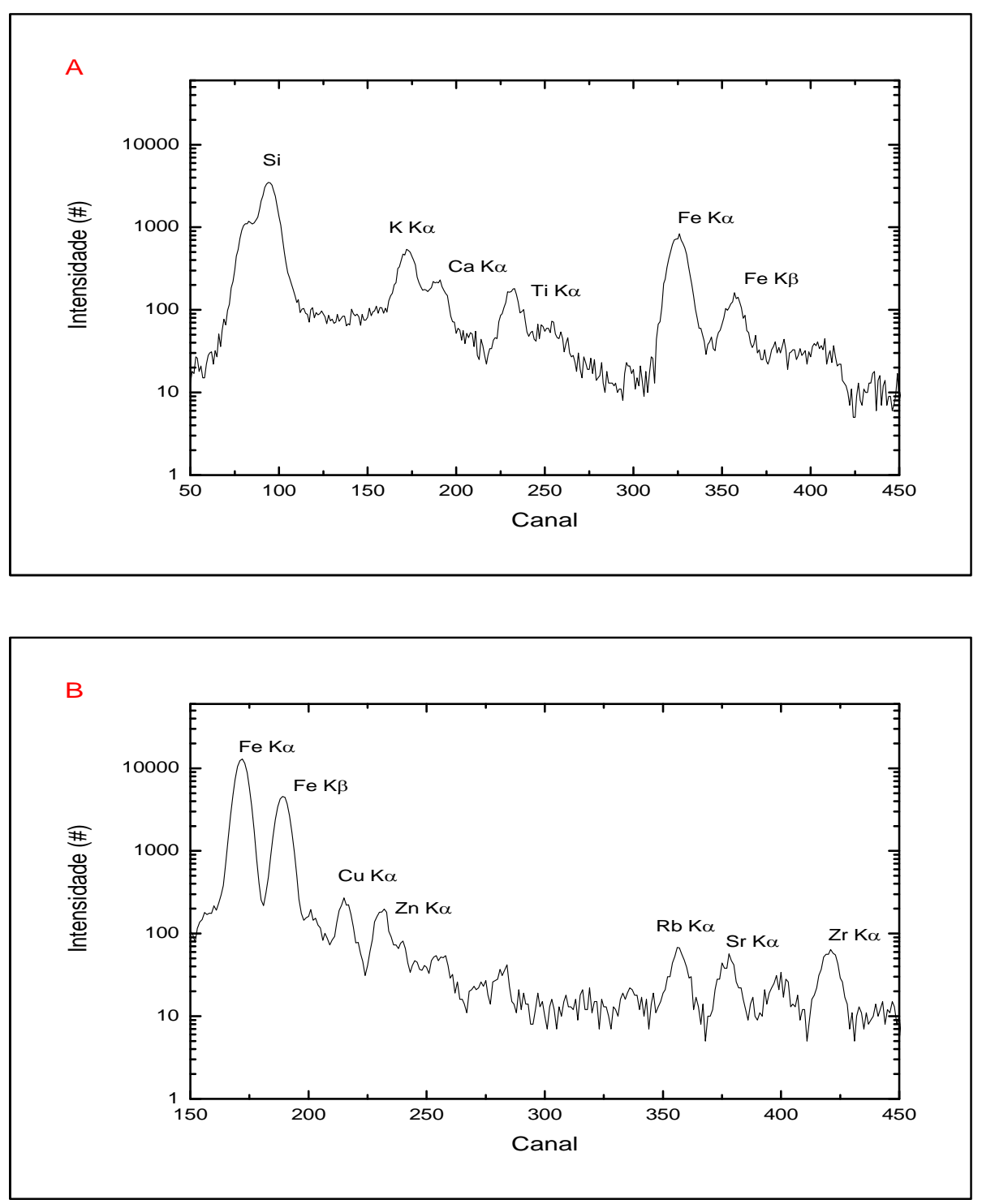

Figura 20. Espectros típicos obtidos pela técnica PIXE para o fragmento cerâmico MI1-1906, obtidos no laboratório Peletron-UNAM. A. Espectro obtido pelo detector Si-Pin dedicado aos elementos com Z ㄴ6; B. Espectro obtido pelo detector LEGe dedicado aos elementos com $\mathrm{Z} \geq 26$.

Por meio deste experimento foi possível determinar a concentração de 15 elementos, entre matriz e elementos traços. Os elementos encontrados foram $\mathrm{Al}, \mathrm{Si}, \mathrm{K}, \mathrm{Ca}, \mathrm{Ti}, \mathrm{Mn}, \mathrm{Fe}$, $\mathrm{Ni}, \mathrm{Cu} \mathrm{Zn}, \mathrm{Rb}, \mathrm{Sr}, \mathrm{Y} \mathrm{Zr}$ e Pb. 
Para analisar os espectros obtidos, as áreas correspondentes a cada elemento foram normalizadas pela soma total das áreas, obtendo desta forma uma relação de concentração normalizada dos elementos observados. Este processo torna a análise independente da variação da carga sobre as amostras.

Gráficos de Amostra versus área normalizada são utilizados para verificar a variação elementar entre as amostras pertencentes às duas tradições encontradas nos dois sítios arqueológicos estudados.

Nas Figuras 21 e 22 são apresentados gráficos de alguns elementos como exemplo. As incertezas associadas aos valores foram determinadas através de propagações de erros. As amostras estão diferenciadas por cores, onde as em cor cinza correspondem aos fragmentos encontrados no Sítio Sede/Córrego Lalima e as em cor vermelha correspondem ao Sítio Asa do Pote.

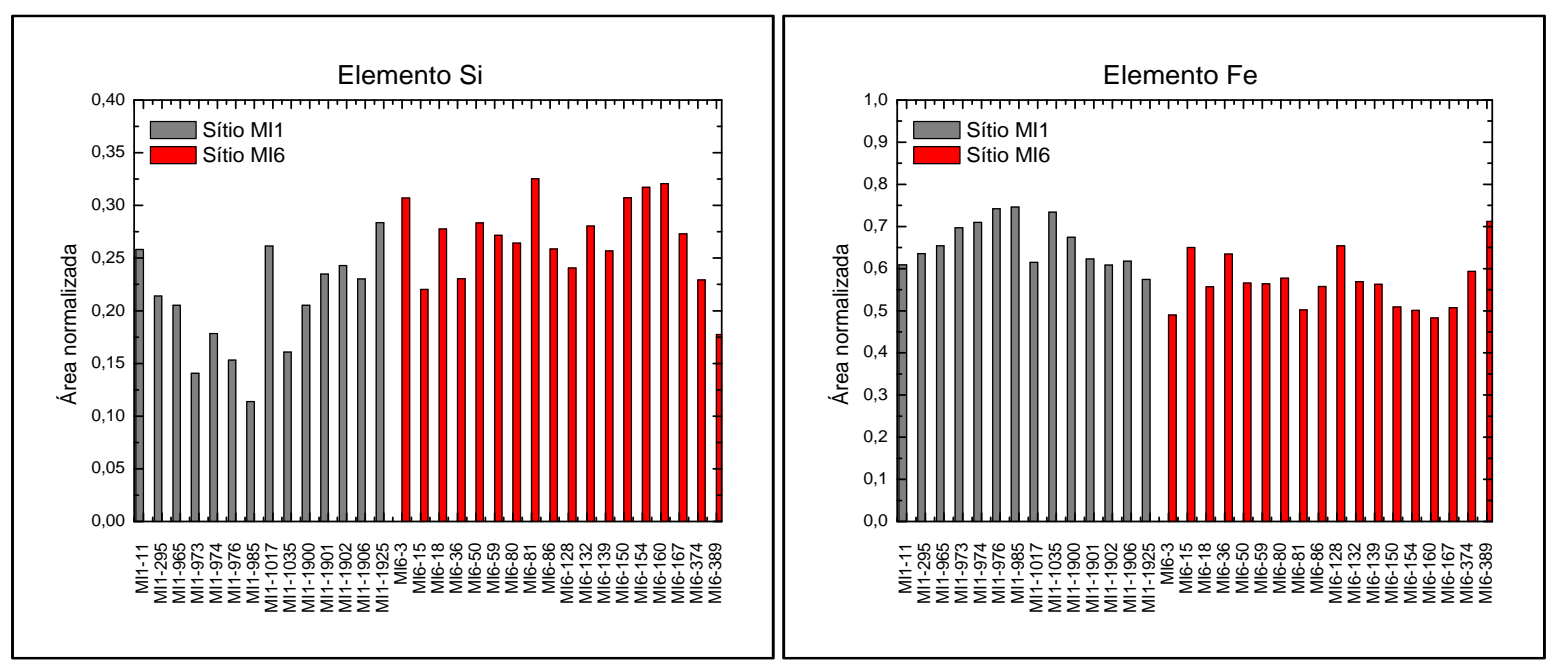

Figura 21. Gráficos de Área normalizada versus Amostras para os elementos Si e Fe. A diferenciação em cores corresponde aos sítios arqueológicos. As incertezas para os elementos Si e Fe variam entre $1 \%$ e $2 \%$ dos valores. 

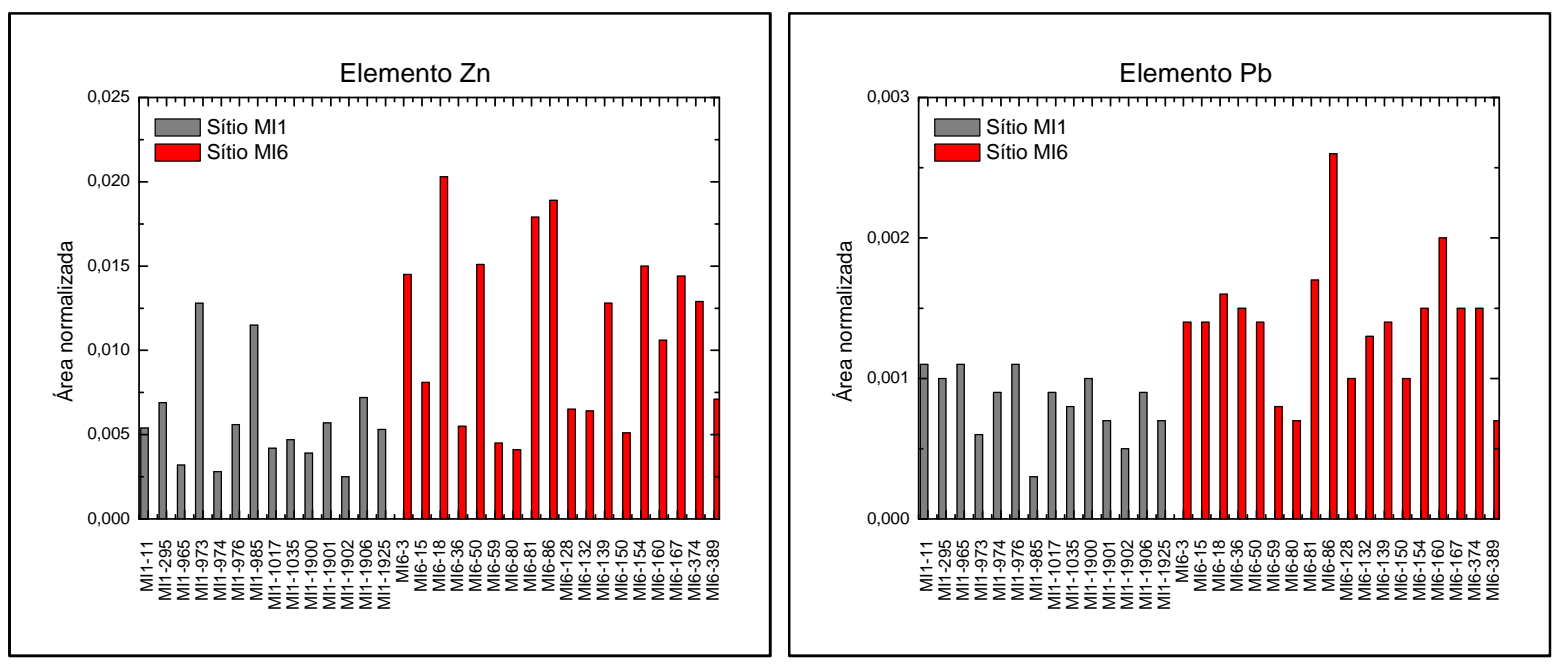

Figura 22. Gráficos de Área normalizada versus Amostras para os elementos Zn e Pb. A diferenciação em cores corresponde aos sítios arqueológicos. As incertezas para os elementos Zn e $\mathrm{Pb}$ variam entre $5 \%$ e $10 \%$ dos valores.

De acordo com os valores encontrados, podemos apontar algumas diferenças entre as peças dos dois sítios arqueológicos. Neste experimento foi verificada a importância de medir elementos com Z>26, que neste estudo são os considerados elementos minoritários e elementos traços. Essa medida indica que tais elementos são fatores relevantes para um possível agrupamento aplicando uma análise estatística multivariada. É possível observar algumas diferenças principalmente nos elementos $\mathrm{Zn}$ e $\mathrm{Pb}$. Essas diferenças estão associadas ao sítio arqueológico onde os fragmentos foram encontrados. No Sítio Asa do Pote (MI6), as amostras possuem, em média, uma concentração maior destes elementos do que no Sítio Sede/Córrego Lalima (MI1).

Analisando a Figura 23, podemos observar que não há diferenças entre as concentrações médias normalizadas quando nos referimos às tradições culturais a que os fragmentos pertencem, dentro de um mesmo sítio arqueológico. Os fragmentos estão diferenciados em cores, onde os indicados em cor verde correspondem aos fragmentos pertencentes à tradição Guarani e os em cor cinza correspondem à tradição Pantanal. 

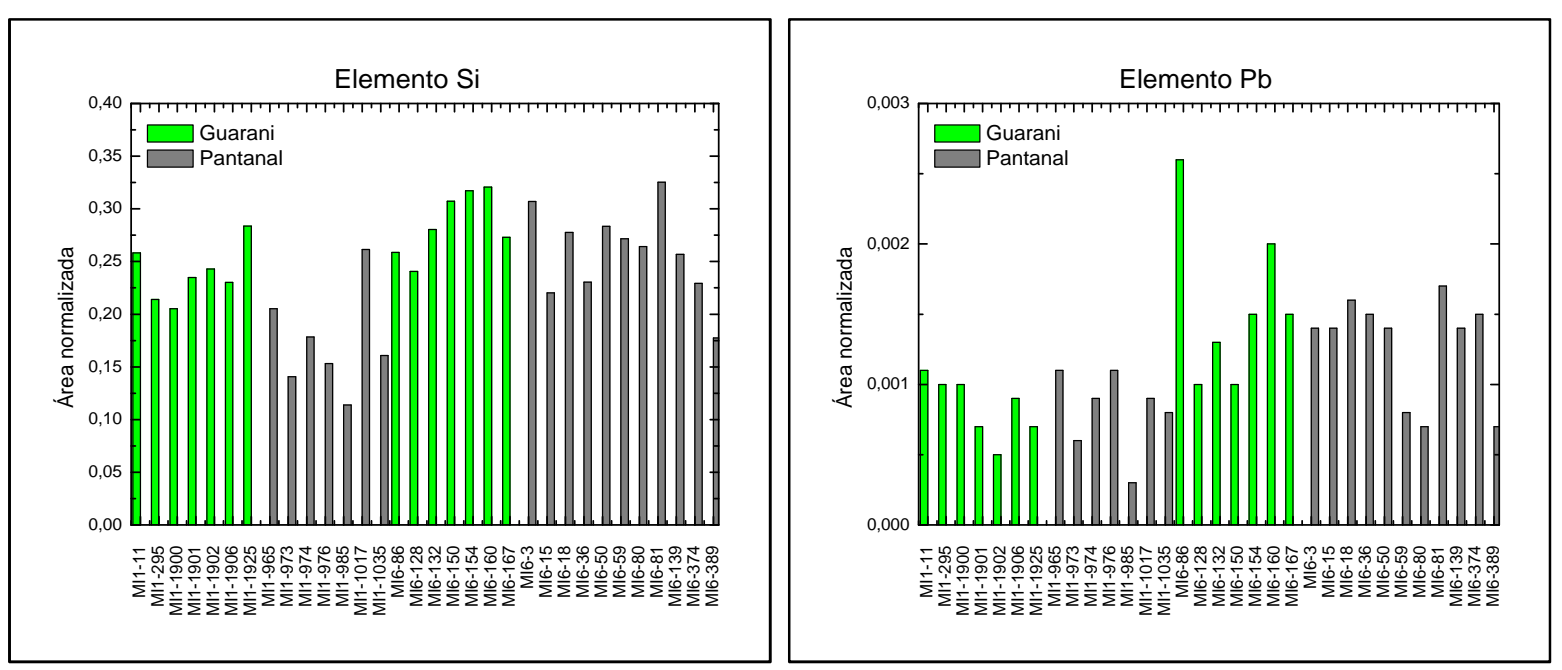

Figura 23. Gráficos de Área normalizada versus Amostras para os elementos Si e Pb. A diferenciação em cores corresponde às tradições às quais os fragmentos pertencem. As incertezas para o elemento Si corresponde à $2 \%$ dos valores e as incertezas para o elemento Pb correspondem à $10 \%$ dos valores.

Para verificar uma correlação elementar simples, foram gerados gráficos de Elemento versus Elemento. Ao analisar essas relações com relação aos sítios arqueológicos, observamos que elementos tais como $\mathrm{Al}, \mathrm{Si}, \mathrm{Fe}, \mathrm{Zn}$ e $\mathrm{Pb}$ mostram-se capazes de separar os fragmentos em dois grupos distintos.

Inicialmente foram gerados os gráficos para a comparação das concentrações elementares entre os sítios arqueológicos. A Figura 24 A mostra o gráfico de $\mathrm{Al}$ versus $\mathrm{Pb}$ onde é possível determinar duas regiões distintas, com algumas poucas sobreposições. Outro gráfico de interesse é Si versus Fe onde é possível notar uma anticorrelação entre os dois elementos majoritários da matriz da pasta cerâmica.

Em ambos os gráficos os fragmentos estão diferenciados por cores. Os de cor vermelha correspondem aos fragmentos encontrados no Sítio Asa do Pote (MI6) e em cor preta os fragmentos encontrados no Sítio Sede/Córrego Lalima (MI1). 


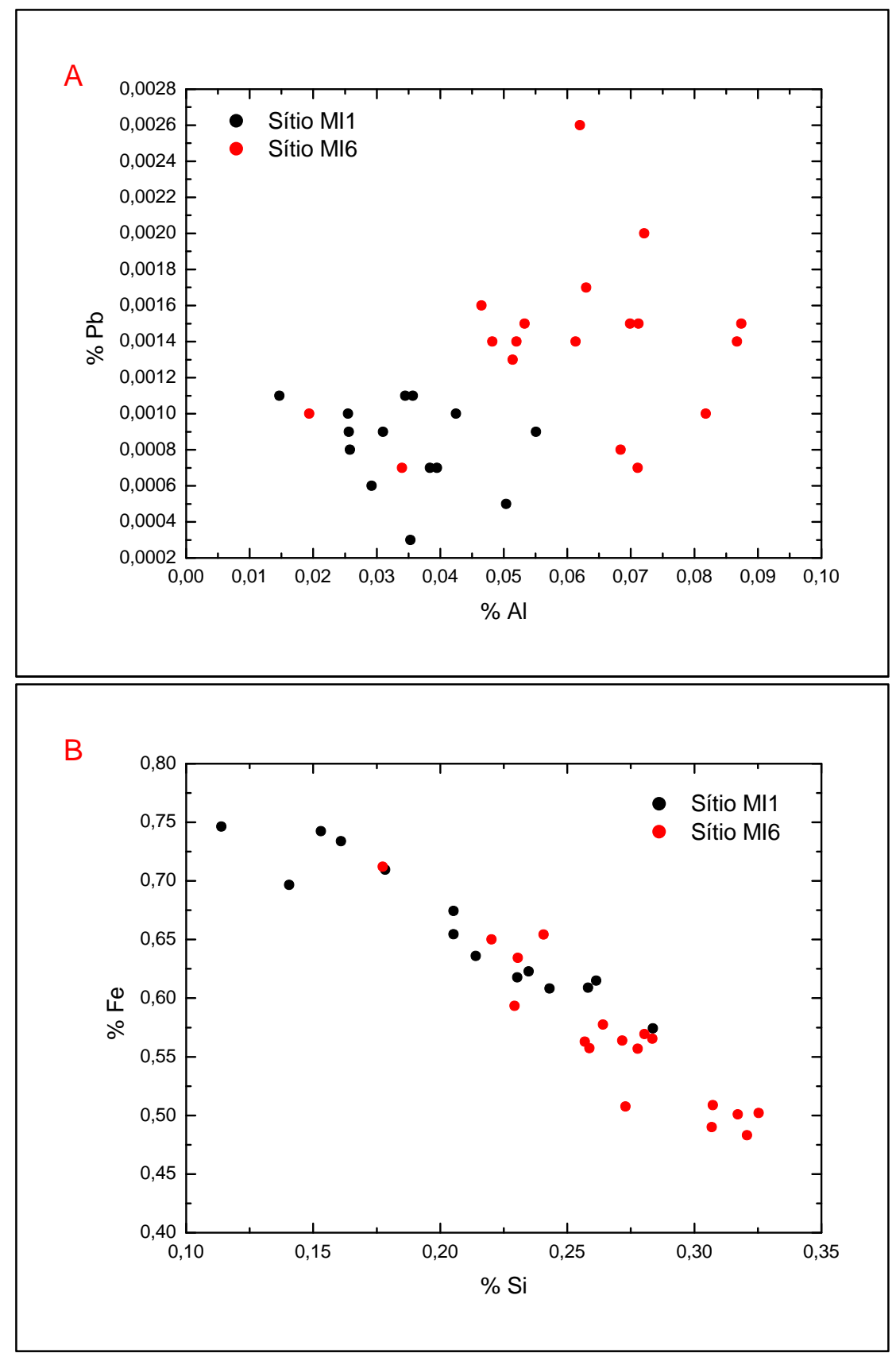

Figura 24. Gráficos de área normalizada obtidos através da técnica PIXE no laboratório PeletronUNAM. A diferenciação em cores corresponde aos sítios arqueológicos. A. Gráfico "Al versus Pb"; B. Gráfico "Si versus Fe".

O mesmo procedimento foi feito separando os fragmentos com relação à sua tradição. Ao avaliar os dados com relação às tradições culturais, não observamos nenhuma combinação que separe os fragmentos cerâmicos de acordo com as informações iniciais. 
Na Figura 25 estão apresentados exemplos de combinações entre elementos, onde se pode notar que os grupos estão sempre sobrepostos. Em ambos os gráficos os fragmentos estão diferenciados por cores. Os de cor verde correspondem aos fragmentos pertencentes à tradição Guarani e os e em cor preta são os fragmentos pertencentes à tradição Pantanal.

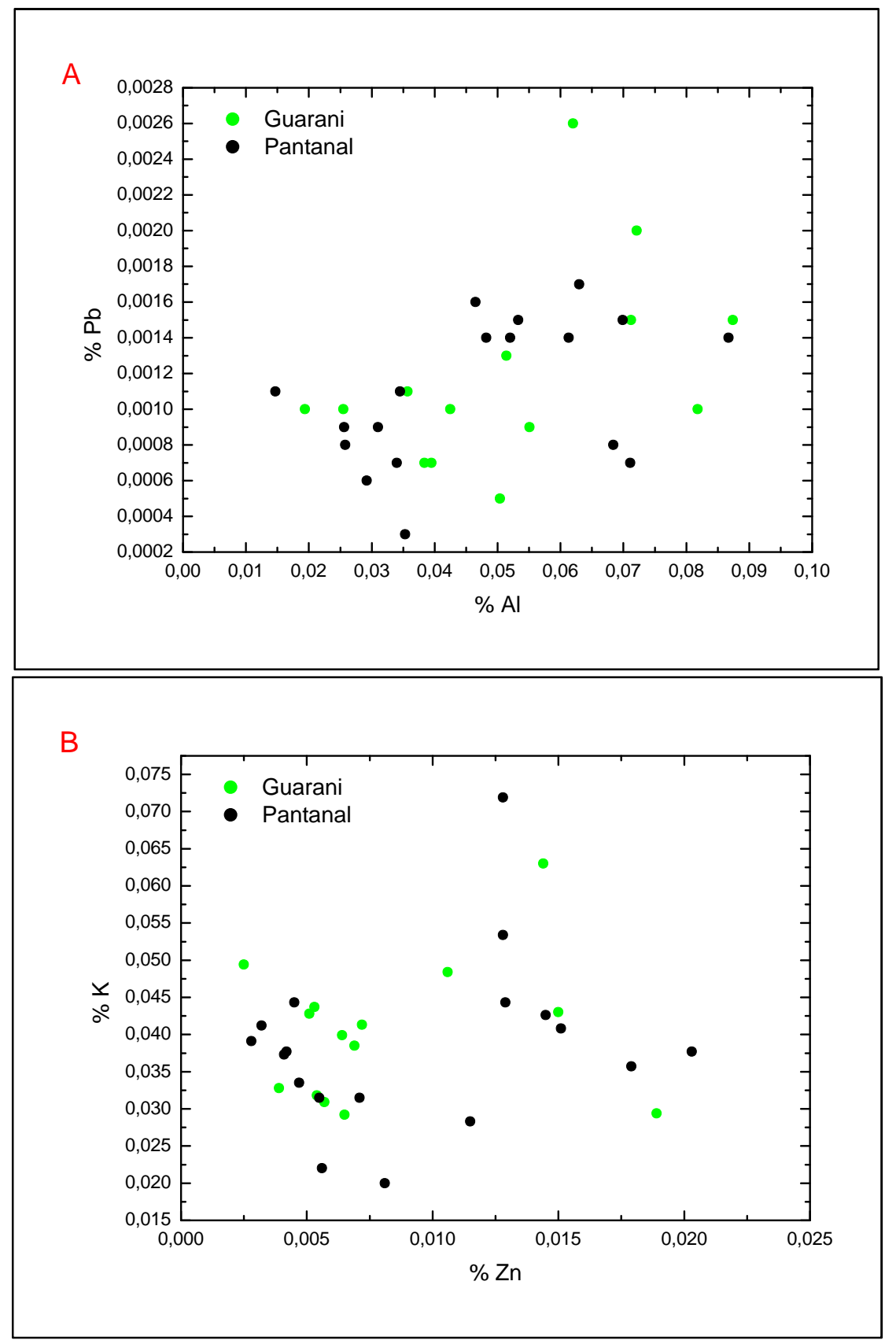

Figura 25. Gráficos de área normalizada obtidos através da técnica PIXE no laboratório PeletronUNAM. A diferenciação em cores corresponde às tradições. A. Gráfico "Al versus Pb"; B. Gráfico "Zn versus $K "$. 
Neste conjunto de dados também foram aplicadas técnicas de análise estatística. A técnica de análise de cluster mostrou-se eficiente quando utilizada para separar os fragmentos cerâmicos com relação ao sítio em que foram encontrados. Utilizando os elementos minoritários ( $\mathrm{Al}, \mathrm{K}, \mathrm{Ca}, \mathrm{Zn}$ e $\mathrm{Rb}$ ) foi possível determinar o dendrograma apresentado na Figura 26. Podemos observar que em uma distância de dissimilaridade no valor de 100 é possível separar um grupo de fragmentos pertencentes ao sítio Asa do Pote. O segundo grupo possui peças predominantemente do sítio Sede/Córrego Lalima e alguns poucos itens pertencente ao sítio Asa do Pote.

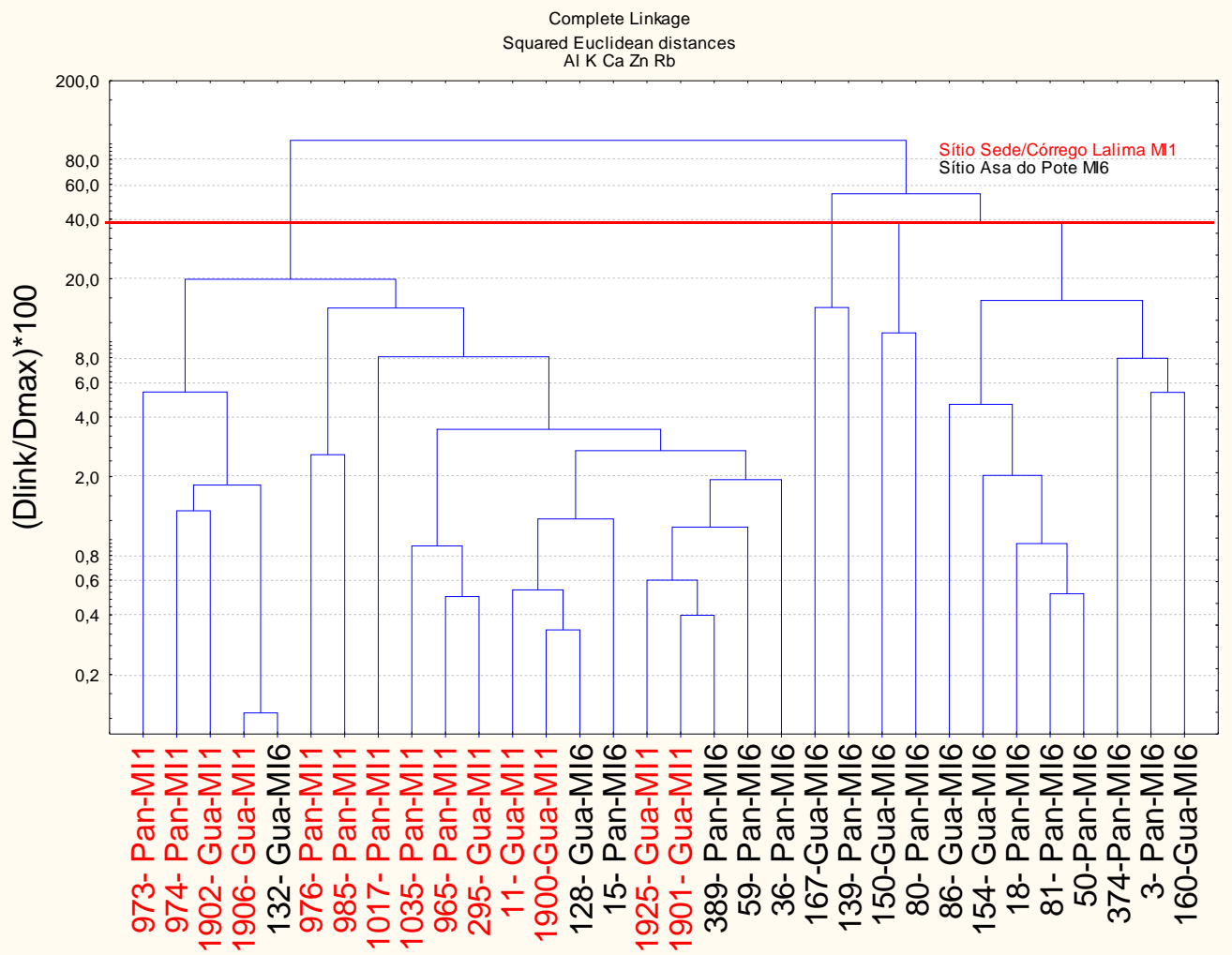

Figura 26. Dendrograma obtido para conjunto de 32 fragmentos cerâmicos analisados com a técnica PIXE no Laboratório Peletron-UNAM. A linha vermelha indica uma distância de dissimilaridade de valor 100. A separação é obtida quando analisado com relação aos sítios arqueológicos indicados em cores, a cor vermelha representa o sítio Sede/Córrego Lalima e a cor preta representa o Sítio Asa do Pote.

Realizando o mesmo procedimento, porém em às tradições, não foi encontrado nenhum conjunto de elementos que agrupasse os fragmentos conforme a classificação inicial fornecida. 
O mesmo ocorre quando aplicamos a análise PCA nos dados. Com os elementos Al, $\mathrm{K}, \mathrm{Zn}$ e Rb, obtemos uma pequena separação com relação ao sítio arqueológico. Essa separação possui algumas sobreposições conforme apresentado na Figura 27. Não foi encontrado nenhum conjunto de elementos que agrupasse os fragmentos conforme as informações iniciais.

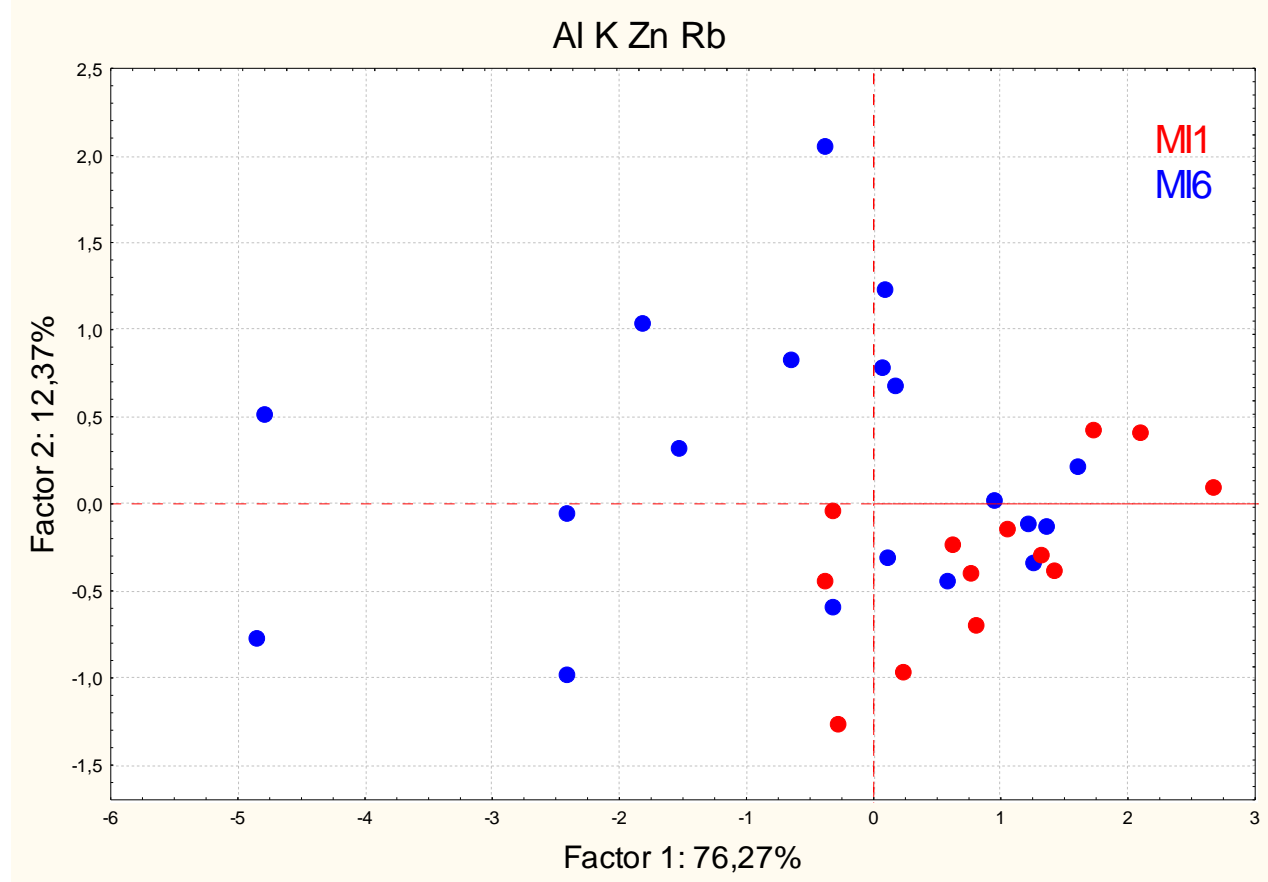

Figura 27. Análise PCA obtida para conjunto de 32 fragmentos cerâmicos analisados com a técnica PIXE no Laboratório Peletron-UNAM. A separação é obtida quando analisado com relação aos sítios arqueológicos, estando estes indicados em cores, a cor vermelha representa o sítio Sede/Córrego Lalima (MI1) e a cor azul representa o sítio Asa do Pote. 


\subsection{Fluorescência de Raios X (XRF)}

Foram realizados neste estudo, dois experimentos utilizando a técnica XRF. O primeiro experimento foi realizado no laboratório Peletron localizado no Instituto de Física da Universidad Autónoma do México, com o auxílio do professor José Luis Ruvalcaba-Sil. Um segundo experimento foi realizado no Instituto de Física da Universidade de São Paulo, com o auxílio do professor Augusto Neiva Camara.

No laboratório Peletron-UNAM foi realizado um período de máquina com a utilização do sistema portátil XRF SANDRA. Foram analisadas 48 amostras de ambos os sítios e ambas as culturas sendo realizadas três irradiações por peça na região da pasta, obtendo um espectro para a parte anterior, posterior e lateral de cada peça. As amostras analisadas nesse período estão apresentadas na Tabela 6 .

Tabela 6. Amostras de cerâmicas brasileiras arqueológicas analisadas utilizando a técnica XRF.

\begin{tabular}{ccc}
\hline \hline Amostra & Sítio & Tradição \\
\hline \hline MI6-128 & Asa do Pote & Guarani \\
\hline MI6-132 & Asa do Pote & Guarani \\
\hline MI6-160 & Asa do Pote & Guarani \\
\hline MI6-86 & Asa do Pote & Guarani \\
\hline MI6-154 & Asa do Pote & Guarani \\
\hline MI6-167 & Asa do Pote & Guarani \\
\hline MI6-150 & Asa do Pote & Guarani \\
\hline MI6-59 & Asa do Pote & Pantanal \\
\hline MI6-139 & Asa do Pote & Pantanal \\
\hline MI6-3 & Asa do Pote & Pantanal \\
\hline MI6-36 & Asa do Pote & Pantanal \\
\hline MI680 & Asa do Pote & Pantanal \\
\hline MI650 & Asa do Pote & Pantanal \\
\hline MI6-374 & Asa do Pote & Pantanal \\
\hline MI6-81 & Asa do Pote & Pantanal \\
\hline MI6-15 & Asa do Pote & Pantanal \\
\hline MI6-389 & Asa do Pote & Pantanal \\
\hline MI6-18 & Asa do Pote & Pantanal \\
\hline MI1-1926 & Sede & Guarani \\
\hline MI1-1902 & Sede & Guarani \\
\hline MI1-1929 & Sede & Guarani \\
\hline MI1-1928 & Sede & Guarani \\
\hline MI1-936 & Sede & Pantanal \\
\hline MI1-1925 & Sede & Guarani \\
\hline \hline & & \\
\hline
\end{tabular}

\begin{tabular}{clc}
\hline \hline Amostra & Sítio & Tradição \\
\hline \hline MI1-295 & Sede & Guarani \\
\hline MI1-993 & Sede & Pantanal \\
\hline MI1-969 & Sede & Pantanal \\
\hline MI1-992 & Sede & Pantanal \\
\hline MI1-1920 & Sede & Guarani \\
\hline MI1-1901 & Sede & Guarani \\
\hline MI1-1906 & Sede & Guarani \\
\hline MI1-1900 & Sede & Guarani \\
\hline MI1-162 & Sede & Guarani \\
\hline MI1-985 & Sede & Pantanal \\
\hline MI1-1035 & Sede & Pantanal \\
\hline MI1-964 & Sede & Pantanal \\
\hline MI1-976 & Sede & Pantanal \\
\hline MI1-974 & Sede & Pantanal \\
\hline MI1-983 & Sede & Pantanal \\
\hline MI1-1017 & Sede & Pantanal \\
\hline MI1-1023 & Sede & Pantanal \\
\hline MI1-965 & Sede & Pantanal \\
\hline MI1-1005 & Sede & Pantanal \\
\hline MI1-959 & Sede & Pantanal \\
\hline MI1-1927 & Sede & Guarani \\
\hline MI1-1914 & Sede & Guarani \\
\hline MI1-11 & Sede & Guarani \\
\hline MI1-1919 & Sede & Guarani \\
\hline \hline & & \\
\hline
\end{tabular}


As condições experimentais desta análise correspondem a uma tensão de aceleração de $45 \mathrm{keV}$ com uma corrente de $0,30 \mathrm{~mA}$ e com um tempo de irradiação de 120 s por ponto. Um espectro típico obtido para o fragmento MI1-1906 é apresentado na Figura 28. O pico correspondente ao elemento Molibdênio é proveniente do tubo de raios X.

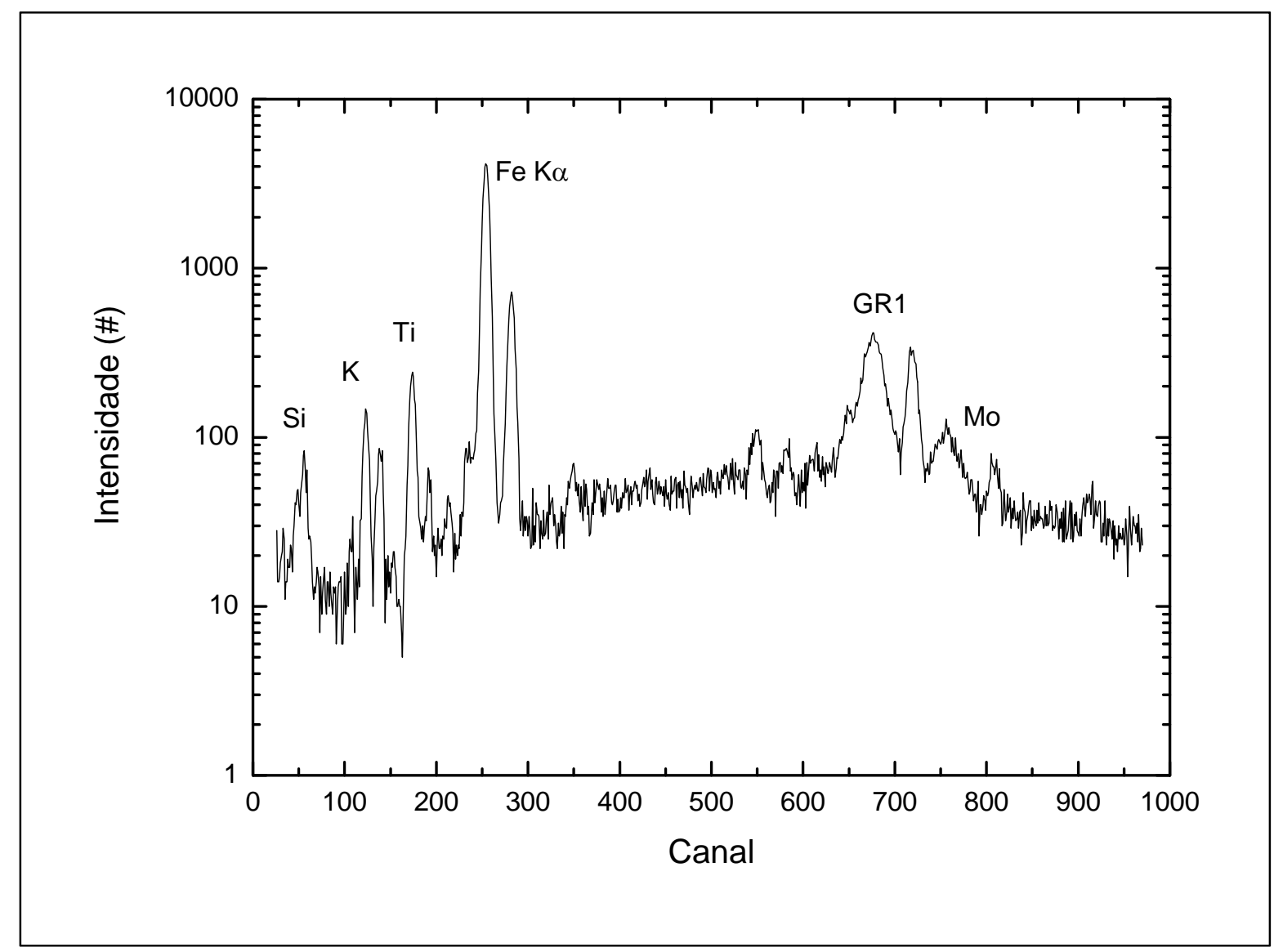

Figura 28. Espectro típico obtido pela técnica XRF para o fragmento cerâmico MI1-1906 no laboratório Peletron-UNAM com a utilização do sistema SANDRA.O pico de Molibdênio é proveniente do tudo de raios $X$.

Nesta análise foram identificados 14 elementos, entre matriz e elementos traços. Os elementos são: Al, Si, K, Ca, Ti, Cr, Mn, Fe, Cu, Zn, Rb, Sr, Y e Zr. Para a obtenção das áreas dos picos de raios X, utilizou-se o programa WinQXAS. A Figura 28 acima apresenta o pico GR1 não identificado. Esse pico não pode ser ajustado com sucesso e possivelmente ele corresponde a algum efeito de difração de raios $\mathrm{X}$ na amostra. 
Para determinar as concentrações elementares das amostras foi utilizado o padrão de referenciado NIST 2704 “Buffalo River Sediment”. Gráficos de Amostra versus Concentração foram utilizados para verificar a variação elementar entre as amostras pertencentes às duas tradições encontradas nos dois sítios arqueológicos estudados. Nas Figuras 29 e 30 são apresentados gráficos de alguns elementos como exemplo. Os elementos $\mathrm{Al}, \mathrm{Mn}, \mathrm{Zn}$ e $\mathrm{Zr}$ foram escolhidos por apresentarem alguma diferenciação. As amostras estão diferenciadas por cores, onde as apresentadas em cor cinza aos fragmentos encontrados no Sítio Sede/Córrego Lalima e as apresentadas em cor vermelha correspondem aos fragmentos do Sítio Asa do Pote. As incertezas foram calculadas através da propagação de erros.
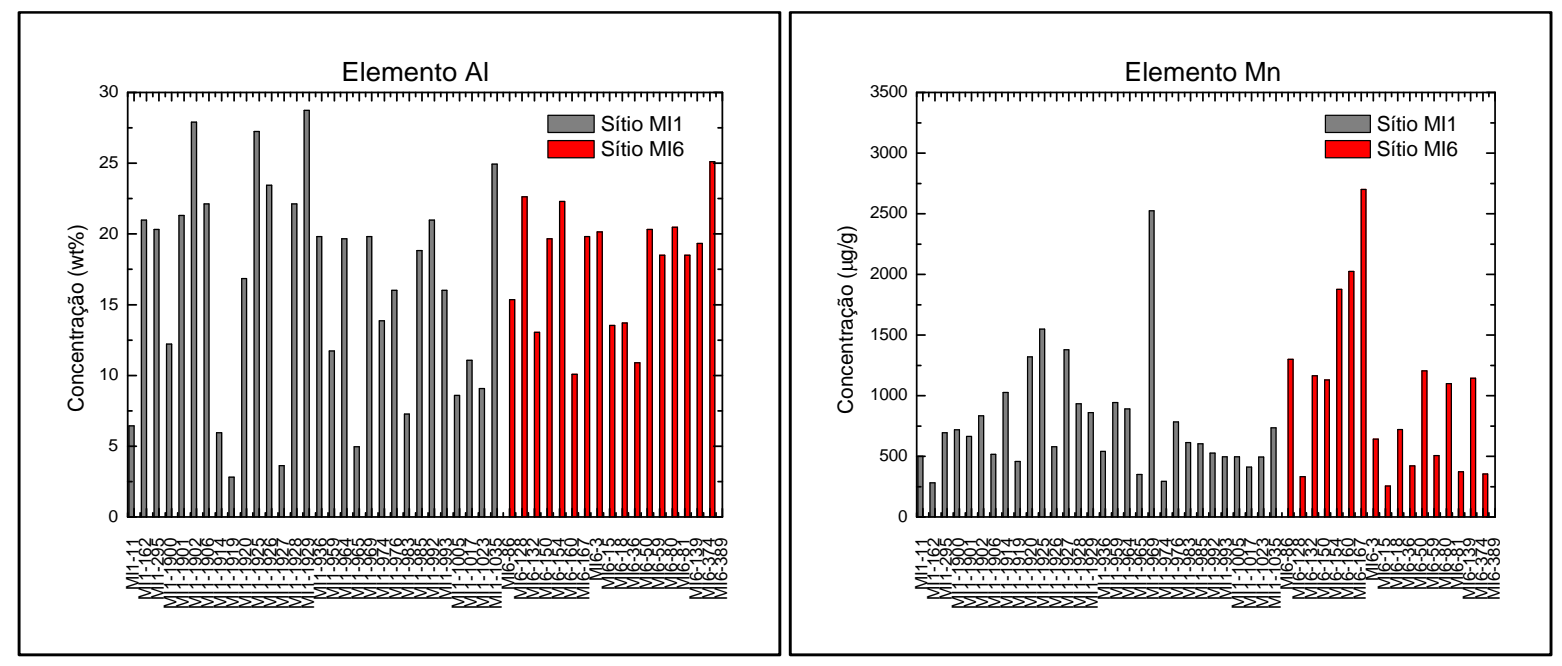

Figura 29. Gráficos de Concentração elementar versus Amostras para os elementos Al e Mn. Os itens em cor cinza pertencem ao Sítio Sede (MI1) e os em cor vermelha pertencem ao Sítio Asa do Pote (MI6). As incertezas correspondem a $30 \%$ do valor do Al e a $10 \%$ do valor do Mn. 


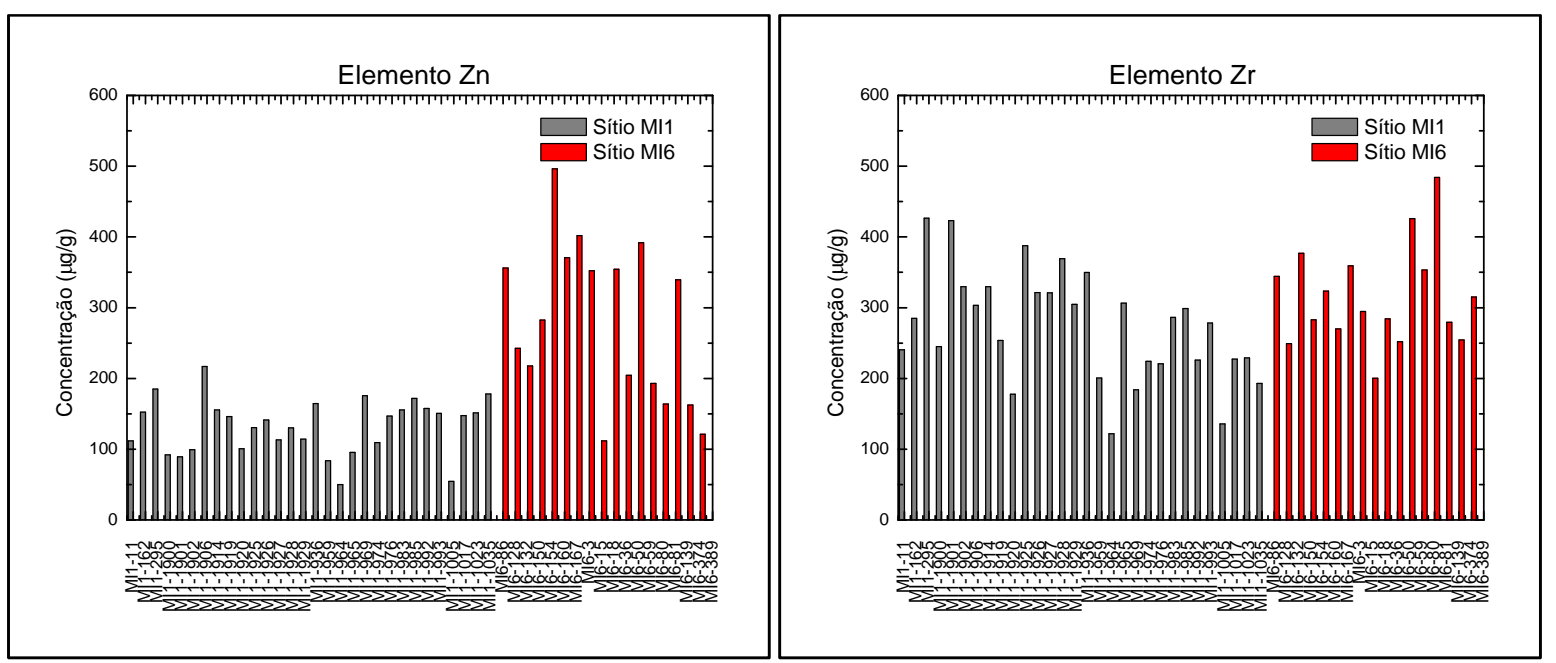

Figura 30. Gráficos de Concentração elementar versus Amostras para os elementos Zn e Zr. Os itens em cor cinza pertencem ao Sítio Sede (MI1) e os em cor vermelha pertencem ao Sítio Asa do Pote (MI6). As incertezas correspondem a $20 \%$ do valor do Zn e a $13 \%$ do valor do Zr.

Observando os gráficos, podemos apontar visualmente algumas diferenças entre as peças dos dois diferentes sítios arqueológicos. É possível observar diferenças principalmente no elemento Zn e em menor escala no elemento Mn. Essas diferenças estão associadas ao sítio arqueológico onde os fragmentos foram encontrados. As amostras do Sítio Asa do Pote (MI6) possuem uma maior concentração de Zn de que no Sítio Sede/Córrego Lalima (MI1).

Há também um conjunto de amostras pertencente ao Sítio Sede que possui uma grande diferença na concentração do elemento $\mathrm{Al}$ quando comparado com outras amostras do mesmo grupo. Este conjunto diferente possui peças das duas tradições estudadas. Observamos uma segunda separação dentro dos fragmentos do deste sítio quando avaliamos o elemento Zr.

O mesmo conjunto de amostra foi analisado com relação à tradição pertencente. Também foram gerados gráficos de Concentração elementar versus Amostra, porém indicando os itens pertencentes a cada cultura, conforme apresentado nas Figuras 31 e 32 . Nestas Figuras os fragmentos pertencentes à tradição Guarani são apresentados em cor verde e os pertencentes à tradição Pantanal são apresentados em cor cinza. 

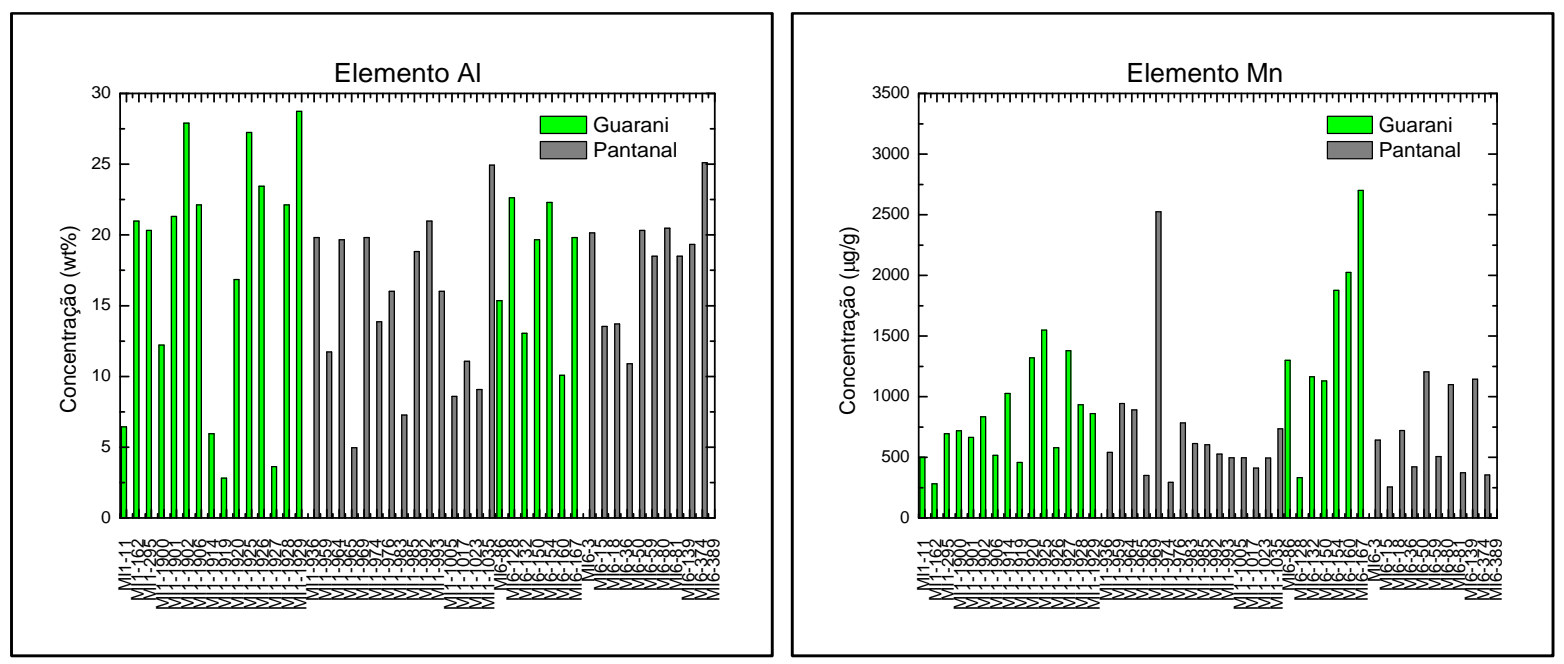

Figura 31. Gráficos de Concentração elementar versus Amostras para os elementos Al e Mn. Os itens em cor verde correspondem aos fragmentos Guarani e os em cor cinza aos fragmentos Pantanal. As incertezas correspondem a $30 \%$ do valor do Al e a $10 \%$ do valor do $\mathrm{Mn}$.
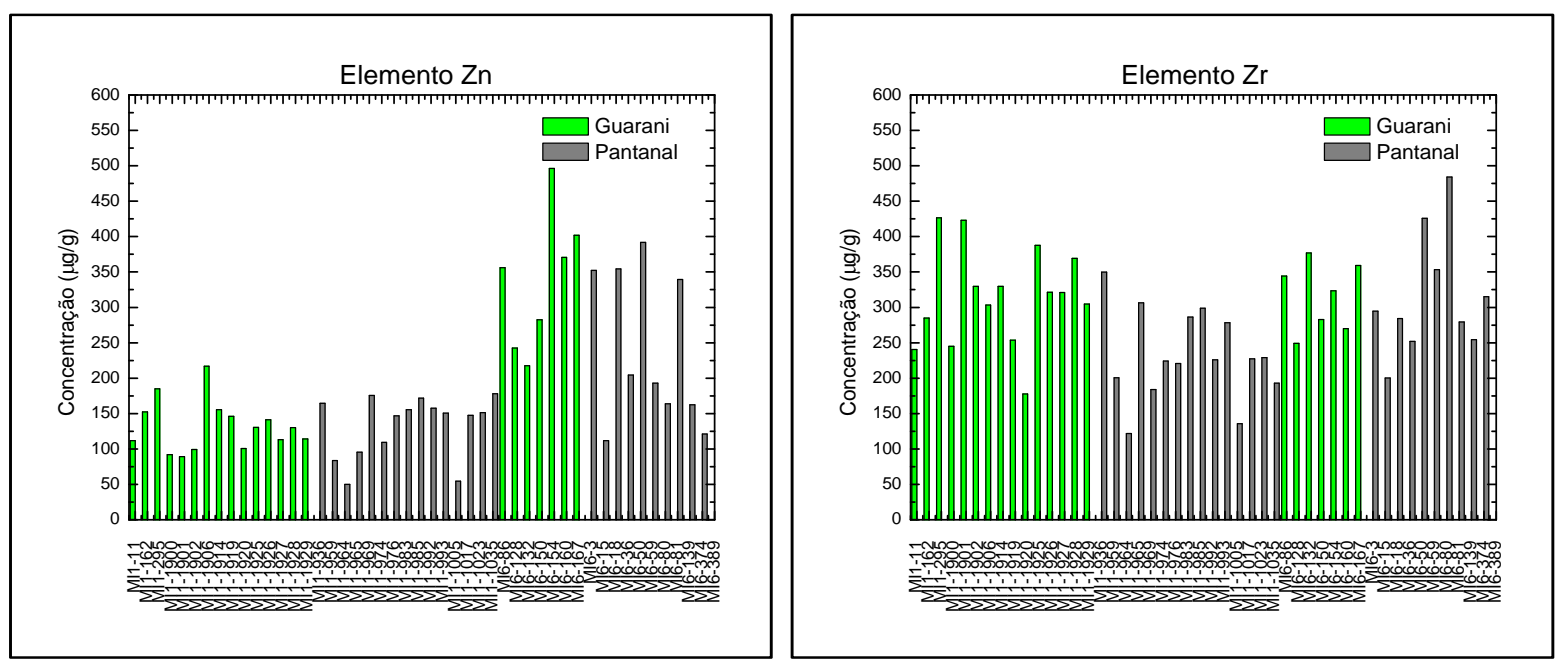

Figura 32. Gráficos de Concentração elementar versus Amostras para os elementos Zn e Zr. Os itens em cor verde correspondem aos fragmentos Guarani e os em cor cinza aos fragmentos Pantanal. As incertezas correspondem a $20 \%$ do valor do Zn e a $13 \%$ do valor do $\mathrm{Zr}$. 
Para comparar as concentrações dos elementos em cada sítio e tradição, foram calculadas as médias dos valores de cada elemento para as quatro combinações possíveis. Esses valores estão apresentados na Tabela 7.

Tabela 7. Valores médios de concentração para os elementos encontrados nas quatro combinações de sítio e tradição.

\begin{tabular}{cccccc}
\hline \hline & & $\begin{array}{c}\text { Sítio Asa do Pote } \\
\text { Guarani }\end{array}$ & $\begin{array}{c}\text { Sítio Asa do Pote } \\
\text { Pantanal }\end{array}$ & $\begin{array}{c}\text { Sítio Sede } \\
\text { Guarani }\end{array}$ & $\begin{array}{c}\text { Sítio Sede } \\
\text { Pantanal }\end{array}$ \\
\hline \hline $\mathrm{Al}$ & $\mathrm{wt} \%$ & $18(5)$ & $18(4)$ & $17(9)$ & $15(6)$ \\
\hline $\mathrm{Si}$ & $\mathrm{wt} \%$ & $20(3)$ & $20(3)$ & $21(4)$ & $19(5)$ \\
\hline $\mathrm{K}$ & $\mathrm{wt} \%$ & $1,5(3)$ & $1,5(5)$ & $1,5(4)$ & $1,5(5)$ \\
\hline $\mathrm{Ca}$ & $\mathrm{wt} \%$ & $0,5(2)$ & $0,5(2)$ & $0,4(1)$ & $0,4(1)$ \\
\hline $\mathrm{Ti}$ & $\mathrm{wt} \%$ & $1,4(2)$ & $1,2(3)$ & $1,4(4)$ & $1,3(4)$ \\
\hline $\mathrm{Cr}$ & $\mathrm{ug} / \mathrm{g}$ & $205(104)$ & $236(75)$ & $282(1377)$ & $430(481)$ \\
\hline $\mathrm{Mn}$ & $\mathrm{ug} / \mathrm{g}$ & $1504(765)$ & $677(339)$ & $821(366)$ & $713(535)$ \\
\hline $\mathrm{Fe}$ & $\mathrm{wt} \%$ & $8(1)$ & $6(2)$ & $7(2)$ & $9(4)$ \\
\hline $\mathrm{Cu}$ & $\mathrm{ug} / \mathrm{g}$ & $78(22)$ & $90(47)$ & $81(34)$ & $62(26)$ \\
\hline $\mathrm{Zn}$ & $\mathrm{ug} / \mathrm{g}$ & $338(98)$ & $250(108)$ & $132(33)$ & $133(43)$ \\
\hline $\mathrm{Rb}$ & $\mathrm{ug} / \mathrm{g}$ & $146(56)$ & $125(26)$ & $132(36)$ & $115(28)$ \\
\hline $\mathrm{Sr}$ & $\mathrm{ug} / \mathrm{g}$ & $41(12)$ & $43(12)$ & $52(18)$ & $43(17)$ \\
\hline $\mathrm{Zr}$ & $\mathrm{ug} / \mathrm{g}$ & $315(48)$ & $318(82)$ & $315(69)$ & $232(63)$ \\
\hline \hline
\end{tabular}

De acordo com os valores encontrados, podemos apontar algumas diferenças entre as peças pertencentes às diferentes tradições culturais e sítios arqueológicos. É possível observar essa diferenciação quando observamos o elemento $\mathrm{Zn}, \mathrm{Zr}$ e em menor escala o elemento Mn. Essas diferenças são observadas quando considerado somente um desvio padrão de incerteza. As incertezas foram calculadas através da propagação de erros, seus altos valores são explicados pela não uniformidade das concentrações elementares dentro de um grupo especifico.

Um segundo experimento utilizando a técnica XRF foi realizado no Instituto de Física da USP. Nesse período foi utilizado o sistema semiportátil XRF desenvolvido no próprio laboratório LABENS. O sistema é formado por um tubo de raios X com ânodo de W e utiliza um detector Si-Pin. 
As condições de trabalho foram $55 \mathrm{kV}$ e $5 \mathrm{~mA}$ e o tempo de aquisição dos espectros de raios X foi de 600 s. Para certificar a calibração do sistema e utilizar como referência para as análises quantitativas, foi utilizado SRM2704 NIST "Buffalo River Sediment" como material referenciado.

Foi analisado o conjunto total de 112 fragmentos cerâmicos pertencentes a ambos os sítios e ambas as culturas sendo realizadas duas irradiações na pasta lateral de cada peça. As amostras analisadas nesse período estão apresentadas no capítulo Catálogo de peças em anexo.

Nesta análise foram identificados 15 elementos, entre matriz e elementos traços. Os elementos são: $\mathrm{K}, \mathrm{Ca}, \mathrm{Ti}, \mathrm{Cr}, \mathrm{Mn}, \mathrm{Fe}, \mathrm{Ni}, \mathrm{Cu}, \mathrm{Zn}, \mathrm{Pb}, \mathrm{Br}, \mathrm{Rb}, \mathrm{Sr}$, Y e $\mathrm{Zr}$. O elemento Y foi determinado utilizando a razão entre as linhas $K_{\alpha}$ e $K_{\beta}$ do $R b$, pois este se encontra sobreposto. Para a obtenção das áreas, utilizou-se o programa WinQXAS e para análise foram feitos os cálculos das áreas relativas para cada elemento. Um espectro típico obtido para o fragmento MI1-1906 é apresentado na Figura 33.

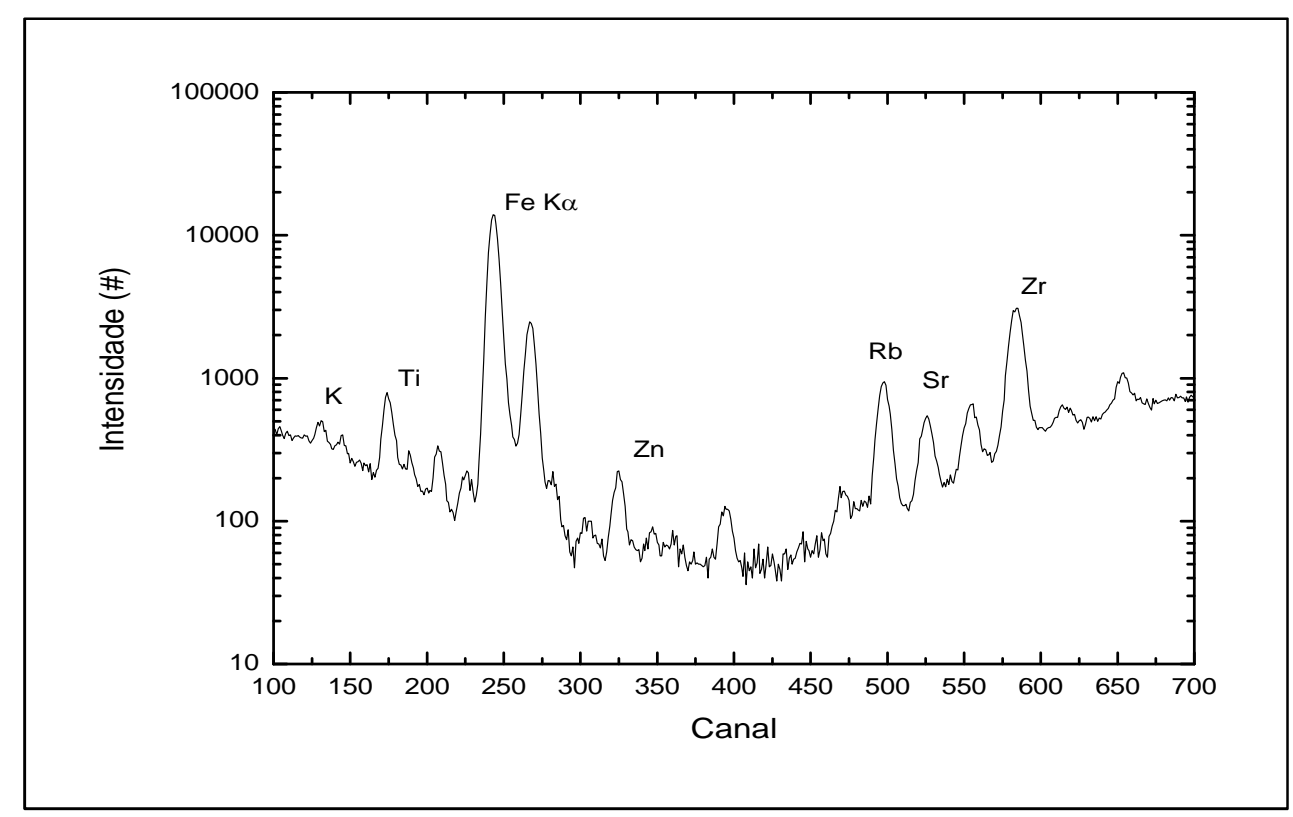

Figura 33. Espectro típico obtido pela técnica XRF para o fragmento cerâmico MI1-1906 no Instituto de Física da USP. 
Inicialmente foram feitas oito medidas na parte lateral de uma única peça para verificar a homogeneidade da pasta e a reprodutibilidade das medidas. A peça foi escolhida de maneira aleatória e tomou-se o cuidado de não realizar medidas sobre antiplástico/tempero ou qualquer deformidade da peça. O fragmento utilizado foi MI1-162, peça encontrada no sítio Sede/Córrego Lalima e pertencente à tradição Pantanal. Os valores obtidos para as concentrações normalizadas pela amostra de referência são apresentados na Tabela 8.

Tabela 8. Valores de concentrações elementares normalizados obtidos para o fragmento MI1-162.

\begin{tabular}{ccccccccccc}
\hline \hline Elemento & Unidade & 1 & 2 & 3 & 4 & 5 & 6 & 7 & 8 & Média \\
\hline \hline $\mathrm{K}$ & $\%$ & $1,5(1)$ & $1,9(2)$ & $1,1(2)$ & $1,2(2)$ & $1,5(2)$ & $1,4(2)$ & $1,4(2)$ & $1,5(1)$ & $1,4(2)$ \\
\hline $\mathrm{Ca}$ & $\%$ & $0,5(1)$ & $0,4(1)$ & $0,1(1)$ & $0,1(1)$ & $0,0(1)$ & $0,2(1)$ & $0,1(1)$ & $0,5(1)$ & $0,2(2)$ \\
\hline $\mathrm{Ti}$ & $\%$ & $0,6(1)$ & $0,8(1)$ & $0,9(1)$ & $0,9(1)$ & $1,0(1)$ & $0,9(1)$ & $1,0(1)$ & $0,6(1)$ & $0,8(2)$ \\
\hline $\mathrm{Cr}$ & $\mu \mathrm{g} / \mathrm{g}$ & $369(22)$ & $201(14)$ & $208(13)$ & $203(13)$ & $232(14)$ & $266(15)$ & $254(15)$ & $365(23)$ & $262(69)$ \\
\hline $\mathrm{Mn}$ & $\mu \mathrm{g} / \mathrm{g}$ & $169(44)$ & $118(57)$ & $98(50)$ & $137(55)$ & $169(54)$ & $140(55)$ & $197(61)$ & $185(47)$ & $152(34)$ \\
\hline $\mathrm{Fe}$ & $\%$ & $3,5(1)$ & $3,8(1)$ & $3,6(1)$ & $3,5(1)$ & $3,4(1)$ & $3,6(1)$ & $4,0(1)$ & $4,0(1)$ & $3,7(2)$ \\
\hline $\mathrm{Ni}$ & $\mu \mathrm{g} / \mathrm{g}$ & $60(5)$ & $61(5)$ & $37(5)$ & $43(5)$ & $49(5)$ & $52(5)$ & $60(5)$ & $66(5)$ & $53(10)$ \\
\hline $\mathrm{Cu}$ & $\mu \mathrm{g} / \mathrm{g}$ & $99(9)$ & $41(5)$ & $37(5)$ & $42(5)$ & $61(6)$ & $69(6)$ & $71(6)$ & $73(8)$ & $62(21)$ \\
\hline $\mathrm{Zn}$ & $\mu \mathrm{g} / \mathrm{g}$ & $201(6)$ & $99(5)$ & $84(5)$ & $59(4)$ & $59(4)$ & $67(4)$ & $86(5)$ & $127(8)$ & $83(23)$ \\
\hline $\mathrm{Pb}$ & $\mu \mathrm{g} / \mathrm{g}$ & $52(6)$ & $49(6)$ & $50(6)$ & $42(5)$ & $41(5)$ & $41(5)$ & $47(6)$ & $51(6)$ & $47(5)$ \\
\hline $\mathrm{Br}$ & $\mu \mathrm{g} / \mathrm{g}$ & $9(2)$ & $10(2)$ & $7(2)$ & $6(2)$ & $12(2)$ & $8(1)$ & $12(2)$ & $8(2)$ & $9(2)$ \\
\hline $\mathrm{Rb}$ & $\mu \mathrm{g} / \mathrm{g}$ & $56(6)$ & $80(8)$ & $73(7)$ & $55(6)$ & $59(6)$ & $51(5)$ & $68(7)$ & $65(7)$ & $63(10)$ \\
\hline $\mathrm{Sr}$ & $\mu \mathrm{g} / \mathrm{g}$ & $35(4)$ & $42(4)$ & $42(5)$ & $35(4)$ & $33(4)$ & $27(3)$ & $35(4)$ & $41(4)$ & $36(5)$ \\
\hline $\mathrm{Zr}$ & $\mu \mathrm{g} / \mathrm{g}$ & $316(32)$ & $320(32)$ & $314(32)$ & $274(28)$ & $332(33)$ & $254(26)$ & $336(34)$ & $331(33)$ & $310(30)$ \\
\hline \hline
\end{tabular}

Os valores das incertezas foram calculados considerando as incertezas das áreas e de propagações de erro, fatores estes que explicam os altos valores encontrados para as incertezas das concentrações normalizadas.

Observando estes valores é possível verificar que a peça não é totalmente homogênea, fato este já esperado devido à natureza da peça. 
Para realizar as análises das amostras, os dados iniciais foram transformados a partir de uma normalização utilizando incerteza das medidas. Essa alteração nos valores maximiza as diferenças encontradas de um elemento entre as amostras. A transformação é dada por:

(1) $T_{E l_{i}}=\frac{Y_{E l_{i}}-\overline{Y_{E l}}}{\sigma_{E l}}$

onde $T_{E l_{i}}$ é o valor final de cada el mento para cada amostra $i, Y_{E l_{i}}$ é o valor inicial obtido do elemento para cada amostra, $\bar{H}_{l}$ é o valor da média do elemento e $\sigma_{E l}$ é o desvio padrão.

Essa transformação, baseada no desvio relativo dos elementos, maximiza os valores quando comparados entre eles, porém não altera os resultados quando se aplicam análises estatísticas multivariadas.

Como primeira análise foram feitos gráficos de amostra versus área normalizada. Estes gráficos são utilizados para examinar a variação elementar entre as amostras e verificar uma possível separação inicial.

Nas Figuras 34 a 36 são apresentados os gráficos dos elementos encontrados. No eixo das abcissas as amostras estão organizadas de acordo com o sítio arqueológico e de acordo com as tradições culturais pertencentes. No eixo das ordenadas estão apresentados os desvios relativos.

As incertezas foram calculadas através de propagação de erros e seus valores variam conforme os elementos: para o Fe a incerteza é cerca de $10 \%$ do valor; para os elementos $\mathrm{Ca}$ e $\mathrm{Cu}$ as incertezas são cerca de $40 \%$ do valor; para o elemento Y a incerteza chega a $60 \%$ do valor; para os demais elementos $(\mathrm{K}, \mathrm{Ti}, \mathrm{Cr}, \mathrm{Mn}, \mathrm{Ni}, \mathrm{Zn}, \mathrm{Pb}, \mathrm{Br}, \mathrm{Rb}, \mathrm{Sr}$ e $\mathrm{Zr}$ ) as incertezas variam entre $15 \%$ e $25 \%$ do valor.

Os elementos $\mathrm{Ca}, \mathrm{Cu}$ e $\mathrm{Y}$ possuem altas incertezas, pois seus picos no espectro de raios $\mathrm{X}$ encontram-se sobrepostos a outros picos. 

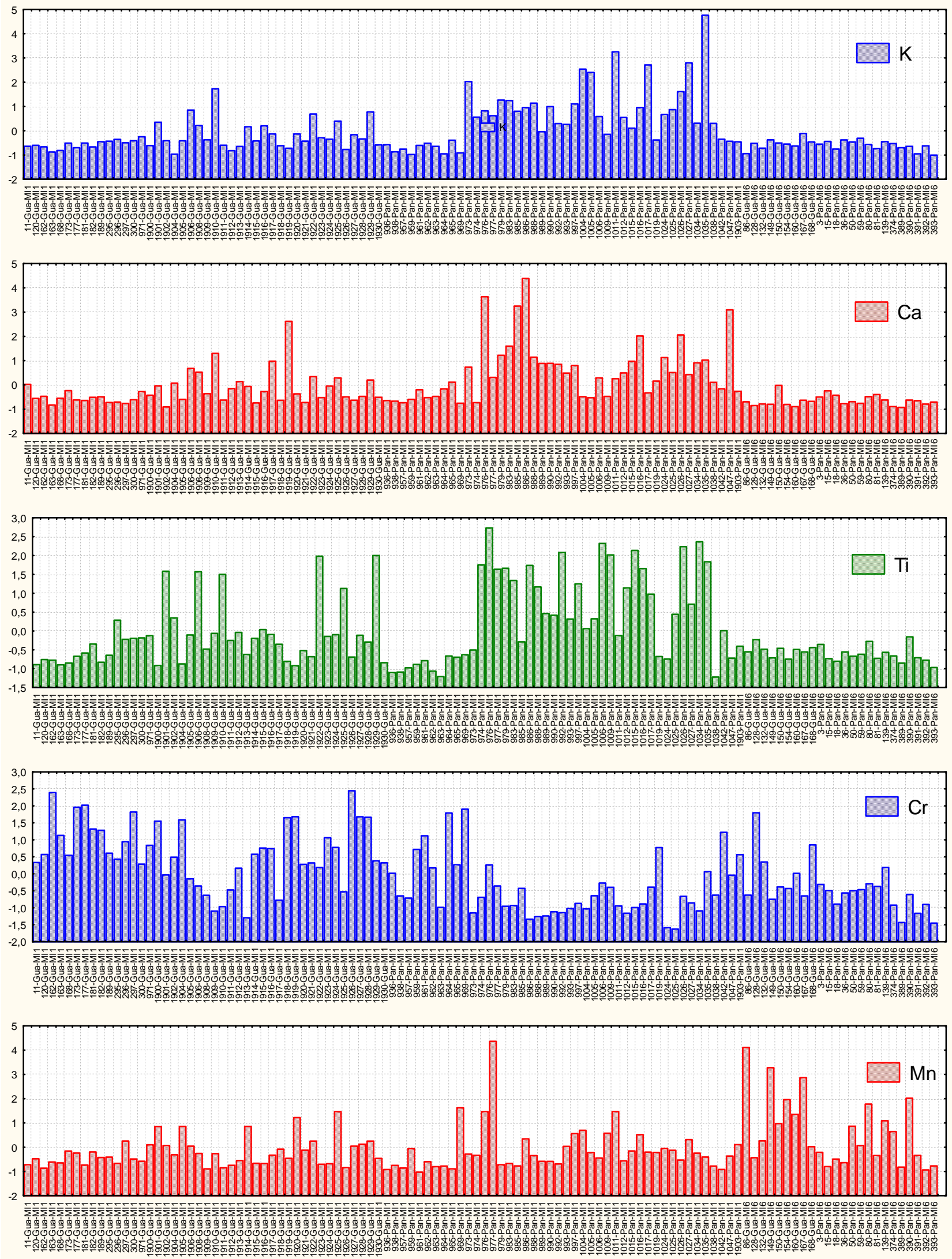

Figura 34. Gráfico de Desvio relativo versus Amostras para os elementos $\mathrm{K}, \mathrm{Ca}, \mathrm{Ti}, \mathrm{Cr}, \mathrm{Mn}$. As incertezas correspondem a cerca de $40 \%$ do valor para o Ca e variam entre $15 \%$ e $25 \%$ para os demais elementos. 

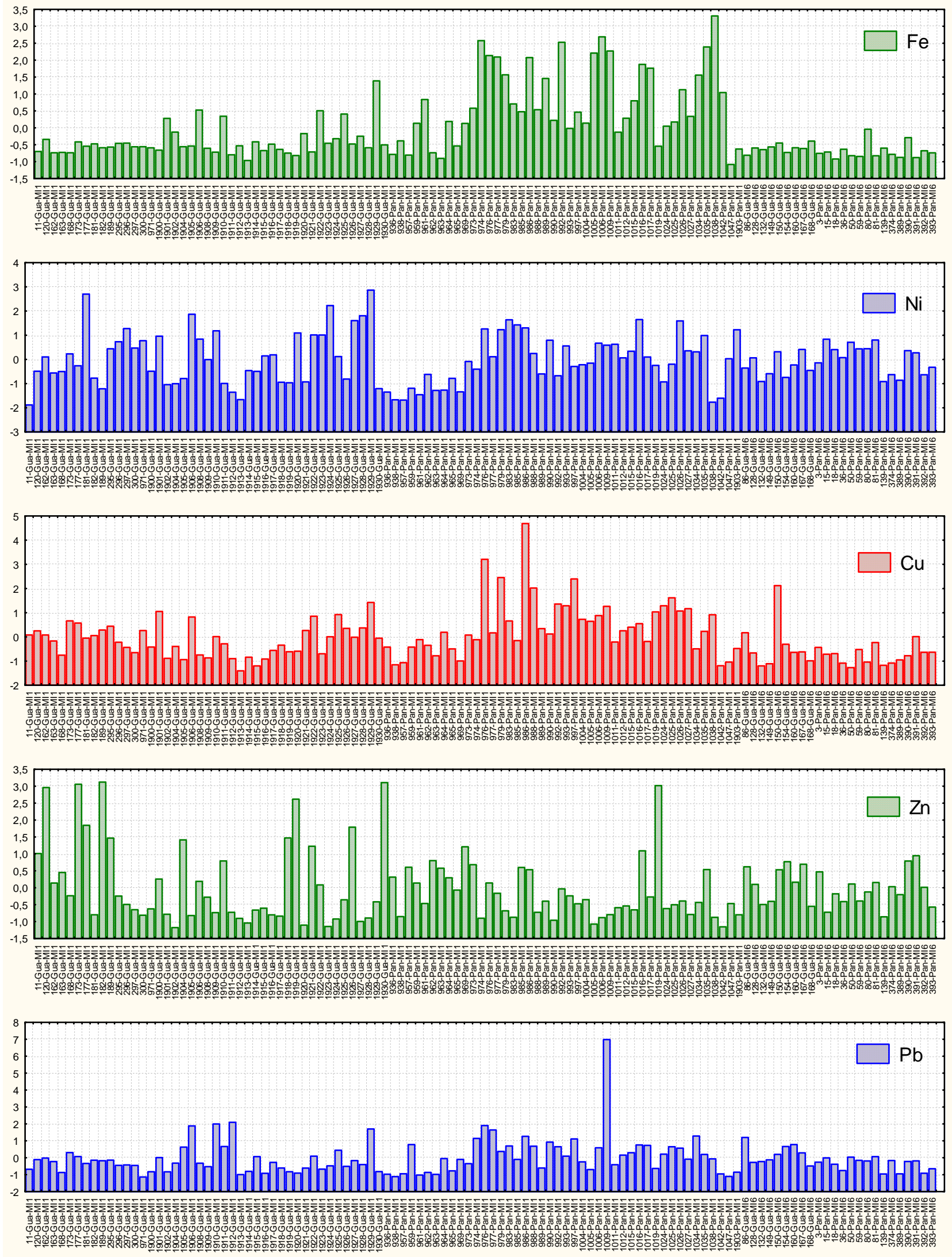

Figura 35. Gráfico de Desvio relativo versus Amostras para os elementos $\mathrm{Fe}, \mathrm{Ni}, \mathrm{Cu}, \mathrm{Zn}$ e Pb. As incertezas correspondem a cerca de $10 \%$ do valor para o $\mathrm{Fe}$, cerca de $40 \%$ para o Cu e variam entre $15 \%$ e $25 \%$ para os demais elementos. 

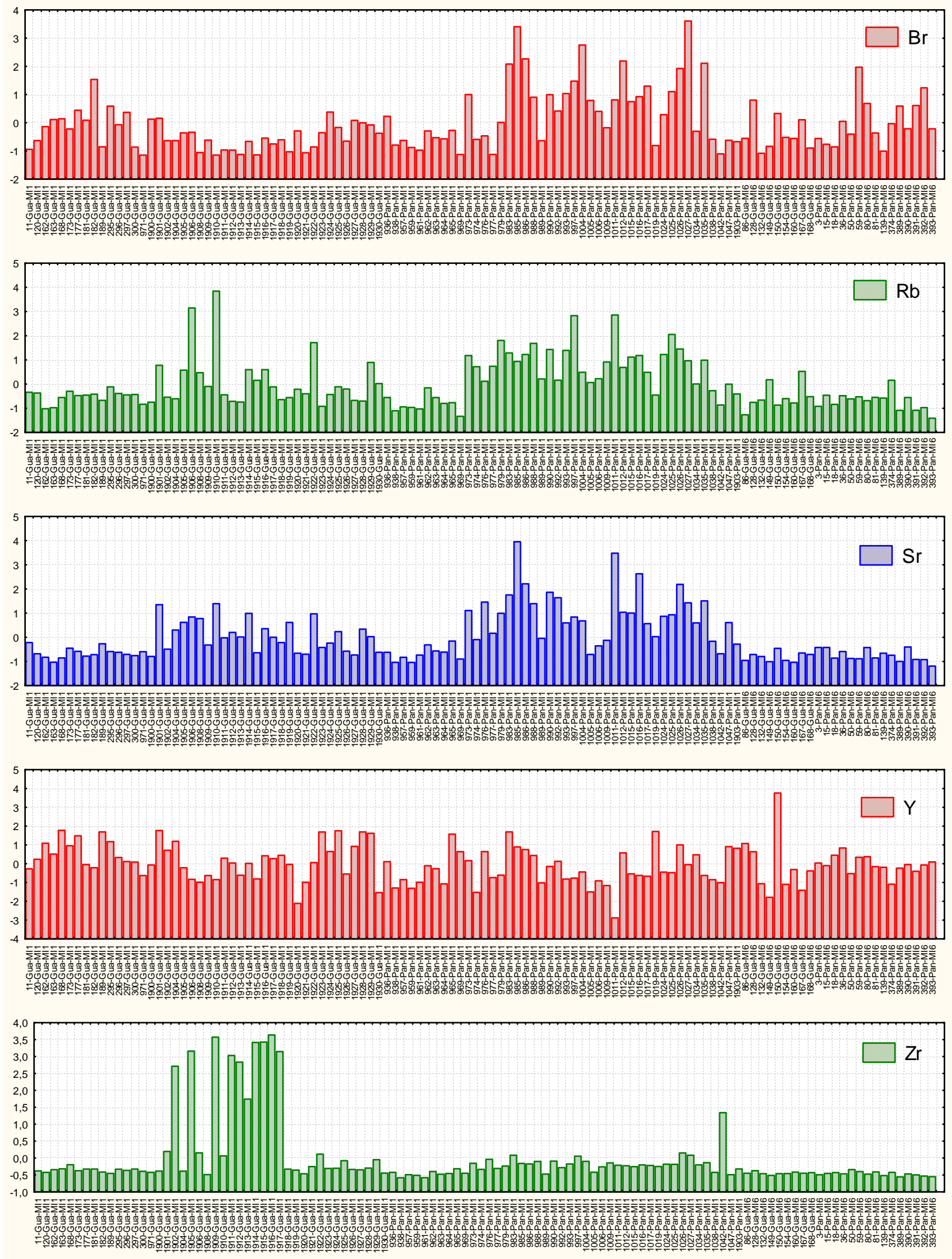

Figura 36. Gráfico de Desvio relativo versus Amostras para os elementos $\mathrm{Br}, \mathrm{Rb}, \mathrm{Sr}, \mathrm{Y}$ e Zr. As incertezas correspondem a cerca de $60 \%$ do valor para o $Y$ e variam entre $15 \%$ e $25 \%$ para os demais elementos. 
Observando os gráficos obtidos, podemos apontar algumas diferenças para os valores das áreas normalizadas em diversos elementos tais como $\mathrm{K}, \mathrm{Ca}, \mathrm{Ti}, \mathrm{Fe}, \mathrm{Br}, \mathrm{Rb}$, e Sr. Estes elementos apontam a presença de um subgrupo nas amostras pertencentes ao sítio Sede/Córrego Lalima e à tradição Pantanal. Também é possível observar claramente um pequeno grupo de fragmentos cuja concentração do elemento $\mathrm{Zr}$ se destaca. Em geral, essas diferenciações não estão associadas a nenhum sítio ou tradição especifica, mas a pequenos conjuntos isolados.

Para observar melhor essas diferenças, foram calculadas as médias das áreas normalizadas e transformadas de acordo com a equação (1), ou seja, os valores médios para os desvios relativos para cada elemento nas quatro combinações distintas inicialmente fornecidas de sítio arqueológico e tradição. Esses valores são apresentados na Tabela 9. Os altos valores das incertezas associadas são devidos às grandes variações dentro de cada conjunto.

Tabela 9. Valores médios dos desvios relativos obtidos para as quatro combinações de sítios arqueológicos e tradições.

\begin{tabular}{ccccc}
\hline \hline Elemento & MI1 & $\begin{array}{c}\text { MI1 } \\
\text { Pan }\end{array}$ & $\begin{array}{c}\text { MI6 } \\
\text { Gua }\end{array}$ & $\begin{array}{c}\text { MI6 } \\
\text { Pan }\end{array}$ \\
\hline \hline $\mathrm{K}$ & $-0,29(8)$ & $0,62(19)$ & $-0,54(8)$ & $-0,61(5)$ \\
\hline $\mathrm{Ca}$ & $-0,21(10)$ & $0,59(18)$ & $-0,69(9)$ & $-0,63(5)$ \\
\hline $\mathrm{Ti}$ & $-0,15(12)$ & $0,48(18)$ & $-0,52(5)$ & $-0,63(6)$ \\
\hline $\mathrm{Cr}$ & $0,65(14)$ & $-0,44(13)$ & $0,02(28)$ & $-0,68(12)$ \\
\hline $\mathrm{Mn}$ & $-0,22(9)$ & $-0,11(14)$ & $1,60(52)$ & $0,07(25)$ \\
\hline $\mathrm{Fe}$ & $-0,40(7)$ & $0,78(17)$ & $-0,60(4)$ & $-0,69(6)$ \\
\hline $\mathrm{Ni}$ & $0,11(18)$ & $-0,06(15)$ & $-0,28(15)$ & $0,06(16)$ \\
\hline $\mathrm{Cu}$ & $-0,14(10)$ & $0,48(18)$ & $-0,36(34)$ & $-0,75(9)$ \\
\hline $\mathrm{Zn}$ & $0,18(20)$ & $-0,17(12)$ & $0,16(18)$ & $-0,06(13)$ \\
\hline $\mathrm{Pb}$ & $-0,16(12)$ & $0,25(20)$ & $0,23(19)$ & $-0,38(9)$ \\
\hline $\mathrm{Br}$ & $-0,39(9)$ & $0,45(19)$ & $-0,36(21)$ & $0,05(21)$ \\
\hline $\mathrm{Rb}$ & $-0,09(15)$ & $0,46(16)$ & $-0,53(18)$ & $-0,71(9)$ \\
\hline $\mathrm{Sr}$ & $-0,16(10)$ & $0,60(18)$ & $-0,81(6)$ & $-0,74(6)$ \\
\hline $\mathrm{Y}$ & $0,26(15)$ & $-0,25(14)$ & $-0,06(57)$ & $-0,04(12)$ \\
\hline $\mathrm{Zr}$ & $0,48(22)$ & $-0,22(5)$ & $-0,44(1)$ & $-0,47(2)$ \\
\hline \hline
\end{tabular}


Apesar dos altos valores de incerteza, ainda é possível notar algumas diferenças entre os quatro conjuntos. Podemos destacar o conjunto do sítio MI1 pertencente à tradição Pantanal, cujos valores, na maioria dos elementos se sobressai aos demais. Os elementos tais como K, $\mathrm{Ca}, \mathrm{Mn}$ e $\mathrm{Zr}$ também possibilitam uma separação inicial dos conjuntos.

Para verificar uma correlação elementar simples, foram realizados gráficos bidimensionais de elemento versus elemento, resultando um total de 120 gráficos. Ao analisar essas relações observamos a separação de pequenos grupos não relacionados aos sítios arqueológicos ou às culturas. Estes grupos surgem quando comparados elementos tais como Ti, $\mathrm{Fe}, \mathrm{Zn}$, Sr e Zr. Abaixo é mostrado na Figura 37 um exemplo destes gráficos, que serão explorados mais adiante quando tratarmos dos sítios arqueológicos e das tradições culturais em separado.

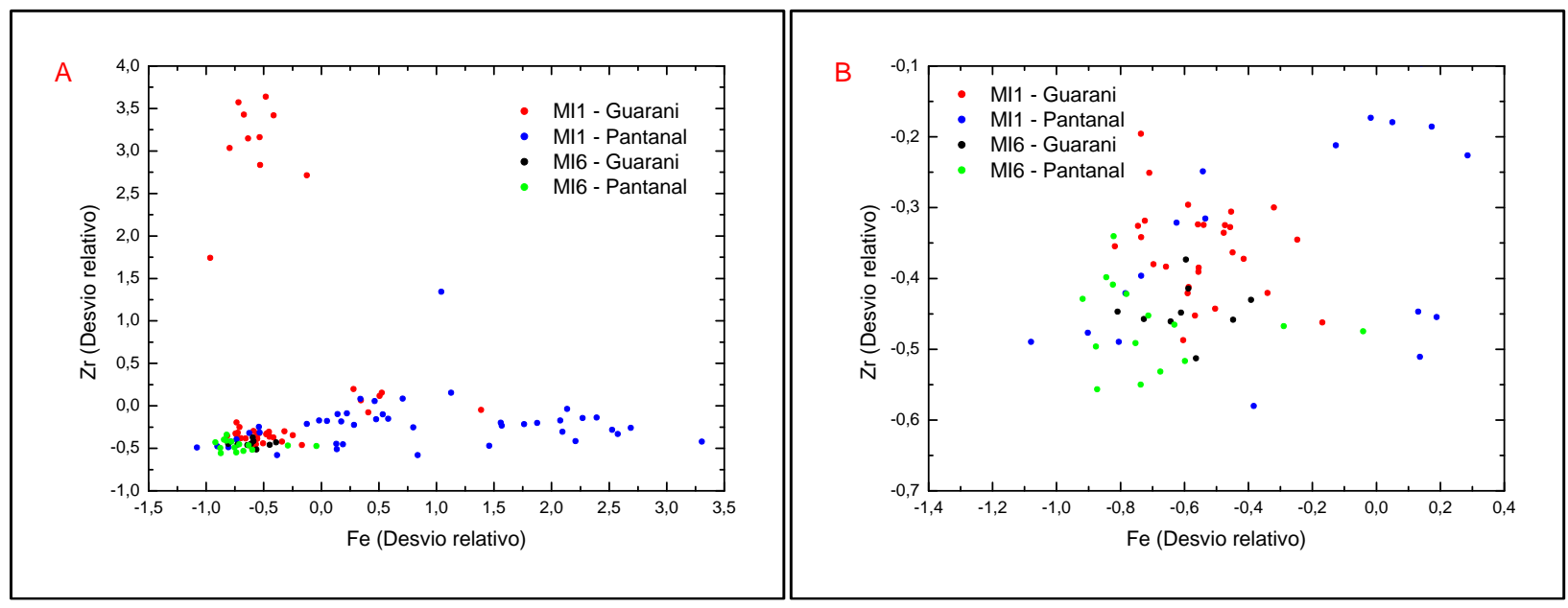

Figura 37. Gráficos dos Desvios relativos dos elementos Zr versus Fe obtidos pela técnica XRF para o conjunto de 112 fragmentos cerâmicos. A. Apresenta o conjunto total; B. Apresenta detalhe em região onde não há uma separação entre os grupos.

Para verificar a possibilidade de possíveis agrupamentos foram aplicadas técnicas de análise estatística nos dados obtidos pela técnica XRF em 112 fragmentos cerâmicos. 
Inicialmente, aplicando-se a técnica de análise de cluster nos dados normalizados obtidos, gerou-se o dendrograma que classifica os elementos de acordo com a dissimilaridade entre eles, como se pode observar na Figura 38. A figura mostra os diferentes comportamentos dos elementos entre as amostras. Os elementos são separados inicialmente, com uma distância de valor 100, em dois grupos. O primeiro grupo é composto por elementos com baixa concentração. O segundo grupo, que abrange a maioria dos elementos, é novamente separado em diferentes distâncias relativas. Podemos notar que os elementos majoritários encontram-se em um grupo separado por um valor de distância relativa igual a 50.

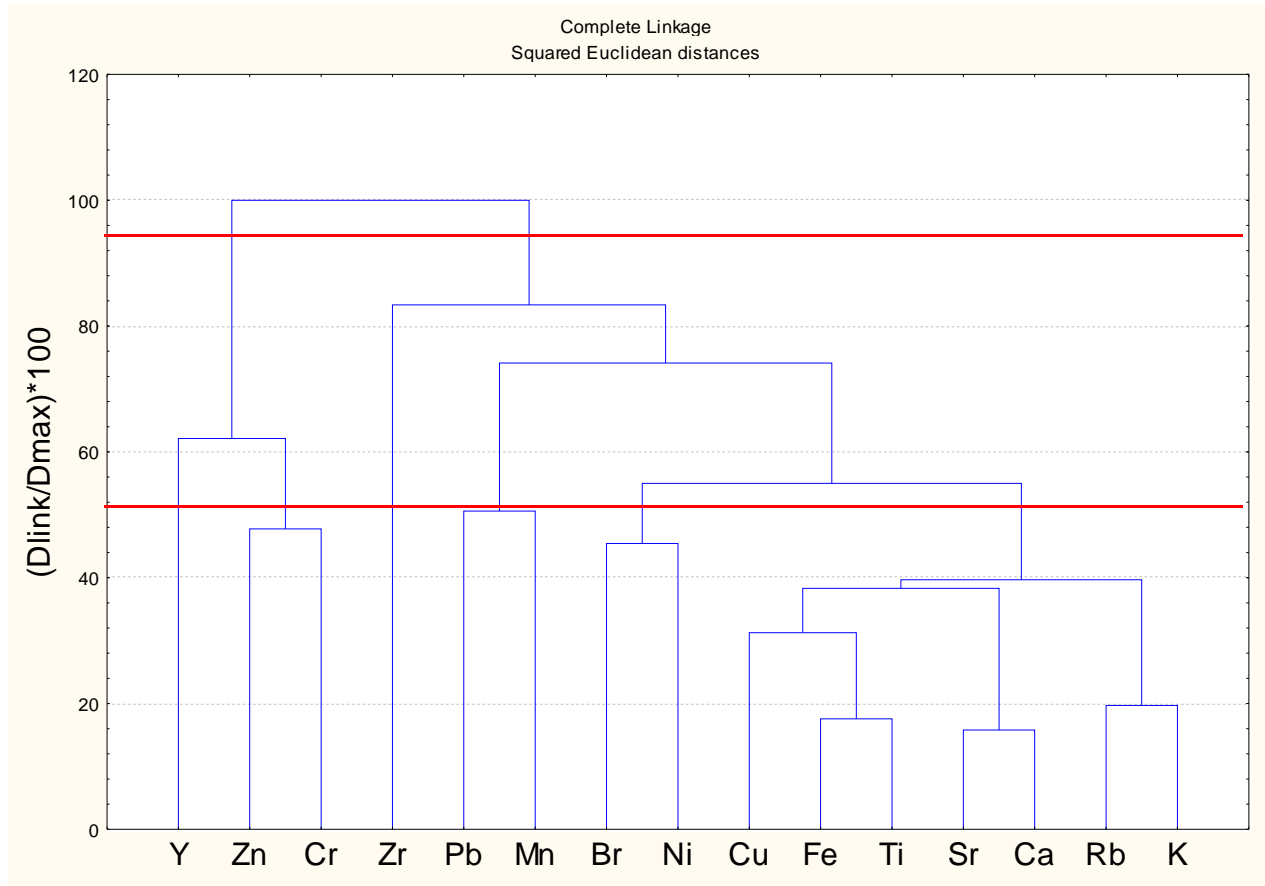

Figura 38. Dendrograma obtido utilizando os 15 elementos determinados através da técnica XRF As linhas em vermelho indicam diferentes níveis de dissimilaridade entre os elementos presentes na pasta cerâmica.

Por meio da técnica de análise de cluster, foram gerados dendrogramas com a combinação de diversos elementos, até que fosse determinada a melhor combinação para cada caso. Para os cálculos foram utilizados os valores de concentração normalizados. Foram avaliados dois casos distintos, o primeiro em relação ao sítio arqueológico e o segundo em relação à tradição. Para isso, utilizou-se a distância Euclidiana quadrática e o método de Complete Linkage. 
A Figura 39 apresenta o dendrograma que utiliza todos os elementos obtidos e indica em cores os diferentes fragmentos de acordo com sua classificação com relação ao sítio arqueológico e à tradição a qual pertence. Podemos dividir os fragmentos em quatro grupos sendo Guarani MI1, Pantanal MI1, Guarani MI6 e Pantanal MI6.

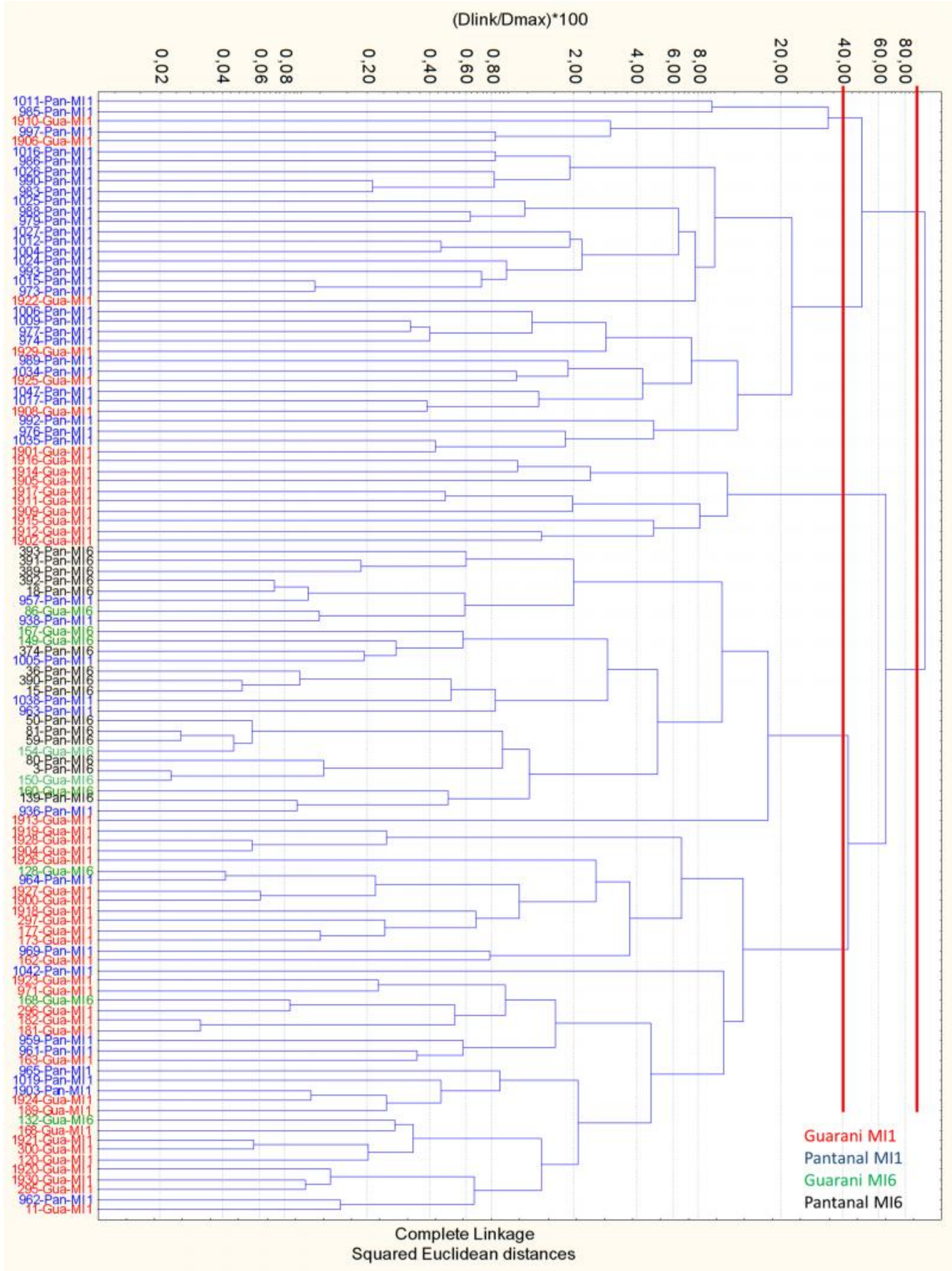

Figura 39. Dendrograma obtido utilizando como parâmetro todos os elementos determinados através da técnica XRF. Os fragmentos são apresentados através de cores de acordo com sua classificação. As linhas vermelhas indicam diferentes níveis de dissimilaridade nos quais há formação de subgrupos. 
Ao analisarmos este primeiro dendrograma completo, podemos observar que existe uma indicação de agrupamento entre as diversas classificações dos fragmentos cerâmicos. Ao observarmos a linha de corte numa distância de valor 100, observamos a separação das amostras em dois grupos, sendo o primeiro grupo predominantemente formado por peças pertencentes ao sítio MI1 e à tradição Pantanal. Em uma distância de dissimilaridade de valor 40, existe a formação de cinco grupos, o primeiro apresentando em sua maioria os fragmentos Pantanal MI1, o segundo formado por algumas peças Guarani MI1, o terceiro formado por diferentes grupos, porém a maioria pertence ao sítio MI6, e o quarto grupo formado predominantemente por peças Guarani MI1.

Para obter um melhor agrupamento das diferentes classificações, os dados apresentados foram estudados parcialmente com relação ao sítio arqueológico e à tradição. Inicialmente analisaremos os dendrogramas obtidos quando analisado em relação ao sítio arqueológico.

A Figura 40 apresenta o dendrograma formado por todos os elementos determinados pela técnica XRF. A Figura 41 apresenta o dendrograma com a combinação dos elementos K, $\mathrm{Ca}, \mathrm{Ti}, \mathrm{Cr}, \mathrm{Ni}, \mathrm{Zn}, \mathrm{Rb}, \mathrm{Sr}$ e Zr que melhor apresenta uma separação das peças cerâmicas com relação ao sítio arqueológico. Os fragmentos pertencentes ao Sítio Asa do Pote estão representados pela cor vermelha.

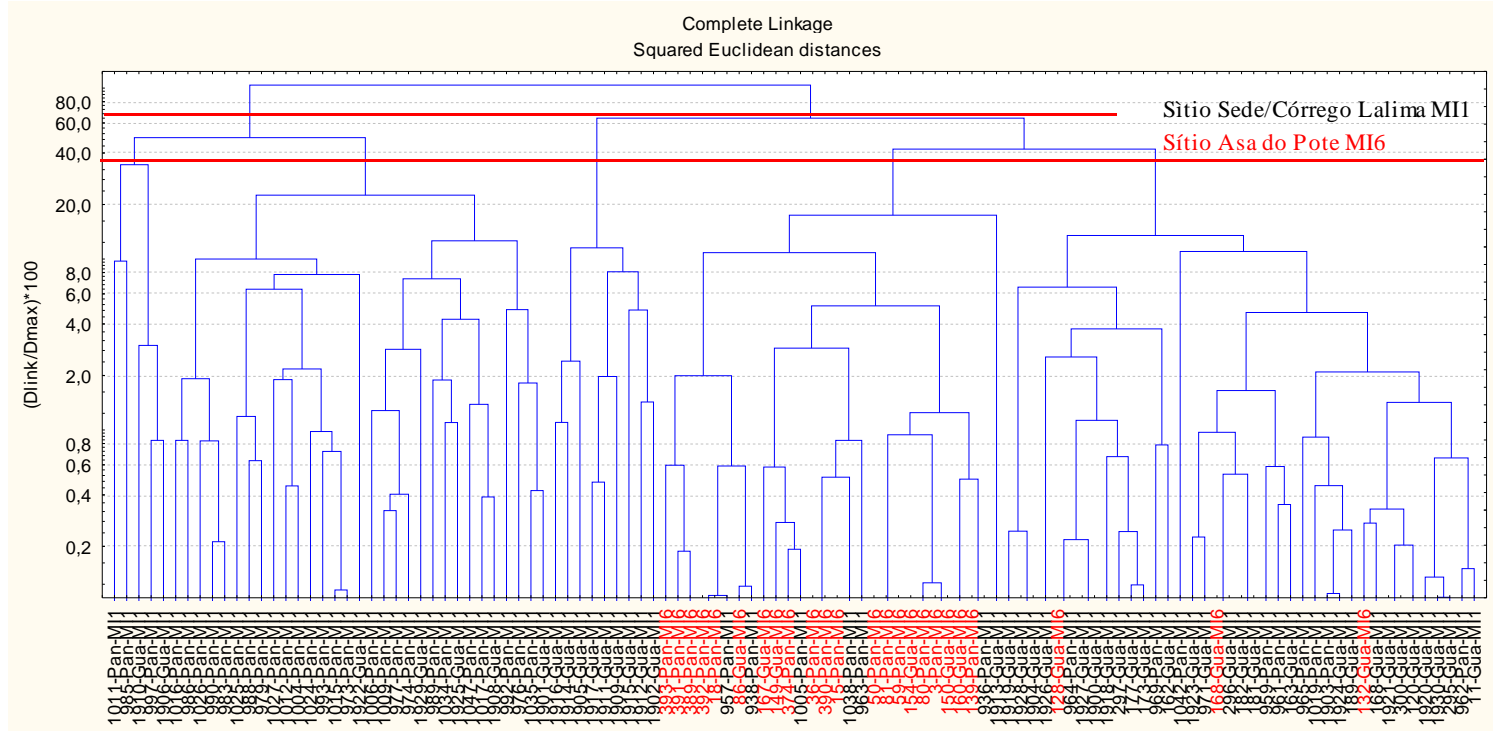

Figura 40. Dendrograma obtido utilizando como parâmetro todos os elementos determinados através da técnica XRF. Os fragmentos pertencentes ao sítio Asa do pote estão destacados em cor vermelha e os pertencentes ao sítio Sede/Córrego Lalima estão em cor preta. 


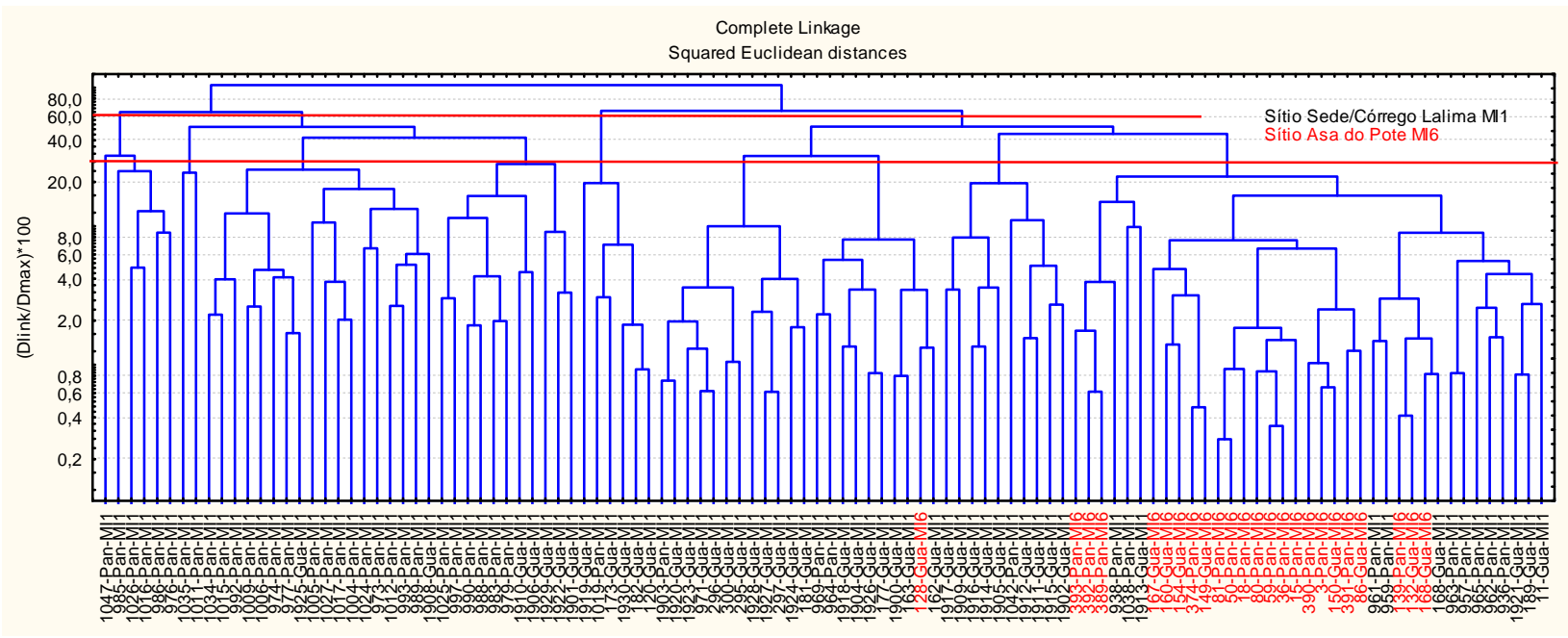

Figura 41. Dendrograma obtido utilizando como parâmetro os elementos $\mathrm{K}, \mathrm{Ca}, \mathrm{Ti}, \mathrm{Cr}, \mathrm{Ni}, \mathrm{Zn}, \mathrm{Rb}, \mathrm{Sr}$ e $\mathrm{Zr}$ determinados através da técnica XRF. Os fragmentos pertencentes ao sítio Asa do pote estão destacados em cor vermelha e os pertencentes ao sítio Sede/Córrego Lalima estão em cor preta.

Ao analisarmos a Figura 40 formada por todos os elementos determinados, podemos observar que os fragmentos não formam um agrupamento único. As peças pertencentes ao sítio Asa do Pote (MI6) se encontram, em sua maioria, em dois subconjuntos determinados por uma distância de dissimilaridade de valor 20. Porém ao avaliarmos o dendrograma formado por apenas alguns elementos selecionados (Figura 41), notamos que há um melhor agrupamento das peças, formando um conjunto determinado por uma distância de dissimilaridade de valor 40. Neste valor de distância podemos observar a formação de sete subgrupos. Este dendrograma foi formado pela combinação de elementos que melhor agrupa os fragmentos destacados em vermelho, porém ainda é possível encontrar peças pertencentes ao outro sítio arqueológico no mesmo agrupamento. 
Utilizando os mesmo valores encontrados pela técnica XRF, podemos analisar os possíveis agrupamentos com relação à tradição dos fragmentos.

O dendrograma obtido utilizando todos os elementos medidos pela técnica XRF considerando a tradição das peças é apresentado na Figura 42. Por meio da combinação de diversos elementos, dois outros dendrogramas foram gerados. A Figura 43 apresenta o dendrograma com a combinação dos elementos Ti, Cr, Zn, Rb, Sr e Zr e a Figura 44 apresenta o dendrograma com a combinação dos elementos $\mathrm{Cr}$, Rb, Sr e Zr. Ambas as figuras apresentam uma separação das peças cerâmicas com relação à tradição dos fragmentos, em diferentes distâncias de dissimilaridade. Nas três figuras apresentadas os fragmentos destacados em cor verde pertencem à tradição Guarani.

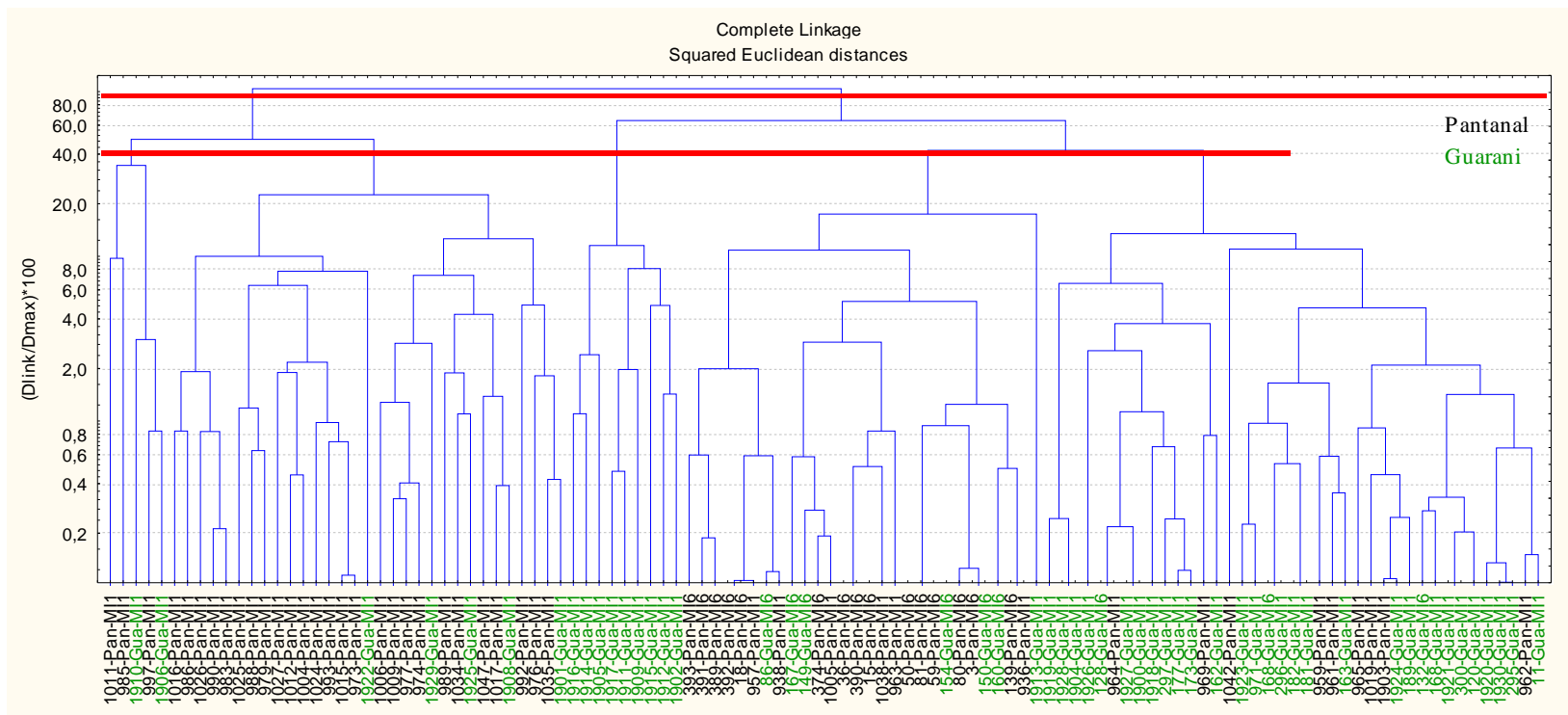

Figura 42. Dendrograma obtido utilizando como parâmetros todos os elementos determinados através da técnica XRF. Os fragmentos apresentados em cor verde pertencem à tradição Guarani e os apresentados em cor preta pertencem à tradição Pantanal. 


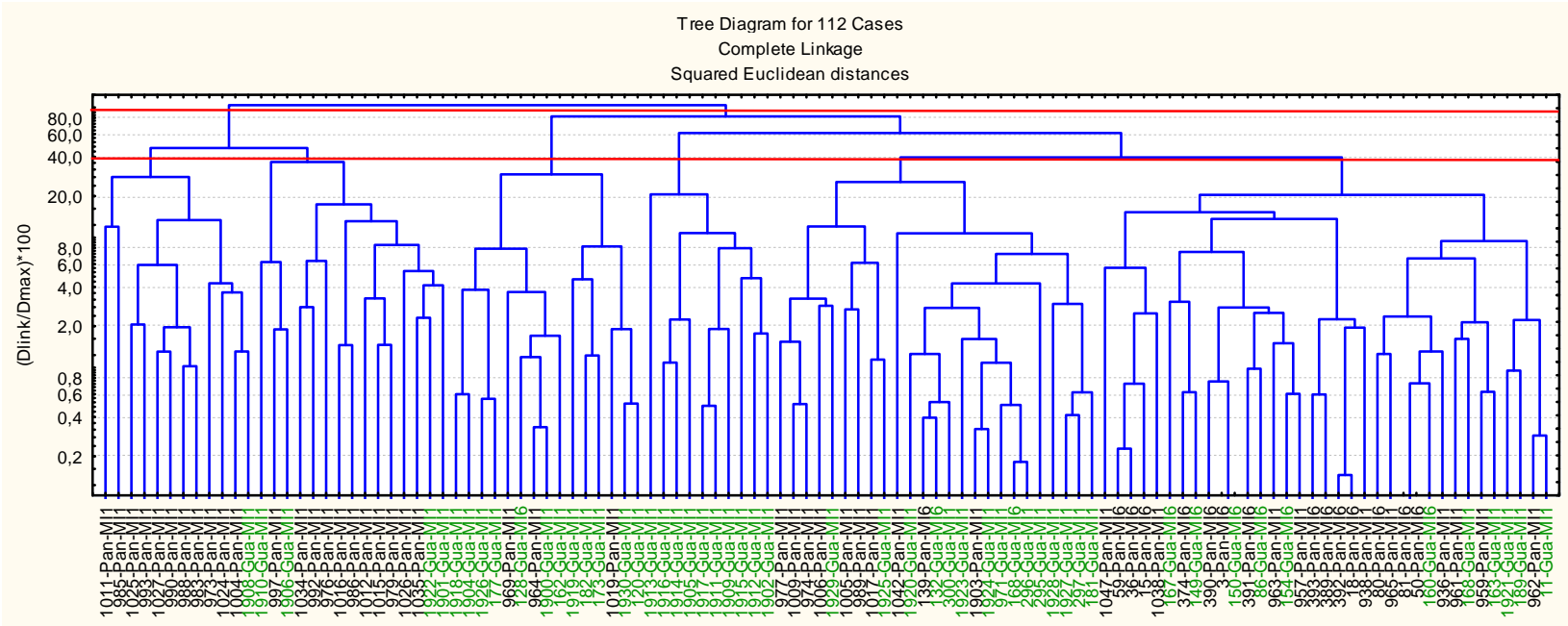

Figura 43. Dendrograma obtido utilizando como parâmetros os elementos $\mathrm{Ti}, \mathrm{Cr}, \mathrm{Zn}, \mathrm{Rb}$, Sr e $\mathrm{Zr}$ determinados através da técnica XRF. Os fragmentos apresentados em cor verde pertencem à tradição Guarani e os apresentados em cor preta pertencem à tradição Pantanal.

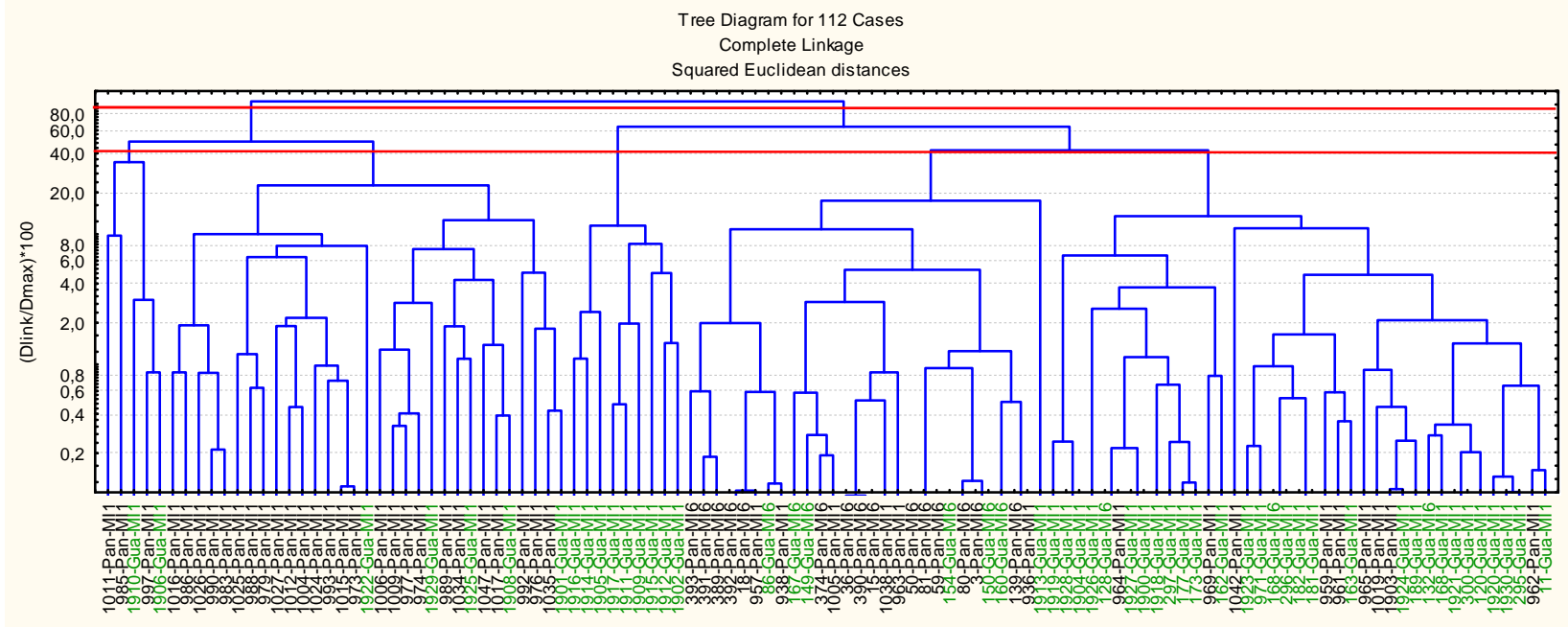

Figura 44. Dendrograma obtido utilizando como parâmetros os elementos $\mathrm{Cr}, \mathrm{Rb}, \mathrm{Sr}$ e $\mathrm{Zr}$ determinados através da técnica XRF. Os fragmentos apresentados em cor verde pertencem à tradição Guarani e os apresentados em cor preta pertencem à tradição Pantanal. 
Ao analisarmos a Figura 42 formada por todos os elementos determinados, podemos observar que os fragmentos não formam um agrupamento único. As peças pertencentes ao sítio Asa do Pote (MI6) se encontram, em sua maioria, na região central do dendrograma, porém somente podem ser separadas quando observamos a distância de dissimilaridade de valor 20. A essa distância podemos observar a formação de cinco subgrupos.

Porém ao avaliarmos os dendrogramas formados por apenas alguns elementos selecionados, notamos que há um melhor agrupamento das peças, formando conjuntos determinados por uma distância de dissimilaridade de valor 40 .

No dendrograma da Figura 43 observamos na distância de valor 40 a formação de seis subgrupos, onde dois grupos são predominantemente formados por fragmentos Pantanal, dois grupos são predominantemente Guarani e dois grupos possuem peças de ambas as tradições culturais.

No dendrograma da Figura 44 observamos na distância de valor 40 a formação de cinco grupos, onde três grupos são predominantemente formados por fragmentos Pantanal e dois grupos são predominantemente Guarani.

A mesma análise detalhada foi feita utilizando as peças previamente separadas de acordo com o sítio arqueológico. Este estudo foi realizado para verificar a existência de diferenças significativas na composição elementar das peças pertencentes a um único sítio.

A Figura 45 apresenta o dendrograma formado por todos os elementos determinados pela técnica XRF, somente para as peças encontradas no sítio MI1. A Figura 46 apresenta o dendrograma com a combinação dos elementos $\mathrm{Fe}, \mathrm{Rb}, \mathrm{Sr}$ e Zr. 


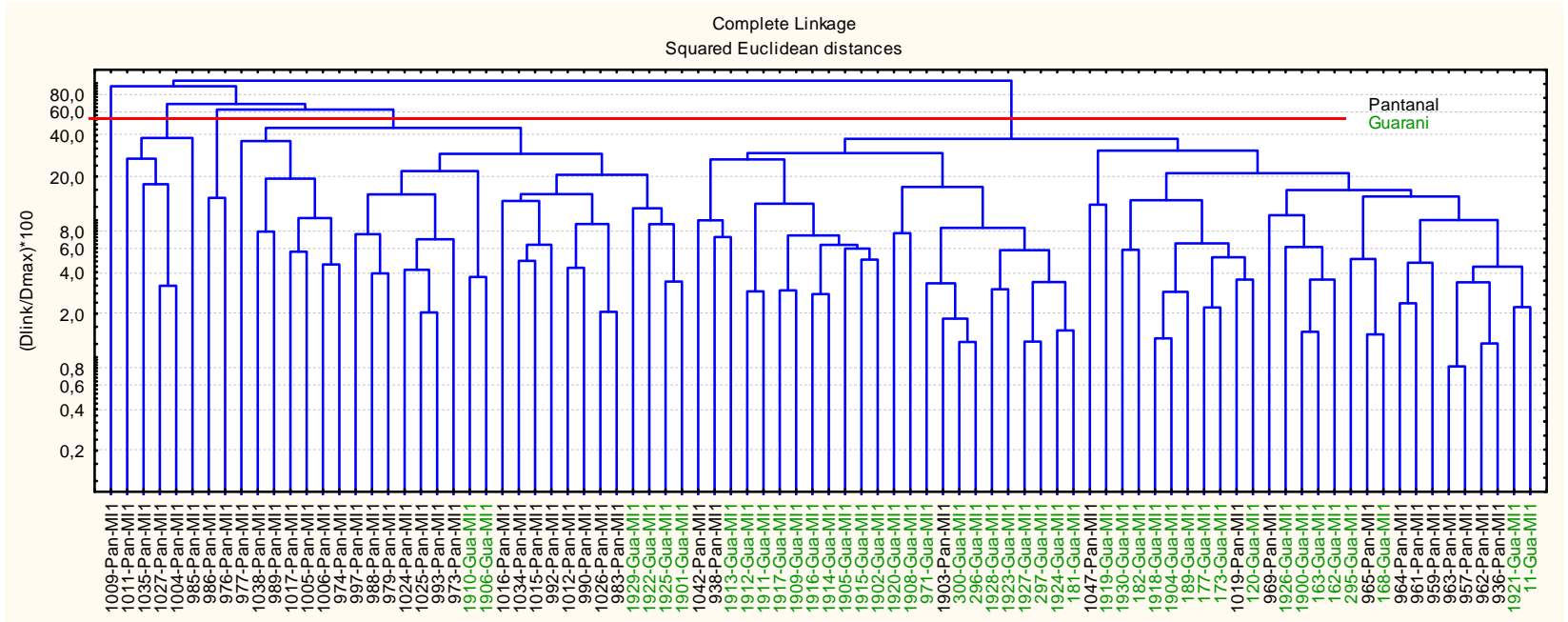

Figura 45. Dendrograma obtido utilizando todos os elementos determinados através da técnica XRF. Os fragmentos apresentados em cor verde pertencem à tradição Guarani e os apresentados em cor preta pertencem à tradição Pantanal.

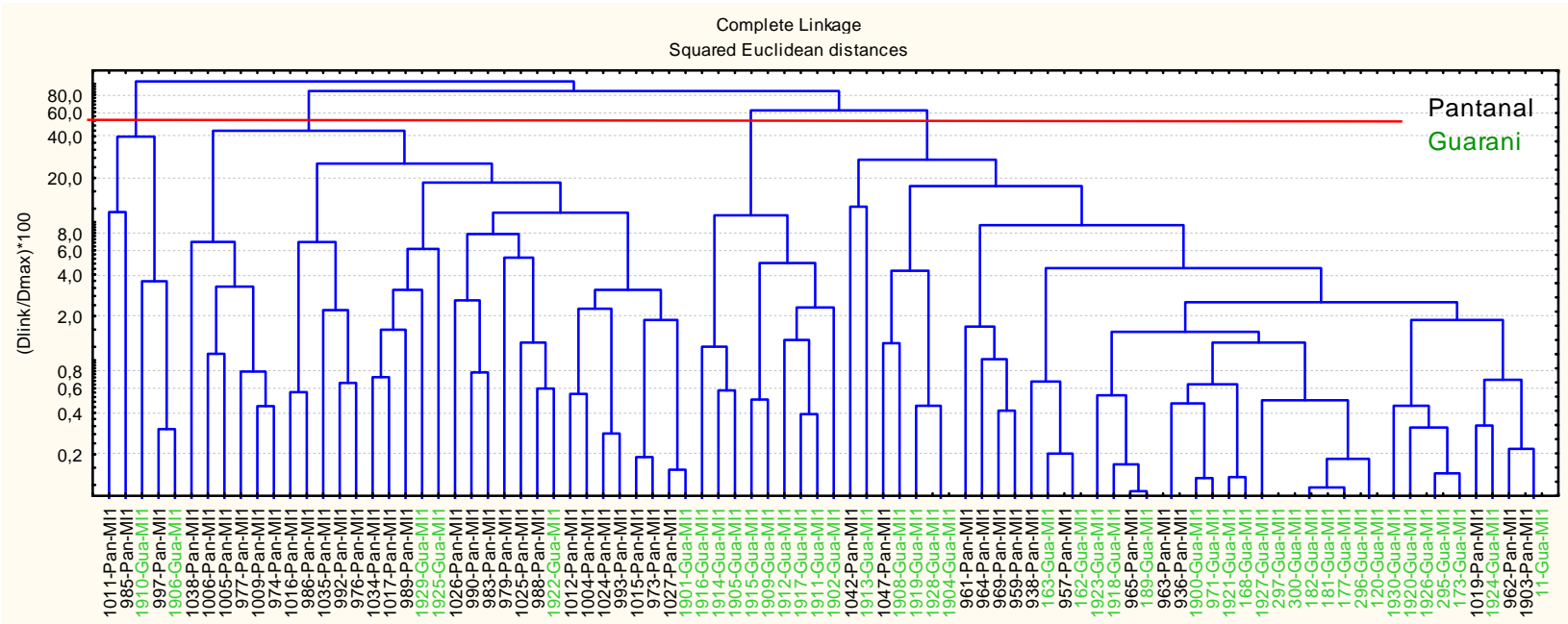

Figura 46. Dendrograma obtido utilizando os elementos $\mathrm{Fe}, \mathrm{Rb}, \mathrm{Sr}$ e $\mathrm{Zr}$ determinados através da técnica XRF. Os fragmentos apresentados em cor verde pertencem à tradição Guarani e os apresentados em cor preta pertencem à tradição Pantanal. 
Analisando os dois dendrogramas obtidos para o sítio MI1 a uma distância de dissimilaridade de valor 80, podemos observar que se formam três grupos, sendo dois predominantemente de tradição Pantanal e um predominantemente Guarani. Também podemos observar que praticamente não há diferenças entre os dois dendrogramas, pois ambos separam os mesmos grupos quando analisados em uma distância de valor mais elevado. O que indica que no caso destes fragmentos, os demais elementos não interferem na técnica de agrupamento.

Da mesma maneira podemos observar os dados obtidos para o sítio MI6. Esta análise se torna um pouco mais difícil pela pouca quantidade de amostras envolvidas.

A Figura 47 apresenta o dendrograma formado por todos os elementos determinados pela técnica XRF, somente para as peças encontradas no sítio Sede MI6. A Figura 48 apresenta o dendrograma com a combinação dos elementos $\mathrm{Fe}, \mathrm{Mn}, \mathrm{Sr}$ e $\mathrm{Cr}$.

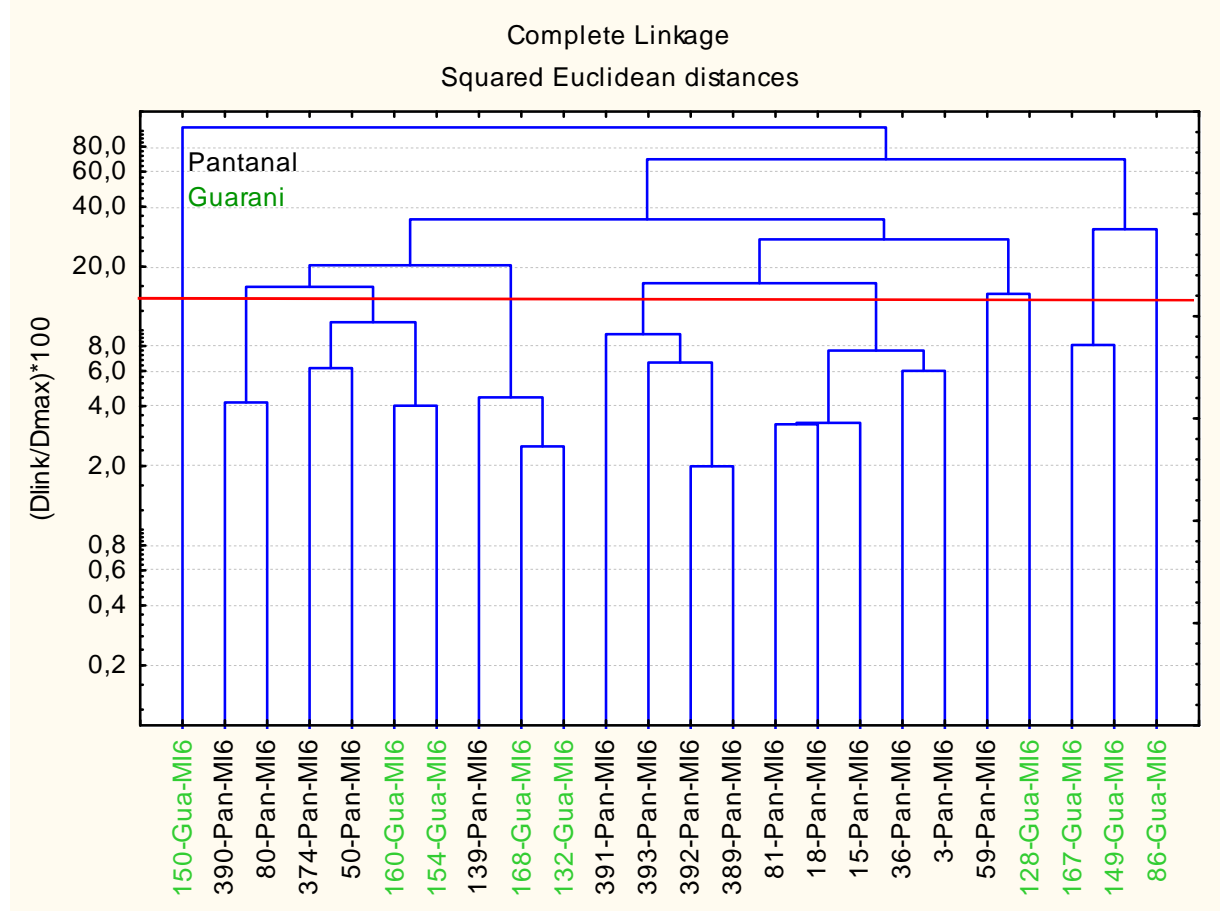

Figura 47. Dendrograma obtido utilizando todos os elementos determinados através da técnica XRF. Os fragmentos apresentados em cor verde pertencem à tradição Guarani e os apresentados em cor preta pertencem à tradição Pantanal. 


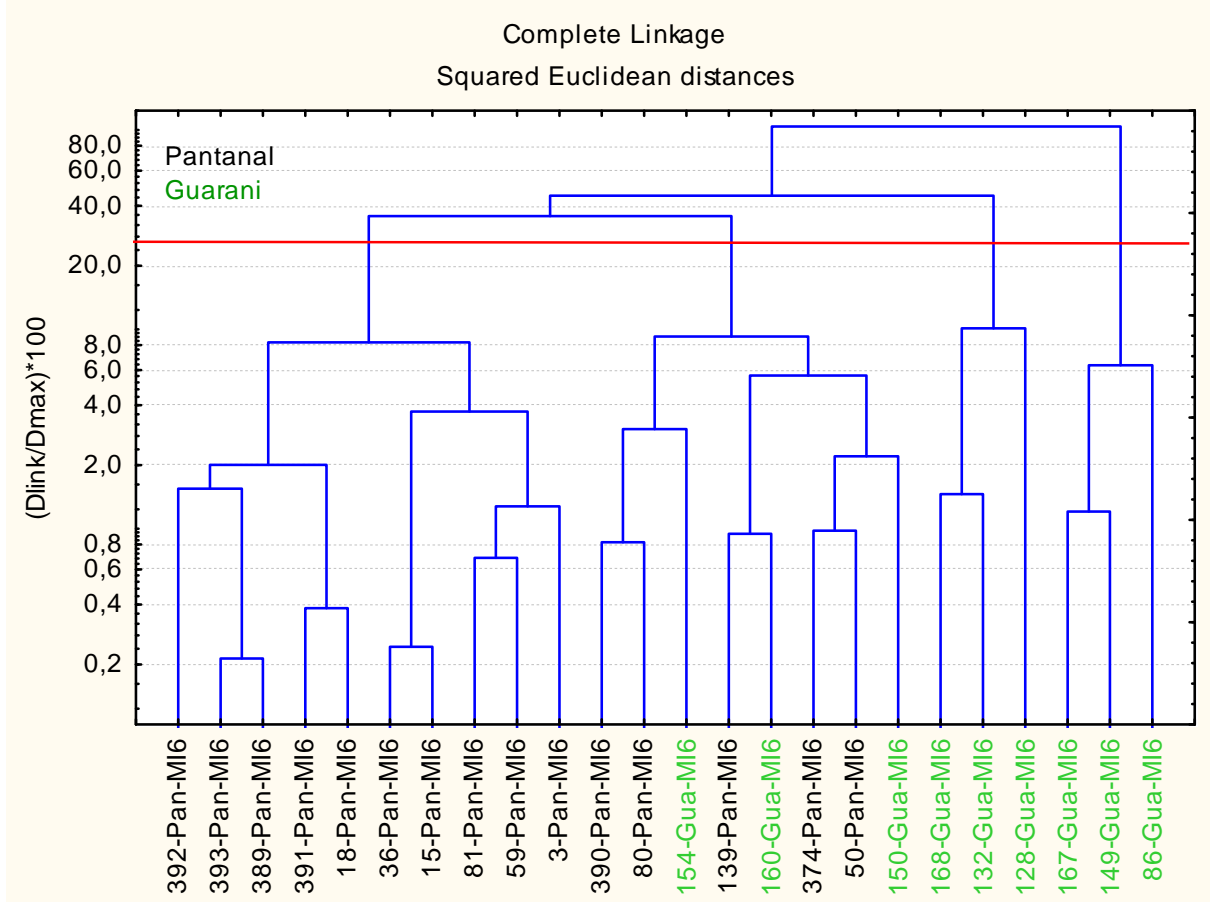

Figura 48. Dendrograma obtido utilizando os elementos $\mathrm{Fe}, \mathrm{Mn}, \mathrm{Sr}$ e $\mathrm{Cr}$ determinados através da técnica XRF. Os fragmentos apresentados em cor verde pertencem à tradição Guarani e os apresentados em cor preta pertencem à tradição Pantanal.

Analisando o dendrograma da Figura 47 observamos que os fragmentos não formam conjuntos bem definidos. A uma distância de valor 20 observamos a existência de seis pequenos grupos, sendo um exclusivamente Guarani, um exclusivamente Pantanal e os demais contendo ambas as culturas.

$\mathrm{Na}$ Figura 48, formada utilizando alguns elementos, podemos observar que a uma distância de valor 40 existe a formação de três pequenos grupos, sendo dois de tradição Guarani e um predominantemente Pantanal.

Para checar os resultados obtidos, a técnica de análise estatística PCA também foi aplicada nos dados obtidos pela técnica XRF. 
Utilizando todos os elementos como variáveis são obtidos, pela técnica PCA, um total de 15 fatores (Figura 49), dos quais os dois primeiros são utilizados nas análises consecutivas.

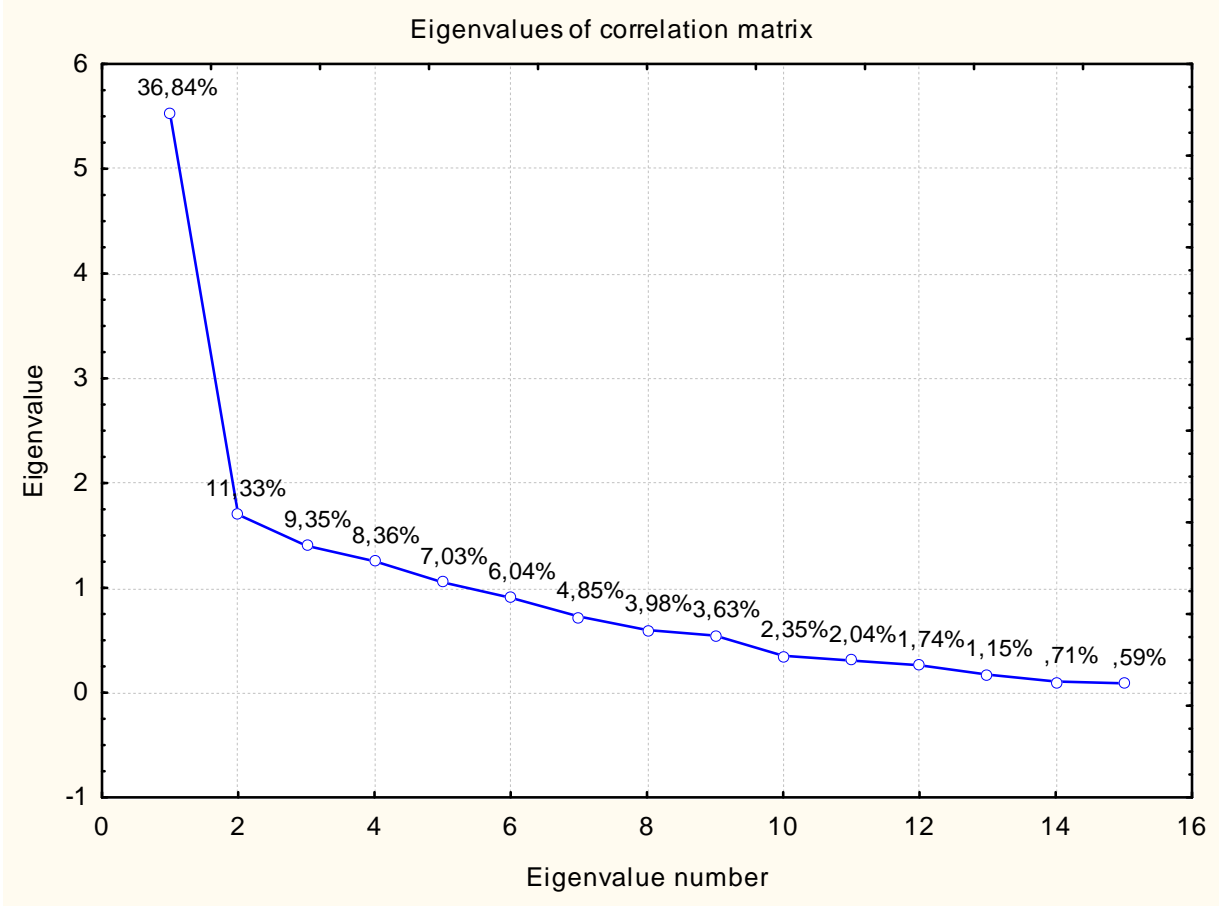

Figura 49. Gráfico onde são apresentadas as porcentagens relativas aos fatores utilizados na análise de PCA para os dados obtidos através da análise XRF.

Inicialmente aplicou-se a técnica nos elementos para verificar quais elementos possuem um comportamento semelhante nas amostras. A Figura 50 mostra que os elementos Cr, Zn, Y, $\mathrm{Zr}$ e $\mathrm{Mn}$, em uma primeira análise se separam dos demais elementos. No conjunto dos elementos que estão mais próximos ainda podemos separar em dois subconjuntos que estão anticorrelacionados no fator 2. O primeiro conjunto é formado pelos elementos $\mathrm{Sr}, \mathrm{Ca}, \mathrm{Br}, \mathrm{Ni}$ e $\mathrm{Cu}$, que possuem um fator 2 positivo, e o segundo grupo é formado pelos elementos $\mathrm{Ti}, \mathrm{Pb}, \mathrm{Fe}$, $\mathrm{K}$ e $\mathrm{Rb}$, que possuem um fator 2 negativo. Outro fato que devemos notar é que a distância das variáveis com relação ao circulo unitário é semelhantes para quase todos os elementos deste caso, com algumas exceções, tais como $\mathrm{Mn}, \mathrm{Zr}, \mathrm{Pb}$ e $\mathrm{Br}$. Isso indica que os demais elementos possuem uma contribuição parecida nos cálculos. Os resultados encontrados concordam com a separação obtida para os elementos utilizando a análise de cluster. 


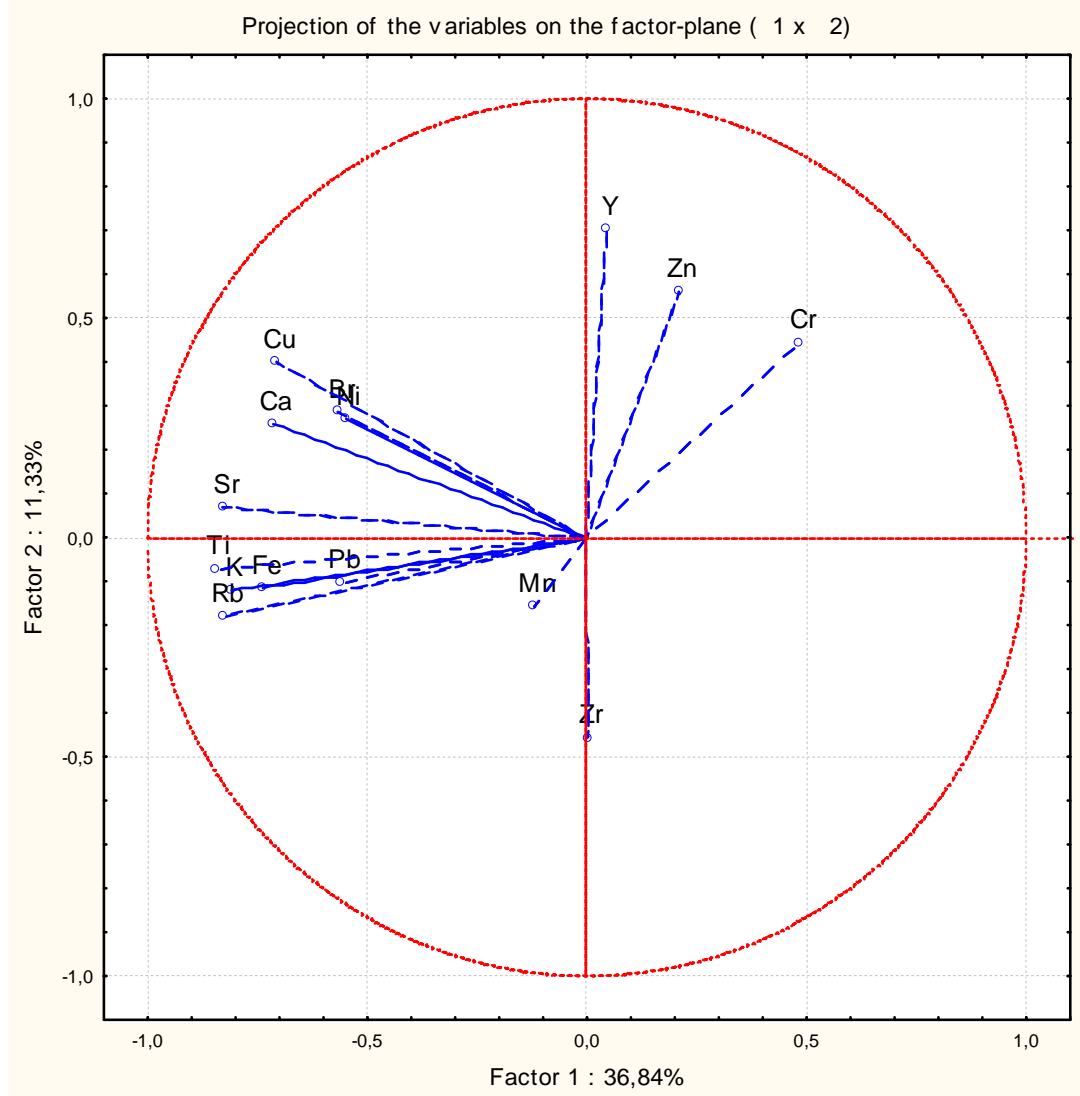

Figura 50. Figura obtida através da análise PCA aplicada aos elementos encontrados pela técnica $X R F$.

Em seguida foram obtidas a relações de fatores para os 112 fragmentos cerâmicos. Novamente foi feito um estudo para verificar qual a combinação de elementos que melhor agrupa as amostras de acordo com as classificações. Esse estudo teve origem na separação proposta pela Figura 50 e se estendeu até ser encontrada a mais satisfatória. A Figura 51 apresenta o resultado PCA utilizando todos os elementos determinados. 


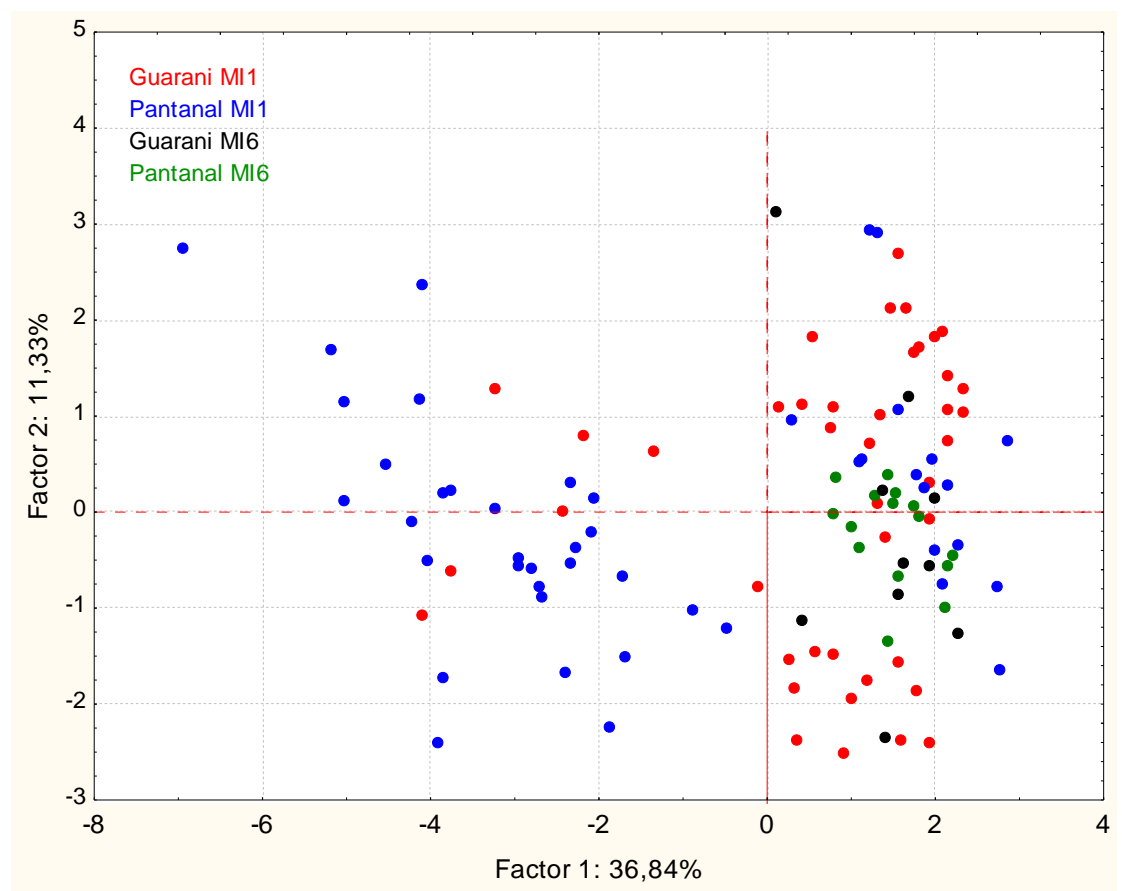

Figura 51. Figura obtida através da análise PCA aplicada aos dados obtidos por XRF em 112 fragmentos e utilizando como variáveis todos os elementos determinados. As peças estão indicadas de acordo com sua classificação.

Podemos observar na Figura 51 a indicação de uma separação dos fragmentos cerâmicos. As peças pertencentes ao conjunto Pantanal MI1, encontram-se em sua maioria na região com o valor do fator 1 negativo, ao contrário das peças do conjunto Guarani MI1, que estão na região positiva. Esses conjuntos estão espalhados em relação ao fator 2. As peças pertencentes ao sítio MI6 encontram-se na região de valores positivos do fator 1 e aglomeradas na região do eixo do fator 2 .

Para obter um melhor agrupamento das diferentes classificações, os dados apresentados foram estudados parcialmente com relação ao sítio arqueológico e à tradição. Inicialmente analisaremos as figuras obtidas quando analisado em relação ao sítio arqueológico. 
A Figura 52 apresenta o gráfico de fatores formado por todos os elementos determinados pela técnica XRF. A Figura 53 apresenta o gráfico com a combinação dos elementos K, Ca, Ti, Cr, Ni, Zn, Rb, Sr e Zr que melhor apresenta uma separação das peças cerâmicas com relação ao sítio arqueológico. Os fragmentos pertencentes ao Sítio Asa do Pote estão representados na cor vermelha.

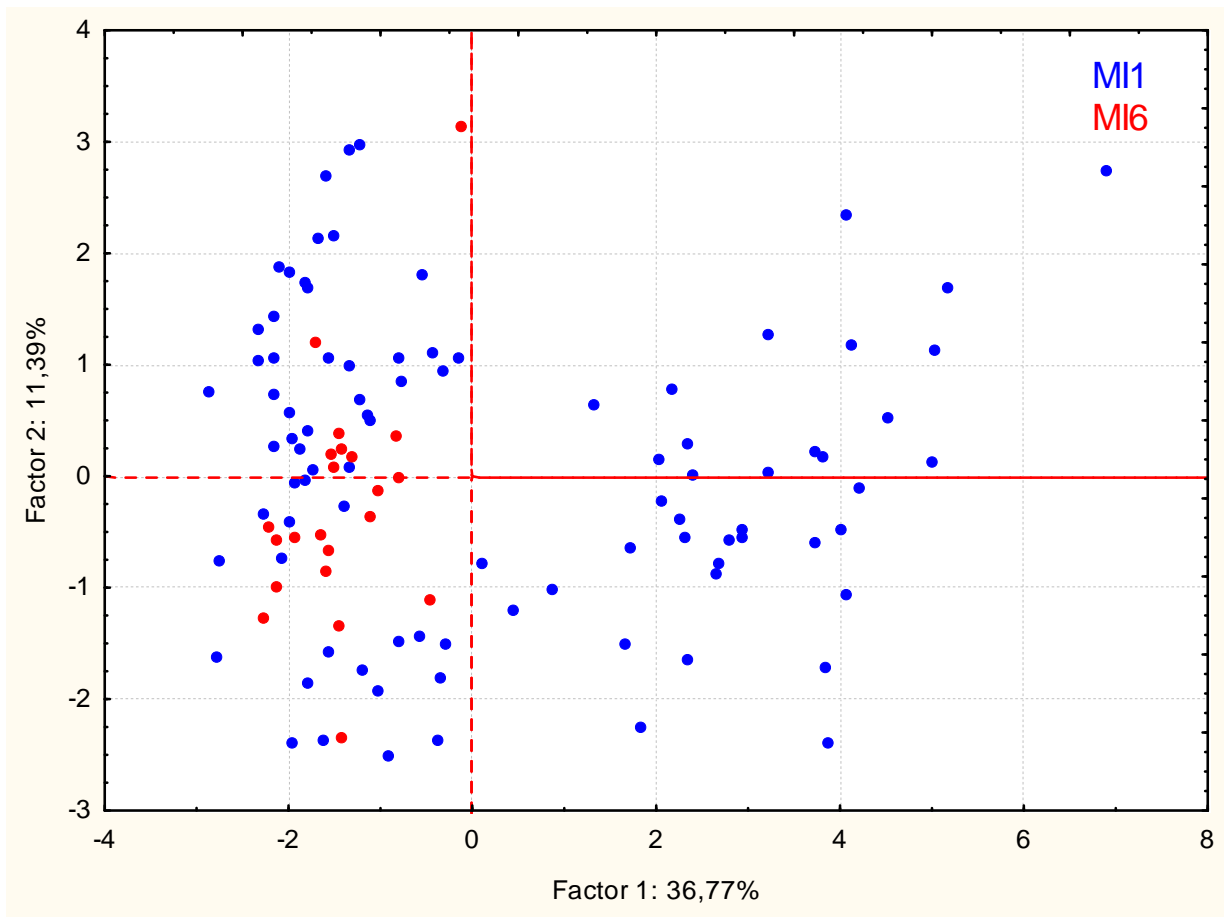

Figura 52. Figura obtida através da análise PCA aplicada aos dados obtidos por XRF em 112 fragmentos e utilizando como variáveis todos os elementos determinados. Os fragmentos indicados em cor vermelha pertencem ao sítio Asa do Pote e os fragmentos indicados em cor azul pertencem aio sítio Sede/Córrego Lalima. 


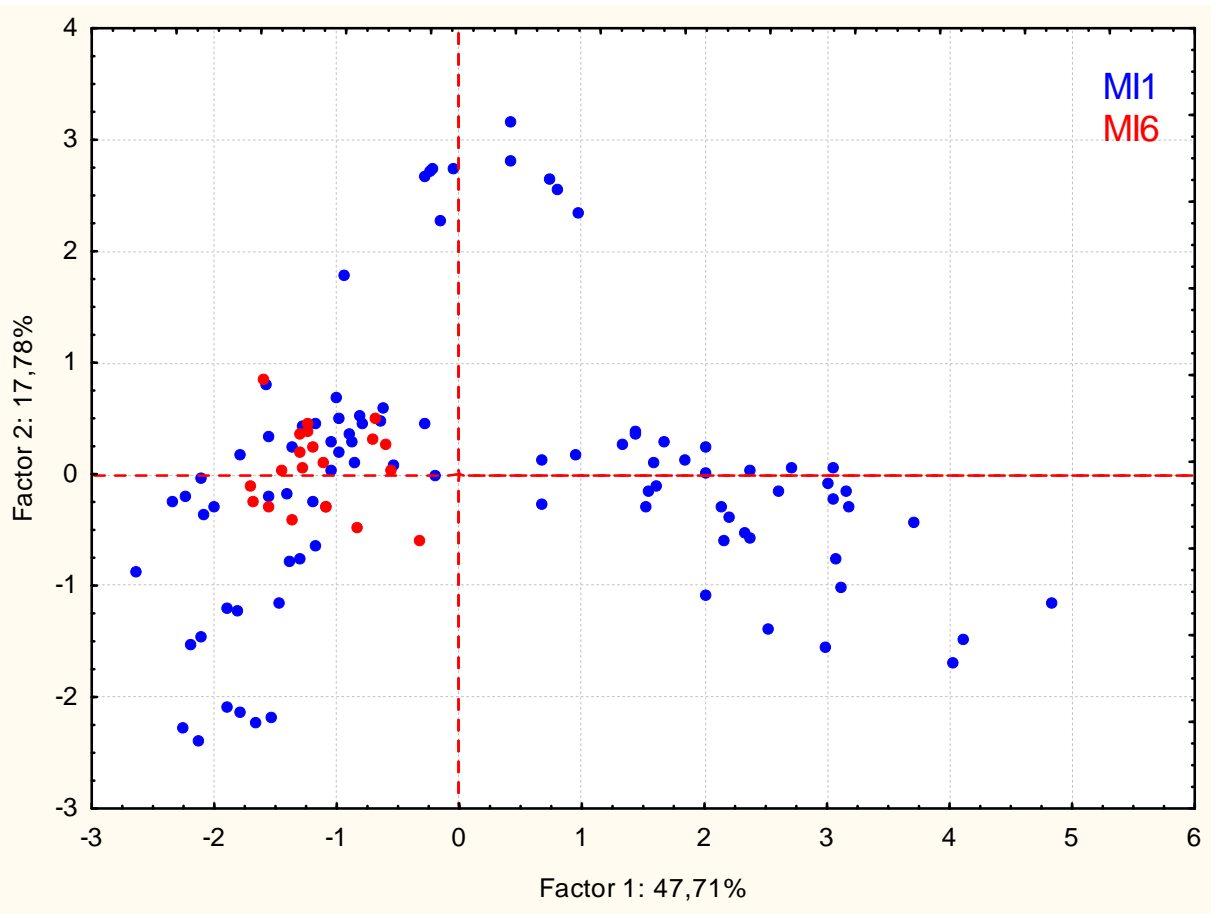

Figura 53. Figura obtida através da análise PCA aplicada aos dados obtidos por XRF em 112 fragmentos e utilizando como variáveis os elementos $\mathrm{K}, \mathrm{Ti}, \mathrm{Cr}, \mathrm{Zn}, \mathrm{Rb}, \mathrm{Sr}$ e Zr. Os fragmentos indicados em cor vermelha pertencem ao sítio Asa do Pote e os fragmentos indicados em cor azul pertencem aio sítio Sede/Córrego Lalima.

Ao analisarmos a Figura 52, que utiliza todos os elementos determinados como variáveis, podemos observar que os fragmentos não formam um agrupamento único. As peças pertencentes ao sítio MI6 se encontram aglomerados, mas não separados dos fragmentos pertencentes ao sítio MI1.

Porém, ao avaliarmos o gráfico de fatores formado por apenas alguns elementos selecionados apresentado na Figura 53, notamos que há um melhor agrupamento das peças, onde é possível diferenciar ao menos três conjuntos formados por peças do sítio MI1. Porém, novamente as peças do sítio MI6 estão aglomeradas, mas não podem ser diferenciadas dos demais fragmentos. 
Utilizando os mesmo dados fornecidos, podemos analisar os possíveis agrupamentos em relação à tradição dos fragmentos.

O gráfico da análise de fatores utilizando todos os elementos determinados pela técnica XRF é apresentado na Figura 54. A Figura 55 apresenta o gráfico gerado a partir da combinação dos elementos $\mathrm{K}, \mathrm{Ti}, \mathrm{Zn}, \mathrm{Pb}, \mathrm{Rb}, \mathrm{Sr}$ e $\mathrm{Zr}$. Ambas as figuras apresentam uma separação das peças cerâmicas com relação à tradição dos fragmentos Os fragmentos destacados em cor verde pertencem à tradição Guarani.

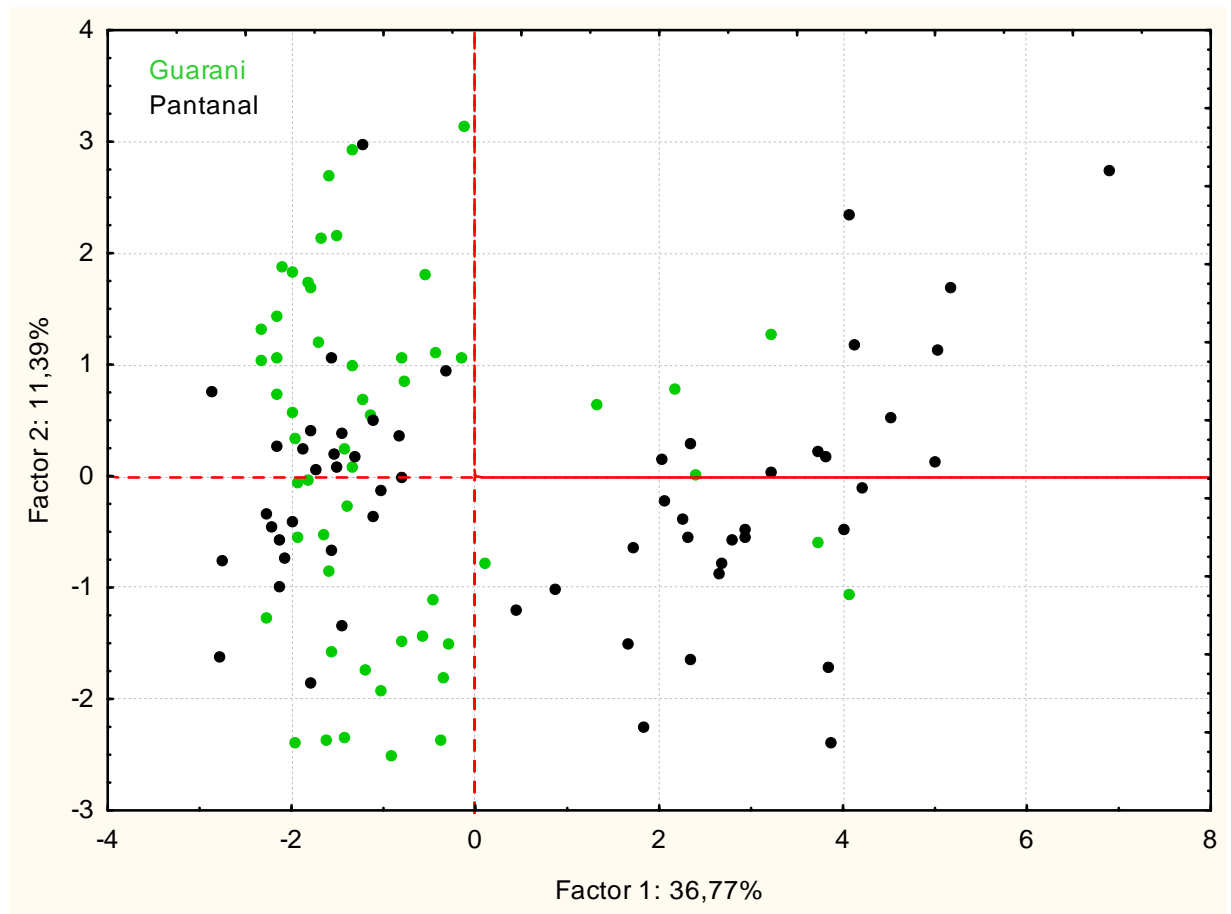

Figura 54. Figura obtida através da análise PCA aplicada aos dados obtidos por XRF em 112 fragmentos e utilizando como variáveis todos os elementos determinados. Os fragmentos indicados em cor verde pertencem à tradição Guarani e os indicados em cor preta pertencem à tradição Pantanal. 


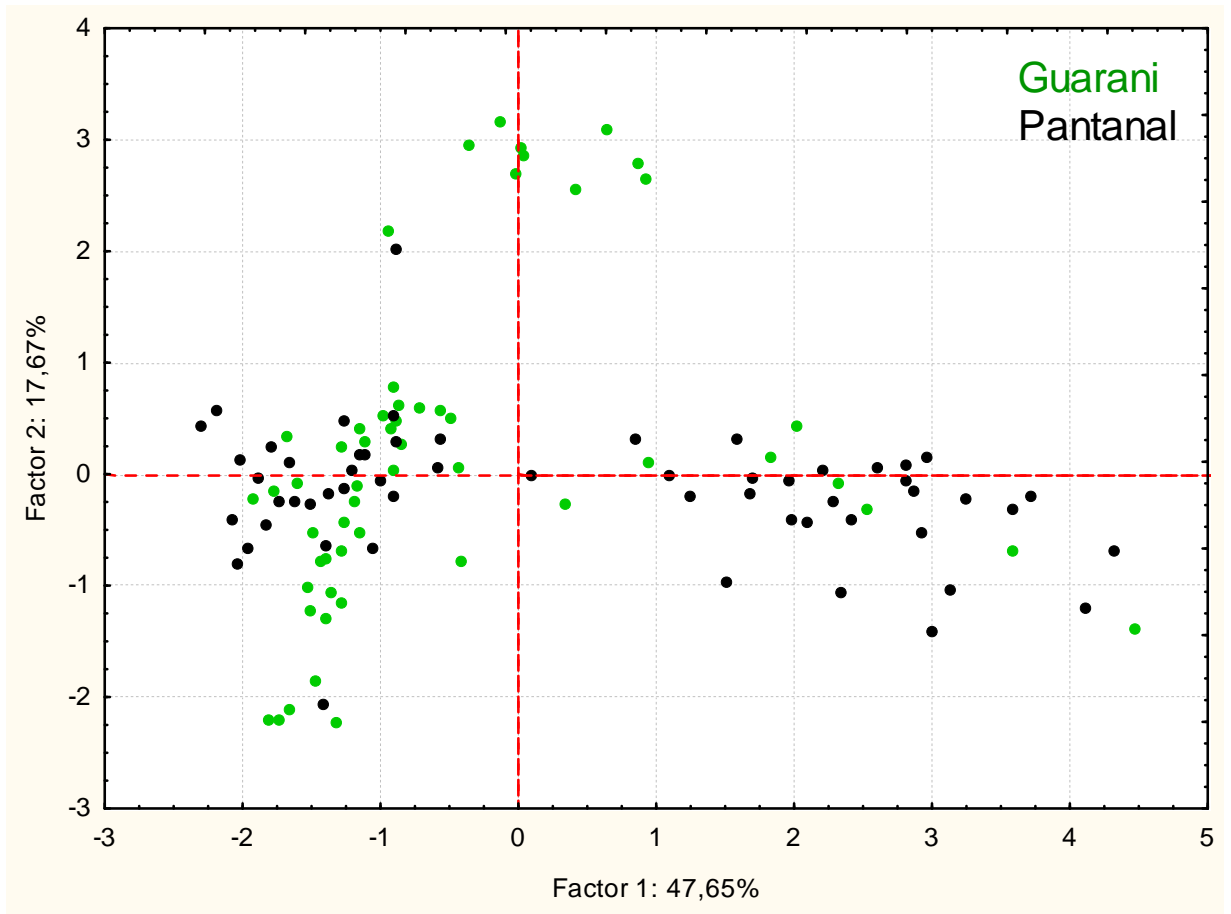

Figura 55. Figura obtida através da análise PCA aplicada aos dados obtidos por XRF em 112 fragmentos e utilizando como variáveis os elementos $K, T i, \mathrm{Zn}, \mathrm{Pb}, \mathrm{Rb}, \mathrm{Sr}$ e $\mathrm{Zr}$. Os fragmentos indicados em cor verde pertencem à tradição Guarani e os indicados em cor preta pertencem à tradição Pantanal.

Ao analisarmos a Figura 54 que utiliza todos os elementos determinados como variáveis, podemos observar que os fragmentos não formam grupos. Fragmentos pertencentes à tradição Pantanal predominam na região de fator 1 positivo.

Ao avaliarmos o gráfico de fatores formado por apenas alguns elementos selecionados, Figura 55, notamos que há uma separação de algumas peças. Podemos definir três regiões, sendo a primeira da região de fator 1 positivo, aonde predominam peças da tradição Pantanal; a segunda área com valores de fator 2 elevado, aonde se encontram algumas peças da tradição Guarani; e a terceira região aonde se concentram os demais fragmentos de ambas as tradições. 
Uma análise mais detalhada foi feita utilizando as peças previamente separadas de acordo com o sítio arqueológico.

A Figura 56 apresenta o gráfico de fatores utilizando todos os elementos determinados pela técnica XRF, somente para as peças encontradas no sítio Sede MI1. A Figura 57 apresenta o dendrograma com a combinação dos elementos $\mathrm{Fe}, \mathrm{Rb}$, $\mathrm{Sr}$ e $\mathrm{Zr}$.

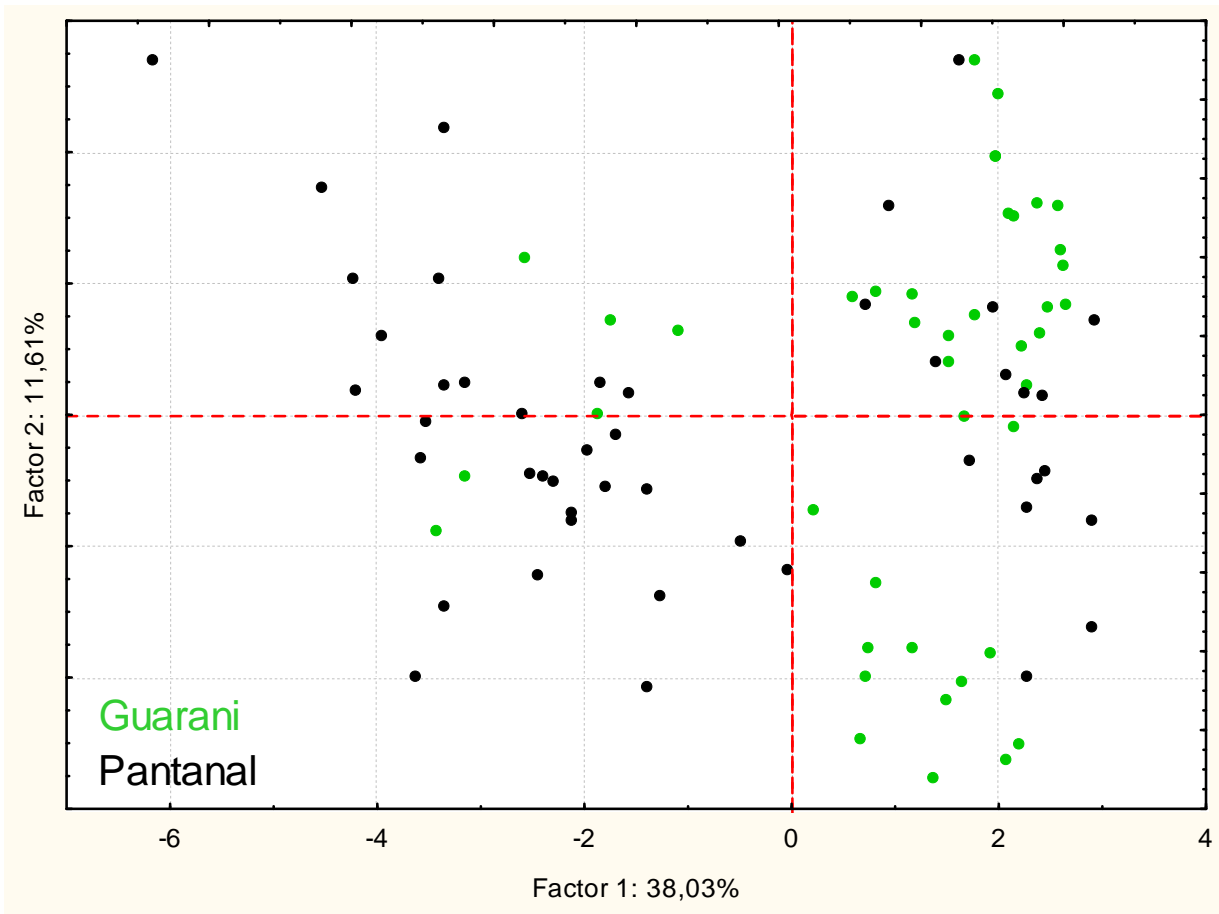

Figura 56. Figura obtida através da análise PCA aplicada aos dados obtidos por XRF em 88 fragmentos encontrados no sítio Sede/Córrego Lalima e utilizando como variáveis todos os elementos determinados. Os fragmentos indicados em cor verde pertencem à tradição Guarani e os indicados em cor preta pertencem à tradição Pantanal. 


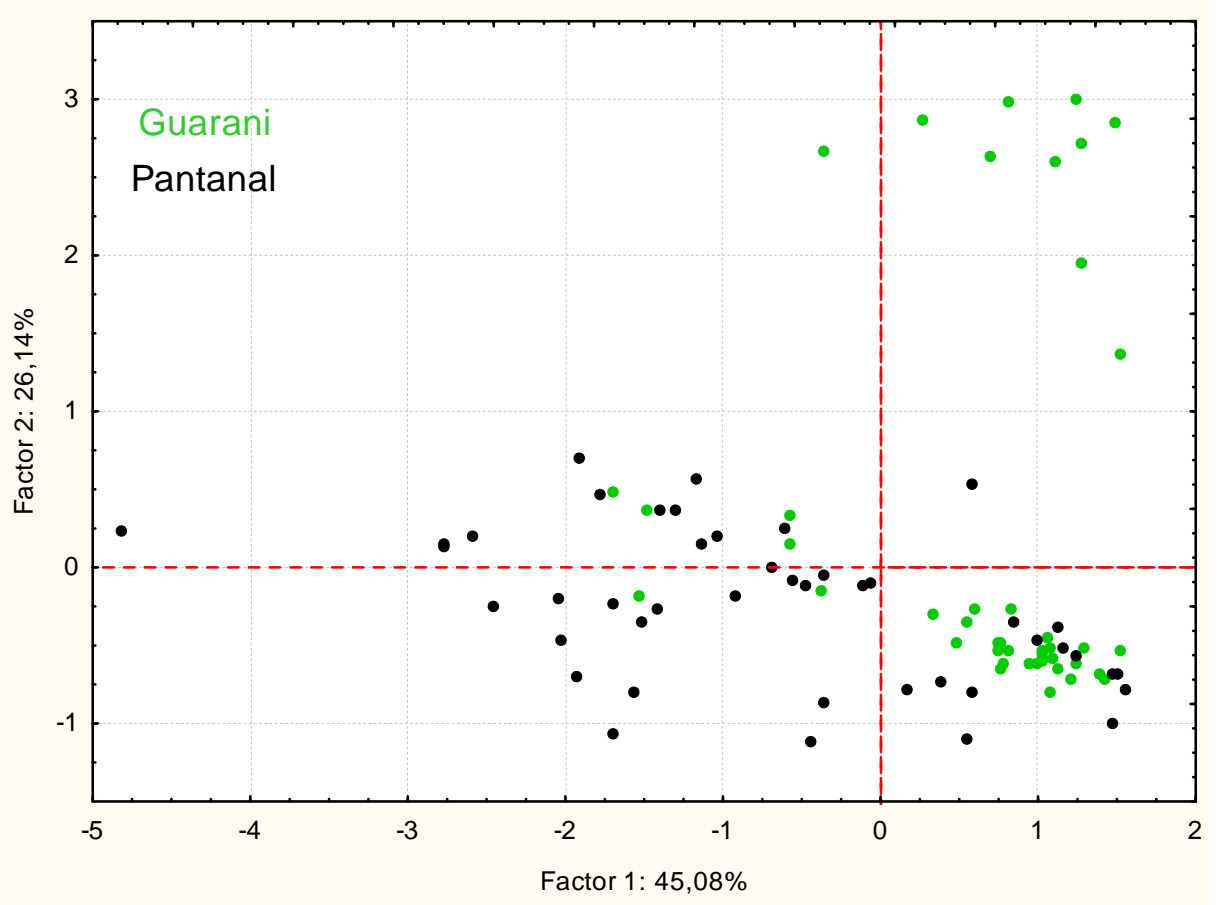

Figura 57. Figura obtida através da análise PCA aplicada aos dados obtidos por XRF em 88 fragmentos encontrados no sítio Sede/Córrego Lalima e utilizando como variáveis os elementos $\mathrm{Fe}, \mathrm{Pb}$, Sr e Zr. Os fragmentos indicados em cor verde pertencem à tradição Guarani e os indicados em cor preta pertencem à tradição Pantanal.

Analisando os dois gráficos de fatores anteriores obtidos para o sítio MI1, podemos observar que se formam três grupos, sendo um predominantemente Pantanal e um predominantemente Guarani e um com ambas as tradições. Também podemos observar que praticamente não há diferenças entre os dois gráficos, pois ambos separam os mesmos grupos quando analisados. O que indica que no caso destes fragmentos, os demais elementos não utilizados na segunda figura não interferem na técnica de agrupamento.

Da mesma maneira podemos observar os dados obtidos para o sítio MI6. Esta análise se torna mais restrita devido à pouca quantidade de amostras envolvidas. 
A Figura 58 apresenta o gráfico de fatores que utiliza todos os elementos determinados pela técnica XRF, somente para as peças encontradas no sítio Sede MI6. A Figura 59 apresenta o dendrograma com a combinação dos elementos $\mathrm{Fe}, \mathrm{Mn}, \mathrm{Sr}$ e $\mathrm{Cr}$.

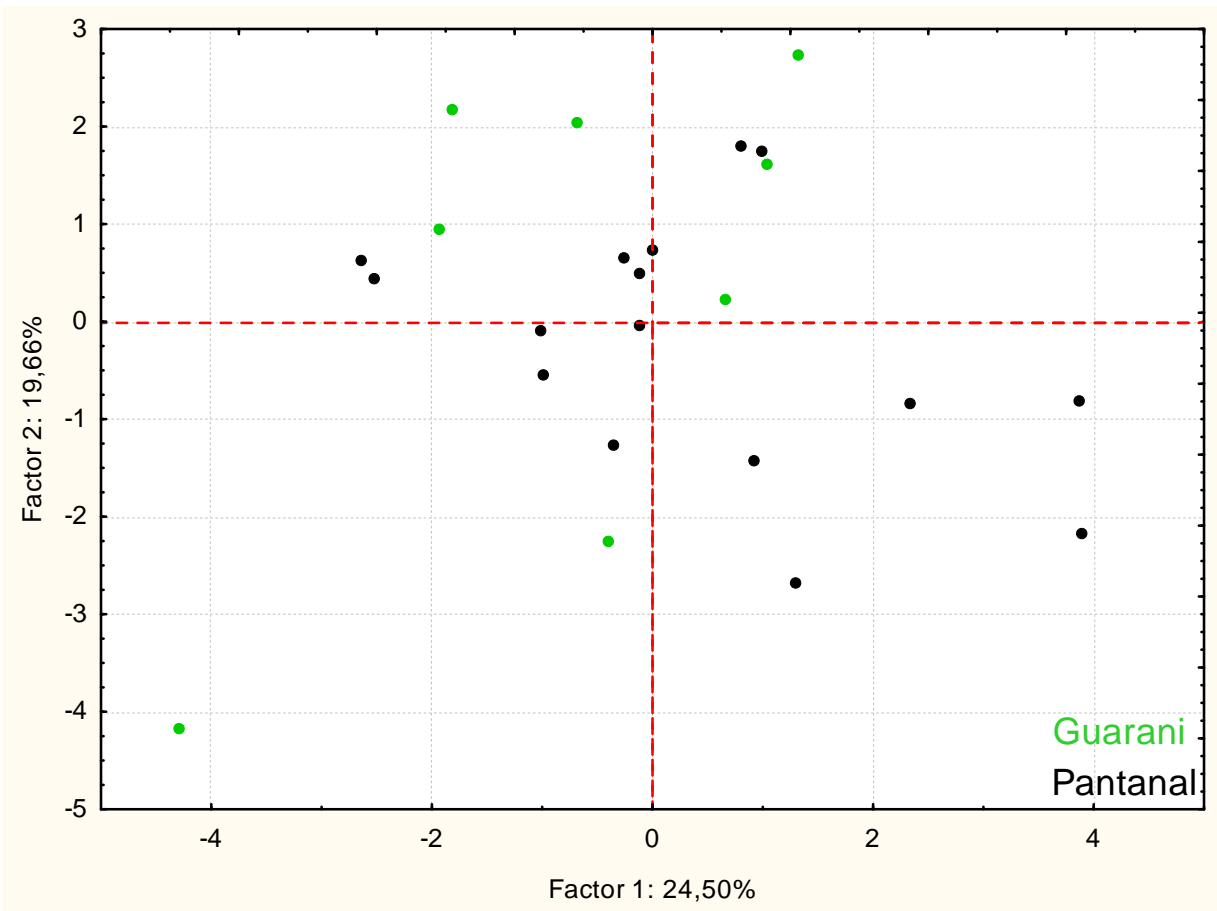

Figura 58. Figura obtida através da análise PCA aplicada aos dados obtidos por XRF em 24 fragmentos encontrados no sítio Asa do Pote e utilizando como variáveis todos os elementos determinados. Os fragmentos indicados em cor verde pertencem à tradição Guarani e os indicados em cor preta pertencem à tradição Pantanal. 


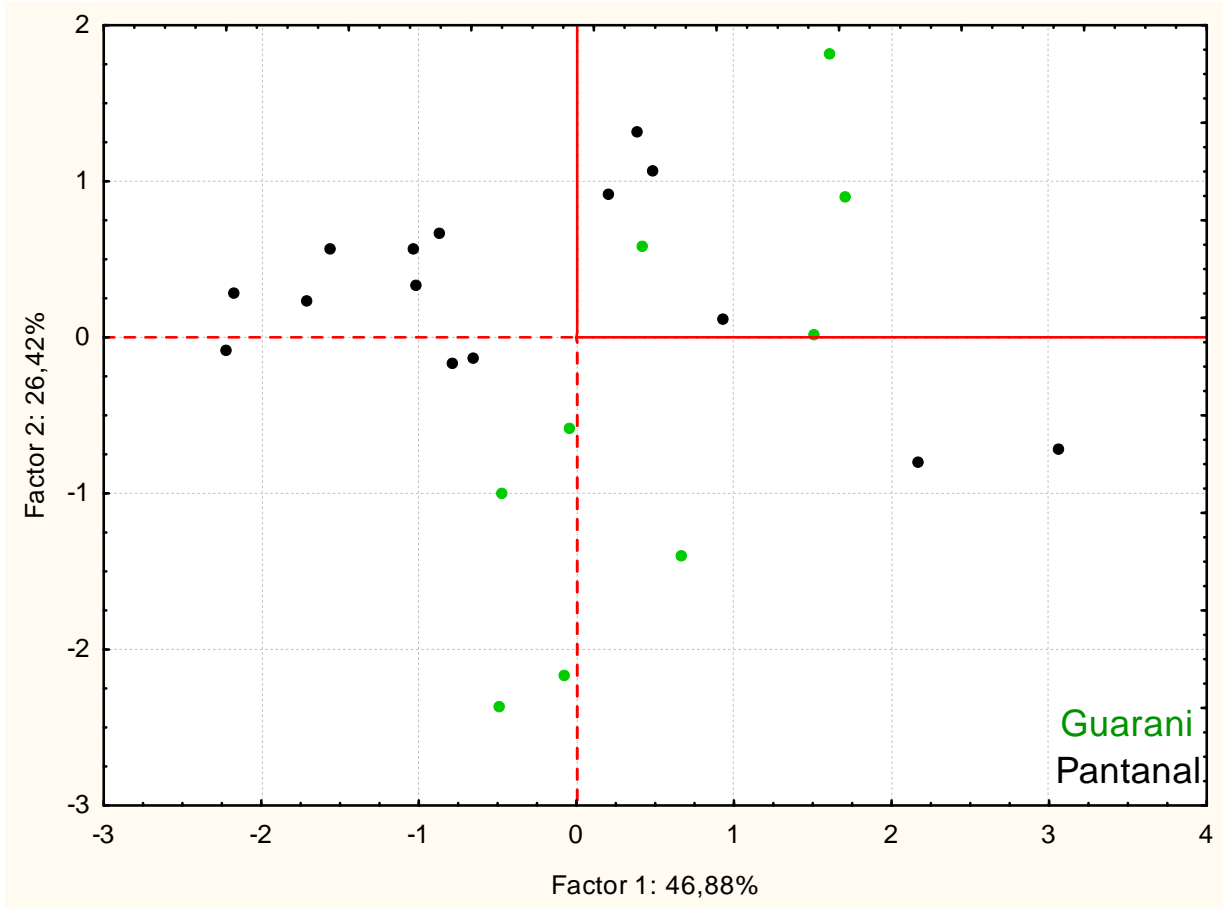

Figura 59. Figura obtida através da análise PCA aplicada aos dados obtidos por XRF em 24 fragmentos encontrados no sítio Asa do Pote e utilizando como variáveis os elementos $\mathrm{Fe}, \mathrm{Mn}$, $\mathrm{Sr}$ e Cr . Os fragmentos indicados em cor verde pertencem à tradição Guarani e os indicados em cor preta pertencem à tradição Pantanal.

Analisando os dois gráficos de fatores anteriores obtidos para o sítio MI6, podemos observar que não existe a formação de grupos. Na Figura 59 existe uma indicação, porém não podemos afirmar devido à pequena quantidade de amostras deste caso. 


\subsection{Técnica de Radiografia}

Com a aplicação da técnica de Radiografia podemos visualizar de uma maneira mais eficiente características externas e internas das peças estudadas. Em uma primeira análise é possível avaliar as características presentes no corpo da peça como a existência ou não de fraturas, seja internas ou externas e a presença de algum tipo de restauro realizado no objeto. Com uma observação mais apurada, é possível caracterizar a pasta cerâmica utilizada, em especial com relação à presença e aos tipos de temperos utilizados e densidade, além de permitir a obtenção de informações sobre a tecnologia empregada na manufatura das peças através das direções dos temperos, de fraturas ou mesmo através de processos de alisamento da pasta.

Para realizar este estudo, foram realizados dois períodos de aquisição de imagens no Laboratório de Dosimetria localizado no Instituto de Física da Universidade de São Paulo ambos com o auxílio da pesquisadora Martha Aldred. O primeiro período foi realizado utilizando a técnica de radiografia tradicional. O segundo período foi realizado utilizando a técnica de radiografia computadorizada. Em ambos os períodos foi utilizado o tubo de raios $\mathrm{X}$ Philips MG450 presente no laboratório.

Antes de realizar as aquisições das imagens, as espessuras das peças foram medidas. Isto porque as condições de irradiação dependem das características do objeto a ser analisado. As peças foram classificadas em dois grupos de acordo com sua espessura, o primeiro grupo contém peças de espessura entre $0,4 \mathrm{~cm}$ e $1,0 \mathrm{~cm}$ e o segundo grupo contém as peças com espessuras superiores a $1 \mathrm{~cm}$.

No primeiro período de aquisição de imagens, foi radiografado o conjunto total de 112 fragmentos cerâmicos utilizando a técnica de radiografia convencional. As condições utilizadas neste primeiro período foram variadas devido às diferentes espessuras das peças. A tensão aplicada variou entre $50 \mathrm{kV}$ e $120 \mathrm{kV}$, o tempo de exposição variou entre 1 e 5 minutos sempre a uma distância de 3,5 metros da fonte. 
Após a irradiação, as chapas radiográficas foram reveladas por métodos químicos no Laboratório de Aplicação em Diagnóstico por Imagens, localizado no IEE ${ }^{[24]} / \mathrm{USP}$. Após este processo as chapas foram digitalizadas. Um exemplo do resultado deste processo é apresentado na Figura 60. As condições de irradiação para esta imagem foram uma tensão aplicada de 50 $\mathrm{kV}$, uma corrente de $15 \mathrm{~mA}$ e um tempo de exposição de 5 minutos.

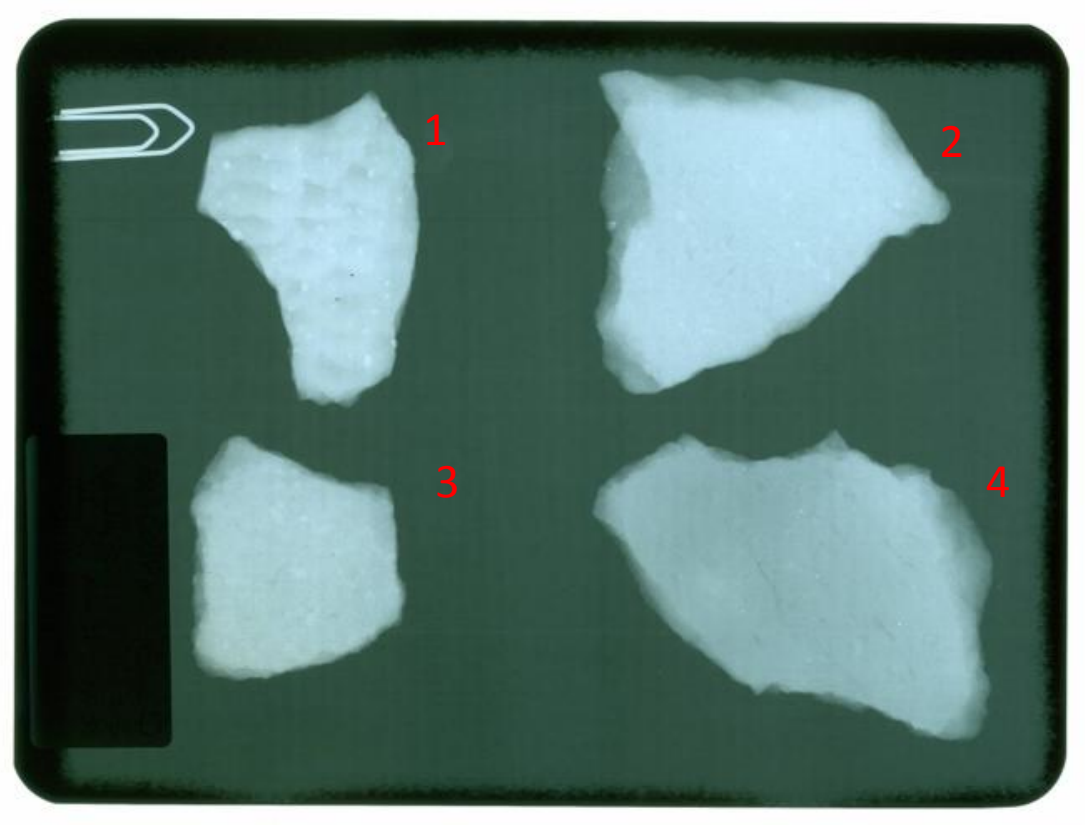

Figura 60. Imagem de fragmentos cerâmicos obtida através de radiografia convencional e posteriormente digitalizada. As condições de irradiação são dadas por $50 \mathrm{kV}$ de tensão aplicada, corrente de 15 mA e um tempo de exposição de 5 minutos.

Como podemos observar na figura acima, a imagem radiográfica obtida possui diversas interferências. Podemos citar como interferências, devidas ao processo de revelação, algumas marcas horizontais presentes na imagem. Essas marcas podem ser associadas ao sistema de rolagem na revelação, à temperatura e não uniformidade dos componentes químicos e interferências na secagem do filme. Nesta imagem em particular também existe a interferência do processo de digitalização que contribui com a perda de resolução e nitidez da imagem. 
Porém, mesmo com as interferências nas imagens obtidas, é possível observar algumas características das peças irradiadas. Na peça 1 podemos observar com mais detalhes a decoração superficial da peça. Pode-se notar também uma diferença com relação à textura da argila empregada na fabricação das peças, assim como uma diferença na presença de tempero. De acordo com a imagem, os fragmentos podem ser diferenciados pela presença de tempero. Nas peças 1 e 3 podemos observar a presença de tempero de origens diferentes e a ausência de tempero na peça 4. Outro detalhe são as linhas existentes no fragmento 4. Estas marcas indicam a orientação do processo de manufatura da peça original. Devido à baixa qualidade das imagens não foi possível realizar maiores estudos nesse período de aquisição.

Para obter imagens com melhor resolução, foi realizado um segundo período de aquisição de imagens. Neste período, foi radiografado o conjunto total de 112 fragmentos cerâmicos utilizando a técnica de radiografia computadorizada utilizando o sistema de digitalização de multiaplicações CR 30-X da Agfa Health Care adquirido pelo laboratório no ano de 2010.

Para realizar estas aquisições as condições de irradiação utilizadas foi uma tensão aplicada de $50 \mathrm{kV}$, uma corrente de $3 \mathrm{~mA}$, e tempo de irradiação dependente da espessura das peças. Peças com espessura entre $0,4 \mathrm{~cm}$ e $1,0 \mathrm{~cm}$ foram irradiadas por um tempo de 10segundos. Peças com espessura superior a $1,0 \mathrm{~cm}$ foram irradiadas por 13 segundos. Todas as irradiações foram feitas a uma distância de 3,5m da fonte. Foi irradiado juntamente com os fragmentos, um padrão de Alumínio escalonado com espessura variando entre $0,2 \mathrm{~cm} \mathrm{e} \mathrm{1,0} \mathrm{cm.}$ Esse padrão foi utilizado para a normalização e controle das imagens obtidas. Foram ao todo utilizadas seis chapas radiográficas.

Para a visualização das imagens, foi utilizado o software NX que é uma ferramenta de controle de qualidade e identificação de imagens juntamente com o software de processamento de imagens MUSICA2, ambos da Agfa. As imagens foram obtidas com uma resolução de 10 pixels/mm. 
A Figura 61 é o resultado obtido para a radiografia denominada Chapa1. Todas as demais imagens foram normalizadas por esta imagem. A normalização foi feita com base no peça padrão de $\mathrm{Al}$ com diferentes espessuras.

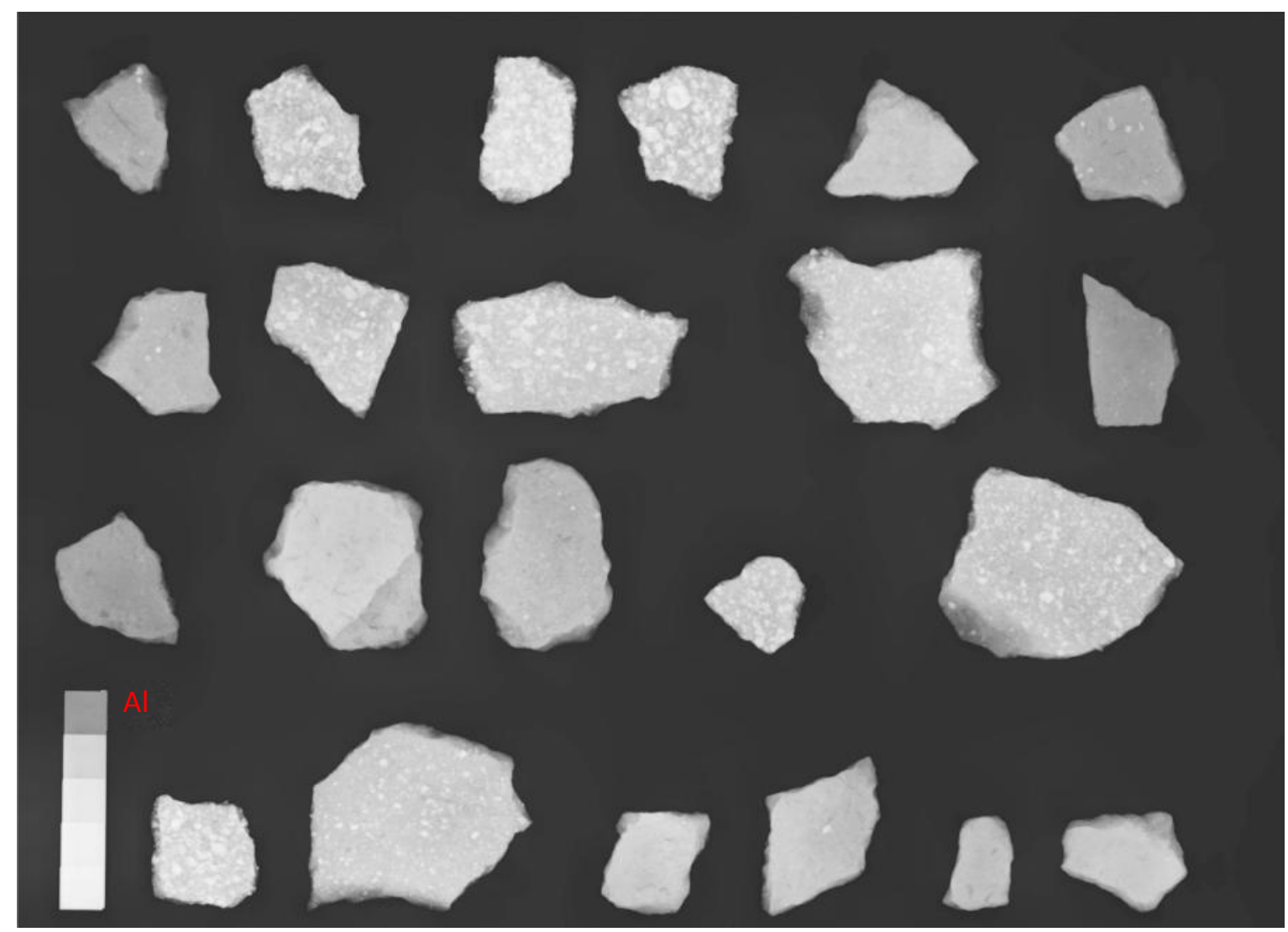

Figura 61. Imagem obtida através de radiografia computadorizada para o estudo de fragmentos cerâmicos. Chapa 1. Na imagem está indicado o padrão de Alumínio (Al) utilizado neste estudo.

Para estudar as imagens obtidas utilizou-se o programa de processamento de imagens de acesso livre UTHSCSA-ImageTool (University of Texas Health Science Center at San Antonio). Este programa permite a manipulação de diversas características da imagem e realizar transformações geométricas. Um dos recursos utilizados transforma uma região delimitada da imagem em um histograma que relaciona o tom de cinza da imagem com sua frequência em contagens. Este mesmo recurso pode fornecer o perfil em tons de cinza sob uma reta na imagem. A Figura 62 mostra um exemplo desta transformação para a peça de Al padrão obtida na Chapa1. 

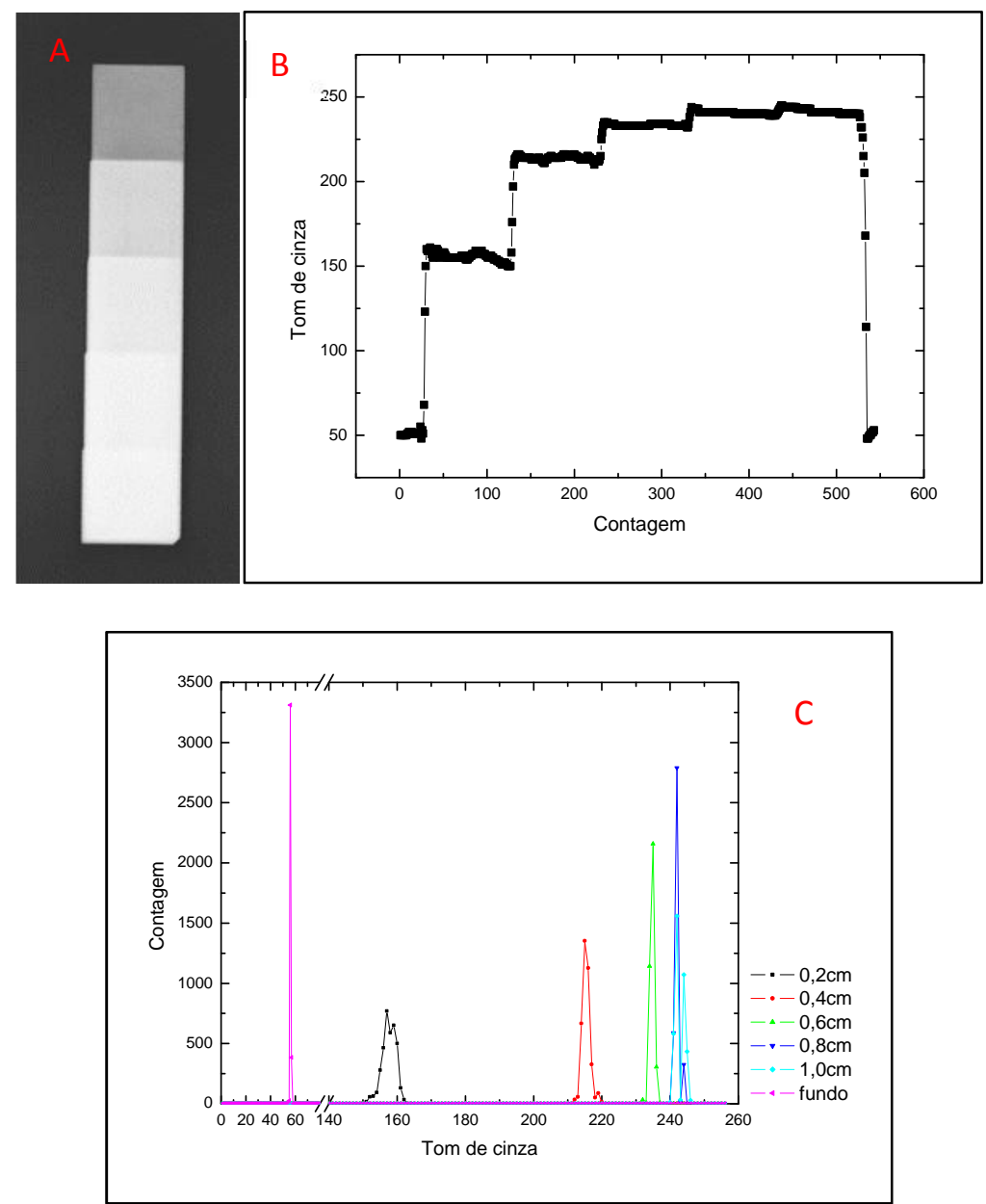

Figura 62. Gráficos obtidos utilizando o programa ImageTool em imagem de padrão de Al obtida através de radiografia computadorizada Chapa 1. A. Imagem radiográfica do padrão d Al; B. Gráfico do perfil do tom de cinza do padrão de Al; C. Gráfico de área em função da contagem obtida para cada espessura do padrão de Al.

$\mathrm{Na}$ figura anterior temos a imagem obtida para o padrão de Al (Figura $62 \mathrm{~A}$ ). É possível identificar facilmente as cinco diferentes espessuras. No primeiro gráfico apresentado (Figura 62 B) temos o perfil obtido traçando uma reta numa área representativa da imagem. Podemos observar que quanto maior a espessura maior o valor de tom de cinza, onde a cor preta é identificada pelo valor 0 e a cor branca é identificada pelo valor 256 . O segundo gráfico (Figura $62 \mathrm{C}$ ) foi obtido através da variação do tom de cinza dentro de uma área previamente selecionada. Foram selecionadas áreas correspondentes a cada espessura do padrão. O chamado fundo corresponde à área de coloração preta da imagem radiográfica. 
A Figura 63 mostra uma comparação entre os tons de cinza obtidos para cada segmento de diferente espessura do padrão de $\mathrm{Al}$ para as seis imagens adquiridas.

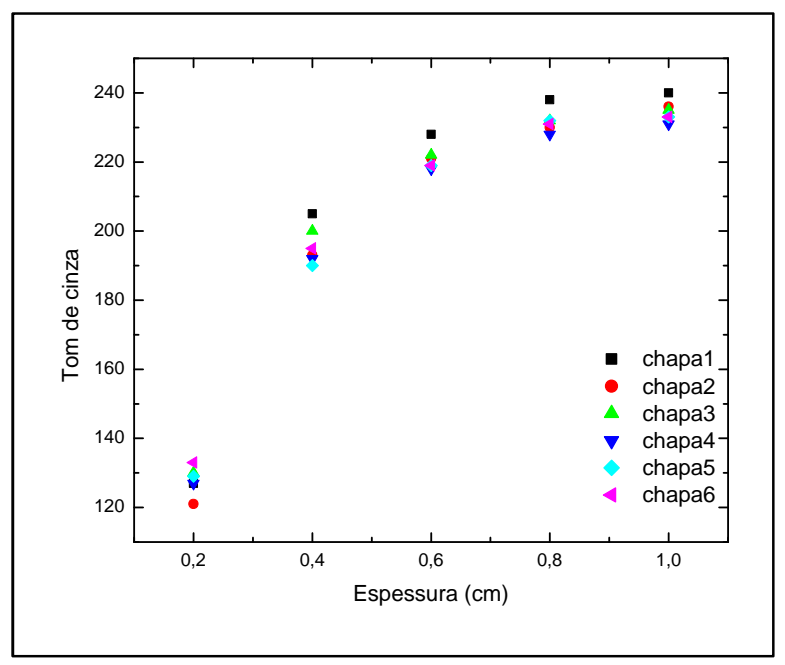

Figura 63. Gráfico de espessura versus tom de cinza obtidos da imagem do padrão de Al para as seis chapas radiográficas adquiridas.

Uma normalização foi realizada entre as imagens das diferentes chapas radiográficas. $\mathrm{O}$ objetivo desta normalização é diminuir qualquer interferência da imagem devido ao pequeno tempo de exposição na irradiação, correspondendo à 10 segundos. Para isso, utilizamos as imagens obtidas para os padrões de Al nas diferentes chapas, e utilizando um programa de análise de imagens alteraram-se os valores de tons de cinza correspondentes a cada espessura do padrão. Em cada imagem foi ajustado o valor correspondente aos picos do branco a 250 e do fundo preto em 50. O resultado é apresentado na Figura 64.

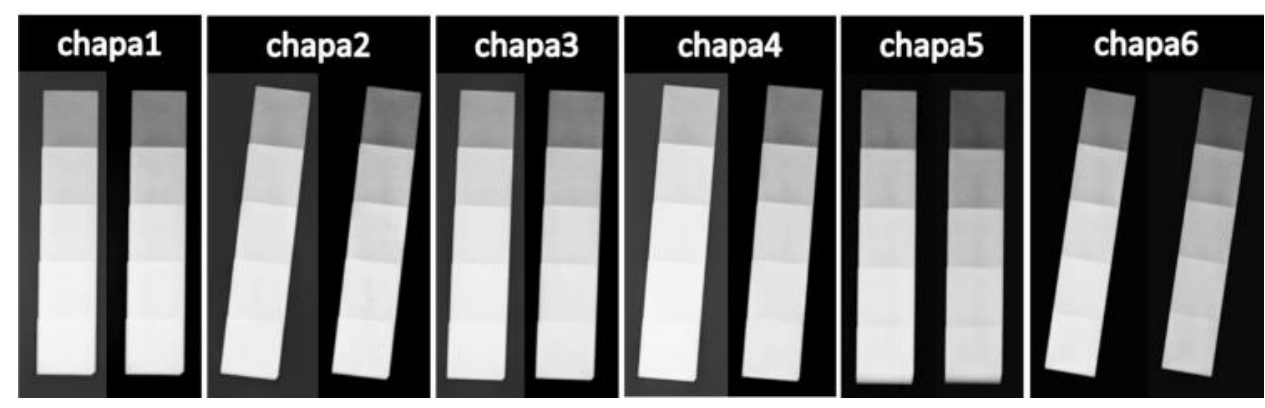

Figura 64. Imagem para o padrão de Al obtida nas diferentes chapas, antes e depois da normalização. 
Após a normalização dos tons de cinza das seis chapas, as imagens correspondentes a cada fragmento cerâmico foram separadas e analisadas individualmente. As imagens dos fragmentos estão apresentadas no anexo Catálogo de Peças. A cada imagem foi realizado o mesmo processo de seleção de área e feito o gráfico de tons de cinza versus contagem, assim como no padrão de Al. Exemplos dos gráficos obtidos são apresentados na Figura 65.
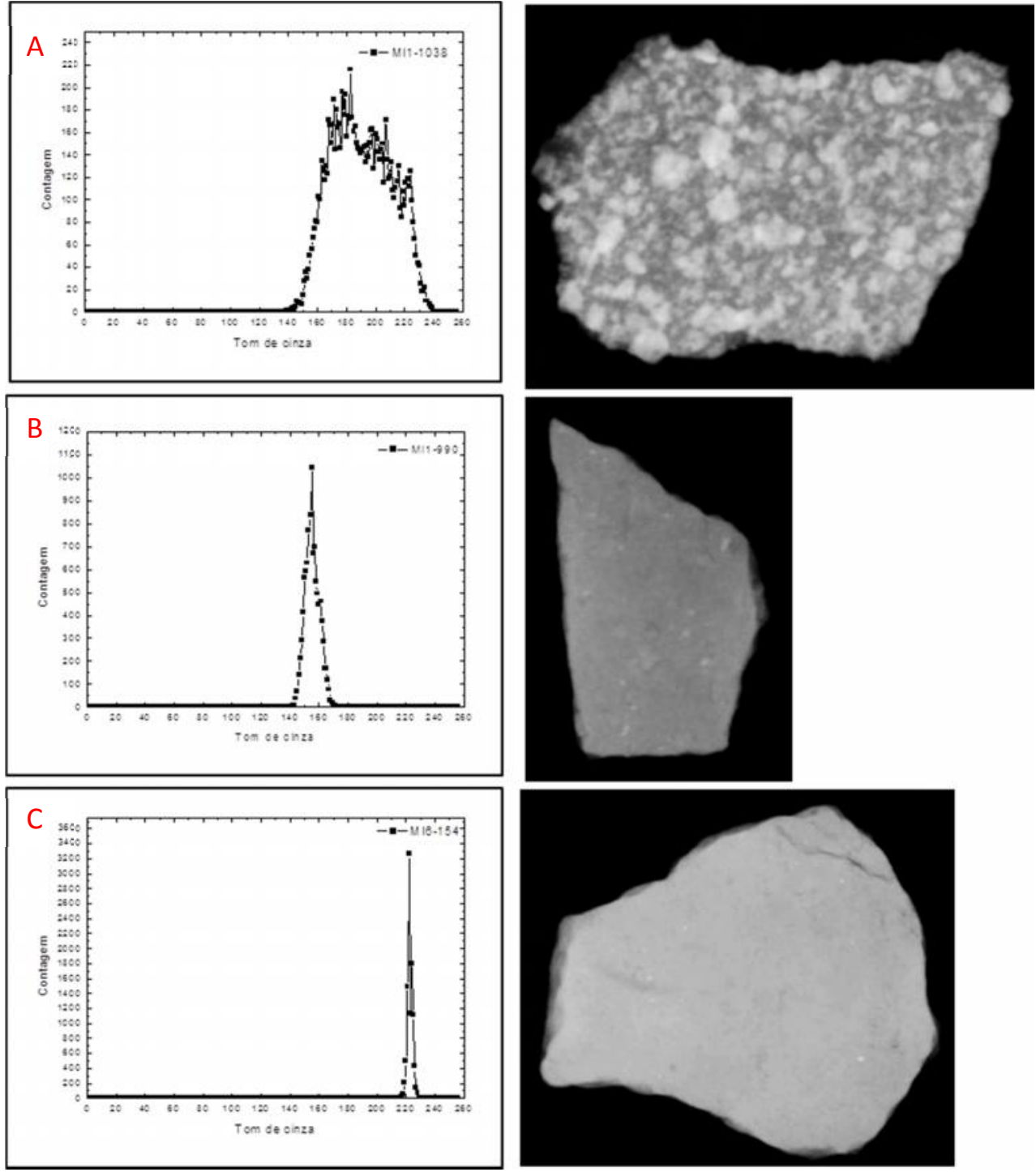

Figura 65. Gráficos obtidos utilizando o programa ImageTool nas imagens de fragmentos cerâmicos obtida através de radiografia computadorizada. A. Fragmento MI1-1038 (Pantanal/com tempero); B. Fragmento MI1-990 (Pantanal/pouco tempero); C. Fragmento MI6-154 (Guarani/sem tempero). 
Como podemos notar na figura anterior, os gráficos de tom de cinza versus contagens são diferentes para cada fragmento. Essa diferença pode estar associada a diversas características de cada peça, tais como espessura, densidade, presença de tempero ou decoração de superfície.

Em fragmentos que possuem tempero, como o primeiro exemplo da Figura 65 (A), o gráfico apresenta uma curva alargada ou com mais de um pico de intensidade, indicando a diferença de densidade entre a pasta e o tempero adicionado. O mesmo não ocorre com a imagem das peças que não possuem adição de tempero, estas apresentam um gráfico formado por um pico estreito e bem definido (C).

Este gráfico também pode estar associado à densidade ou à espessura do fragmento. Se a peça apresentar uma menor espessura ou uma menor densidade, os raios $\mathrm{X}$ são menos absorvidos pela peça e apresentam um tom de cinza mais escuro na imagem radiográfica. Em alguns casos, cujas peças possuem uma decoração em sua superfície, este gráfico apresenta uma curva mais larga, devido ao fato de a espessura da peça não ser constante, porém este fato é facilmente identificado.

Para analisar estes gráficos obtidos, foi feito o ajuste de uma curva gaussiana, obtendo desta forma o centróide de cada pico e seu desvio. Foi escolhido o ajuste gaussiano por este ser suficientemente adequado para a maioria dos picos, em especial os picos simples. Os gráficos com curvas mais complicadas também foram ajustados por uma gaussiana para uma primeira aproximação. Conforme observado anteriormente, a posição deste pico depende da quantidade de raios $X$ que são transmitidos ao filme radiográfico e o desvio padrão depende de fatores como a presença e a quantidade de tempero e a existência de decoração superficial em alguns casos.

Uma primeira análise visual não aponta separação entre as peças dos diferentes sítios e tradições culturais com respeito à presença de tempero.

Para dar continuidade a este estudo, foi realizada uma separação de acordo com a presença de tempero nos fragmentos. Essa separação foi feita de maneira subjetiva por meio da análise visual das imagens radiográficas. As peças foram separadas em três grupos: as que possuem tempero, as que possuem pouco tempero e as que não possuem tempero em sua estrutura. A Figura 66 exemplifica esta separação. 

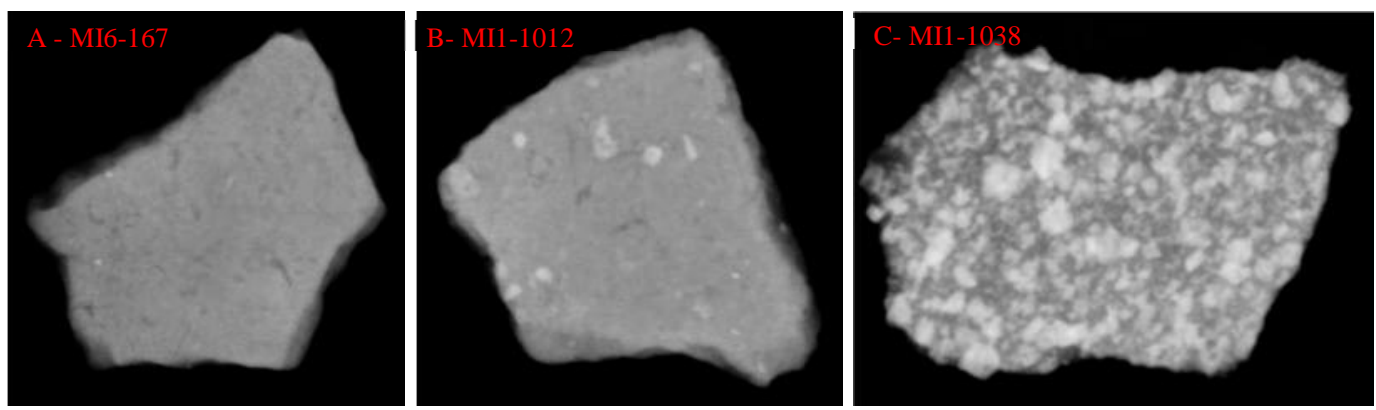

Figura 66. Exemplo de classificação de peças de acordo com a presença de tempero. A. Fragmento MI6-167, não possui tempero; B. Fragmento MI1-1012 possui pouco tempero; C. Fragmento MI11038 possui tempero.

Estas informações obtidas podem ser visualizadas melhor com a construção de gráficos. Com estes gráficos, podemos relacionar a existência de tempero com a intensidade do pico e seu desvio padrão, como apresentado na Figura 67.

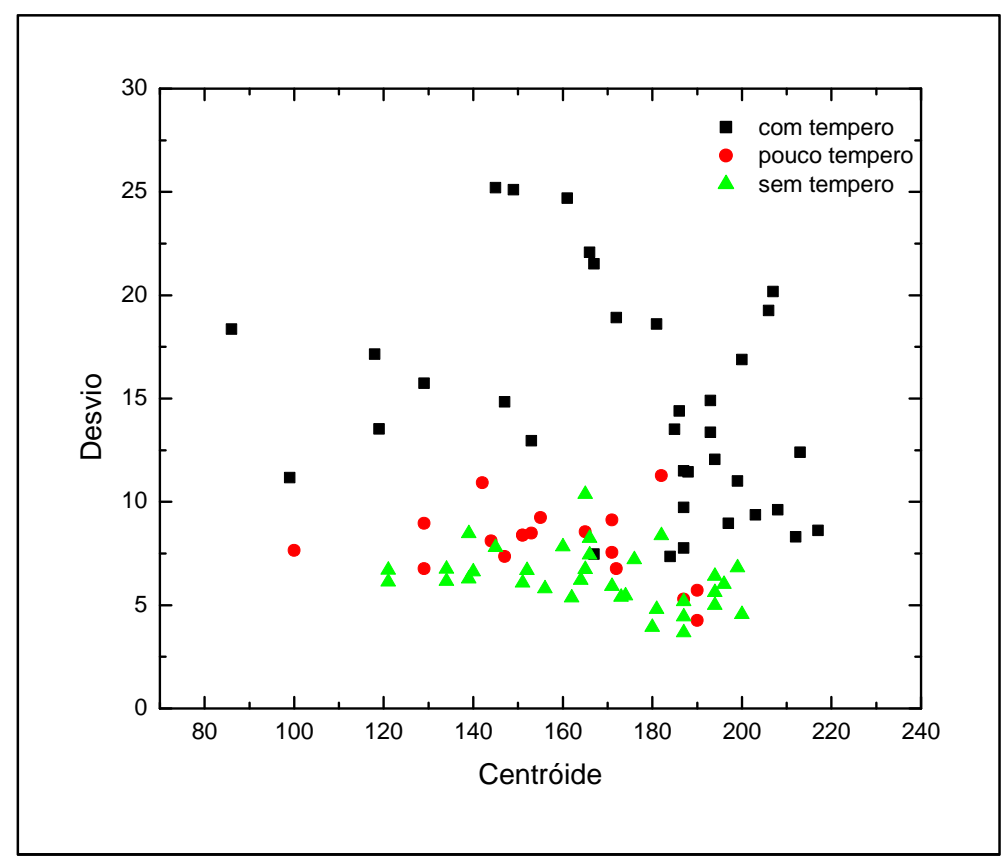

Figura 67. Gráfico relacionando posição do pico, desvio e a presença de tempero para as imagens obtidas através de radiografia computadorizada. 
Como podemos observar na Figura 67, a presença de tempero está diretamente relacionada com a largura do pico obtido nas imagens radiográficas. O centróide, que caracteriza o tom de cinza predominante na imagem, também pode sofrer interferência da presença do material adicionado ao corpo cerâmico.

Um segundo gráfico é gerado comparando o centróide do pico com a espessura media de cada fragmento cerâmico, apresentado na Figura 68. Neste gráfico estão apresentados somente os fragmentos com espessura inferior a $1,0 \mathrm{~cm}$.

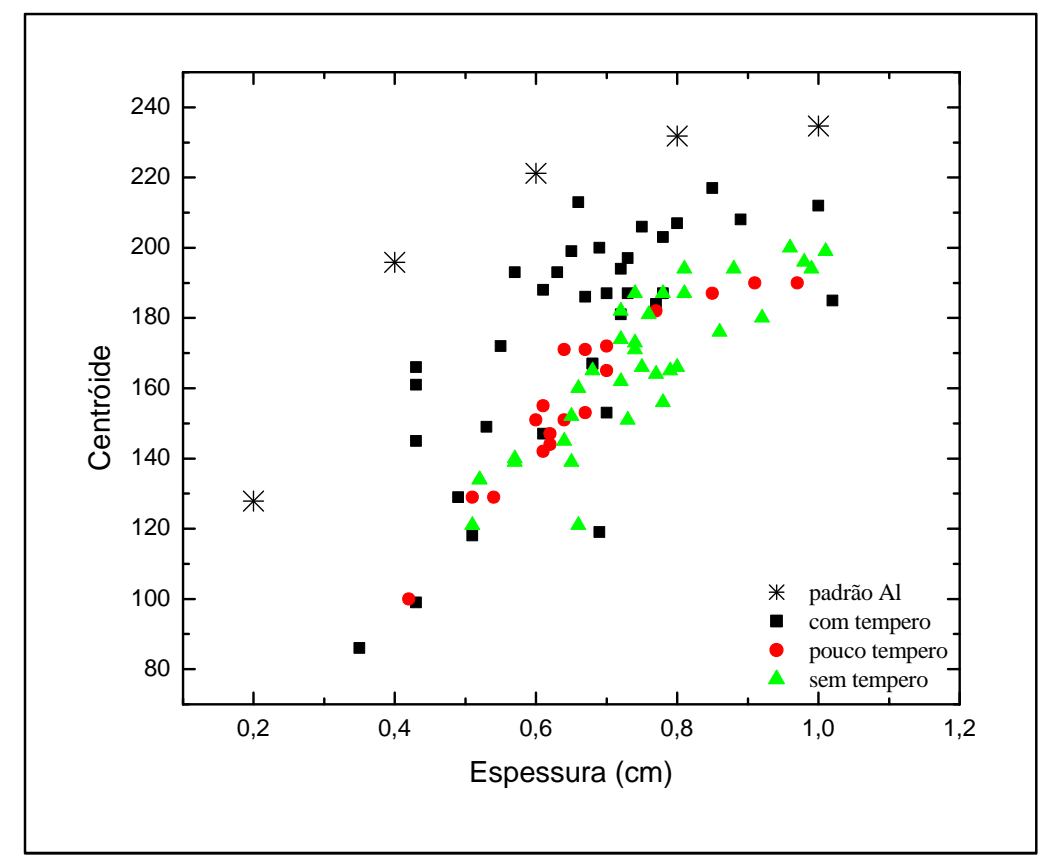

Figura 68. Gráfico relacionando centróide do pico com a espessura média de cada fragmento e a presença de tempero para s imagens obtidas através de radiografia computadorizada.

O gráfico da figura acima sugere uma relação não linear entre a espessura do fragmento e o centróide determinado na imagem radiográfica, conforme o esperado pela teoria da absorção (lei de atenuação). Analisando somente os pontos referentes ao padrão de alumínio podemos inferir que o posicionamento da curva está relacionado com a curva de absorção do material, que por sua vez depende da densidade do material. 
Para checar esta afirmação utilizamos três métodos que permitem calcular a densidade dos fragmentos cerâmicos. O primeiro método consiste em medir diretamente a densidade utilizando a relação massa e volume. O segundo método consiste em determinar os valores de densidade através da composição elementar determinada anteriormente pela técnica PIXE. O terceiro método consiste em comparar as informações das imagens radiográficas dos fragmentos cerâmicos com as imagens obtidas para materiais de densidade e curva de absorção conhecidas.

O primeiro método utilizado foi a medida direta da densidade dos fragmentos cerâmicos. Para isto aplicamos uma variação do Princípio de Arquimedes. O método se aplica a objetos com formas geométricas irregulares e permite obter a densidade através do seu peso aparente imerso em água e do peso imerso em ar. Porém por se tratar de fragmentos cerâmicos arqueológicos e para evitar qualquer dano às peças, foi utilizado areia fina ao invés de água.

Para realizar este experimento utilizamos um pote de massa conhecida 6,8(1) g e areia comum peneirada duas vezes para obter grãos finos. A densidade obtida para a areia foi de $1,35(10) \mathrm{g} / \mathrm{cm}^{3}$ e o volume total do conjunto pote/areia é de 84(6) $\mathrm{cm}^{3}$. As massas dos fragmentos cerâmicos foram pré-determinadas com o auxílio de uma balança digital. Para determinar o volume de um fragmento, colocou-se a peça dentro do pote e completou-se o volume com areia. Foi seguido o mesmo procedimento para compactar a areia. Desta maneira podemos determinar o peso do conjunto pote/peça/areia e por consequência a massa de areia utilizada:

$$
\begin{aligned}
& m=m_{\text {pote }}+m_{\text {peça }}+m_{\text {areia }} \\
& m_{\text {areia }}=m-m_{\text {peça }}-m_{\text {pote }}
\end{aligned}
$$

onde $m$ é o valor final do conjunto pote/peça/areia.

Conhecendo a massa de areia utilizada podemos determinar o volume de areia e por consequência o volume do fragmento cerâmico:

$$
\begin{gathered}
V_{\text {areia }}=\frac{m_{\text {areia }}}{d_{\text {areia }}} \\
V_{\text {peça }}=V-V_{\text {areia }}
\end{gathered}
$$

onde $V$ é o volume total do pote e $d_{\text {areia }}$ é a densidade da areia utilizada. 
Com estas informações podemos calcular a densidade dos fragmentos como sendo

$$
d_{p e c ̧ a}=\frac{m_{p e c ̧ a}}{V_{p e c ̧ a}}
$$

Para checar o procedimento, foram realizadas as medidas de objetos padrões de densidade conhecida. Os materiais utilizados foram o alumínio cuja densidade fornecida é 2,7 $\mathrm{g} / \mathrm{cm}^{3}$, Teflon cuja densidade fornecida está entre $2,0 \mathrm{~g} / \mathrm{cm}^{3}$ e $2,3 \mathrm{~g} / \mathrm{cm}^{3}$, Polytec de densidade fornecida entre $1,0 \mathrm{~g} / \mathrm{cm}^{3}$ e $1,4 \mathrm{~g} / \mathrm{cm}^{3}$ e massa de modelar com a adição de sal, sem densidade fornecida.

Esses objetos possuem uma geometria simples tornando-se fácil a medida do volume e por consequência da densidade experimental da peça. Desta forma, é possível comparar o valor obtido pelo princípio de Arquimedes com o valor calculado experimentalmente através do volume e os valores fornecidos pela literatura. Podemos observar na Tabela 10 que os valores encontrados para as densidades são compatíveis dentro das incertezas. Este resultado indicou a possibilidade de determinar a densidade dos fragmentos cerâmicos arqueológicos.

Tabela 10. Valores de densidade obtidos para objetos padrões de composições conhecidas.

\begin{tabular}{llllll}
\hline \hline Padrão & $\begin{array}{l}\text { Peso } \\
(\mathrm{g})\end{array}$ & $\begin{array}{l}\text { Volume } \\
\left(\mathrm{cm}^{3}\right)\end{array}$ & $\begin{array}{l}\text { Densidade } \\
\text { literatura } \\
\left(\mathrm{g} / \mathrm{cm}^{3}\right)\end{array}$ & $\begin{array}{l}\text { Densidade } \\
\text { experimental } \\
\left(\mathrm{g} / \mathrm{cm}^{3}\right)\end{array}$ & $\begin{array}{l}\text { Densidade } \\
\text { Arquimedes } \\
\left(\mathrm{g} / \mathrm{cm}^{3}\right)\end{array}$ \\
\hline \hline Alumínio & $8,1(1)$ & $3,00(1)$ & 2,7 & $2,70(3)$ & $2,60(12)$ \\
\hline Teflon & $3,2(1)$ & $3,50(1)$ & $2,0-2,3$ & $2,25(3)$ & $2,28(12)$ \\
\hline Polytec & $5,4(1)$ & $2,40(1)$ & $1,0-1,4$ & $0,91(4)$ & $0,93(12)$ \\
\hline \hline
\end{tabular}

Através deste método foram obtidos valores de densidade entre 1,3(5) $\mathrm{g} / \mathrm{cm}^{3}$ e 2,5(5) $\mathrm{g} / \mathrm{cm}^{3}$. Estes valores podem ser melhores visualizados quando adicionados ao gráfico de espessura e presença de tempero como na Figura 69. 


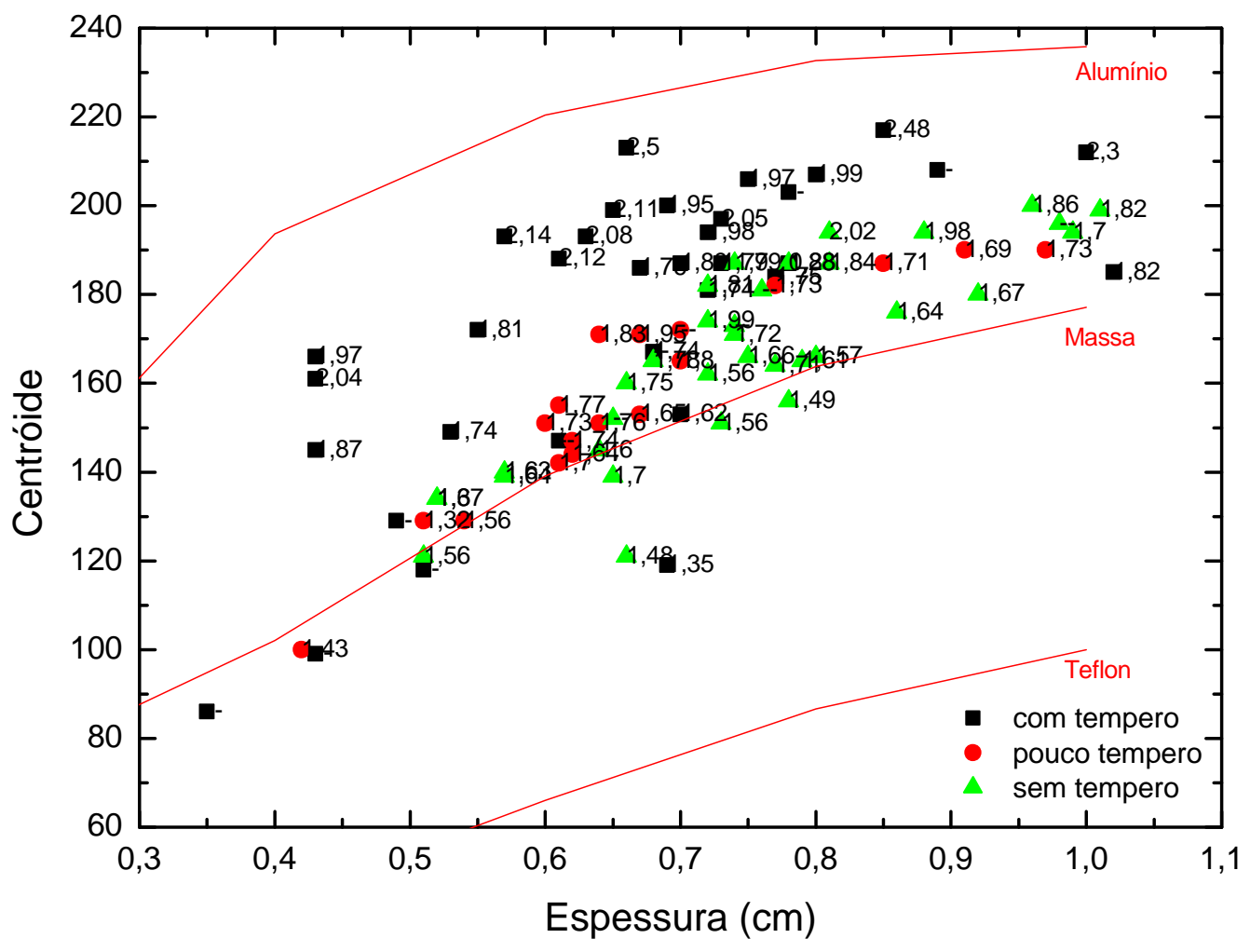

Figura 69. Gráfico centróide versus espessura de cada fragmento e materiais com densidades conhecidas (Alumínio, Massa de modelar e Teflon). Estão indicados os valores obtidos para a densidade dos fragmentos através do método de Arquimedes.

Apesar do excesso de informações em uma mesma figura, podemos observar na figura acima que os valores de densidade encontrados pelo método de Arquimedes para os fragmentos que possuem tempero em sua estrutura são, em sua maioria, os mais elevados, conforme apresentado nas Tabelas 11 e 12. 
Tabela 11. Valores de densidade e outras características obtidas para os fragmentos cerâmicos estudados. A incerteza da espessura é dada por 0,05 cm, a incerteza da massa é dada por 0,1 g e a incerteza da densidade foi determinada através de cálculos de propagação.

\begin{tabular}{|c|c|c|c|c|c|}
\hline Fragmento & Tradição & $\begin{array}{c}\text { Presença } \\
\text { tempero }\end{array}$ & $\begin{array}{c}\text { Espessura } \\
(\mathrm{cm})\end{array}$ & $\begin{array}{c}\text { Massa } \\
(\mathrm{g})\end{array}$ & $\begin{array}{c}\text { Densidade } \\
\left(\mathrm{g} / \mathrm{cm}^{3}\right)\end{array}$ \\
\hline MI1-11 & Guarani & Não & 0,72 & 11,7 & $1,56(3)$ \\
\hline MI1-120 & Guarani & Não & 0,79 & 4,9 & $1,61(7)$ \\
\hline MI1-163 & Guarani & Não & 0,86 & 13,0 & $1,64(3)$ \\
\hline MI1-168 & Guarani & Sim & 0,70 & 10,9 & $1,62(3)$ \\
\hline MI1-189 & Guarani & Não & 0,81 & 4,9 & $1,84(9)$ \\
\hline MI1-936 & Pantanal & Não & 0,66 & 10,4 & $1,48(3)$ \\
\hline MI1-938 & Pantanal & Sim & 0,53 & 2,7 & $1,74(15)$ \\
\hline MI1-959 & Pantanal & Sim & 0,72 & 7,1 & $1,74(6)$ \\
\hline MI1-961 & Pantanal & Sim & 0,55 & 6,3 & $1,81(7)$ \\
\hline MI1-962 & Pantanal & Pouco & 0,61 & 10,3 & $1,70(4)$ \\
\hline MI1-964 & Pantanal & Sim & 0,75 & 22,9 & $1,97(2)$ \\
\hline MI1-965 & Pantanal & Não & 0,68 & 11,2 & $1,78(4)$ \\
\hline MI1-969 & Pantanal & Sim & 0,80 & 13,4 & $1,99(4)$ \\
\hline MI1-973 & Pantanal & Pouco & 0,42 & 1,7 & $1,43(17)$ \\
\hline MI1-974 & Pantanal & Sim & 0,70 & 4,2 & $1,89(11)$ \\
\hline MI1-977 & Pantanal & Sim & 1,00 & 6,8 & $2,30(10)$ \\
\hline MI1-979 & Pantanal & Sim & 0,73 & 6,3 & $1,77(7)$ \\
\hline MI1-983 & Pantanal & Pouco & 0,62 & 9,7 & $1,64(4)$ \\
\hline MI1-985 & Pantanal & Sim & 0,69 & 11,8 & $1,35(2)$ \\
\hline MI1-986 & Pantanal & Sim & 0,67 & 15,0 & $1,76(3)$ \\
\hline MI1-988 & Pantanal & Pouco & 0,54 & 8,2 & $1,56(4)$ \\
\hline MI1-989 & Pantanal & Sim & 0,43 & 6,7 & $1,97(8)$ \\
\hline MI1-990 & Pantanal & Pouco & 0,67 & 9,3 & $1,65(4)$ \\
\hline MI1-992 & Pantanal & Sim & 0,43 & 4,7 & $1,87(10)$ \\
\hline MI1-993 & Pantanal & Pouco & 0,60 & 12,2 & $1,73(3)$ \\
\hline MI1-997 & Pantanal & Não & 0,66 & 9,2 & $1,75(5)$ \\
\hline MI1-1004 & Pantanal & Pouco & 0,64 & 4,7 & $1,76(9)$ \\
\hline MI1-1005 & Pantanal & Sim & 0,57 & 6,5 & $2,14(9)$ \\
\hline MI1-1006 & Pantanal & Sim & 0,85 & 8,8 & $2,48(9)$ \\
\hline MI1-1009 & Pantanal & Sim & 0,69 & 7,5 & $1,95(7)$ \\
\hline MI1-1011 & Pantanal & Não & 0,74 & 7,8 & $1,99(7)$ \\
\hline MI1-1012 & Pantanal & Pouco & 0,62 & 5,8 & $1,74(7)$ \\
\hline MI1-1015 & Pantanal & Pouco & 0,64 & 6,1 & $1,83(7)$ \\
\hline MI1-1016 & Pantanal & Sim & 0,63 & 8,3 & $2,08(7)$ \\
\hline MI1-1017 & Pantanal & Sim & 0,65 & 14,4 & $2,11(4)$ \\
\hline MI1-1024 & Pantanal & Pouco & 0,51 & 4,8 & $1,32(5)$ \\
\hline
\end{tabular}


Tabela 12. Valores de densidade e outras características obtidas para os fragmentos cerâmicos estudados. A incerteza da espessura é dada por 0,05 cm, a incerteza da massa é dada por 0,1 g e a incerteza da densidade foi determinada através de cálculos de propagação.

\begin{tabular}{|c|c|c|c|c|c|}
\hline Fragmento & Tradição & $\begin{array}{l}\text { Presença } \\
\text { tempero }\end{array}$ & $\begin{array}{c}\begin{array}{c}\text { Espessura } \\
(\mathrm{cm})\end{array} \\
\end{array}$ & $\begin{array}{c}\text { Massa } \\
(\mathrm{g})\end{array}$ & $\begin{array}{c}\text { Densidade } \\
\left(\mathrm{g} / \mathrm{cm}^{3}\right) \\
\end{array}$ \\
\hline MI1-1025 & Pantanal & Não & 0,52 & 5,0 & $1,1,30(5)$ \\
\hline MI1-1026 & Pantanal & Não & 0,81 & 14,2 & $2,02(4)$ \\
\hline MI1-1027 & Pantanal & Pouco & 0,67 & 10,7 & $1,95(5)$ \\
\hline MI1-1034 & Pantanal & Sim & 0,72 & 4,1 & $1,98(13)$ \\
\hline MI1-1035 & Pantanal & Sim & 0,61 & 18,8 & $2,12(3)$ \\
\hline MI1-1038 & Pantanal & Sim & 0,43 & 5,6 & $2,04(10)$ \\
\hline MI1-1042 & Pantanal & Sim & 0,66 & 6,3 & $2,50(13)$ \\
\hline MI1-1901 & Guarani & Não & 0,92 & 13,6 & $1,67(3)$ \\
\hline MI1-1902 & Guarani & Sim & 0,73 & 20,0 & $2,05(3)$ \\
\hline MI1-1905 & Guarani & Não & 0,88 & 6,3 & $1,98(8)$ \\
\hline MI1-1906 & Guarani & Pouco & 0,91 & 17,8 & $1,69(2)$ \\
\hline MI1-1907 & Guarani & Não & 0,72 & 8,2 & $1,81(6)$ \\
\hline MI1-1909 & Guarani & Não & 0,72 & 3,1 & $1,99(17)$ \\
\hline MI1-1910 & Guarani & Não & 0,78 & 6,0 & $1,88(8)$ \\
\hline MI1-1911 & Guarani & Não & 0,78 & 3,3 & $1,49(9)$ \\
\hline MI1-1912 & Guarani & Não & 0,80 & 2,8 & $1,57(12)$ \\
\hline MI1-1913 & Guarani & Não & 0,51 & 1,5 & $1,56(22)$ \\
\hline MI1-1914 & Guarani & Sim & 1,02 & 11,6 & $1,82(4)$ \\
\hline MI1-1915 & Guarani & Não & 1,01 & 6,6 & $1,82(7)$ \\
\hline MI1-1916 & Guarani & Não & 0,96 & 5,5 & $1,86(9)$ \\
\hline MI1-1917 & Guarani & Não & 0,64 & 3,8 & $1,60(9)$ \\
\hline MI1-1921 & Guarani & Não & 0,73 & 8,3 & $1,56(4)$ \\
\hline MI1-1925 & Guarani & Pouco & 0,97 & 9,2 & $1,73(5)$ \\
\hline MI1-1929 & Guarani & Não & 0,99 & 24,5 & $1,70(2)$ \\
\hline MI1-1930 & Guarani & Não & 0,57 & 6,4 & $1,63(6)$ \\
\hline MI6-3 & Pantanal & Não & 0,65 & 9,8 & $1,70(4)$ \\
\hline MI6-15 & Pantanal & Não & 0,74 & 5,6 & $1,72(7)$ \\
\hline MI6-18 & Pantanal & Pouco & 0,61 & 5,9 & $1,77(7)$ \\
\hline MI6-36 & Pantanal & Pouco & 0,70 & 13,2 & $1,80(3)$ \\
\hline MI6-50 & Pantanal & Não & 0,75 & 8,5 & $1,66(5)$ \\
\hline MI6-80 & Pantanal & Pouco & 0,77 & 8,2 & $1,73(5)$ \\
\hline MI6-81 & Pantanal & Não & 0,77 & 4,3 & $1,71(9)$ \\
\hline MI6-139 & Pantanal & Sim & 0,77 & 11,8 & $1,75(4)$ \\
\hline MI6-149 & Guarani & Sim & 0,68 & 2,7 & $1,74(15)$ \\
\hline MI6-150 & Guarani & Pouco & 0,85 & 10,9 & $1,71(4)$ \\
\hline MI6-167 & Guarani & Não & 0,57 & 5,7 & $1,64(7)$ \\
\hline MI6-374 & Pantanal & Não & 0,52 & 3,1 & $1,67(12)$ \\
\hline
\end{tabular}


O segundo método utilizado foi o cálculo da densidade utilizando os resultados obtidos pela técnica PIXE. Esta técnica permite a determinação da densidade da pasta cerâmica do material sem ser afetada pelos níveis de porosidade das peças. A técnica PIXE permitiu a identificação e quantificação dos elementos presentes na amostra, especialmente os elementos leves, que são os principais constituintes da matriz da pasta cerâmica. Foram utilizados os valores encontrados pela técnica PIXE para os principais componentes encontrados no solo, apresentado na Tabela 13. Estes compostos são formados pelos principais elementos medidos nas amostras, sendo responsáveis por mais de $93 \%$ da composição elementar.

Tabela 13. Principais compostos presentes na composição do solo e nos fragmentos cerâmicos estudados.

\begin{tabular}{c}
\hline $\begin{array}{c}\text { Principais } \\
\text { componentes } \\
\text { do solo }\end{array}$ \\
\hline \hline $\mathrm{Al}_{2} \mathrm{O}_{3}$ \\
\hline $\mathrm{SiO}_{2}$ \\
\hline $\mathrm{K}_{2} \mathrm{O}$ \\
\hline $\mathrm{CaO}$ \\
\hline $\mathrm{TiO}_{2}$ \\
\hline $\mathrm{Fe}_{2} \mathrm{O}_{3}$ \\
\hline
\end{tabular}

Para determinar a densidade através destes compostos, necessitamos calcular a massa molar de cada um. Este cálculo é feito utilizando a massa atômica dos elementos e a estequiometria dos compostos, como no caso do $\mathrm{Al}_{2} \mathrm{O}_{3}$. A massa atômica do alumínio é dada por 26,98 uma, correspondendo a 52,93\% da massa do composto e a massa atômica do oxigênio é dada por 16uma, sendo correspondente a 47,07\% da massa do composto.

Por meio desse cálculo podemos determinar a quantidade de oxigênio presente nas amostras. Para uma amostra cuja concentração de alumínio é dada por 5,79 wt\%, determinado por uma técnica experimental tal PIXE, a quantidade de oxigênio relativa a essa concentração é dada por:

$$
[O]=\frac{[A l] * m_{A l}}{m_{O}}=\frac{5,79 * 47,07}{52,93}=5,15 w t \%
$$

onde $m_{A l}$ e $m_{O}$ são as respectivas massas atômicas do alumínio e do oxigênio. 
Após obter os valores da concentração de oxigênio para cada composto, devemos normalizar pela massa total dos elementos medidos. Por exemplo, em uma amostra cuja soma total das concentrações para todos os elementos equivale a $54,80 \%$, conforme exemplo apresentado na Tabela 14, a normalização para a concentração do elemento alumínio é dada por:

$$
[A l]_{n o r m}=\frac{S_{A l} * 100}{54,80}=\frac{5,79 * 100}{54,80}=10,57 \%
$$

A Tabela 14 apresenta os valores obtidos para uma amostra típica exemplificando os cálculos realizados para todos os compostos.

Tabela 14. Cálculos realizados para cálculo de massa molar normalizada.

\begin{tabular}{cccc}
\hline Elemento & $\begin{array}{c}{[\text { Elem] }} \\
\mathrm{Wt} \%\end{array}$ & $\begin{array}{c}{[\mathrm{O}]} \\
\mathrm{Wt} \%\end{array}$ & $\begin{array}{c}{\left[\text { Elem }_{\text {norm }}\right]} \\
\mathrm{Wt} \%\end{array}$ \\
\hline \hline $\mathrm{Al}$ & 5,79 & 5,15 & 10,57 \\
\hline $\mathrm{Si}$ & 17,39 & 19,81 & 31,74 \\
\hline $\mathrm{K}$ & 1,18 & 0,24 & 2,16 \\
\hline $\mathrm{Ca}$ & 0,14 & 0,06 & 0,26 \\
\hline $\mathrm{Ti}$ & 0,77 & 0,51 & 1,40 \\
\hline $\mathrm{Fe}$ & 2,62 & 1,12 & 4,78 \\
\hline \hline Soma & 27,89 & 26,89 & 50,91 \\
\hline \hline
\end{tabular}

Para o cálculo da concentração total do oxigênio utilizamos o mesmo raciocínio de normalização:

$$
[O]_{\text {norm }}=\frac{S_{O} * 100}{54,80}=\frac{26,89 * 100}{54,80}=49,09
$$

onde $\mathrm{S}_{\mathrm{O}}$ é a soma da concentração do elemento oxigênio para todos os compostos. 
Conhecendo os valores das massas molares normalizadas podemos determinar o valor aproximado da densidade da matriz cerâmica dos fragmentos analisados. Este cálculo foi realizado utilizando o programa CLARA, desenvolvido no laboratório LAMFI. Este programa permite, entre outros, o cálculo da densidade de uma determinada matriz de composição conhecida. O software não fornece valores de incerteza, mas estes valores foram estimados entre $5 \%$ e $10 \%$ de acordo com a variação das composições elementares. Os valores encontrados para algumas amostras estão apresentados na Tabela 15 , com incertezas de $10 \%$.

Tabela 15. Valores de densidade determinados utilizando a técnica PIXE.

\begin{tabular}{cc}
\hline \hline Fragmentos & $\begin{array}{c}\text { Densidade PIXE } \\
\left(\mathrm{g} / \mathrm{cm}^{3}\right)\end{array}$ \\
\hline \hline MI1-11 & $2,16(22)$ \\
\hline MI1-295 & $2,27(23)$ \\
\hline MI1-965 & $2,32(23)$ \\
\hline MI1-973 & $2,43(24)$ \\
\hline MI1-974 & $2,38(24)$ \\
\hline MI1-976 & $2,57(26)$ \\
\hline MI1-985 & $2,65(27)$ \\
\hline MI1-1017 & $2,30(23)$ \\
\hline MI1-1035 & $2,42(24)$ \\
\hline MI1-1900 & $2,35(23)$ \\
\hline MI1-1901 & $2,17(22)$ \\
\hline MI1-1902 & $2,12(21)$ \\
\hline MI1-1906 & $2,22(22)$ \\
\hline MI1-1925 & $2,13(21)$ \\
\hline MI6-3 & $2,03(20)$ \\
\hline MI6-15 & $2,22(22)$ \\
\hline \hline
\end{tabular}

\begin{tabular}{cc}
\hline Fragmentos & $\begin{array}{c}\text { Densidade PIXE } \\
\left(\mathrm{g} / \mathrm{cm}^{3}\right)\end{array}$ \\
\hline \hline MI6-18 & $2,06(21)$ \\
\hline MI6-36 & $2,14(21)$ \\
\hline MI6-50 & $2,10(21)$ \\
\hline MI6-59 & $2,04(20)$ \\
\hline MI6-80 & $2,08(21)$ \\
\hline MI6-81 & $1,97(20)$ \\
\hline MI6-86 & $2,08(21)$ \\
\hline MI6-128 & $2,17(22)$ \\
\hline MI6-132 & $2,07(21)$ \\
\hline MI6-139 & $2,07(21)$ \\
\hline MI6-150 & $2,00(20)$ \\
\hline MI6-154 & $2,03(20)$ \\
\hline MI6-160 & $1,91(12)$ \\
\hline MI6-167 & $2,04(20)$ \\
\hline MI6-374 & $2,14(21)$ \\
\hline MI6-389 & $2,42(24)$ \\
\hline \hline
\end{tabular}

Podemos comparar os valores obtidos para as densidades através dos dois métodos, conforme apresentado na Tabela 16. 
Tabela 16. Valores de densidade obtidos utilizando a técnica PIXE e o método de Arquimedes.

\begin{tabular}{ccc}
\hline \hline Fragmentos & $\begin{array}{c}\text { Densidade } \\
\text { PIXE } \\
\left(\mathrm{g} / \mathrm{cm}^{3}\right)\end{array}$ & $\begin{array}{c}\text { Densidade } \\
\text { Arquimedes } \\
\left(\mathrm{g} / \mathrm{cm}^{3}\right)\end{array}$ \\
\hline \hline MI1-11 & $2,16(22)$ & $1,56(3)$ \\
\hline MI1-965 & $2,32(23)$ & $1,78(4)$ \\
\hline MI1-973 & $2,43(24)$ & $1,43(17)$ \\
\hline MI1-974 & $2,38(24)$ & $1,89(11)$ \\
\hline MI1-985 & $2,65(27)$ & $1,35(2)$ \\
\hline MI1-1017 & $2,30(23)$ & $2,11(4)$ \\
\hline MI1-1035 & $2,42(24)$ & $2,12(3)$ \\
\hline MI1-1901 & $2,17(22)$ & $1,67(3)$ \\
\hline MI1-1902 & $2,12(21)$ & $2,05(3)$ \\
\hline MI1-1906 & $2,22(22)$ & $1,69(2)$ \\
\hline MI1-1925 & $2,13(21)$ & $1,73(5)$ \\
\hline \hline
\end{tabular}

\begin{tabular}{ccc}
\hline \hline Fragmentos & $\begin{array}{c}\text { Densidade } \\
\text { PIXE } \\
\left(\mathrm{g} / \mathrm{cm}^{3}\right)\end{array}$ & $\begin{array}{c}\text { Densidade } \\
\text { Arquimedes } \\
\left(\mathrm{g} / \mathrm{cm}^{3}\right)\end{array}$ \\
\hline \hline MI6-3 & $2,03(20)$ & $1,70(4)$ \\
\hline MI6-15 & $2,22(22)$ & $1,72(7)$ \\
\hline MI6-18 & $2,06(21)$ & $1,77(7)$ \\
\hline MI6-36 & $2,14(21)$ & $1,80(3)$ \\
\hline MI6-50 & $2,10(21)$ & $1,66(5)$ \\
\hline MI6-80 & $2,08(21)$ & $1,73(5)$ \\
\hline MI6-81 & $1,97(20)$ & $1,71(9)$ \\
\hline MI6-139 & $2,07(21)$ & $1,75(4)$ \\
\hline MI6-150 & $2,00(20)$ & $1,71(4)$ \\
\hline MI6-167 & $2,04(20)$ & $1,64(7)$ \\
\hline \hline
\end{tabular}

Essa informação pode ser visualizada no gráfico comparativo entre as duas densidades, como apresentado na Figura 70. Podemos observar que os valores encontrados pela técnica PIXE são mais elevados e não são compatíveis com os valores obtidos pelo método de Arquimedes para uma mesma amostra. Isto ocorre devido à existência de porosidade no material cerâmico.

A técnica PIXE não é afetada pelo nível de porosidade existente nos fragmentos, pois a técnica utiliza as informações de composição elementar para determinar a densidade dos objetos. Ao contrário do método de Arquimedes que determina a densidade utilizando o volume de cada objeto, sendo afetado pelos níveis de porosidade e, portanto, pela técnica de manufatura da peça. 


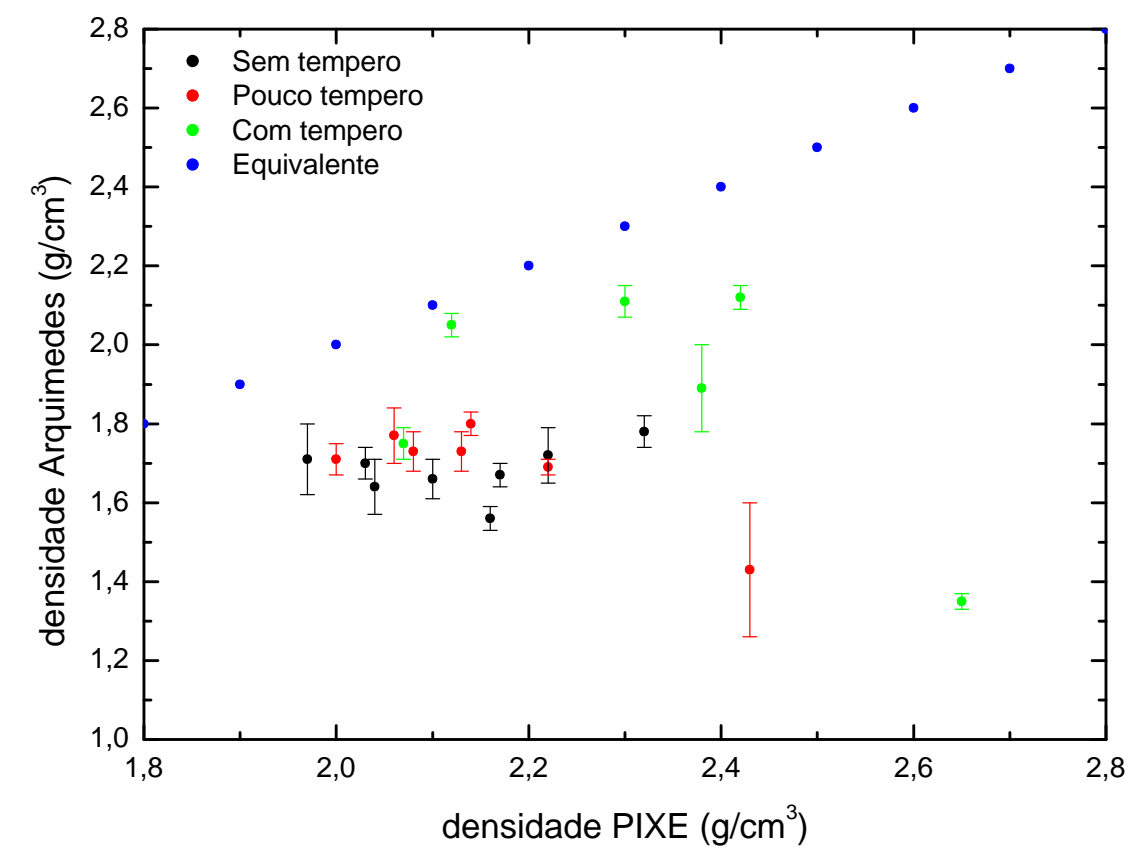

Figura 70. Gráfico comparativo entre as densidades para os fragmentos cerâmicos, obtidas pela técnica PIXE e pelo método de Arquimedes.

O terceiro método é a determinação da densidade dos materiais a partir do tom de cinza da radiografia. Os parâmetros do feixe de raios $X$ são fatores importantes para a obtenção da imagem. A tensão aplicada ao tubo de raios $\mathrm{X}$ determina a distribuição de energia dos fótons e a corrente determina a intensidade do feixe de raios $\mathrm{X}$.

Num tubo de raios $\mathrm{X}$, ao aplicarmos uma tensão, estamos determinando a energia máxima do feixe emitido. Este feixe não é monocromático e apresenta um espectro de distribuição de energias emitidas, como apresentado no exemplo da Figura 71, onde são apresentadas a curva experimental e teórica para um tubo de raios X Phillips, com uma tensão aplicada de $73 \mathrm{kV}$ [43]. Podemos observar na figura que para essa tensão aplicada obtemos uma intensidade máxima próxim1 ao valor de energia $35 \mathrm{keV}$. 


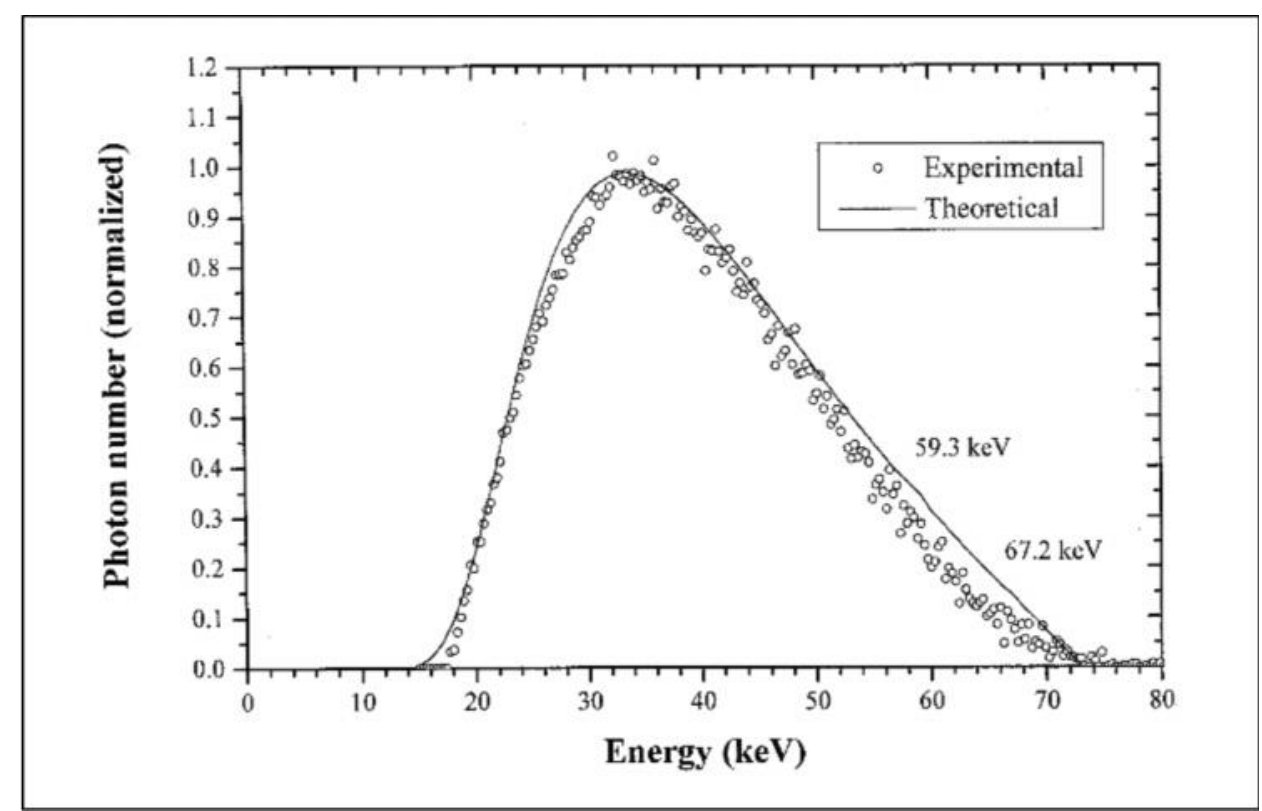

Figura 71. Espectro de emissão de tubo de raios X Phillips para uma tensão aplicada de $73 \mathrm{kV}$. Fonte: R.A.Terini, 1999 [33].

$\mathrm{Na}$ medida experimental foi aplicada uma tensão de $50 \mathrm{kV}$, valor que indica a energia máxima do feixe de raios $\mathrm{X}$ emitidos pelo tubo. Como primeira aproximação, supomos o valor de energia de $30 \mathrm{keV}$ para a intensidade máxima de emissão. Para um cálculo mais aprimorado devemos levar em consideração a composição de todas as energias emitidas pelo tubo.

Para realizar o terceiro método, novamente utilizamos materiais com densidade conhecida próxima à densidade esperada para materiais cerâmicos, que está em torno de $2,0 \mathrm{~g} / \mathrm{cm}^{3}$. Foram utilizados os materiais Alumínio, Teflon, Polytec e massa de modelar misturado com sal. Estes materiais possuem uma geometria simples com espessuras variando entre $0,2 \mathrm{~cm}$ e $1,0 \mathrm{~cm}$. As densidades apresentadas foram determinadas através da massa e do volume conhecidos.

Estes materiais foram irradiados nas mesmas condições dos fragmentos cerâmicos e a imagem obtida está apresentada na Figura 72. 


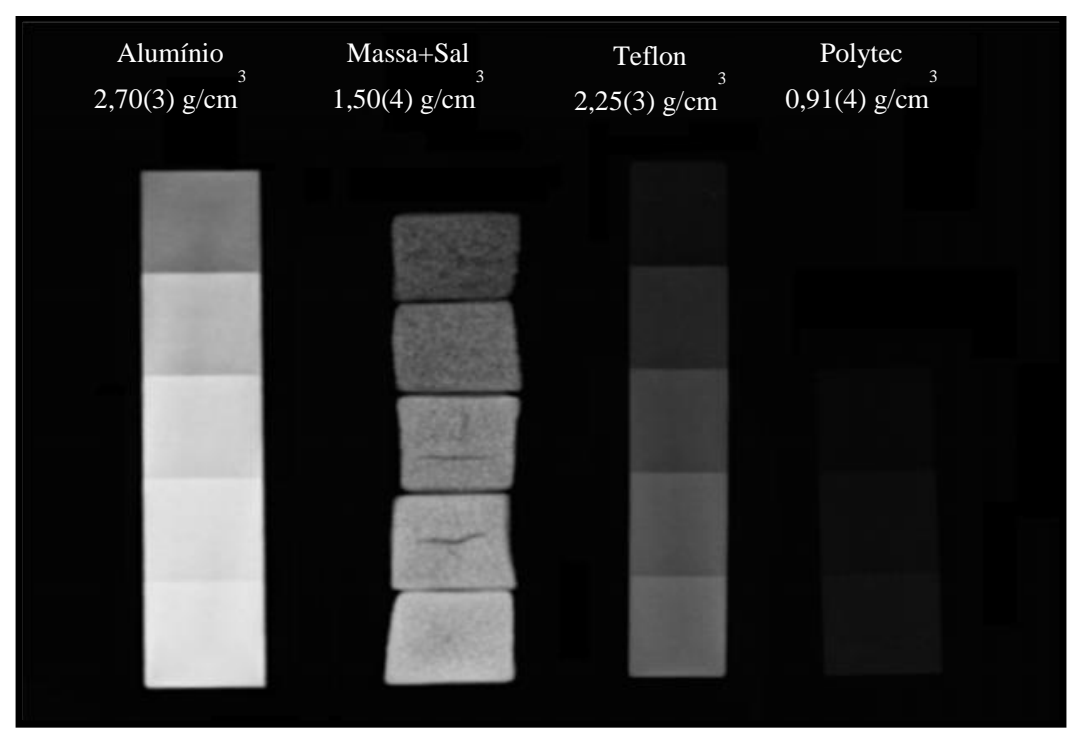

Figura 72. Imagem radiográfica obtida para materiais conhecidos com espessuras vareáveis entre $0,2 \mathrm{~cm}$ e 1,0 cm. Na imagem são apresentados os materiais Alumínio, Massa de modelar, Teflon e Polytec.

Por meio da imagem radiográfica foram obtidos os valores predominantes de tom de cinza (centróide do pico) para as espessuras de cada material, conforme apresentado anteriormente. O gráfico comparando o tom de cinza do centróide do pico com as diferentes espessuras de cada material é apresentado na Figura 73.

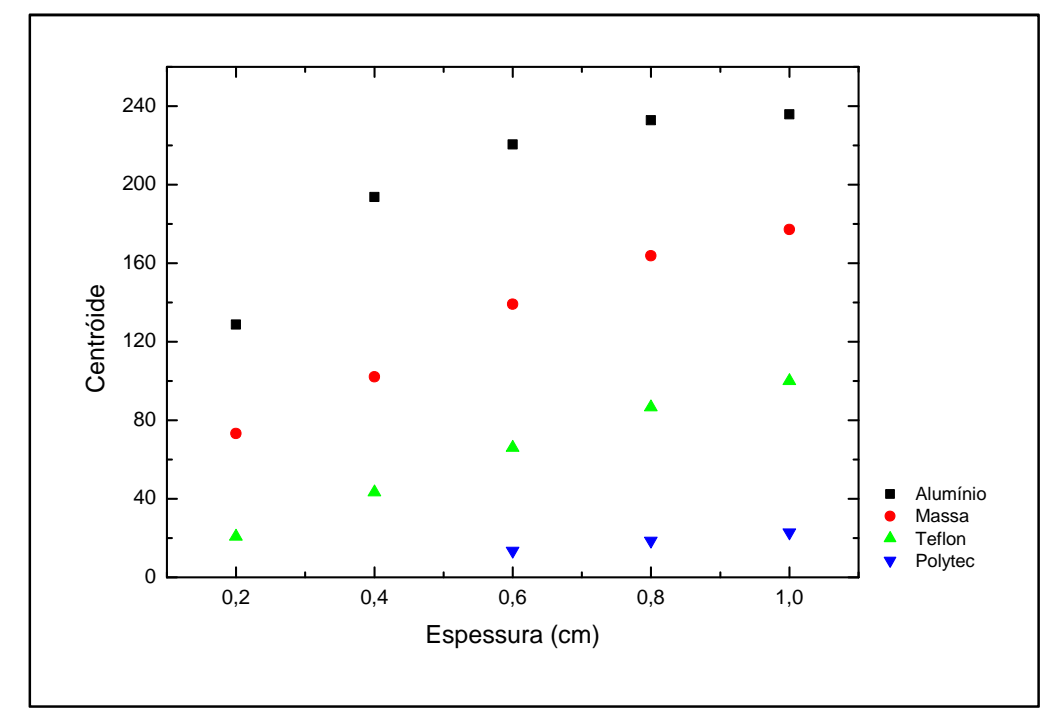

Figura 73. Gráfico relacionando centróide do pico (tom de cinza) com a espessura de cada segmento de diferentes materiais radiografados: Alumínio, Massa de modelar, Teflon e Polytec. 
Podemos observar que a curva obtida para os três materiais compactos, o Alumínio, o Teflon e o Polytec seguem uma ordem de acordo com a absorção do material, quanto maior a taxa de absorção $\left(\mathrm{I} / \mathrm{I}_{0}\right)$, mais alto é o valor do centróide dos picos, ou seja, mais branca é a imagem radiográfica.

Para checar esse comportamento devemos calcular a taxa de absorção/transmissão dos materiais. O valor da taxa de absorção pode ser determinado utilizando a lei de atenuação. Para este cálculo é necessário conhecer o coeficiente de absorção de massa $(\mu / \rho)$ de cada material. O valor deste coeficiente depende da composição elementar do material e da energia em que foram realizados os experimentos.

Para determinar o coeficiente de absorção de massa dos materiais utilizamos o valor do coeficiente de absorção de massa $(\mu / \rho)$ fornecido pelo NIST (National Institute of Standards and Technology) para os diversos elementos encontrados nos materiais utilizados a uma energia de $30 \mathrm{keV}$ apresentados na Tabela 17. O material formado pela massa de modelar adicionado com sal não será utilizado nestes cálculos, pois não foi possível determinar a composição deste material.

Tabela 17. Valores de coeficiente de absorção de massa ( $\mu / \rho)$ a uma energia de $30 \mathrm{keV}$.

\begin{tabular}{ccc}
\hline Elemento & $\begin{array}{c}\text { Número } \\
\text { atômico Z }\end{array}$ & $\begin{array}{c}\mu / \rho \\
\left(\mathrm{cm}^{2} / \mathrm{g}\right)\end{array}$ \\
\hline \hline $\mathrm{H}$ & 1 & 0,357 \\
\hline $\mathrm{C}$ & 6 & 0,256 \\
\hline $\mathrm{O}$ & 8 & 0,213 \\
\hline $\mathrm{F}$ & 9 & 0,378 \\
\hline $\mathrm{Al}$ & 13 & 1,128 \\
\hline $\mathrm{Si}$ & 14 & 1,436 \\
\hline $\mathrm{F}$ & 19 & 0,449 \\
\hline $\mathrm{Ca}$ & 20 & 4,080 \\
\hline $\mathrm{Ti}$ & 22 & 4,972 \\
\hline $\mathrm{Fe}$ & 26 & 8,176 \\
\hline \hline
\end{tabular}


O valor do coeficiente de absorção de um material composto é calculado utilizando a relação de massa dos elementos constituintes e os dados fornecidos pela Tabela 17 anteriormente apresentada. Como exemplo, apresentamos o cálculo feito com o material Teflon $\left(\mathrm{CF}_{2}\right)$. A razão de massa entre os elementos constituintes do $\mathrm{CF}_{2}$ é dada por:

$$
\begin{gathered}
f_{C}=\frac{m_{C}}{m_{\text {total }}}=\frac{12,0107}{50,0075}=0,24 \\
f_{F}=\frac{m_{F}}{m_{\text {total }}}=\frac{2 * 18,9984}{50,0075}=0,76
\end{gathered}
$$

onde $\mathrm{m}_{\mathrm{C}}$ e $\mathrm{m}_{\mathrm{F}}$ são as massas do $\mathrm{C}$ e do $\mathrm{F}$ respectivamente.

Para determinarmos o $(\mu / \rho)$ fazemos a soma da razão de massa dos elementos multiplicado pelo $(\mu / \rho)$ fornecido pelo NIST:

$$
\begin{gathered}
\left(\frac{\mu}{\rho}\right)=\sum_{1} f_{n} *\left(\frac{\mu}{\rho}\right)_{N I S T} \\
\left(\frac{\mu}{\rho}\right)_{C F_{2}}=f_{C} *\left(\frac{\mu}{\rho}\right)_{C_{N I S T}}+f_{F} *\left(\frac{\mu}{\rho}\right)_{F_{N I S T}} \\
\left(\frac{\mu}{\rho}\right)_{C F_{2}}=0,24 * 0,256+0,76 * 0,449=0,4025 \mathrm{~cm}^{2} / \mathrm{g}
\end{gathered}
$$

O valor de $(\mu / \rho)$ fornecido pelo NIST para o Teflon é de $0,4025 \mathrm{~cm}^{2} / \mathrm{g}$ estando em pleno acordo com o valor calculado. 
Uma segunda maneira de determinarmos o coeficiente de absorção de massa $(\mu / \rho)$ é utilizando o número atômico do material. Utilizando a tabela fornecida pelo NIST é possível obter uma relação entre o número atômico e $(\mu / \rho)$ a uma dada energia.

A Figura 74 mostra a relação entre os números atômicos de elementos simples e seus respectivos $(\mu / \rho)$ a uma energia de $30 \mathrm{keV}$. O ajuste apresentado corresponde a um ajuste polinomial de segunda ordem.

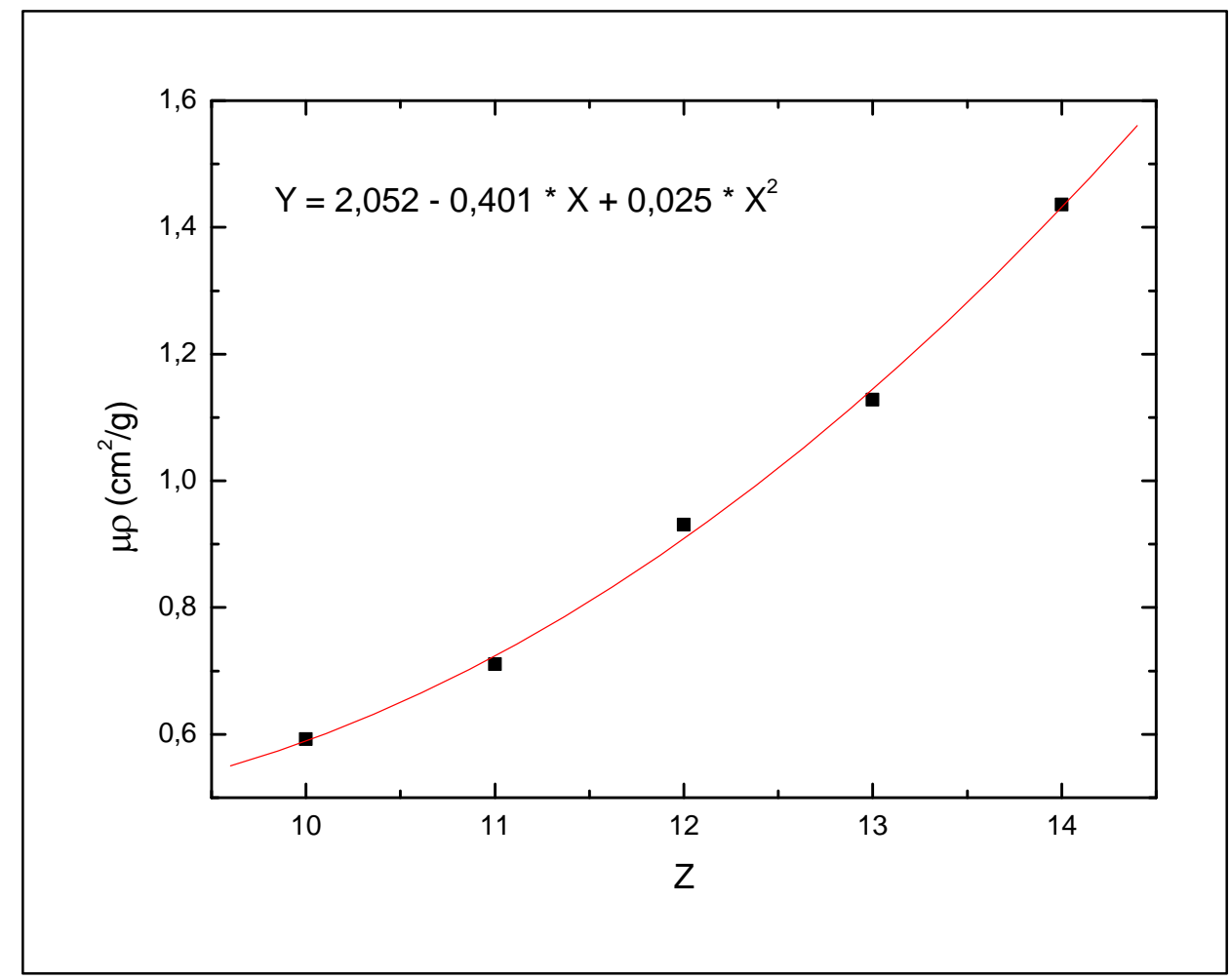

Figura 74. Gráfico $(\mu / \rho)$ versus $Z$ para uma energia de 30keV.Dados fornecidos pelo NIST.

Para o cálculo do número atômico efetivo de um composto heterogêneo foi aplicada a formulação proposta por Murty [44]:

$$
Z_{\text {eff }}=\sqrt[2,94]{f_{1} * Z_{1}^{2,94}+f_{2} * Z_{2}^{2,94}+\cdots}
$$

onde $\mathrm{f}_{\mathrm{n}}$ é a fração total do número de prótons associada a cada elemento e $\mathrm{Z}_{\mathrm{n}}$ é o número atômico de cada elemento. 
Os valores obtidos por esta equação para os materiais padrões estão apresentados na Tabela 18. Também são apresentados os valores de $(\mu / \rho)$ calculados através do ajuste apresentado anteriormente para uma energia de $30 \mathrm{keV}$.

Tabela 18. Valores calculados para $Z_{\text {eff }}$ e $(\mu / \rho)(30 \mathrm{keV})$ de diferentes materiais.

\begin{tabular}{cccc}
\hline Material & Fórmula & $\mathrm{Z}_{\mathrm{eff}}$ & $\begin{array}{c}\mu / \rho \\
\left(\mathrm{cm}^{2} / \mathrm{g}\right)\end{array}$ \\
\hline \hline Teflon & $\mathrm{CF}_{2}$ & 8,43 & 0,4265 \\
\hline Polytec & $\mathrm{CH}_{2} \mathrm{O}$ & 4,30 & 0,1959 \\
\hline Alumínio & $\mathrm{Al}$ & 13,00 & 1,2326 \\
\hline \hline
\end{tabular}

Os valores encontrados de $\mathrm{Z}_{\mathrm{eff}}$ para os fragmentos cerâmicos estudados se encontram entre os valores 11,8 e 13,6, próximos ao Z do alumínio.

Ao compararmos os valores obtidos para $(\mu / \rho)$ (Tabela 19) podemos supor que a maneira mais adequada para o cálculo do coeficiente de absorção de massa para materiais compostos é utilizando a fração de massa dos elementos presentes nas amostras, baseado nos valores obtidos para o Teflon.

Tabela 19. Comparação entre os valores obtidos para $(\mu / \rho)$ a uma energia de $30 \mathrm{keV}$.

\begin{tabular}{ccccc}
\hline \hline Material & Fórmula & $\begin{array}{c}\mu / \rho \\
\left(\mathrm{cm}^{2} / \mathrm{g}\right)\end{array}$ & $\begin{array}{c}\mu / \rho\left(\mathrm{Z}_{\text {eff }}\right) \\
\left(\mathrm{cm}^{2} / \mathrm{g}\right)\end{array}$ & $\begin{array}{c}\mu / \rho(\mathrm{NIST}) \\
\left(\mathrm{cm}^{2} / \mathrm{g}\right)\end{array}$ \\
\hline \hline Teflon & $\mathrm{CF}_{2}$ & 0,4025 & 0,4265 & 0,4025 \\
\hline Polytec & $\mathrm{CH}_{2} \mathrm{O}$ & 0,3278 & 0,1959 & - \\
\hline Alumínio & $\mathrm{Al}$ & 1,1280 & 1,2326 & 1,1280 \\
\hline \hline
\end{tabular}

Os valores dos coeficientes de absorção de massa para as amostras cerâmicas foram encontrados através do cálculo de fração de massa dos elementos presentes nas amostras. 
Conhecendo os coeficientes $(\mu / \rho)$ e aplicando a lei de atenuação, podemos determinar os valores das taxas de absorção dos materiais padrões utilizados neste estudo e de acordo com cada espessura. A taxa de absorção é complementar à transmissão de raios $\mathrm{X}$ pelo material e indica a taxa de raios $\mathrm{X}$ passaram sem interagir diretamente com a matéria.

Para o cálculo exato de taxa de transmissão é necessário considerar todas as interações do feixe em seu percurso o que inclui a coluna de ar entre a saída do tubo e a amostra e a própria chapa/filme radiográfico. Ao sair do tubo de raios X o feixe perde sua intensidade a cada interação com o meio. A Figura 75 apresenta de forma esquemática essa perda de intensidade.

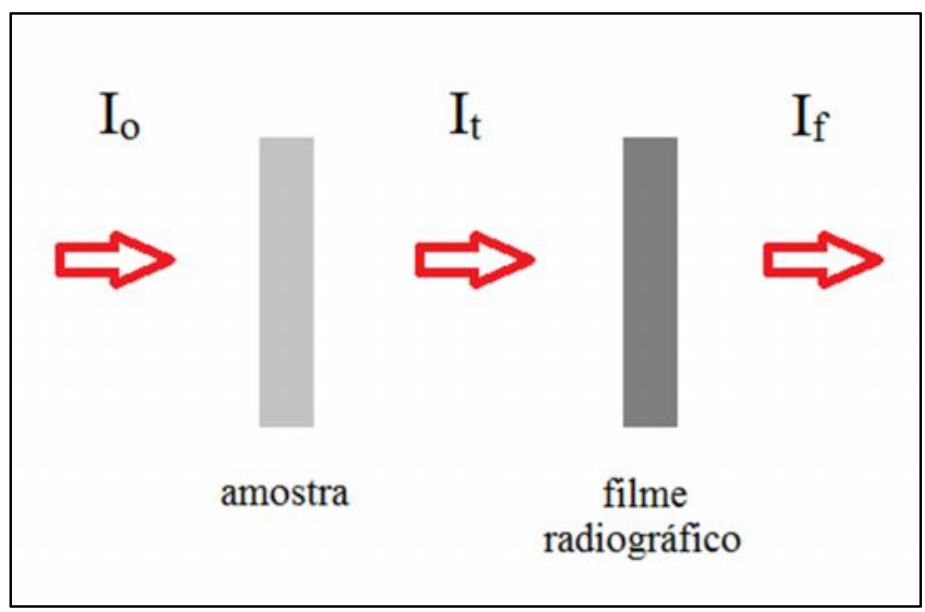

Figura 75. Representação esquemática da variação da intensidade do feixe de raio $X$ ao interagir com os materiais (amostra e filme radiográfico). 
No esquema apresentado, $I_{0}$ representa a intensidade do feixe ao atingir a amostra e $\mathrm{I}_{\mathrm{t}}$ é a intensidade do feixe ao passar através da amostra. Seu valor é dado pela lei de atenuação e seus termos são referentes à amostra radiografada. Após o feixe interagir com o filme radiográfico, novamente há uma perda de intensidade resultando um valor $\mathrm{I}_{\mathrm{f}}$ cujos termos são dados em função do filme. Podemos unir as equações obtendo uma relação entra a intensidade inicial e a intensidade após as diferentes interações. $\mathrm{O}$ valor $\mathrm{I}_{\mathrm{f}}$ corresponde à intensidade que atravessa o filme radiográfico, desta forma o valor que esta associado à imagem radiográfica é dado por $\left(1-\mathrm{I}_{\mathrm{f}}\right)$ que é a intensidade absorvida pelo material.

$$
\begin{gathered}
I_{t}=I_{0} e^{-(\mu / \rho)_{\text {amostra }}(\rho x)_{\text {amostra }}} \\
I_{f}=I_{t} e^{-(\mu / \rho)_{\text {filme }}(\rho x)_{\text {filme }}} \\
I_{f}=I_{0} e^{-(\mu / \rho)_{\text {amostra }}(\rho x)_{\text {amostra }}} e^{-(\mu / \rho)_{f i l m e}(\rho x)_{f i l m e}} \\
1-I_{f}=1-I_{0} e^{-(\mu / \rho)_{\text {amostra }}(\rho x)_{\text {amostra }}} e^{-(\mu / \rho)_{\text {filme }}(\rho x)_{\text {filme }}}
\end{gathered}
$$

Durante o experimento foi utilizado o mesmo filme radiográfico sendo o termo $e^{-(\mu / \rho)_{\text {filme }}(\rho x)_{\text {filme }}}$ aproximadamente constante, devemos lembrar que o coeficiente $(\mu / \rho)$ é calculado em função da energia.

Considerando essas aproximações, os valores de transmissão estão apresentados nas Tabelas 20 e 21 para energias de $50 \mathrm{keV}$ e $30 \mathrm{keV}$ respectivamente.

Tabela 20. Valores de taxa de transmissão de raios X para diferentes materiais e espessuras para uma energia de $50 \mathrm{keV}$.

\begin{tabular}{cccc}
\hline $\begin{array}{c}\text { Espessura } \\
(\mathrm{cm})\end{array}$ & $\begin{array}{c}\mathrm{I} / \mathrm{I}_{0}-\mathrm{Al} \\
\text { (alumínio) }\end{array}$ & $\begin{array}{c}\mathrm{I} / \mathrm{I}_{0}-\mathrm{CF}_{2} \\
\text { (teflon) }\end{array}$ & $\begin{array}{c}\mathrm{I} / \mathrm{I}_{0}-\mathrm{CH}_{2} \mathrm{O} \\
\text { (polytec) }\end{array}$ \\
\hline \hline $0,20(5)$ & 0,82 & 0,91 & 0,95 \\
\hline $0,40(5)$ & 0,67 & 0,83 & 0,90 \\
\hline $0,60(5)$ & 0,55 & 0,75 & 0,86 \\
\hline $0,80(5)$ & 0,45 & 0,69 & 0,82 \\
\hline $1,00(5)$ & 0,37 & 0,63 & 0,78 \\
\hline \hline
\end{tabular}


Tabela 21. Valores de taxa de transmissão de raios $X$ para diferentes materiais e espessuras para uma energia de $30 \mathrm{keV}$.

\begin{tabular}{cccc}
\hline $\begin{array}{c}\text { Espessura } \\
(\mathrm{cm})\end{array}$ & $\begin{array}{c}\mathrm{I} / \mathrm{I}_{0}-\mathrm{Al} \\
\text { (alumínio) }\end{array}$ & $\begin{array}{c}\mathrm{I} / \mathrm{I}_{0}-\mathrm{CF}_{2} \\
\text { (teflon) }\end{array}$ & $\begin{array}{c}\mathrm{I} / \mathrm{I}_{0}-\mathrm{CH}_{2} \mathrm{O} \\
\text { (polytec) }\end{array}$ \\
\hline \hline $0,20(5)$ & 0,54 & 0,84 & 0,92 \\
\hline $0,40(5)$ & 0,30 & 0,70 & 0,85 \\
\hline $0,60(5)$ & 0,16 & 0,59 & 0,79 \\
\hline $0,80(5)$ & 0,09 & 0,49 & 0,73 \\
\hline $1,00(5)$ & 0,05 & 0,41 & 0,67 \\
\hline \hline
\end{tabular}

Para uma melhor visualização dos valores obtidos podemos utilizar o gráfico de Taxa de transmissão versus Espessura para os diferentes materiais nas energias de $30 \mathrm{keV}$ e $50 \mathrm{keV}$, como apresentado na Figura 76.

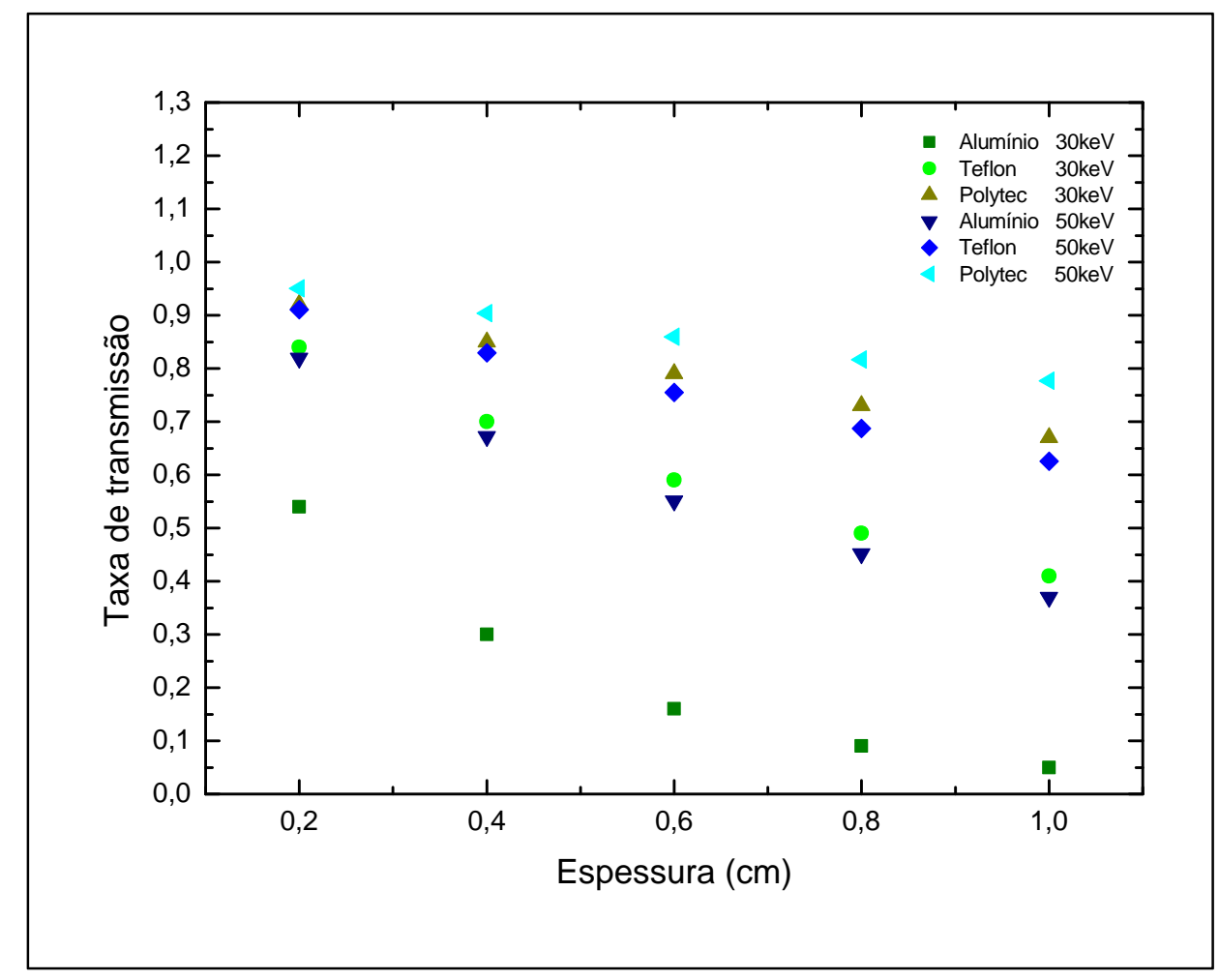

Figura 76. Gráfico taxa de transmissão versus espessura para diferentes materiais para nas energias de radiação $30 \mathrm{keV}$ e $50 \mathrm{keV}$. 
Neste gráfico podemos observar o comportamento já esperado da taxa de transmissão com relação aos diferentes materiais e espessuras. Este comportamento pode ser visualizado diretamente da imagem radiográfica, onde ao compararmos os diferentes materiais a uma mesma espessura, observamos uma variação no tom de cinza que está associado à absorção do material. Quanto mais escura a imagem, menor a taxa de transmissão.

Outro gráfico que deve ser analisado é a comparação entre a taxa de transmissão dos materiais, a uma energia de $30 \mathrm{keV}$, e o tom de cinza predominante nas imagens radiológicas para cada espessura, como apresentado na Figura 77. Na figura estão indicadas as espessuras dos materiais, onde o ponto com a taxa de transmissão mais elevada indica uma espessura de $0,2 \mathrm{~cm}$.

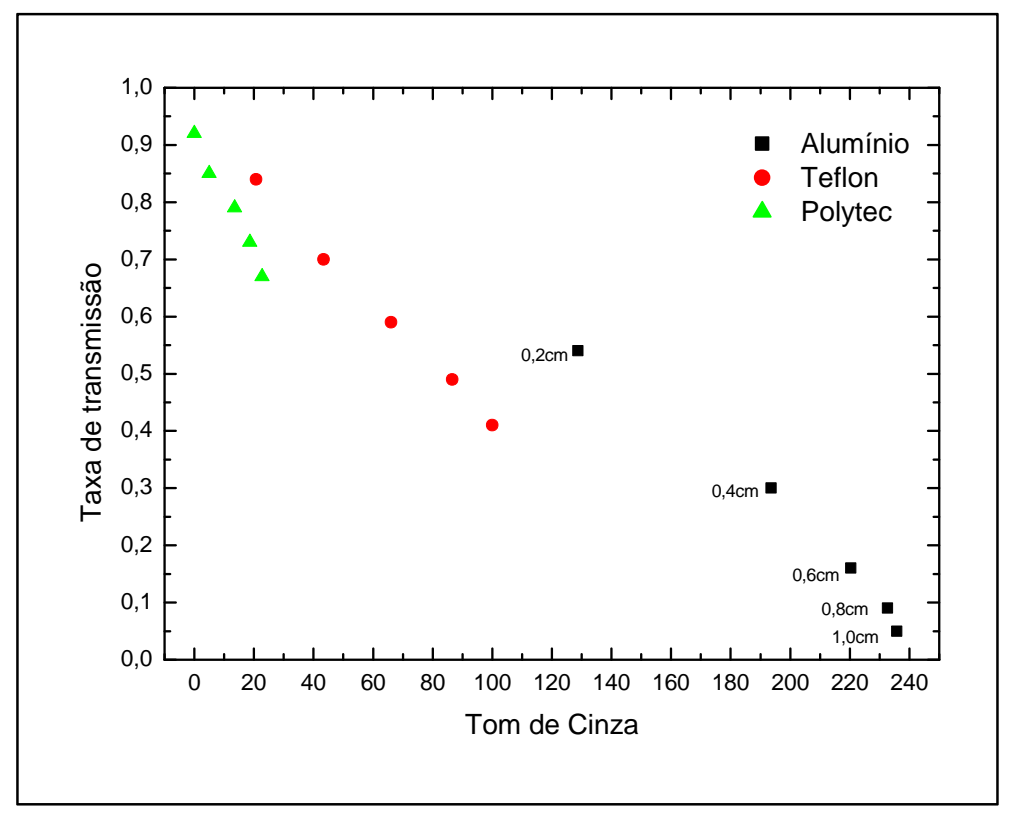

Figura 77. Gráfico de taxa de transmissão versus tom de cinza para diferentes materiais em uma energia de radiação de $30 \mathrm{keV}$. 
O gráfico de Taxa de absorção versus Tom de cinza deveria apresentar uma relação linear entre os eixos, porém não observamos esse comportamento no gráfico apresentado. Este fato pode ser explicado por duas proposições, envolvendo diferentes aspectos no cálculo da taxa de transmissão.

A primeira envolve a determinação de $\mathrm{I} / \mathrm{I}_{0}$ dos materiais. Para realizar esse cálculo foi desconsiderada a absorção de energia pelo filme radiológico e pelo caminho de ar entre a saída do tubo de raios $\mathrm{X}$ e a amostra. Em uma primeira avaliação consideramos esses termos desprezíveis quando comparados com a amostra.

A segunda e mais considerada hipótese corresponde ao fato de que para realizar o cálculo de $\mathrm{I} / \mathrm{I}_{0}$ considerou-se uma energia de feixe predominante, neste caso $30 \mathrm{keV}$. Porém, como mostrado anteriormente, o feixe de raios $\mathrm{X}$ possui um espectro de distribuição de energias que deveriam ser incorporadas aos cálculos, tornando este cálculo não trivial.

Apesar das falhas apontadas, a curva de Taxa de transmissão versus Tom de cinza para o Alumínio foi utilizada para determinarmos em uma aproximação o valor da taxa de transmissão para os fragmentos cerâmicos estudados. A curva de alumínio foi escolhida pelo fato de que as peças cerâmicas possuem um $\mathrm{Z}_{\text {eff }}$ próximo ao $\mathrm{Z}$ do alumínio. A curva e o ajuste utilizado são apresentados na Figura 78.

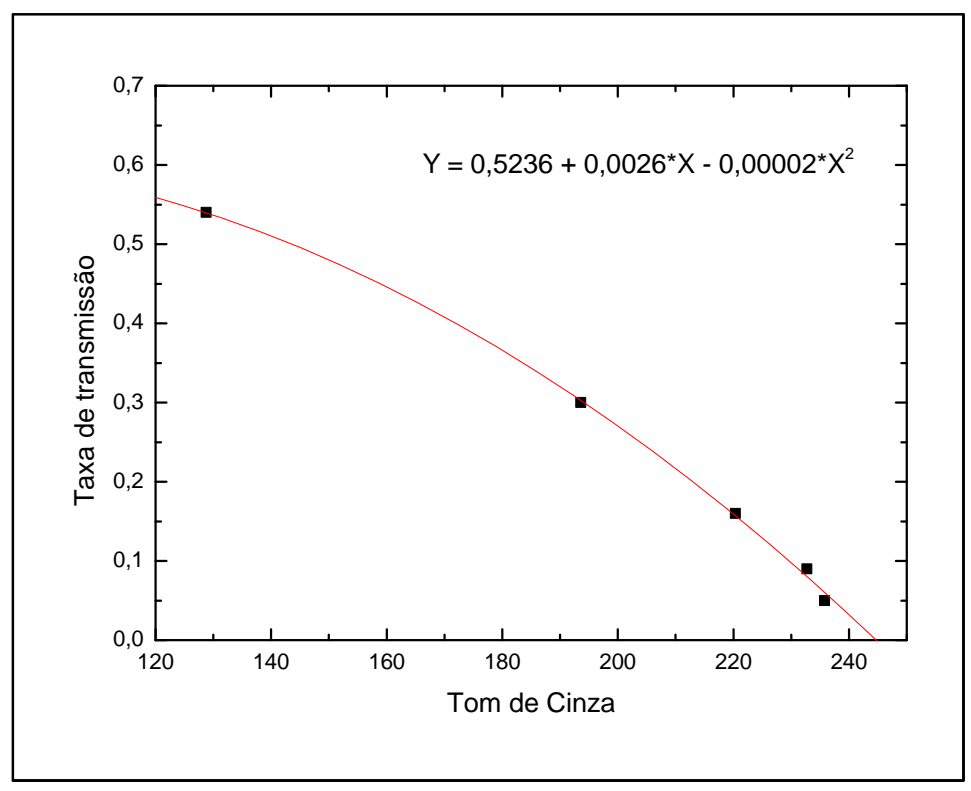

Figura 78. Gráfico de Taxa de transmissão versus Tom de cinza para o elemento alumínio em uma energia de radiação de $30 \mathrm{keV}$. 
Os valores de taxa de transmissão obtidos utilizando o ajuste apresentado estão indicados na Tabela 22.

Tabela 22. Valores de Taxa de transmissão obtidos para os fragmentos cerâmicos em uma energia de $30 \mathrm{keV}$.

\begin{tabular}{cc}
\hline \hline $\begin{array}{c}\text { Fragmento } \\
\text { cerâmico }\end{array}$ & $\begin{array}{c}\text { Taxa de transmissão } \\
\text { I/I }\end{array}$ \\
\hline \hline MI1-11 & $0,44(19)$ \\
\hline MI1-965 & $0,43(20)$ \\
\hline MI1-973 & $0,59(14)$ \\
\hline MI1-974 & $0,34(22)$ \\
\hline MI1-985 & $0,56(16)$ \\
\hline MI1-1017 & $0,28(23)$ \\
\hline MI1-1035 & $0,33(22)$ \\
\hline MI1-1901 & $0,37(21)$ \\
\hline MI1-1902 & $0,29(23)$ \\
\hline MI1-1906 & $0,32(22)$ \\
\hline MI1-1925 & $0,32(22)$ \\
\hline MI6-3 & $0,51(17)$ \\
\hline MI6-15 & $0,40(20)$ \\
\hline MI6-18 & $0,46(19)$ \\
\hline MI6-36 & $0,43(20)$ \\
\hline MI6-50 & $0,42(20)$ \\
\hline MI6-80 & $0,36(21)$ \\
\hline MI6-81 & $0,43(19)$ \\
\hline MI6-139 & $0,35(21)$ \\
\hline MI6-150 & $0,34(21)$ \\
\hline MI6-167 & $0,51(17)$ \\
\hline \hline
\end{tabular}

As incertezas foram calculadas utilizando a propagação de erros. Os valores encontrados são altos, consequência das aproximações realizadas e do próprio ajuste. 
Após determinarmos o coeficiente de absorção $(\mu / \rho)$ e a taxa de transmissão $\left(\mathrm{I} / \mathrm{I}_{0}\right)$ dos fragmentos cerâmicos, podemos calcular a densidade aproximada das amostras utilizando a relação inversa da lei de atenuação dada por:

$$
\rho=\frac{-\ln \left(\frac{I}{I_{0}}\right)}{\left(\frac{\mu}{\rho}\right) * x}
$$

onde $\rho$ é a densidade e $x$ é a espessura média dos fragmentos.

Os valores encontrados para as densidades são apresentados na Tabela 23. O cálculo das incertezas foi realizado através da propagação de erros.

Tabela 23. Valores de Densidade obtidos para os fragmentos cerâmicos utilizando a técnica de radiografia.

\begin{tabular}{cc}
\hline $\begin{array}{c}\text { Fragmento } \\
\text { cerâmico }\end{array}$ & $\begin{array}{c}\text { Densidade } \\
\left(\mathrm{g} / \mathrm{cm}^{3}\right)\end{array}$ \\
\hline \hline MI1-11 & $1,17(25)$ \\
\hline MI1-965 & $1,17(25)$ \\
\hline MI1-973 & $0,99(23)$ \\
\hline MI1-974 & $1,39(29)$ \\
\hline MI1-985 & $0,64(14)$ \\
\hline MI1-1017 & $1,94(42)$ \\
\hline MI1-1035 & $1,54(33)$ \\
\hline MI1-1901 & $1,10(23)$ \\
\hline MI1-1902 & $1,73(36)$ \\
\hline MI1-1906 & $1,25(26)$ \\
\hline MI1-1925 & $1,24(26)$ \\
\hline MI6-3 & $1,13(24)$ \\
\hline MI6-15 & $1,23(26)$ \\
\hline MI6-18 & $1,34(29)$ \\
\hline MI6-36 & $1,22(26)$ \\
\hline MI6-50 & $1,23(26)$ \\
\hline MI6-80 & $1,40(29)$ \\
\hline MI6-81 & $1,23(26)$ \\
\hline MI6-139 & $1,41(30)$ \\
\hline MI6-150 & $1,41(29)$ \\
\hline MI6-167 & $1,25(27)$ \\
\hline \hline
\end{tabular}


Após os cálculos de densidade pelos três métodos propostos (método de Arquimedes, PIXE e radiografia) podemos comparar os valores obtidos conforme apresentado na Tabela 24. Na tabela também é indicado a presença de tempero e a espessura dos fragmentos.

Tabela 24. Tabela comparativa entre as densidades obtidas por diferentes métodos.

\begin{tabular}{cccccc}
\hline \hline Fragmento & $\begin{array}{c}\text { Densidade } \\
\text { Arquimedes } \\
\text { cerâmico }\end{array}$ & $\begin{array}{c}\text { Densidade } \\
\text { PIXE } \\
\end{array}$ & $\begin{array}{c}\text { Densidade } \\
\text { radiografia } \\
\left(\mathrm{g} / \mathrm{cm}^{3}\right)\end{array}$ & $\begin{array}{c}\text { Espessura } \\
\left(\mathrm{g} / \mathrm{cm}^{3}\right)\end{array}$ & $\begin{array}{c}\text { Tempero } \\
(\mathrm{cm})\end{array}$ \\
\hline \hline MI1-11 & $1,56(3)$ & $2,16(22)$ & $1,17(25)$ & $0,72(5)$ & Não \\
\hline MI1-965 & $1,78(4)$ & $2,32(23)$ & $1,17(25)$ & $0,68(5)$ & Não \\
\hline MI1-973 & $1,43(17)$ & $2,43(24)$ & $0,99(23)$ & $0,42(5)$ & Pouco \\
\hline MI1-974 & $1,89(11)$ & $2,38(24)$ & $1,39(29)$ & $0,70(5)$ & Sim \\
\hline MI1-985 & $1,35(2)$ & $2,65(27)$ & $0,64(14)$ & $0,69(5)$ & Sim \\
\hline MI1-1017 & $2,11(4)$ & $2,30(23)$ & $1,94(42)$ & $0,65(5)$ & Sim \\
\hline MI1-1035 & $2,12(3)$ & $2,42(24)$ & $1,54(33)$ & $0,61(5)$ & Sim \\
\hline MI1-1901 & $1,67(3)$ & $2,17(22)$ & $1,10(23)$ & $0,92(5)$ & Não \\
\hline MI1-1902 & $2,05(3)$ & $2,12(21)$ & $1,73(36)$ & $0,73(5)$ & Não \\
\hline MI1-1906 & $1,69(2)$ & $2,22(22)$ & $1,25(26)$ & $0,91(5)$ & Pouco \\
\hline MI6-3 & $1,73(5)$ & $2,13(21)$ & $1,24(26)$ & $0,97(5)$ & Pouco \\
\hline MI6-15 & $1,70(4)$ & $2,03(20)$ & $1,13(24)$ & $0,65(5)$ & Não \\
\hline MI6-18 & $1,72(7)$ & $2,22(22)$ & $1,23(26)$ & $0,74(5)$ & Não \\
\hline MI6-36 & $1,77(7)$ & $2,06(21)$ & $1,34(29)$ & $0,61(5)$ & Pouco \\
\hline MI6-50 & $1,80(3)$ & $2,14(21)$ & $1,22(26)$ & $0,70(5)$ & Pouco \\
\hline MI6-80 & $1,66(5)$ & $2,10(21)$ & $1,23(26)$ & $0,75(5)$ & Não \\
\hline MI6-81 & $1,73(5)$ & $2,08(21)$ & $1,40(29)$ & $0,77(5)$ & Pouco \\
\hline MI6-139 & $1,71(9)$ & $1,97(20)$ & $1,23(26)$ & $0,77(5)$ & Não \\
\hline MI6-150 & $1,71(4)$ & $2,07(21)$ & $1,41(30)$ & $0,77(5)$ & Sim \\
\hline MI6-167 & $1,64(7)$ & $2,00(20)$ & $1,41(29)$ & $0,85(5)$ & Pouco \\
\hline \hline & & & & & Não \\
\hline
\end{tabular}

A comparação entre as densidades encontradas pode ser visualizada nos gráficos comparativos apresentados nas Figuras 78 e 80. 
A Figura 79 apresenta o gráfico comparativo entre os valores obtidos pelo método de Arquimedes e pela técnica de radiografia.

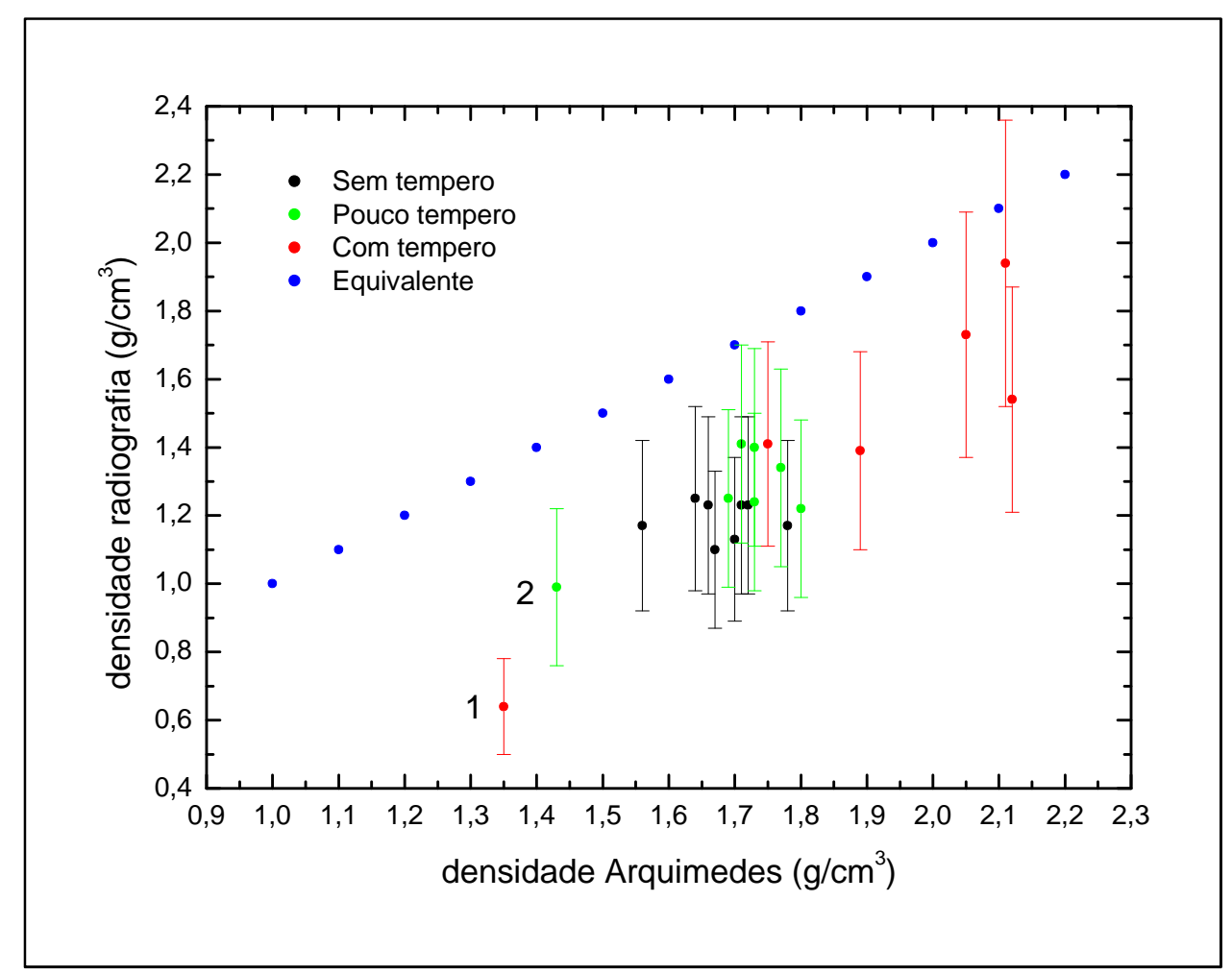

Figura 79. Gráfico comparativo entre as densidades para os fragmentos cerâmicos, obtidas pelo método de Arquimedes e pela técnica de radiografia.

Podemos observar que os valores encontrados pela técnica de radiografia são sistematicamente mais baixos do que os valores obtidos pelo método de Arquimedes para uma mesma amostra. Estes valores seguem um comportamento linear através do qual podemos sugerir a existência de um erro sistemático em algum ou ambos os métodos. Outro fato que podemos observar está relacionado à presença de tempero nas amostras. Os fragmentos que possuem tempero em sua massa apresentam densidades mais altas em ambas as técnicas, com exceção de duas peças, MI1-985 e MI1-973, indicadas na figura com os números 1 e 2 respectivamente. 
Ao analisarmos a radiografia do fragmento MI1-985, podemos observar que ela difere das demais, pois apresenta em sua constituição um tempero de tom mais escuro, o que indica menor densidade do que a pasta cerâmica. Na Figura 80 podemos comparar a imagem do fragmento MI1-985 com a imagem de outro fragmento típico, MI1-959. Ambas as peças pertencem à tradição Pantanal e tem espessuras semelhantes.
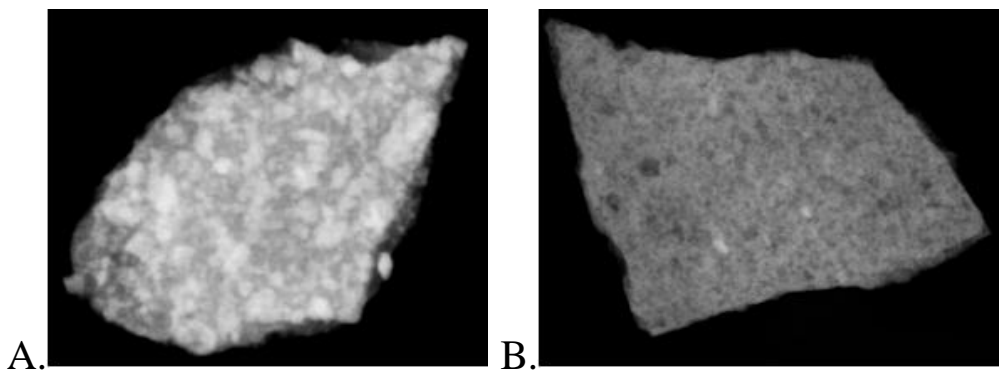

Figura 80. Imagens radiográficas de fragmentos pertencentes à tradição Pantanal, com espessuras semelhantes e temperos diferentes. A.MI1-959; B. MI1-985.

Ao analisarmos o fragmento MI1-973, podemos observar que sua imagem radiográfica apresenta em geral um tom mais escuro do que as demais peças. Esse fato pode ser explicado devido à diferença de espessuras entre as peças, o fragmento MI1-973 possui uma espessura de $0,43(5) \mathrm{cm}$, bem inferior às demais que apresentam espessuras entre $0,60(5) \mathrm{cm} \mathrm{1,00(5)} \mathrm{cm}$. Uma das possibilidades é de que a tensão aplicada para a análise radiográfica foi acima da necessária no caso deste fragmento.

Podemos também comparar os valores de densidades obtidos pelas técnicas PIXE e de radiografia, apresentado na Figura 81. 


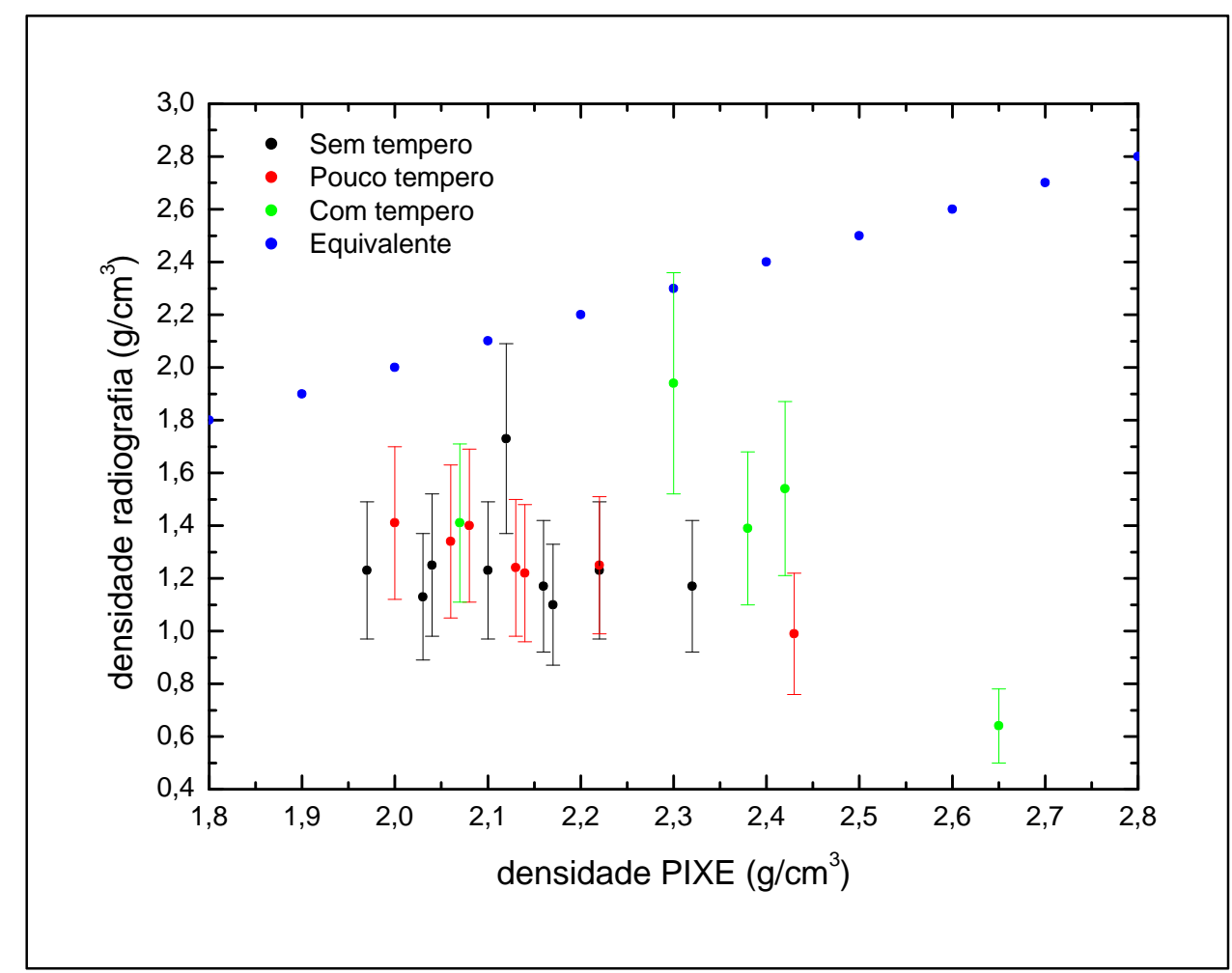

Figura 81. Gráfico comparativo entre as densidades para os fragmentos cerâmicos, obtidas pelas técnicas PIXE e de radiografia.

Podemos observar que os valores encontrados pela técnica de radiografia são inferiores aos valores obtidos pela técnica PIXE, porém não podemos descrever uma relação entre as duas técnicas. As densidades avaliadas pelas técnicas são diferentes. A técnica PIXE calcula a densidade relativa à composição da pasta cerâmica, não considerando a presença de porosidade ou tempero, ao contrário da técnica de radiografia que é fortemente afetada pela presença de tempero no material.

Após obter os diferentes resultados para a densidade dos fragmentos, não foi possível associar nenhuma variação nos valores aos sítios ou às tradições culturais, os valores encontrados para as três técnicas se encontram dispersos nas diferentes categorias, conforme apresentado nas Figuras 82 e 83. A Figura 82 apresenta as amostras encontradas no sítio MI1 na cor vermelha. A Figura 83 apresenta as amostras pertencentes à tradição Guarani na cor verde. 


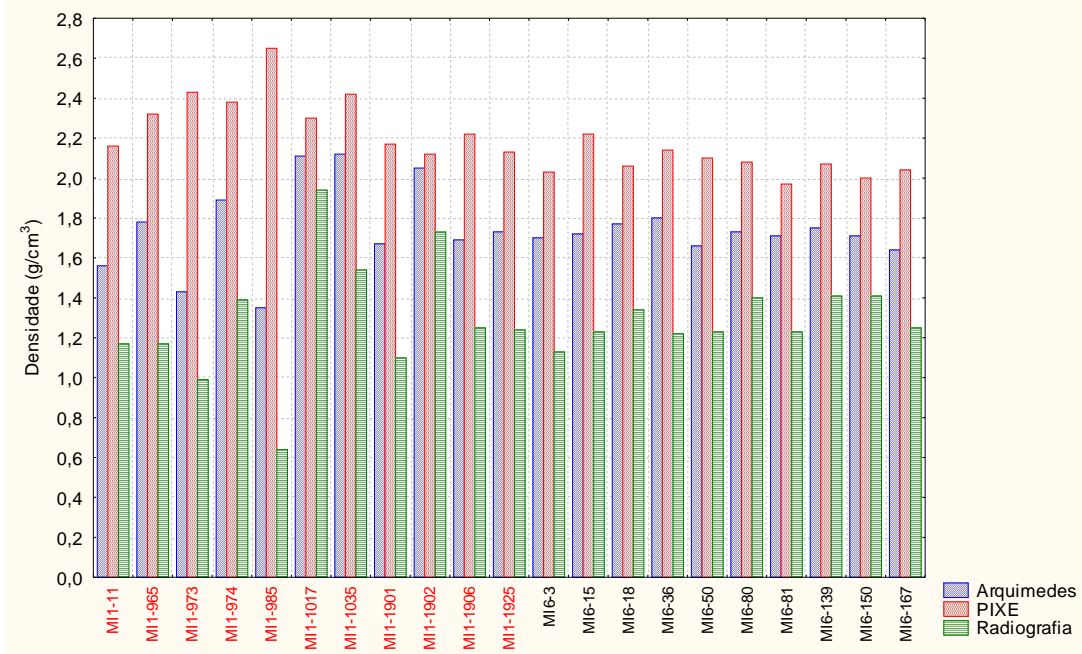

Figura 82. Gráfico de densidade versus amostra. As amostras indicadas pela cor vermelha pertencem ao sítio Sede/Córrego Lalima (MI1) e as indicadas pela cor preta pertencem ao sítio Asa do Pote (MI6).

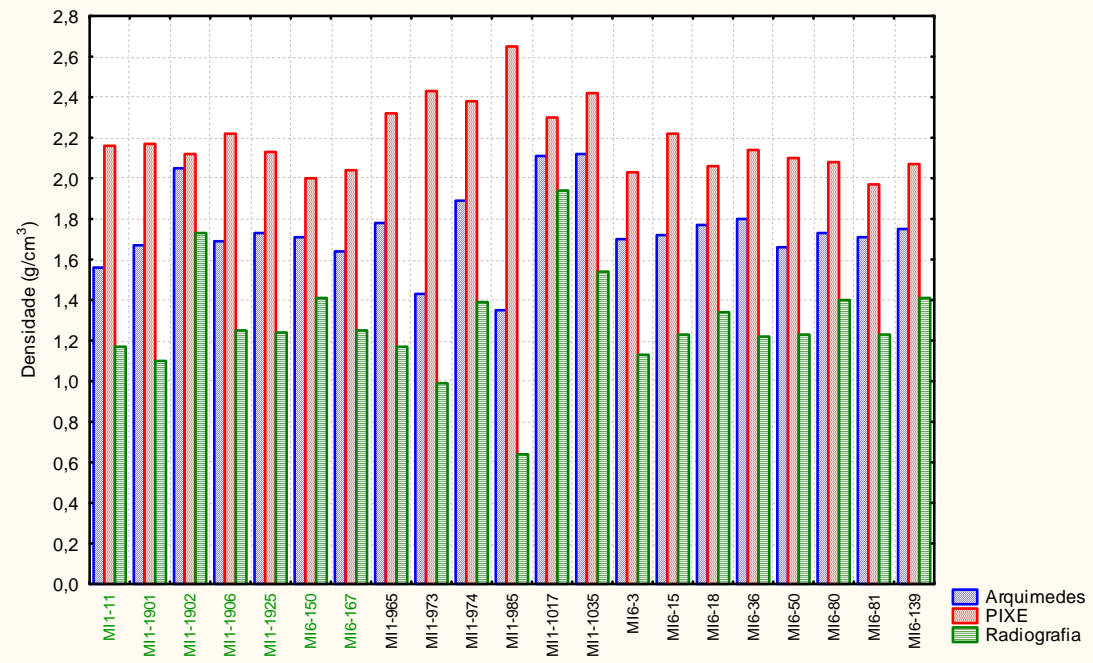

Figura 83. Gráfico de densidade versus amostra. As amostras indicadas pela cor verde pertencem à tradição Guarani e as indicadas pela cor preta pertencem à tradição Pantanal. 


\section{Capítulo 8}

\section{Considerações Finais}

O presente trabalho teve por objetivo caracterizar e identificar a natureza de recursos cerâmicos arqueológicos brasileiros utilizando métodos físicos não destrutivos. Para a realização deste estudo foram aplicadas diferentes técnicas experimentais e de análise estatística que ao serem combinadas permitiram um melhor entendimento do conjunto de amostras. As amostras estudadas foram encontradas em dois sítios arqueológicos de uma mesma região e pertencem a duas tradições culturais. $\mathrm{O}$ intuito principal deste estudo é determinar possíveis agrupamentos entre os fragmentos e suas caraterísticas de acordo com as informações fornecidas pelos arqueólogos responsáveis.

A primeira técnica aplicada ao estudo foi o método PIXE, que permite identificar e quantificar a composição elementar das amostras, em especial, com maior eficiência, os elementos compreendidos entre o Alumínio $(Z=13)$ e o Ferro $(Z=26)$. As medidas foram feitas em três períodos experimentais, duas no laboratório LAMFI localizado no Instituro de Física da Universidade de São Paulo e uma no Laboratório Peletron localizado no Instituto de Física da Universidad Autónoma de México.

O primeiro período experimental (LAMFI) foi de caráter exploratório em amostras de cerâmica moderna, cerâmicas arqueológicas e etnográfica. Foram determinados 15 elementos sendo os majoritários $\mathrm{Si}, \mathrm{K}, \mathrm{Ca}$, Ti e Fe e os minoritários $\mathrm{Al}, \mathrm{S}, \mathrm{Cl}, \mathrm{V}, \mathrm{Cr}, \mathrm{Mn}$, $\mathrm{Ni}, \mathrm{Cu}, \mathrm{Zn}$ e Ba. Neste experimento verificou-se a grande distinção entre o fragmento de origem arqueológica do etnográfico e a importância da análise de elementos metálicos tais como Zn. 
O segundo período de aquisição de dados foi realizado novamente no laboratório LAMFI utilizando a canalização dedicada à experimentos com feixe externo, porém sem as ultimas e atuais melhorias, tais como o quadrupolo, fato que limitou as análises elementares. Foram medidos 7 elementos ( $\mathrm{Al}, \mathrm{Si}, \mathrm{K}, \mathrm{Ca}, \mathrm{Ti}, \mathrm{Mn}$ e $\mathrm{Fe}$ ) e não foi possível determinar uma correlação relevante para a formação de agrupamentos entre os fragmentos. Podemos concluir que somente a análise de elementos mais leves, responsáveis pela composição da pasta cerâmica, predominantemente majoritários, dificulta a separação das amostras com relação à sua composição.

A terceira tomada de dados com a técnica PIXE foi realizada no Laboratório Peletron (UNAM) utilizando a linha de feixe externo dedicada a análises arqueométricas. Neste experimento foram determinadas as concentrações de 15 elementos, entre matriz e elementos traços. Os elementos encontrados foram $\mathrm{Al}, \mathrm{Si}, \mathrm{K}, \mathrm{Ca}, \mathrm{Ti}, \mathrm{Mn}, \mathrm{Fe}, \mathrm{Ni}, \mathrm{Cu} \mathrm{Zn}$, $\mathrm{Rb}, \mathrm{Sr}, \mathrm{Y} \mathrm{Zr}$ e $\mathrm{Pb}$. Em uma primeira análise, observando simplesmente a área normalizada dos elementos é possível confirmar a importância dos elementos com Z>26, para estes conjuntos de amostras. Alguns elementos, tais como $\mathrm{Zn}$ e $\mathrm{Pb}$, apresentaram algumas diferenças em suas concentrações quando associadas ao sítio arqueológico onde os fragmentos foram encontrados. Ao observarmos as relações simples entre elementos, podese destacar o gráfico de $\mathrm{Al}$ versus $\mathrm{Pb}$ onde é possível determinar duas regiões distintas também relacionadas aos sítios. No conjunto total de dados foram aplicadas as técnicas de análise estatística cluster e PCA e os resultados obtidos confirmaram o agrupamento das peças com relação à informação do sítio arqueológico de origem.

Através dos experimentos realizados com a técnica PIXE nos conjuntos de fragmentos cerâmicos verificou-se a importância da determinação tanto dos elementos com baixo $\mathrm{Z}(\mathrm{Z} \bumpeq$ 26$)$, que formam a matriz cerâmica, quanto dos elementos com $\mathrm{Z}$ mais alto $(Z \geq 26)$. Estes elementos, em sua maioria, são considerados elementos traços que podem ser associados às diferentes características para o agrupamento das peças. Devemos lembrar que nenhum dos experimentos realizados com a técnica PIXE foram aplicados ao conjunto total de fragmentos cerâmicos e que as peças analisadas foram escolhidas aleatoriamente dentro dos conjuntos pré-definidos. 
Neste estudo, também foram feitas medidas utilizando a técnica XRF, técnica que também permite qualificar e quantificar a composição elementar das amostras, com destaque para os elementos com $Z$ mais altos $(Z \geq 26)$. Este método foi aplicado em especial para a determinação dos elementos traços presentes nas amostras. As medidas foram feitas em dois períodos experimentais, o primeiro foi realizada no Laboratório Peletron UNAM e o segundo no IFUSP com a utilização do equipamento pertencente ao LABENS.

No primeiro período experimental, de caráter exploratório e realizado em um conjunto parcial de amostras, foram determinados 14 elementos entre elementos da matriz e elementos traços. Os elementos determinados foram Al, Si, K, Ca, Ti, Cr, Mn, Fe, Cu, $\mathrm{Zn}, \mathrm{Rb}, \mathrm{Sr}, \mathrm{Y}$ e Zr. Ao analisarmos as relações de áreas normalizadas das amostras podemos destacar os elementos $\mathrm{Al}, \mathrm{Mn}, \mathrm{Zn}$ e $\mathrm{Zr}$ como elementos que permitem uma diferenciação quando comparamos as peças de diferentes tradições culturais e sítios arqueológicos.

No segundo conjunto de dados obtidos através do método XRF, realizado no IFUSP, foram determinados 15 elementos, $\mathrm{K}, \mathrm{Ca}, \mathrm{Ti}, \mathrm{Cr}, \mathrm{Mn}, \mathrm{Fe}, \mathrm{Ni}, \mathrm{Cu}, \mathrm{Zn}, \mathrm{Pb}, \mathrm{Br}, \mathrm{Rb}$, $\mathrm{Sr}, \mathrm{Y}$ e Zr. Por se tratar de um experimento realizado no conjunto total de fragmentos estudados, a análise passou por diversas etapas, desde a avaliação visual dos dados obtidos até a aplicação de métodos de análise estatística.

Inicialmente, ao observarmos as relações de área versus amostra, podemos visualmente agrupar e destacar algumas diferenças entre os fragmentos. Elementos com baixo $\mathrm{Z}$, tais como $\mathrm{K}$ e $\mathrm{Ca}$, assim como elementos mais pesados tais como $\mathrm{Br}$ e $\mathrm{Rb}$, apontam a existência de um subgrupo dentro das amostras pertencentes ao sítio Sede e à tradição Pantanal. Claramente, também é possível destacar o elemento Zr que indica um segundo subgrupo nas amostras deste conjunto. Ao verificarmos as relações entre os elementos, podemos apontar a existência de subgrupos não diretamente relacionados aos sítios arqueológicos ou às culturas. Estes subgrupos surgem quando comparamos os elementos Ti, Fe, Zn, Sr e Zr. 
Neste conjunto de dados foram aplicadas as técnicas de análise estatística. Ambas as técnicas (análise de cluster e PCA) foram aplicadas em duas etapas. A primeira etapa foi feita com a utilização de todos os elementos determinados como variáveis do processo e a segunda etapa com elementos determinados através da sequência de análises, utilizando uma combinação que evidencie as diferenças entre os grupos. Estas técnicas foram aplicadas em três conjuntos de amostras. O primeiro conjunto é formado por todos os fragmentos cerâmicos cedidos ao estudo, o segundo conjunto pelas peças encontradas no sítio Sede/Córrego Lalima e o terceiro pelas peças encontradas no sítio Asa do Pote.

Os resultados encontrados através das análises de cluster apontam a separação dos fragmentos em subgrupos que em sua grande maioria correspondem às informações previamente fornecidas pelos arqueólogos responsáveis. Nos dendrogramas formados podemos observar uma separação de grupos quase completa entre os níveis de dissimilaridade com valores entre 40 e 100. Estes valores são encontrados em todas as situações de análise, seja com relação ao sítio arqueológico ou à tradição. Podemos destacar a Figura 38. Nesta figura, podemos apontar a criação de 5 subgrupos. Os subgrupos apresentam predominantemente os fragmentos de uma categoria. A separação se torna clara quando selecionadas as peças de acordo com o sítio arqueológico, neste caso podemos afirmar uma diferenciação entre as peças encontradas nos diferentes sítios.

A análise se torna mais complexa quando considerado o requisito tradição. $\mathrm{O}$ estudo realizado para os sítios apresenta em ambos os casos o agrupamento não completo das amostras quando comparadas com as informações sobre tradição inicialmente conhecida. Porém, os resultados obtidos são satisfatórios. As amostras que não correspondem ao seu grupo de origem deverão ser reavaliadas ou analisadas individualmente.

Um dos resultados encontrados é a existência de dois subgrupos de peças dentro do conjunto de fragmentos da tradição Guarani encontrados no sítio MI1. Essa separação pode ser observada nas análises estatísticas ou simplesmente nos valores de concentração obtidos para o elemento Zr. A existência desta separação deverá ser melhor investigada levando em consideração o contexto arqueológico dos fragmentos. 
O terceiro método experimental empregado neste estudo foi a técnica de radiografia computadorizada, que permite a investigação das estruturas internas dos objetos estudados, tal como a presença de tempero ou fraturas internas e a melhor observação das características das técnicas de manufatura e decoração.

O conjunto total de 112 fragmentos cerâmicos foi radiografado em diferentes etapas devido às diferentes espessuras das peças e à grande quantidade das mesmas. As peças foram separadas em dois grupos de acordo com a espessura, sendo o primeiro grupo com espessuras entre $0,4 \mathrm{~cm}$ e $1,0 \mathrm{~cm}$ e o segundo grupo com espessuras superiores a $1,0 \mathrm{~cm}$. Esta separação foi adotada para definir as condições experimentais que podem variar conforme as características dos objetos de estudo. Uma peça padrão de Alumínio foi irradiada juntamente com os fragmentos cerâmicos para normalizar as imagens obtidas. Essa normalização é necessária apesar do uso das mesmas condições experimentais aplicadas nas diferentes chapas, isto devido ao curto tempo de irradiação. O tubo de raios $\mathrm{X}$ necessita de um pequeno intervalo de tempo para estabilizar a emissão do feixe e este tempo não é reprodutível.

Com a aplicação de um critério visual nas imagens radiográficas as peças foram separadas de acordo com a presença de tempero em sua estrutura. Esta primeira delimitação das peças não está associada nem ao sítio arqueológico ou a tradição. Este mesmo critério visual permite afirmar que os temperos encontrados nestes fragmentos cerâmicos possuem maior densidade do que a pasta cerâmica, devido ao tom mais claro na imagem radiográfica, excluindo raras exceções neste conjunto de amostras.

As imagens foram estudadas e trabalhadas através de programas de tratamento de imagem. Um dos recursos utilizados neste estudo transforma uma região delimitada da imagem em um histograma relacionando o tom de cinza da imagem com sua frequência em contagens. Através de um ajuste gaussiano deste gráfico, podemos assumir em uma primeira aproximação, um valor de tom de cinza predominante e seu desvio padrão. Estes dois valores estão vinculados à diferentes características das peças, entre as quais podemos citar a presença de tempero, espessura e densidade da peça. A partir dos valores determinados, foram gerados diferentes gráficos, sendo de destaque o gráfico da Figura 67. 
Neste gráfico podemos associar as informações das imagens radiográficas, tom de cinza (centróide) e presença de tempero, com a informação da espessura das peças. Esta figura esta de acordo com a teoria de absorção (Lei de Lambert-Beer), fato observado através da curva do material Al e sugere uma dependência entre o posicionamento das curvas e densidades dos materiais cerâmicos. Para verificar esta relação foram aplicadas três metodologias para o cálculo da densidade dos fragmentos cerâmicos, o conhecido método de Arquimedes, que utiliza a relação massa/volume do objeto, o cálculo de densidade através da composição elementar obtida utilizando a técnica PIXE e através das imagens radiográficas. Para realizar estes cálculos foram necessárias estimativas de vários fatores tais como volume das peças, absorção de massa e taxa de transmissão para determinado material.

Ao compararmos os resultados obtidos pelos diferentes métodos, observamos uma grande discrepância entre os valores encontrados, mesmo considerando as incertezas. Esta variação nos valores pode ser explicada por dois fatores, o primeiro é a diferença na grandeza mensurada e o segundo são as várias fontes de incertezas dos métodos.

Comparando os valores, podemos observar que os encontrados pela técnica PIXE são mais elevados do que os valores obtidos pelo método de Arquimedes e pelas imagens radiográficas, para uma mesma amostra. Isto ocorre devido à existência de porosidade no material cerâmico. A técnica PIXE não é afetada pelo nível de porosidade existente nos fragmentos, pois utiliza as informações de composição elementar da pasta cerâmica para determinar a densidade dos objetos, ao contrário dos outros métodos propostos.

Confrontando as densidades encontradas pela técnica de imagem e pelo método de Arquimedes verificamos que os valores encontrados pela técnica de radiografia são sistematicamente mais baixos para uma mesma amostra, porém seguem um comportamento linear através do qual podemos sugerir a existência de um erro sistemático em algum ou ambos os métodos. De acordo com as duas técnicas, a densidade dos fragmentos está associada à presença de tempero na estrutura da amostra, pois os fragmentos que possuem tempero em sua massa apresentam densidades mais altas em ambas as técnicas. 
Confrontando os diferentes resultados para a densidade dos fragmentos, não foi possível associar nenhuma variação dos valores aos sítios ou às tradições culturais, os valores encontrados para as três técnicas se encontram dispersos nas diferentes categorias, característica já conhecida e esperada.

Um dos erros que podem ser apontados é a correção realizada para a energia de irradiação do tubo de raios X. Ao aplicarmos uma tensão ao tubo, estamos determinando a energia máxima do feixe emitido. Este feixe não é monocromático e apresenta um espectro de distribuição de energias emitidas que deve ser considerado ao realizar os cálculos de densidade de um objeto. Deve ser feito um estudo anterior com relação ao espectro de emissão do equipamento para determinar com segurança as condições experimentais. Uma das alternativas para contornar essa questão é a utilização de um conjunto de objetos padrões com composição, espessura e densidade conhecidos, características que devem ser parecidas às esperadas no estudo. No caso do estudo de objetos cerâmicos, devemos criar padrões com espessuras variadas e com diferentes quantidades de tempero. Em determinados ocasiões podem ser utilizados diferentes tipos de temperos, de acordo com a tradição ou conjunto estudado.

Como conclusão deste trabalho, foi possível estabelecer uma relação entre os fragmentos cerâmicos estudados às suas tradições, assim como aos sítios arqueológicos onde as peças foram coletadas. Características que envolvem os processos de manufatura também puderam ser analisadas, tais como a presença de antiplástico e a densidade dos materiais, características que não podem ser associadas a um grupo específico. Essas informações devem ser reavaliadas dentro de um contexto geral arqueológico, levando em consideração a história e os processos evolutivos da região e das comunidades envolvidas.

Tendo em vista os resultados obtidos podemos destacar o grande potencial das técnicas empregadas neste estudo na área da arqueometria. São técnicas rápidas e de fácil aplicação experimental que permitem a análise à pressão atmosférica sendo não destrutivas ou não-invasivas, fornecendo uma riqueza de informações sobre a caracterização de materiais. Quando associada às técnicas de análise estatísticas, os resultados se mostram aptos a resolver os problemas apresentados aos pesquisadores, tais como a determinação do local de origem, tradição a qual pertence e diferenças nas técnicas de manufatura. 


\section{Glossário}

\section{Capítulo 1}

1. IBA sigla para "Ion Beam Analysis" (Análise com Feixes Iônicos).

2. PIXE sigla para "Particle Induced X-Ray Emission" (Emissão de Raio X induzido por Partícula).

3. XRF sigla para "X-Ray Fluorescence" (Fluorescência de Raios X).

4. Tempero material adicionado à pasta cerâmica. Pode ter origem orgânica (casca de árvore ou plantas) ou origem inorgânica (areia, conchas e caco moído).

\section{Capítulo 2}

5. AP sigla para "Antes do Presente".

6. Engobo Camada superficial de argila. Em cerâmicas modernas serve de base para o vidrado ou esmaltado.

7. Líticos relativo à pedra, materiais líticos são feitos a partir de pedras.

8. ppm abreviação para "Partes por milhão".

\section{Capítulo 3}

9. INCRA sigla para "Instituto de Colonização e Reforma Agrária"

10. UTM sigla para "Universal Transversa de Mercator". Sistema de localização terrestre baseado em coordenadas

11. SPI sigla para "Serviço de Proteção aos Índios"

12. Taqueômetro Instrumento eletrônico utilizado na media de ângulos e distâncias

13. FUNAI sigla para "Fundação Nacional do Índio"

14. FUNASA sigla para "Fundação Nacional de Saúde" 


\section{Capítulo 4}

15. CR sigla em inglês para "Computerized Radiography" ou Radiografia Computadorizada.

16. DR sigla em inglês para "Digital Radiography" ou Radiografia Digital.

\section{Capítulo 5}

17. LAMFI sigla para "Laboratório de Análise de Materiais e Feixes Iônicos"

18. LABENS sigla para "Laboratório de caracterização de Bens culturais"

19. NIST sigla para "National Institute of Standards and Technology"

20. LEGe sigla para "Low Energy Germanium"

\section{Capítulo 6}

21. PCA

sigla para "Principal Components Analysis" (Análise de Componentes Principais)

22. Scree plot Gráfico formado por segmentos de retas simples que mostra a variação total nos valores representados pelos eixos em uma análise PCA

\section{Capítulo 7}

23. Etnografia Ramo das ciências humanas que tem por objetivo o estudo descritivo de todas as atividades dos diversos grupos humanos. De maneira resumida, o estudo etnográfico consiste no estudo de um objecto por vivência directa da realidade onde este se insere.

24. IEE

Instituto de Eletrostática e Energia 


\section{Referencias bibliográficas}

[1] CABRAL, J. M. P. Arqueometria, ISSN0870-7650, Lisboa, A.3, n.7, Mar. 1991, p.58-78.

[2] SALAMANACA, M. A. O.; RUVALCABA-SIL, BUCIO, L.; MANZANILLA, L.; MIRANDA, J. Ion beam analysis of pottery from Teotihuacan, Mexico, Nuclear Instr. Meth.. B 161-163 (2000) 762-768.

[3] SILVA, F. A.; APPOLONI, C. R.; QUIÑONES, F. R. E.; SANTOS, A. O.; SILVA, L. M.; BARBIERI, P. F.; FILHO, V. F. N. A arqueometria e a análise de artefatos cerâmicos: um estudo de fragmentos cerâmicos etnográficos e arqueológicos por fluorescência de raios-X (EDXRF) e transmissão Gama, Revista de Arqueologia, 17: 41-61, 2004.

[4] LANG, J.; MIDDLETON, A. Radiography of Cultural Material, Elsevier Butterworth-Heinemann, 2nd edition, 2005.

[5] RICE, P. M. On the origins of pottery, Journal of Archaeological Method and Theory Volume 6, Number 1, 1-54, DOI: 10.1023/A:1022924709609.

[6] Fonte IBGE, Censo demográfico 2010, http://www.ibge.gov.br

[7] PROUS, A. Arqueologia Brasileira, Editora UnB, 1991.

[8] SCHMITZ, P. I.; ROGGE, J. H.; ROSA, A. O., BEBER, M. V. Aterros indígenas no Pantanal do Mato Grosso do Sul. Pesquisas, Antropologia $n^{\circ}$ 54, 1998, São Leopoldo, Instituto Anchietano de Pesquisas.

[9] ROGGE, J. H. A Tradição Pantanal: uma nova Tradição Cerâmica nas Terras Baixas Sul-Americanas, In: Simposio internacional de arqueología de las tierras bajas, Anais n. 1, p. 195-206, 1996.

[10] PEIXOTO, J. L.; BEZERRA, M. A. Os povos ceramistas que ocuparam a planície aluvial antes da conquista européia, Pantanal, IV Simpósio sobre recursos naturais e socioeconômicos do Pantanal, Corumbá, Anais 2004.

[11] SALVIA, F.; BROCHADO, J. P. Cerâmica Guarani, Editora Porsenato Arte e Cultura, 1989.

[12] RICE, P. M. Pottery analysis: a sourcebook, The University of Chicago Press, 1987.

[13] LIMA, S. C. Especificidades na restauração de cerâmicas arqueológicas: um estudo de caso, Per. Do Museu de Arqueologia e Etnologia, São Paulo, 12: 269-281, 2002. 
[14] BESPALEZ, E. Levantamento arqueológico e etnoarqueologia na Aldeia Lalima, Miranda/MS: um estudo sobre a trajetória histórica da ocupação indígena regional, Tese MAEUSP, 2009.

[15] OLIVEIRA, E. Da pré-história à história indígena: $(\mathrm{Re})$ pensando a arqueologia e os povos canoeiros do Pantanal. Revista de arqueologia, 16: 71-86. São Paulo.

[16] PEIXOTO, J. L. S. A ocupação dos povos indígenas pré-coloniais nos grandes lagos do Pantanal Sul-mato-grossense, 2003. 262 p. Tese, Faculdade de Filosofia e Ciências Humanas da Pontifícia Universidade Católica do Rio Grande do Sul, Porto Alegre, 2003.

[17] YAMAKAWA, Q. A. C.; SOUSA, N. M. Historiografia dos índios e colonos em Santiago de Xerez: da invisibilidade à política indígena, III Seminário povos indígenas e sustentabilidade: saberes locais, educação e autonomia, Set 2009, Campo Grande.

[18] EISBERG, RESNICK, Física Quântica, Editora Campus, 1979, 17ª tiragem.

[19] SERWAY, R. A.; JEWETT, J. W. Princípios de Física, Óptica e Física Moderna, Volume 4, $3^{\text {a }}$ edição, Cengage Learning, 2005.

[20] JOHANSSON, S. A. E.; CAMPBELL, J. L.; MALMQVIST, K. G. Particle Induced X-Ray Emission Spectrometry (PIXE), John Wiley \& Sons, inc., 1995.

[21] OKUNO, E.; YOSHIMURA, E. Física das Radiações, Editora Oficina de Textos, $1^{\mathrm{a}}$ edição, 2010.

[22] LANG, J.; MIDDLETON, A. Radiography of Cultural Material, Elsevier Butterworth-Heinemann, 2nd edition, 2005.

[23] ABURAYA, J. H.; ADDED, N.; TABACNIKS, M. H.; RIZZUTTO, M. A.; BARBOSA, M. D. L. X-Ray production yield in standardized thick target PIXE, Nuclear Instruments and Methods in Physics

[24] LINDON, J. C.; TRAINER, G. E.; HOLMES, J. L. Encyclopedia of Spectroscopy \& Spectrometry II, X-Ray Fluorescence Spectroscopy, Academic Press, 2000.

[25] CILIBERTO, E; SPOTO, G. Modern Analytical Methods in Art and Archaeology, Editors Wiley-Interscience, 2000.

[26] APPOLONI, C. R.; QUIÑONES, F. R. E.; ARAGÃO, P. H. A.; SANTOS, A. O.; SILVA, L. M.; BARBIERI, P. F.; FILHO, V. F. N.; COIMBRA, M. M. EDXRF study of Tupi-Guarani archaeological ceramics, Radiation Physics and Chemistry, Volume 61, Issues 3-6, June 2001, Pages 711-712.

[27] VALE, S. Pequena história da radiografia, Contemporânea, n13, 2009.

[28] QUINN, R. A.; SIGL, C. C.; CALLINAN, J. J. Radiography in Modern Industry, Eastman Kodak Company, 1980. 
[29] CARROL, Q. B. Fuchs's Radiographic Exposure Processing and Quality Control, $6^{\text {th }}$ edition, Charles C Thomas Publisher, LTD., 1998.

[30] BERG, I. Looking through pots: recent advances in ceramics X-radiography, Journal of Archaeological Science, Volume 35, Issue 5, May 2008, Pages 1177-1188.

[31] BRAUN, D.P. Radiographic Analysis of Temper in Ceramic Vessels: Goals and Initial Methods, Journal of Field Archaeology, Vol. 9, No. 2 (Summer, 1982), pp. 183192.

[32] Fonte NEC, http://www.pelletron.com/negion.htm

[33] Fonte Amptek, http://www.amptek.com/xr100cr.html

[34] Fonte AGFA, http://www.agfahealthcare.com/

[35] RUVALCABA-SIL, J. L.; MIRANDA, D. R.; Melo, V. A.; Picazo, F. SANDRA: a portable XRF system for the study of Mexican cultural heritage, X-Ray Spectrometry, Volume 39, Issue 5, pages 338-345, September/October 2010

[36] Fonte Canberra, http://www.canberra.com/products/493.asp

[37] MINGOTI, S. A. Análise de dados através de métodos de estatística multivariada, Editora UFMG, 2007.

[38] VICINI, L. Análise multivariada, da teoria à prática, monografia, Universidade Federal de Santa Maria, 2005.

[39] VARELlA, C. A. A. Análise de componentes Principais, Universidade Federal Rural do Rio de Janeiro, 2008

[40] Ferreira, P. L. Estatística Multivariada Aplicada, Faculdade de Economia da Universidade de Coimbra, 2000.

[41] StatSoft, Inc. (2004). STATISTICA (data analysis software system), version 7. www.statsoft.com.

[42] "WinQXAS - Quantitative X-ray Analysis System for MS Windows operating systems", Manual do usuário, IAEA.

[43] TERINI, R. A.; COSTA, P. R.; FURQUIM, T. A. C.; HERDADE, S. B. Measurements of Discrete and Conditions X-Ray Spectra with a Photodiode at Room Temperature, Applied Radiation and Isotopes, v. 50, p. 343-353, 1999.

[44] MURTY, R. C. Effective Atomic Numbers of Heterogeneous Materials, Nature 207, 398-399 (1965). 


\section{Catálogo de Peças}

$\begin{array}{ll}\text { Peça } & \text { MI1-11 } \\ \text { Sítio } & \text { MI1 } \\ \text { Cultura } & \text { Guarani } \\ \text { Espessura } & 0,72 \mathrm{~cm} \\ \text { Medidas } & \text { R-X; XRF; PIXE }\end{array}$

Peça MI1-120

Sítio MI1

Cultura Guarani

Espessura $\quad 0,79 \mathrm{~cm}$

Medidas $\mathrm{R}-\mathrm{X}$; XRF

$\begin{array}{ll}\text { Peça } & \text { MI1-162 } \\ \text { Sítio } & \text { MI1 } \\ \text { Cultura } & \text { Guarani } \\ \text { Espessura } & 1,18 \mathrm{~cm} \\ \text { Medidas } & \mathrm{R}-\mathrm{X} ; \mathrm{XRF}\end{array}$

$\begin{array}{ll}\text { Peça } & \text { MI1-163 } \\ \text { Sítio } & \text { MI1 } \\ \text { Cultura } & \text { Guarani } \\ \text { Espessura } & 0,86 \mathrm{~cm} \\ \text { Medidas } & \text { R-X; XRF }\end{array}$

$\begin{array}{ll}\text { Peça } & \text { MI1-168 } \\ \text { Sítio } & \text { MI1 } \\ \text { Cultura } & \text { Guarani } \\ \text { Espessura } & 0,70 \mathrm{~cm} \\ \text { Medidas } & \text { R-X; XRF }\end{array}$
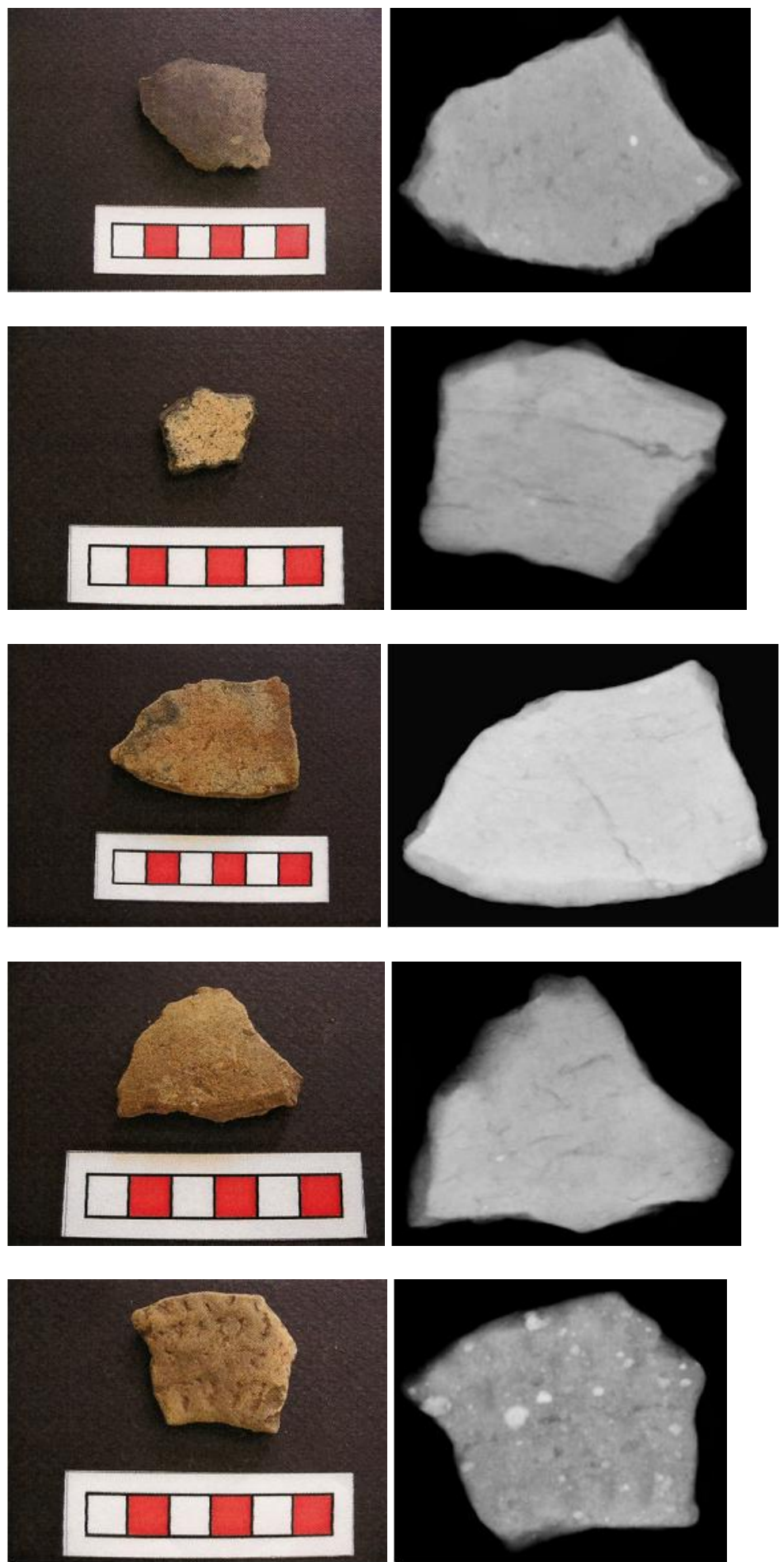
Peça MI1-173

Sítio MI1

Cultura Guarani

Espessura $\quad 1,22 \mathrm{~cm}$

Medidas R-X; XRF

Peça MI1-177

Sítio MI1

Cultura Guarani

Espessura $1,30 \mathrm{~cm}$

Medidas R-X; XRF

Peça MI1-181

Sítio MI1

Cultura Guarani

Espessura $1,63 \mathrm{~cm}$

Medidas R-X; XRF

Peça MI1-182

Sítio MI1

Cultura Guarani

Espessura $1,13 \mathrm{~cm}$

Medidas R-X; XRF

Peça MI1-189

Sítio MI1

Cultura Guarani

Espessura $\quad 0,81 \mathrm{~cm}$

Medidas R-X; XRF

Peça MI1-295

Sítio MI1

Cultura Guarani

Espessura $1,31 \mathrm{~cm}$

Medidas R-X; XRF; PIXE
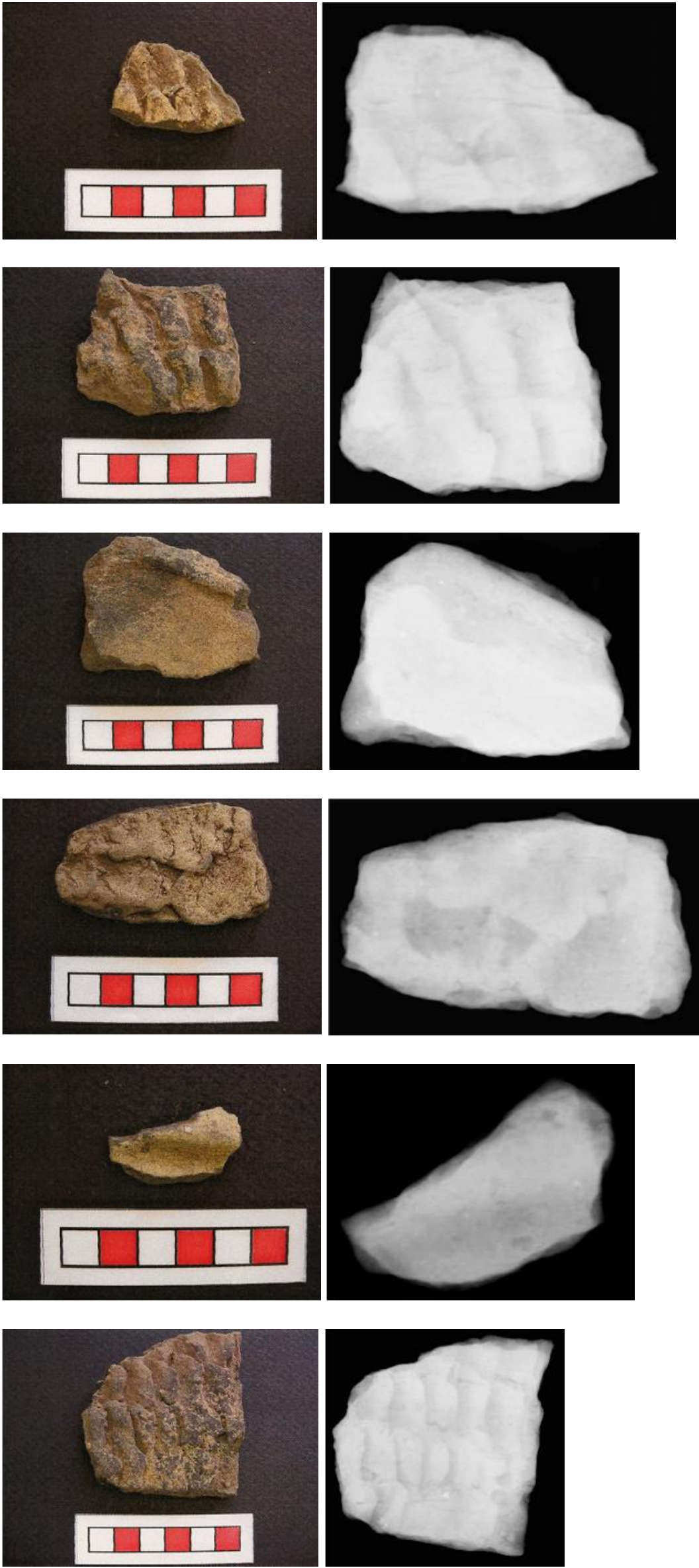
Peça MI1-296

Sítio MI1

Cultura Guarani

Espessura $\quad 2,13 \mathrm{~cm}$

Medidas $\mathrm{R}-\mathrm{X}$; XRF

Peça MI1-297

Sítio MI1

Cultura Guarani

Espessura $\quad 2,64 \mathrm{~cm}$

Medidas R-X; XRF

Peça MI1-300

Sítio MI1

Cultura Guarani

Espessura $1,09 \mathrm{~cm}$

Medidas R-X; XRF

Peça MI1-936

Sítio MI1

Cultura Pantanal

Espessura $\quad 0,66 \mathrm{~cm}$

Medidas R-X; XRF

Peça MI1-938

Sítio MI1

Cultura Pantanal

Espessura $\quad 0,53 \mathrm{~cm}$

Medidas R-X; XRF

Peça MI1-957

Sítio MI1

Cultura Pantanal

Espessura $\quad 0,49 \mathrm{~cm}$

Medidas R-X; XRF
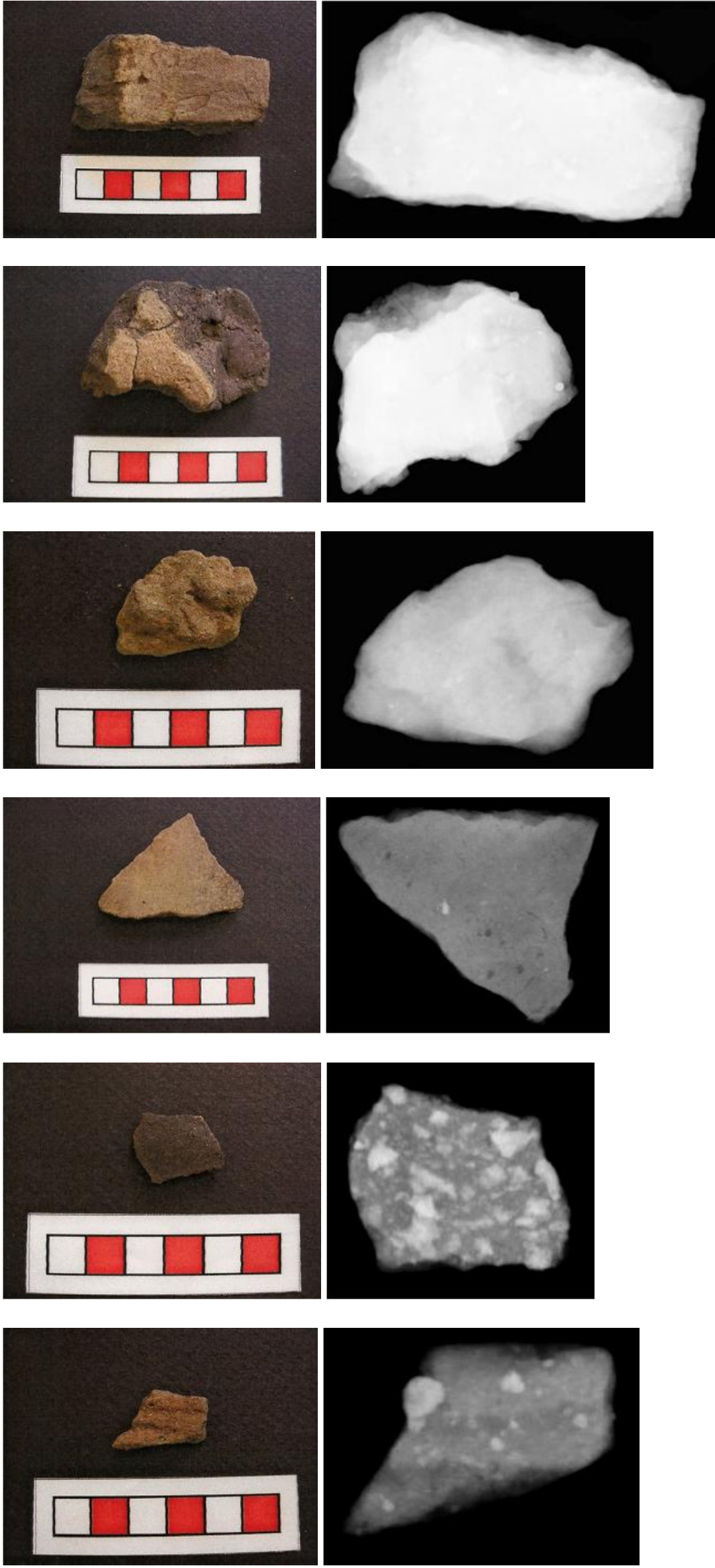
Peça MI1-959

Sítio MI1

Cultura Pantanal

Espessura $\quad 0,72 \mathrm{~cm}$

Medidas R-X; XRF

Peça MI1-961

Sítio MI1

Cultura Pantanal

Espessura $\quad 0,55 \mathrm{~cm}$

Medidas R-X; XRF

Peça MI1-962

Sítio MI1

Cultura Pantanal

Espessura $\quad 0,61 \mathrm{~cm}$

Medidas R-X; XRF

Peça MI1-964

Sítio MI1

Cultura Pantanal

Espessura $\quad 0,75 \mathrm{~cm}$

Medidas R-X; XRF

$\begin{array}{ll}\text { Peça } & \text { MI1-965 } \\ \text { Sítio } & \text { MI1 } \\ \text { Cultura } & \text { Pantanal } \\ \text { Espessura } & 0,68 \mathrm{~cm} \\ \text { Medidas } & \text { R-X; XRF; PIXE }\end{array}$

Peça MI1-969

Sítio MI1

Cultura Pantanal

Espessura $\quad 0,80 \mathrm{~cm}$

Medidas R-X; XRF
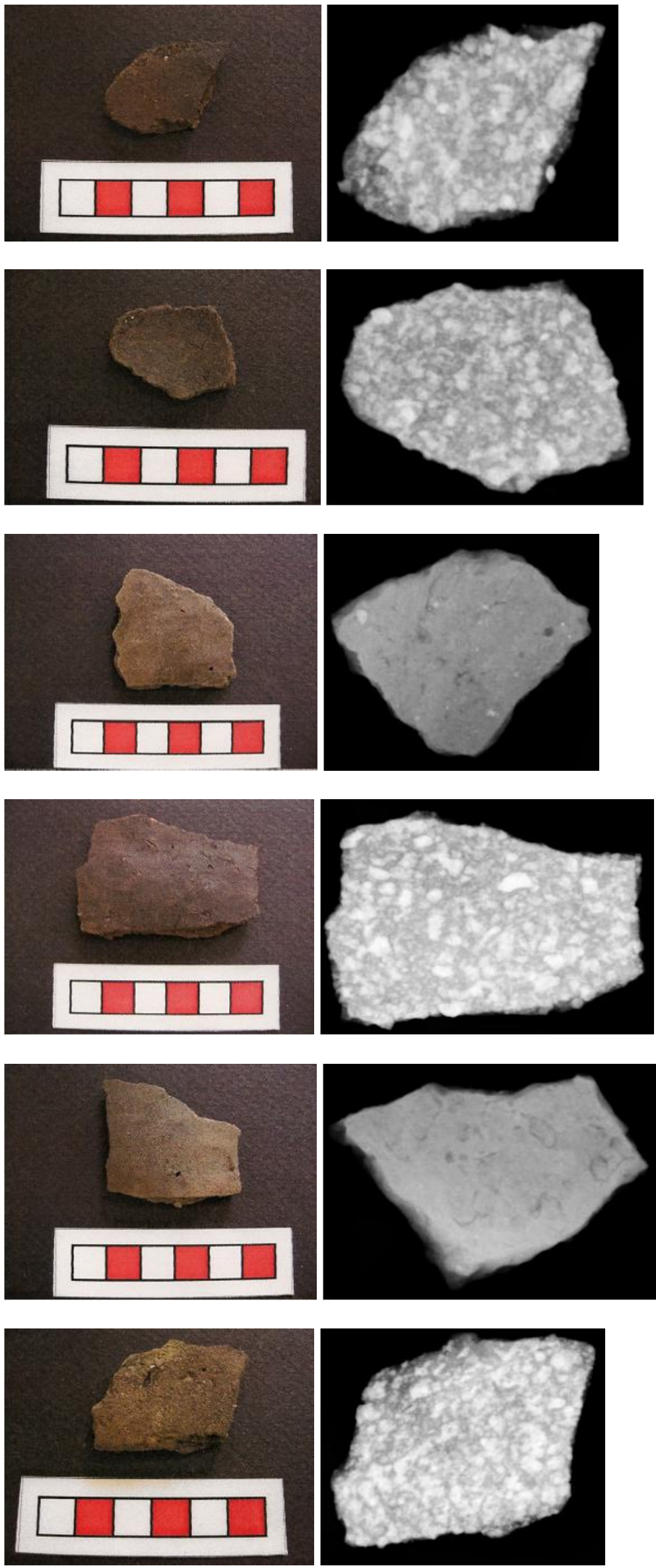


$\begin{array}{ll}\text { Peça } & \text { Ml1-971 } \\ \text { Sítio } & \text { MI1 } \\ \text { Cultura } & \text { Guarani } \\ \text { Espessura } & 1,34 \mathrm{~cm} \\ \text { Medidas } & \text { R-X; XRF }\end{array}$

$\begin{array}{ll}\text { Peça } & \text { MI1-973 } \\ \text { Sítio } & \text { MI1 }\end{array}$

Cultura Pantanal

Espessura $\quad 0,43 \mathrm{~cm}$

Medidas R-X; XRF; PIXE

$\begin{array}{ll}\text { Peça } & \text { MI1-974 } \\ \text { Sítio } & \text { MI1 } \\ \text { Cultura } & \text { Pantanal } \\ \text { Espessura } & 0,70 \mathrm{~cm} \\ \text { Medidas } & \text { R-X; XRF; PIXE }\end{array}$

$\begin{array}{ll}\text { Peça } & \text { MI1-976 } \\ \text { Sítio } & \text { MI1 } \\ \text { Cultura } & \text { Pantanal } \\ \text { Espessura } & 0,89 \mathrm{~cm} \\ \text { Medidas } & \text { R-X; XRF; PIXE }\end{array}$

Peça MI1-977

Sítio MI1

Cultura Pantanal

Espessura $1,00 \mathrm{~cm}$

Medidas R-X; XRF

$\begin{array}{ll}\text { Peça } & \text { MI1-979 } \\ \text { Sítio } & \text { MI1 } \\ \text { Cultura } & \text { Pantanal } \\ \text { Espessura } & 0,73 \mathrm{~cm} \\ \text { Medidas } & \mathrm{R}-\mathrm{X} ; \mathrm{XRF}\end{array}$
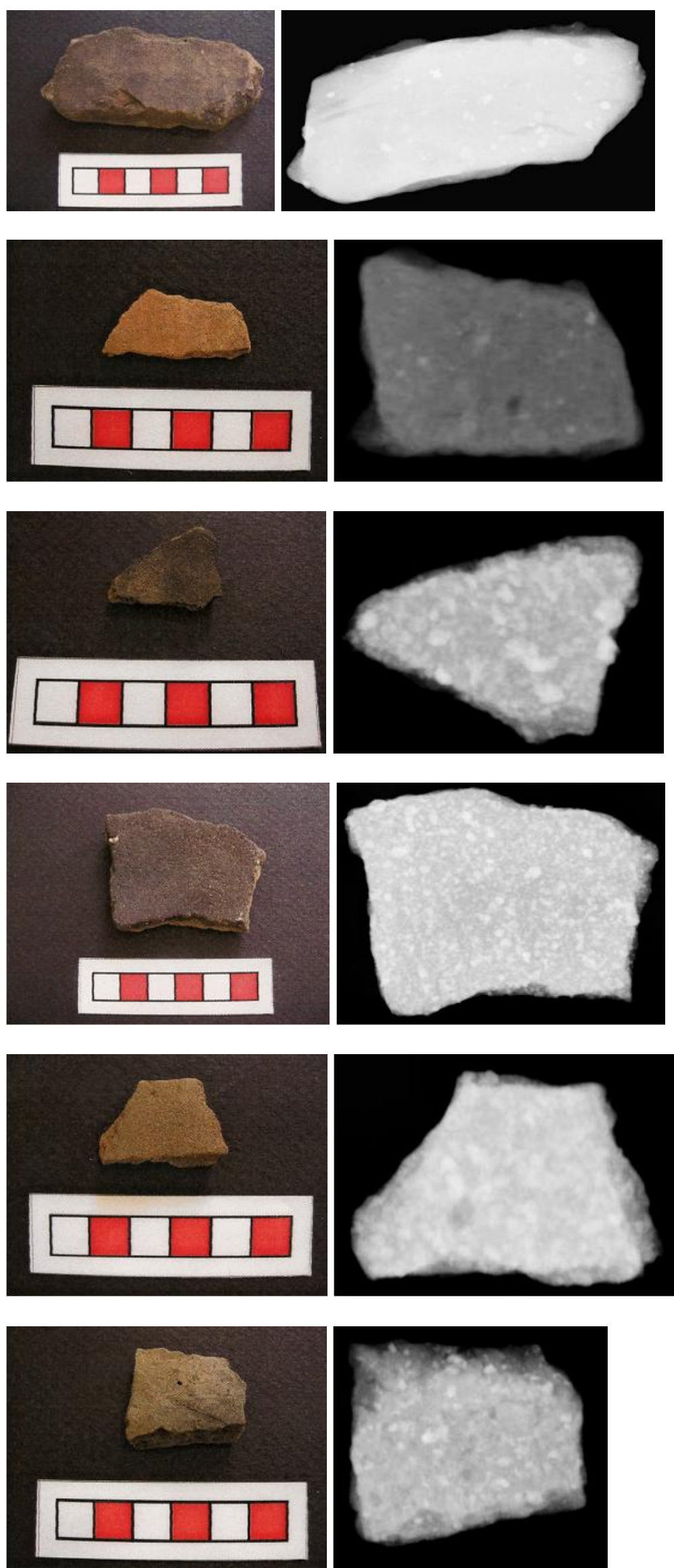


$\begin{array}{ll}\text { Peça } & \text { MI1-983 } \\ \text { Sítio } & \text { MI1 } \\ \text { Cultura } & \text { Pantanal } \\ \text { Espessura } & 0,62 \mathrm{~cm} \\ \text { Medidas } & \text { R-X; XRF }\end{array}$

Peça MI1-985

Sítio MI1

Cultura Pantanal

Espessura $\quad 0,69 \mathrm{~cm}$

Medidas R-X; XRF; PIXE

$\begin{array}{ll}\text { Peça } & \text { MI1-986 } \\ \text { Sítio } & \text { MI1 } \\ \text { Cultura } & \text { Pantanal } \\ \text { Espessura } & 0,67 \mathrm{~cm} \\ \text { Medidas } & \text { R-X; XRF }\end{array}$

Peça MI1-988

Sítio MI1

Cultura Pantanal

Espessura $\quad 0,54 \mathrm{~cm}$

Medidas R-X; XRF

$\begin{array}{ll}\text { Peça } & \text { MI1-989 } \\ \text { Sítio } & \text { MI1 } \\ \text { Cultura } & \text { Pantanal } \\ \text { Espessura } & 0,43 \mathrm{~cm} \\ \text { Medidas } & \text { R-X; XRF }\end{array}$

$\begin{array}{ll}\text { Peça } & \text { MI1-990 } \\ \text { Sítio } & \text { MI1 } \\ \text { Cultura } & \text { Pantanal } \\ \text { Espessura } & 0,67 \mathrm{~cm} \\ \text { Medidas } & \mathrm{R}-\mathrm{X} ; \mathrm{XRF}\end{array}$
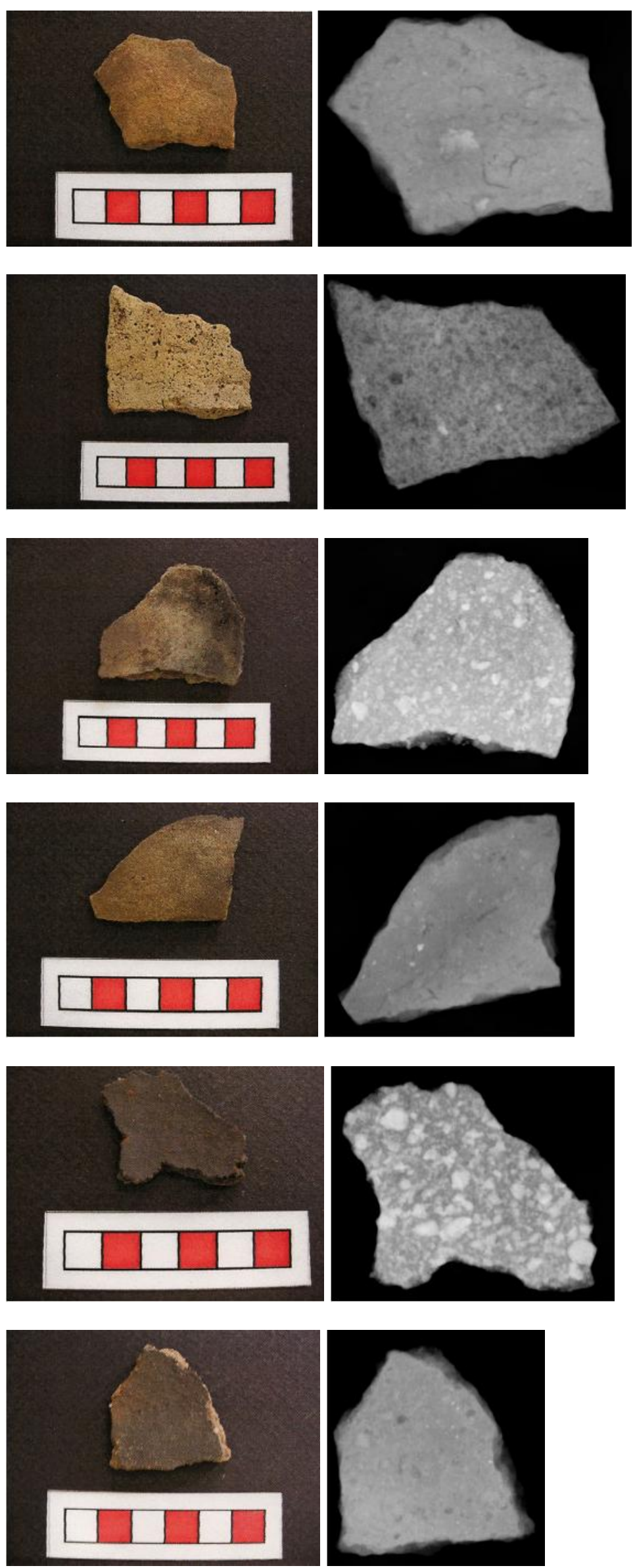
Peça MI1-992

Sítio MI1

Cultura Pantanal

Espessura $\quad 0,43 \mathrm{~cm}$

Medidas $\mathrm{R}-\mathrm{X}$; XRF

Peça MI1-993

Sítio MI1

Cultura Pantanal

Espessura $\quad 0,60 \mathrm{~cm}$

Medidas R-X; XRF

Peça MI1-997

Sítio MI1

Cultura Pantanal

Espessura $\quad 0,66 \mathrm{~cm}$

Medidas R-X; XRF

Peça MI1-1004

Sítio MI1

Cultura Pantanal

Espessura $\quad 0,64 \mathrm{~cm}$

Medidas R-X; XRF

Peça MI1-1005

Sítio MI1

Cultura Pantanal

Espessura $\quad 0,57 \mathrm{~cm}$

Medidas R-X; XRF

$\begin{array}{ll}\text { Peça } & \text { MI1-1006 } \\ \text { Sítio } & \text { MI1 } \\ \text { Cultura } & \text { Pantanal } \\ \text { Espessura } & 0,85 \mathrm{~cm} \\ \text { Medidas } & \text { R-X; XRF }\end{array}$
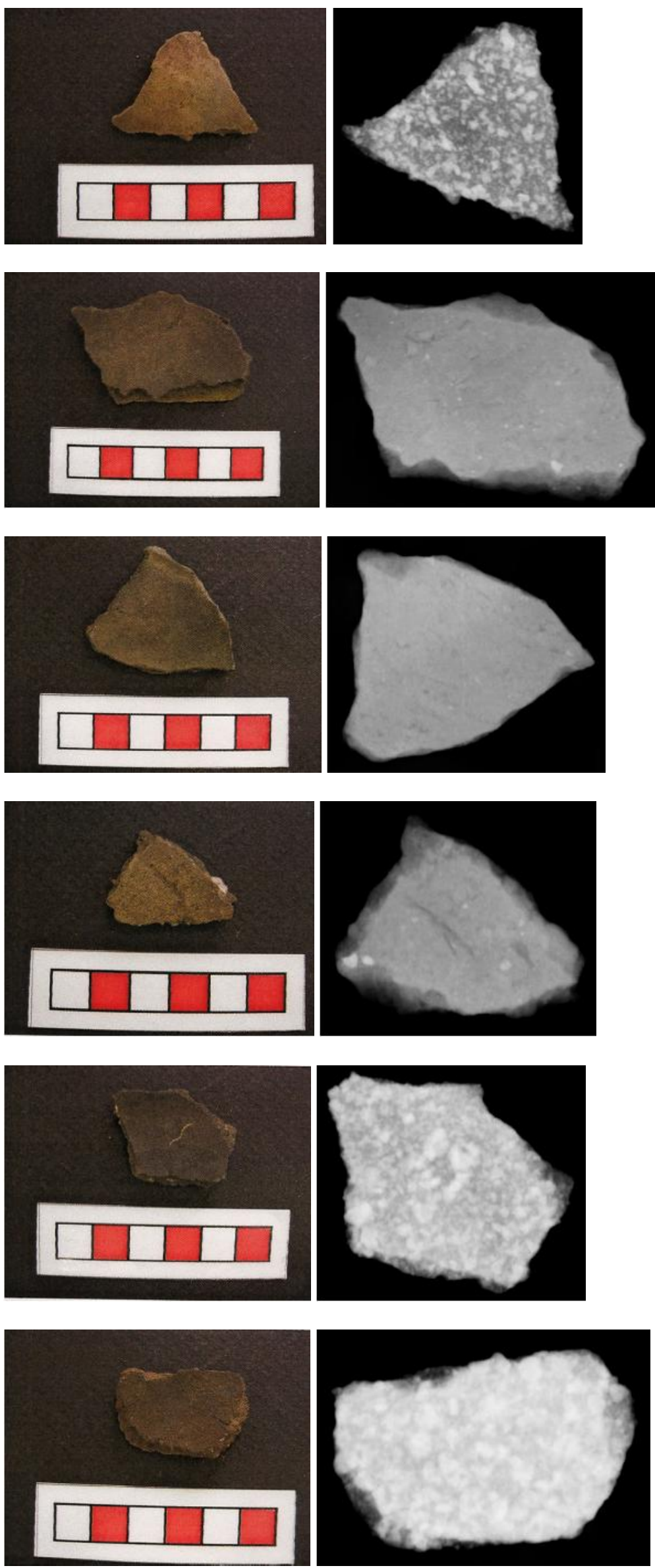


$\begin{array}{ll}\text { Peça } & \text { MI1-1009 } \\ \text { Sítio } & \text { MI1 } \\ \text { Cultura } & \text { Pantanal } \\ \text { Espessura } & 0,69 \mathrm{~cm} \\ \text { Medidas } & \mathrm{R}-\mathrm{X} ; \mathrm{XRF}\end{array}$

Peça MI1-1011

Sítio MI1

Cultura Pantanal

Espessura $\quad 0,74 \mathrm{~cm}$

Medidas R-X; XRF

$\begin{array}{ll}\text { Peça } & \text { MI1-1012 } \\ \text { Sítio } & \text { MI1 } \\ \text { Cultura } & \text { Pantanal } \\ \text { Espessura } & 0,62 \mathrm{~cm} \\ \text { Medidas } & \text { R-X; XRF }\end{array}$

$\begin{array}{ll}\text { Peça } & \text { MI1-1015 } \\ \text { Sítio } & \text { MI1 } \\ \text { Cultura } & \text { Pantanal } \\ \text { Espessura } & 0,64 \mathrm{~cm} \\ \text { Medidas } & \mathrm{R}-\mathrm{X} ; \mathrm{XRF}\end{array}$

Peça MI1-1016

Sítio MI1

Cultura Pantanal

Espessura $\quad 0,63 \mathrm{~cm}$

Medidas R-X; XRF

$\begin{array}{ll}\text { Peça } & \text { MI1-1017 } \\ \text { Sítio } & \text { MI1 } \\ \text { Cultura } & \text { Pantanal } \\ \text { Espessura } & 0,65 \mathrm{~cm} \\ \text { Medidas } & \text { R-X; XRF; PIXE }\end{array}$
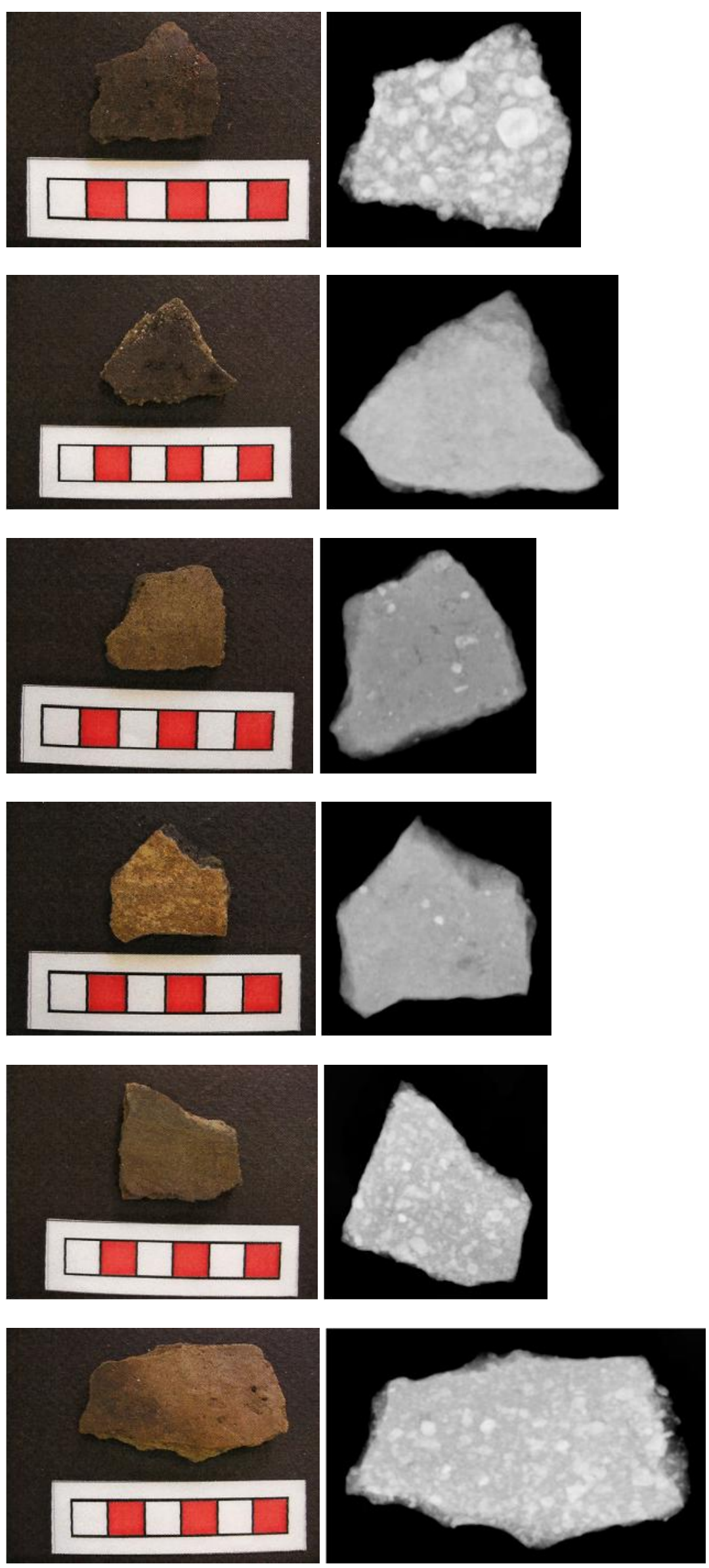
Peça MI1-1019

Sítio MI1

Cultura Pantanal

Espessura $1,06 \mathrm{~cm}$

Medidas $\mathrm{R}-\mathrm{X}$; XRF

Peça MI1-1023

Sítio MI1

Cultura Pantanal

Espessura $0,78 \mathrm{~cm}$

Medidas R-X

Peça MI1-1024

Sítio MI1

Cultura Pantanal

Espessura $\quad 0,51 \mathrm{~cm}$

Medidas R-X; XRF

Peça MI1-1025

Sítio MI1

Cultura Pantanal

Espessura $\quad 0,52 \mathrm{~cm}$

Medidas R-X; XRF

Peça MI1-1026

Sítio MI1

Cultura Pantanal

Espessura $\quad 0,81 \mathrm{~cm}$

Medidas R-X; XRF

$\begin{array}{ll}\text { Peça } & \text { MI1-1027 } \\ \text { Sítio } & \text { MI1 } \\ \text { Cultura } & \text { Pantanal } \\ \text { Espessura } & 0,67 \mathrm{~cm} \\ \text { Medidas } & \text { R-X; XRF }\end{array}$
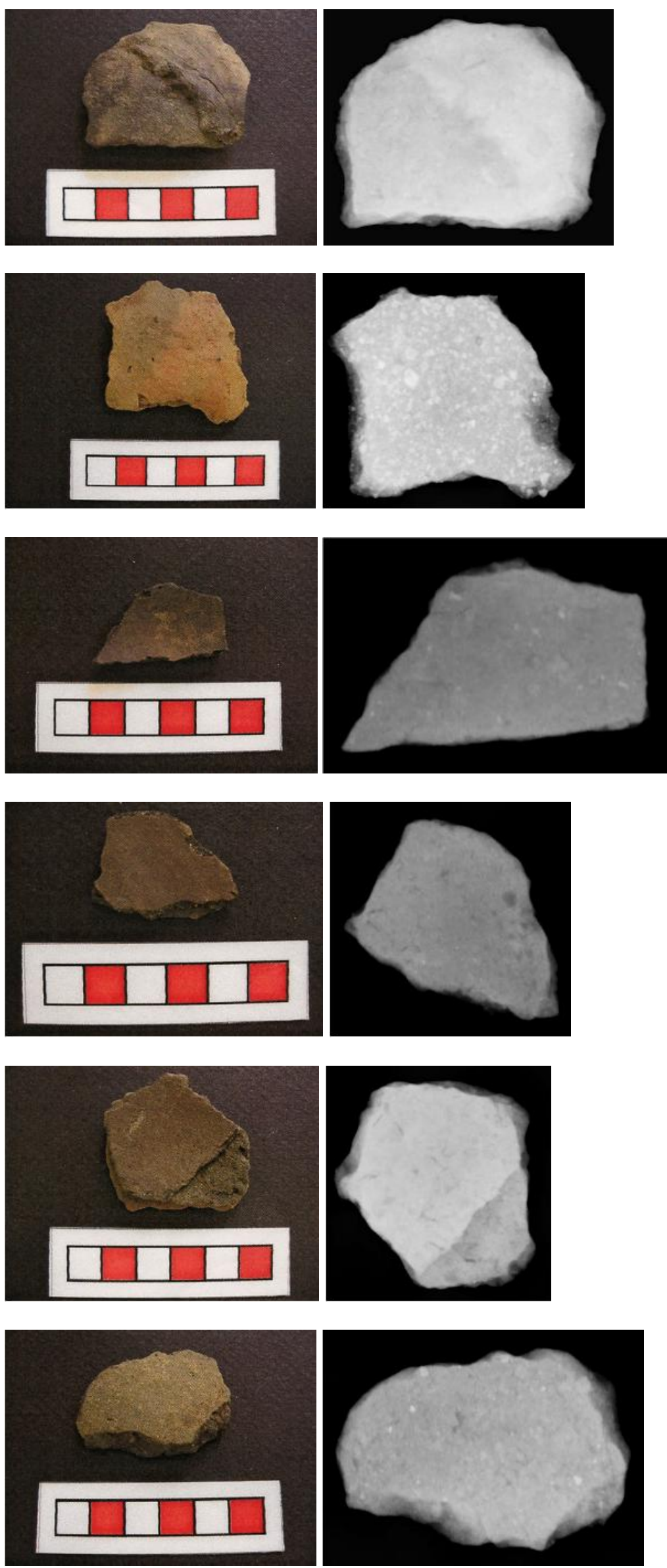


$\begin{array}{ll}\text { Peça } & \text { MI1-1034 } \\ \text { Sítio } & \text { MI1 } \\ \text { Cultura } & \text { Pantanal } \\ \text { Espessura } & 0,72 \mathrm{~cm} \\ \text { Medidas } & \mathrm{R}-\mathrm{X} ; \mathrm{XRF}\end{array}$

Peça MI1-1035

Sítio MI1

Cultura Pantanal

Espessura $\quad 0,61 \mathrm{~cm}$

Medidas R-X; XRF; PIXE

$\begin{array}{ll}\text { Peça } & \text { MI1-1038 } \\ \text { Sítio } & \text { MI1 } \\ \text { Cultura } & \text { Pantanal } \\ \text { Espessura } & 0,43 \mathrm{~cm} \\ \text { Medidas } & \mathrm{R}-\mathrm{X} ; \mathrm{XRF}\end{array}$

Peça MI1-1042

Sítio MI1

Cultura Pantanal

Espessura $0,66 \mathrm{~cm}$

Medidas R-X; XRF

$\begin{array}{ll}\text { Peça } & \text { MI1-1047 } \\ \text { Sítio } & \text { MI1 } \\ \text { Cultura } & \text { Pantanal } \\ \text { Espessura } & 1,10 \mathrm{~cm} \\ \text { Medidas } & \mathrm{R}-\mathrm{X} ; \mathrm{XRF}\end{array}$

$\begin{array}{ll}\text { Peça } & \text { MI1-1900 } \\ \text { Sítio } & \text { MI1 } \\ \text { Cultura } & \text { Guarani } \\ \text { Espessura } & 1,30 \mathrm{~cm} \\ \text { Medidas } & \text { R-X; XRF; PIXE }\end{array}$
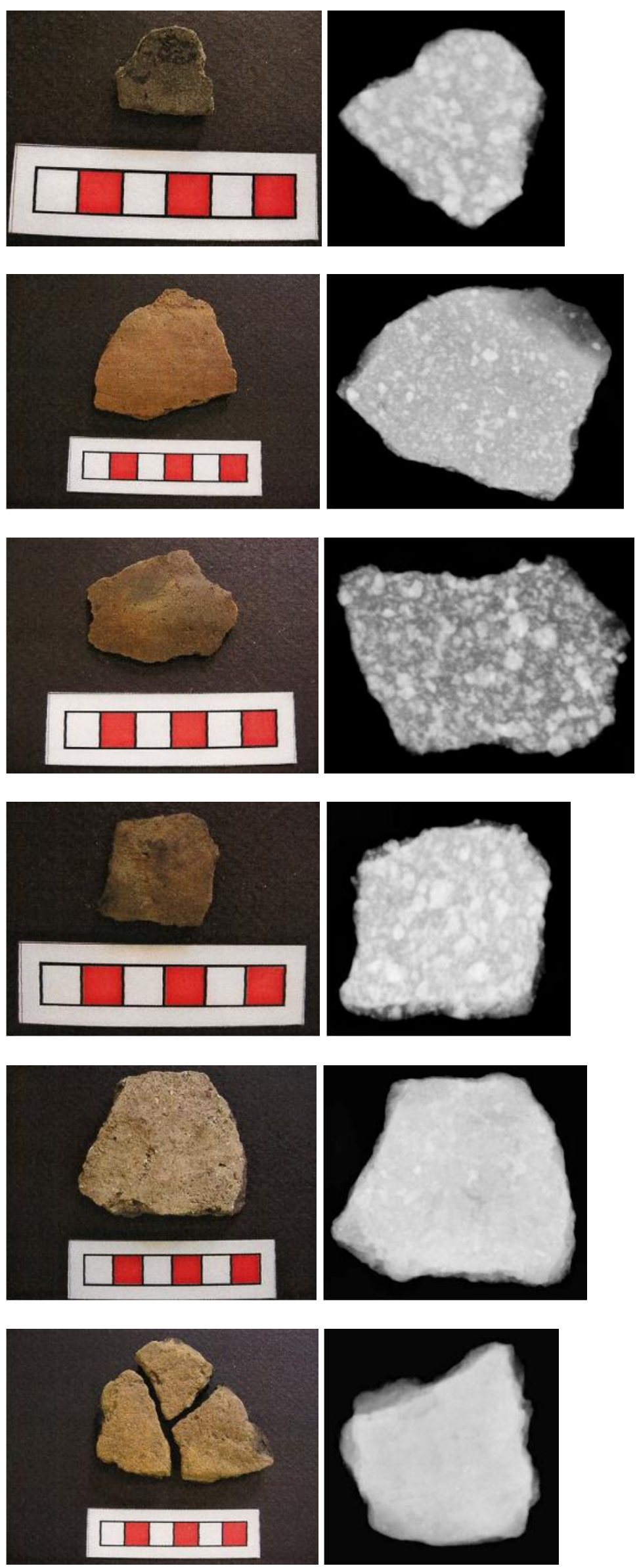


$\begin{array}{ll}\text { Peça } & \text { MI1-1901 } \\ \text { Sítio } & \text { MI1 } \\ \text { Cultura } & \text { Guarani } \\ \text { Espessura } & 0,92 \mathrm{~cm} \\ \text { Medidas } & \text { R-X; XRF; PIXE }\end{array}$

Peça MI1-1902

Sítio MI1

Cultura Guarani

Espessura $\quad 0,73 \mathrm{~cm}$

Medidas R-X; XRF; PIXE

$\begin{array}{ll}\text { Peça } & \text { MI1-1903 } \\ \text { Sítio } & \text { MI1 } \\ \text { Cultura } & \text { Guarani } \\ \text { Espessura } & 1,17 \mathrm{~cm} \\ \text { Medidas } & \mathrm{R}-\mathrm{X} ; \mathrm{XRF}\end{array}$

$\begin{array}{ll}\text { Peça } & \text { MI1-1904 } \\ \text { Sítio } & \text { MI1 } \\ \text { Cultura } & \text { Guarani } \\ \text { Espessura } & 1,15 \mathrm{~cm} \\ \text { Medidas } & \mathrm{R}-\mathrm{X} ; \mathrm{XRF}\end{array}$

$\begin{array}{ll}\text { Peça } & \text { MI1-1905 } \\ \text { Sítio } & \text { MI1 } \\ \text { Cultura } & \text { Guarani } \\ \text { Espessura } & 0,88 \mathrm{~cm} \\ \text { Medidas } & \text { R-X; XRF }\end{array}$

$\begin{array}{ll}\text { Peça } & \text { MI1-1906 } \\ \text { Sítio } & \text { MI1 } \\ \text { Cultura } & \text { Guarani } \\ \text { Espessura } & 0,91 \mathrm{~cm} \\ \text { Medidas } & \text { R-X; XRF; PIXE }\end{array}$
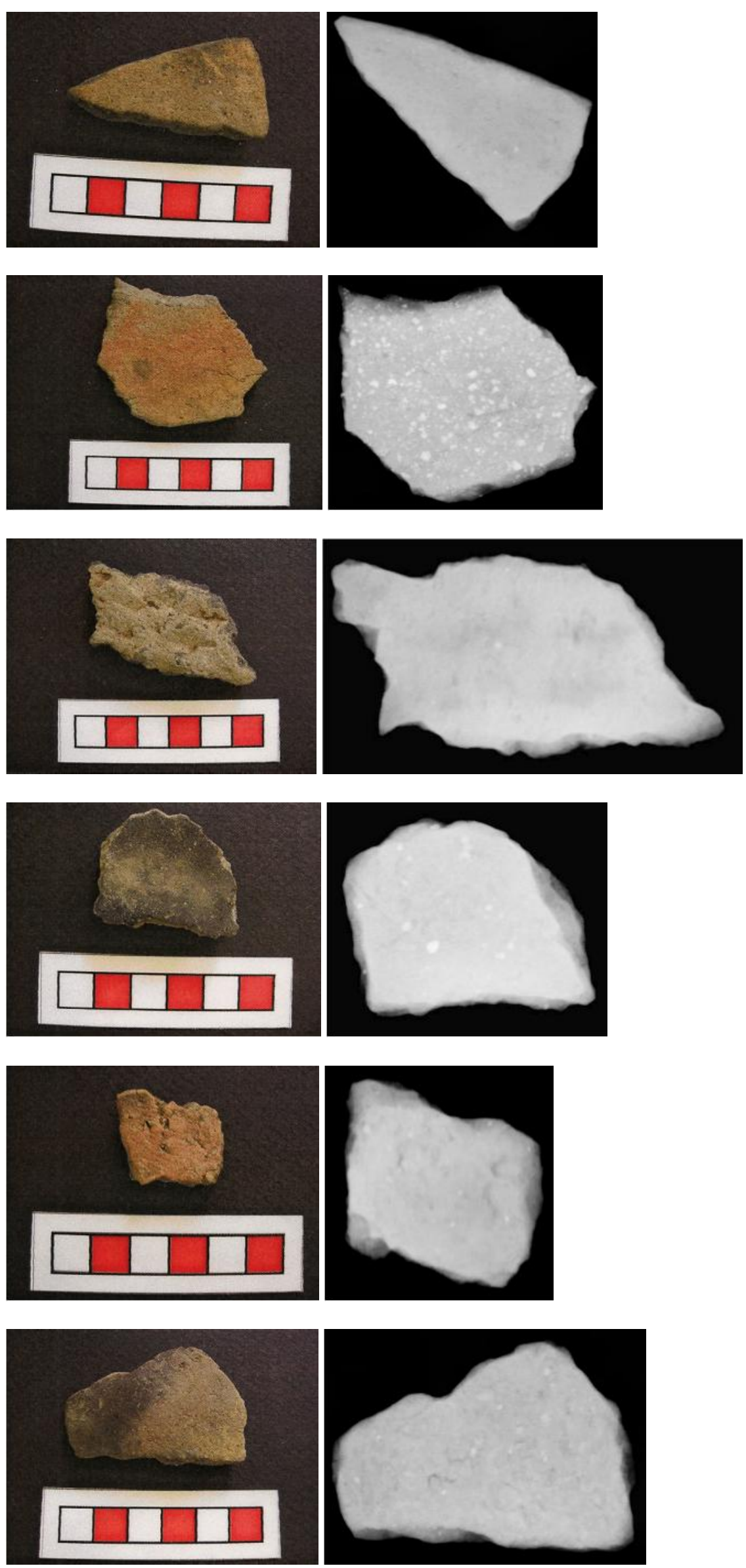
Peça MI1-1907

Sítio MI1

Cultura Guarani

Espessura $\quad 0,72 \mathrm{~cm}$

Medidas R-X
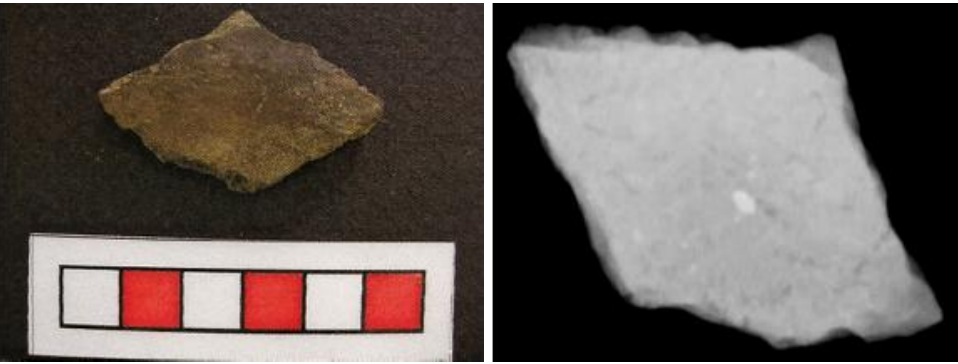

Peça

MI1-1908

Sítio

MI1

Cultura

Guarani

Espessura

$1,12 \mathrm{~cm}$

Medidas

$\mathrm{R}-\mathrm{X} ; \mathrm{XRF}$

Peça MI1-1909

Sítio MI1

Cultura Guarani

Espessura $\quad 0,72 \mathrm{~cm}$

Medidas R-X; XRF

Peça MI1-1910

Sítio MI1

Cultura Guarani

Espessura $\quad 0,78 \mathrm{~cm}$

Medidas R-X; XRF

Peça MI1-1911

Sítio MI1

Cultura Guarani

Espessura $\quad 0,78 \mathrm{~cm}$

Medidas R-X; XRF
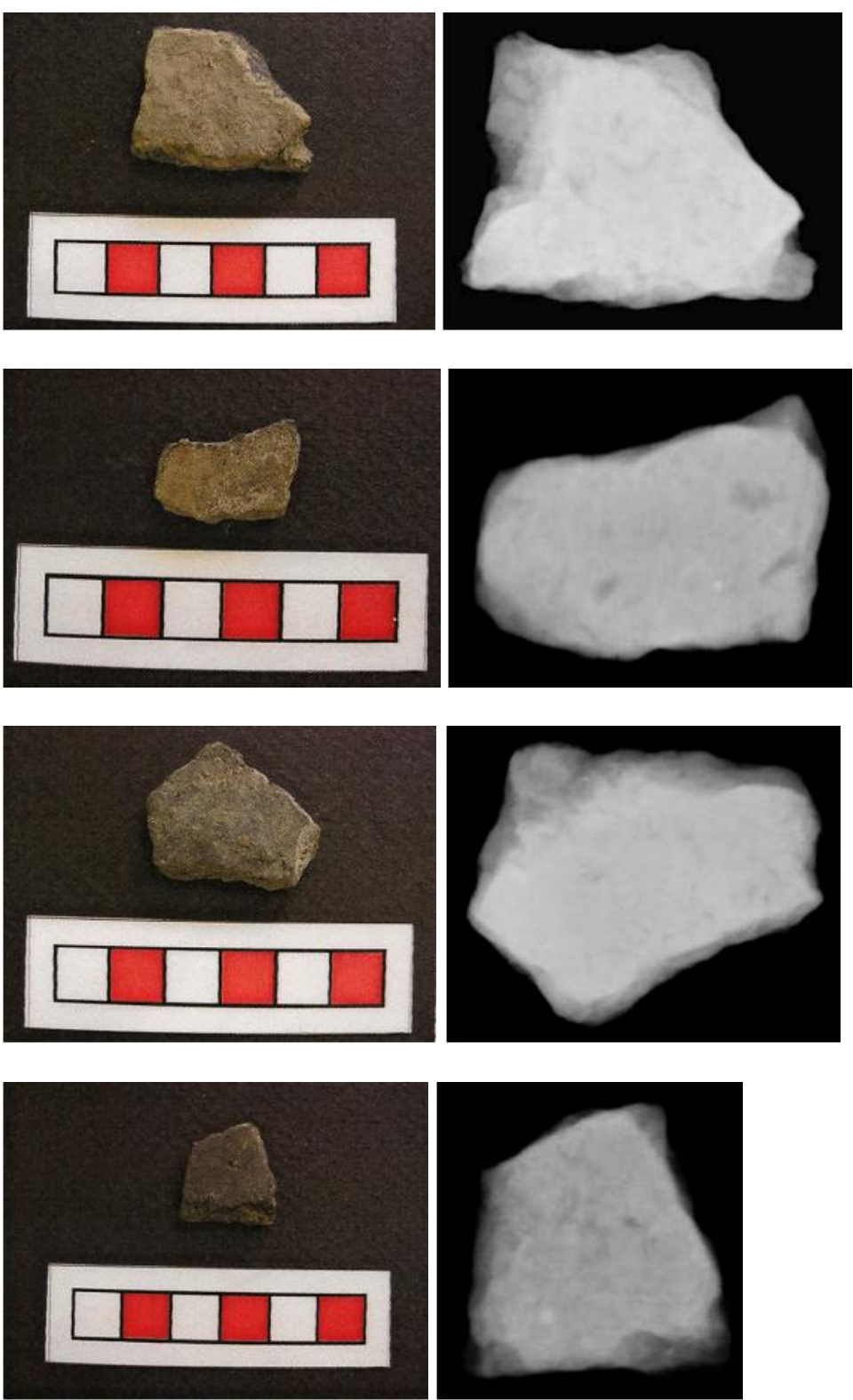

Peça MI1-1912

Sítio MI1

Cultura Guarani

Espessura $\quad 0,80 \mathrm{~cm}$

Medidas R-X; XRF
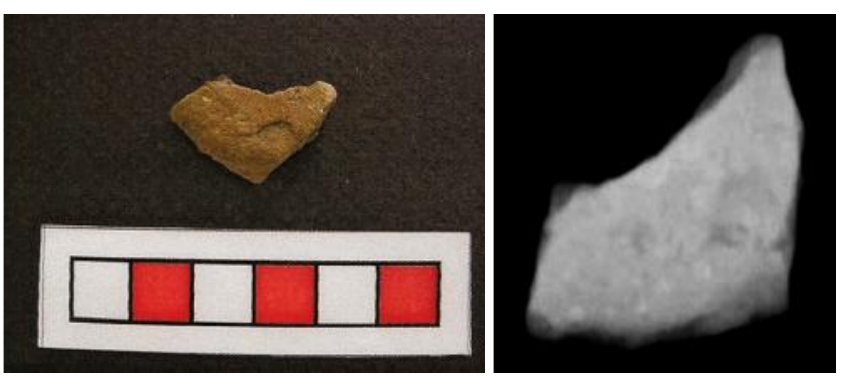
Peça MI1-1913

Sítio MI1

Cultura Guarani

Espessura $\quad 0,51 \mathrm{~cm}$

Medidas R-X; XRF

Peça MI1-1914

Sítio MI1

Cultura Guarani

Espessura $\quad 1,02 \mathrm{~cm}$

Medidas R-X; XRF

Peça MI1-1915

Sítio MI1

Cultura Guarani

Espessura $1,01 \mathrm{~cm}$

Medidas R-X; XRF

Peça MI1-1916

Sítio MI1

Cultura Guarani

Espessura $\quad 0,96 \mathrm{~cm}$

Medidas R-X; XRF

Peça MI1-1917

Sítio MI1

Cultura Guarani

Espessura $\quad 0,64 \mathrm{~cm}$

Medidas R-X; XRF

Peça MI1-1918

Sítio MI1

Cultura Guarani

Espessura $1,26 \mathrm{~cm}$

Medidas R-X; XRF
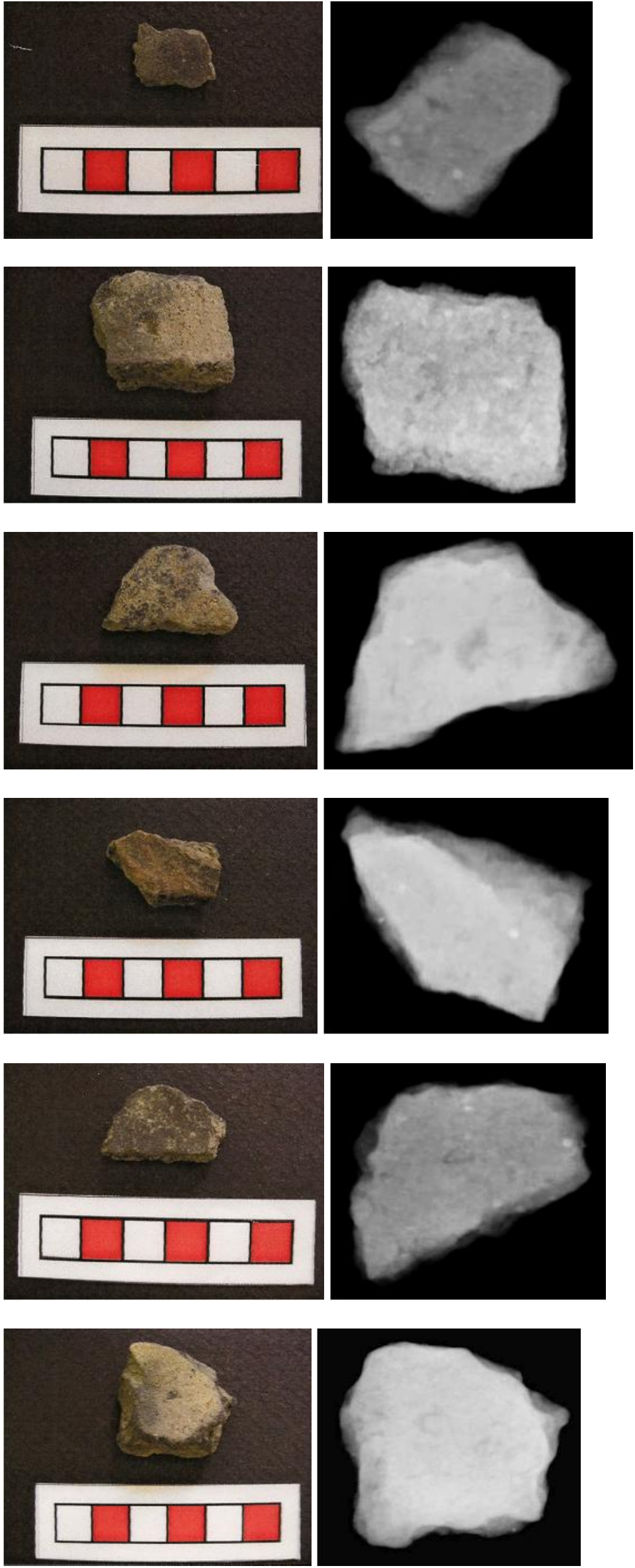
Peça MI1-1919

Sítio MI1

Cultura Guarani

Espessura $1,08 \mathrm{~cm}$

Medidas $\mathrm{R}-\mathrm{X}$; XRF

Peça MI1-1920

Sítio MI1

Cultura Guarani

Espessura $1,09 \mathrm{~cm}$

Medidas R-X; XRF

Peça MI1-1921

Sítio MI1

Cultura Guarani

Espessura $\quad 0,73 \mathrm{~cm}$

Medidas R-X; XRF

Peça MI1-1922

Sítio MI1

Cultura Guarani

Espessura $\quad 0,98 \mathrm{~cm}$

Medidas R-X; XRF

Peça MI1-1923

Sítio MI1

Cultura Guarani

Espessura $1,39 \mathrm{~cm}$

Medidas R-X; XRF

Peça MI1-1924

Sítio MI1

Cultura Guarani

Espessura $1,03 \mathrm{~cm}$

Medidas R-X; XRF
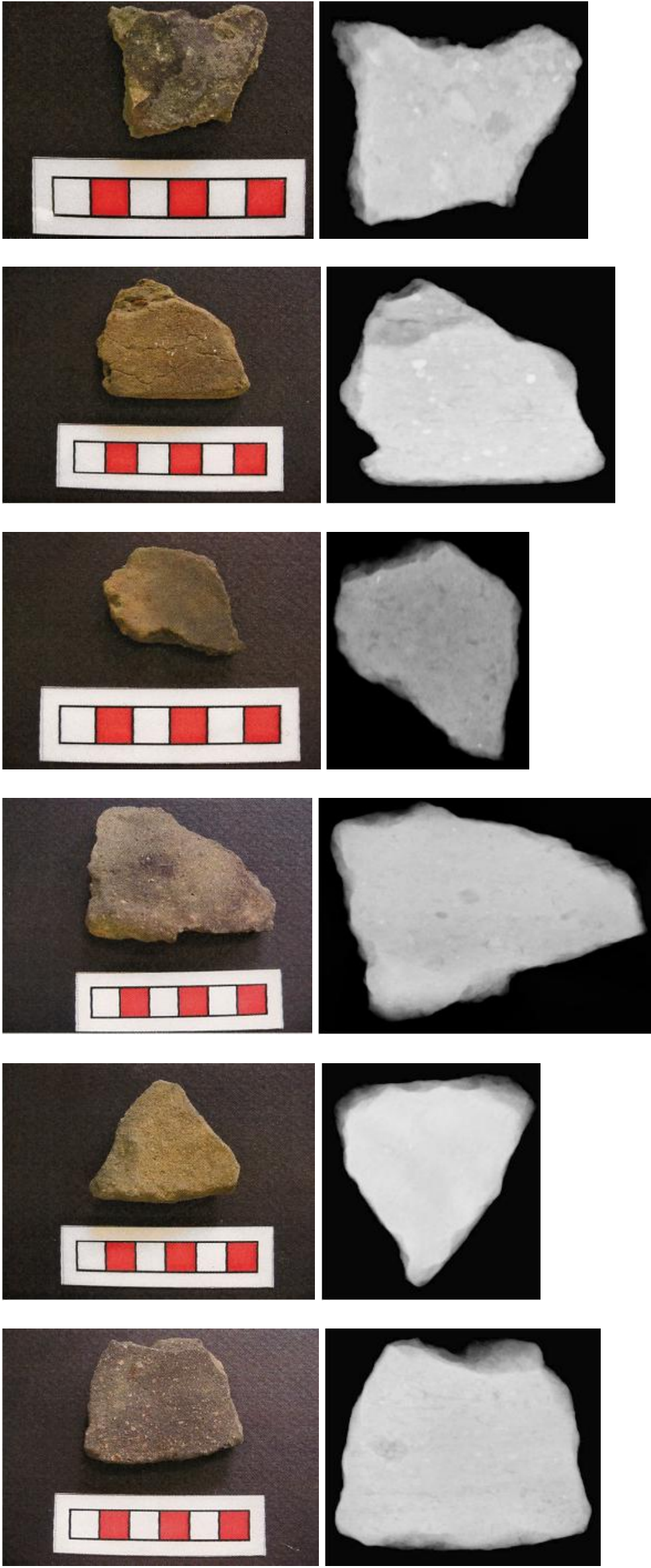
Peça MI1-1925

Sítio MI1

Cultura Guarani

Espessura $\quad 0,97 \mathrm{~cm}$

Medidas R-X; XRF; PIXE

Peça MI1-1926

Sítio MI1

Cultura Guarani

Espessura $1,09 \mathrm{~cm}$

Medidas R-X; XRF

Peça MI1-1927

Sítio MI1

Cultura Guarani

Espessura $1,45 \mathrm{~cm}$

Medidas R-X; XRF

Peça MI1-1928

Sítio MI1

Cultura Guarani

Espessura $1,49 \mathrm{~cm}$

Medidas R-X; XRF

Peça MI1-1929

Sítio MI1

Cultura Guarani

Espessura $\quad 0,99 \mathrm{~cm}$

Medidas R-X; XRF

$\begin{array}{ll}\text { Peça } & \text { MI1-1930 } \\ \text { Sítio } & \text { MI1 } \\ \text { Cultura } & \text { Guarani } \\ \text { Espessura } & 0,57 \mathrm{~cm} \\ \text { Medidas } & \text { R-X; XRF }\end{array}$
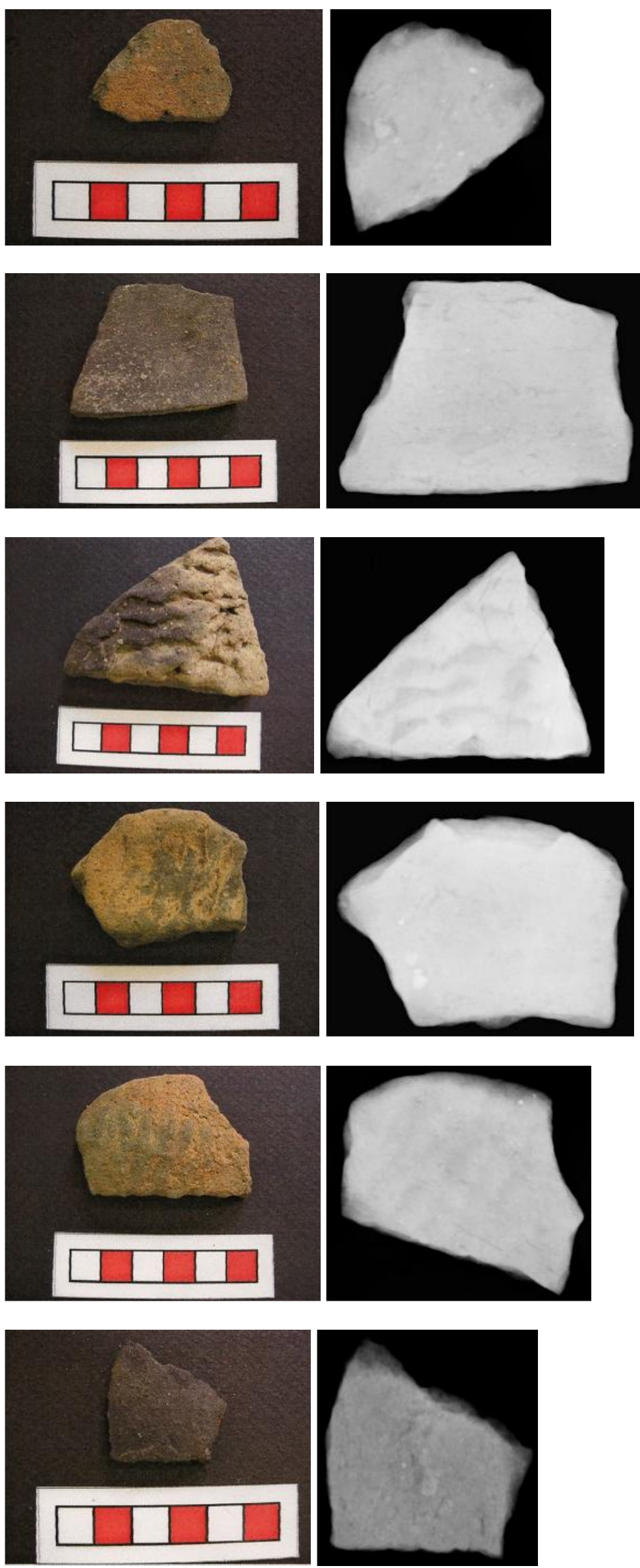


$\begin{array}{ll}\text { Peça } & \text { MI6-3 } \\ \text { Sítio } & \text { MI6 } \\ \text { Cultura } & \text { Pantanal } \\ \text { Espessura } & 0,65 \mathrm{~cm} \\ \text { Medidas } & \text { R-X; XRF; PIXE }\end{array}$

Peça MI6-15

Sítio MI6

Cultura Pantanal

Espessura $\quad 0,74 \mathrm{~cm}$

Medidas R-X; XRF; PIXE

$\begin{array}{ll}\text { Peça } & \text { MI6-18 } \\ \text { Sítio } & \text { MI6 } \\ \text { Cultura } & \text { Pantanal } \\ \text { Espessura } & 0,61 \mathrm{~cm} \\ \text { Medidas } & \text { R-X; XRF; PIXE }\end{array}$

Peça MI6-36

Sítio MI6

Cultura Pantanal

Espessura $\quad 0,70 \mathrm{~cm}$

Medidas R-X; XRF; PIXE

$\begin{array}{ll}\text { Peça } & \text { MI6-50 } \\ \text { Sítio } & \text { MI6 } \\ \text { Cultura } & \text { Pantanal } \\ \text { Espessura } & 0,75 \mathrm{~cm} \\ \text { Medidas } & \text { R-X; XRF; PIXE }\end{array}$

$\begin{array}{ll}\text { Peça } & \text { MI6-59 } \\ \text { Sítio } & \text { MI6 } \\ \text { Cultura } & \text { Pantanal } \\ \text { Espessura } & 0,65 \mathrm{~cm} \\ \text { Medidas } & \text { R-X; XRF; PIXE }\end{array}$
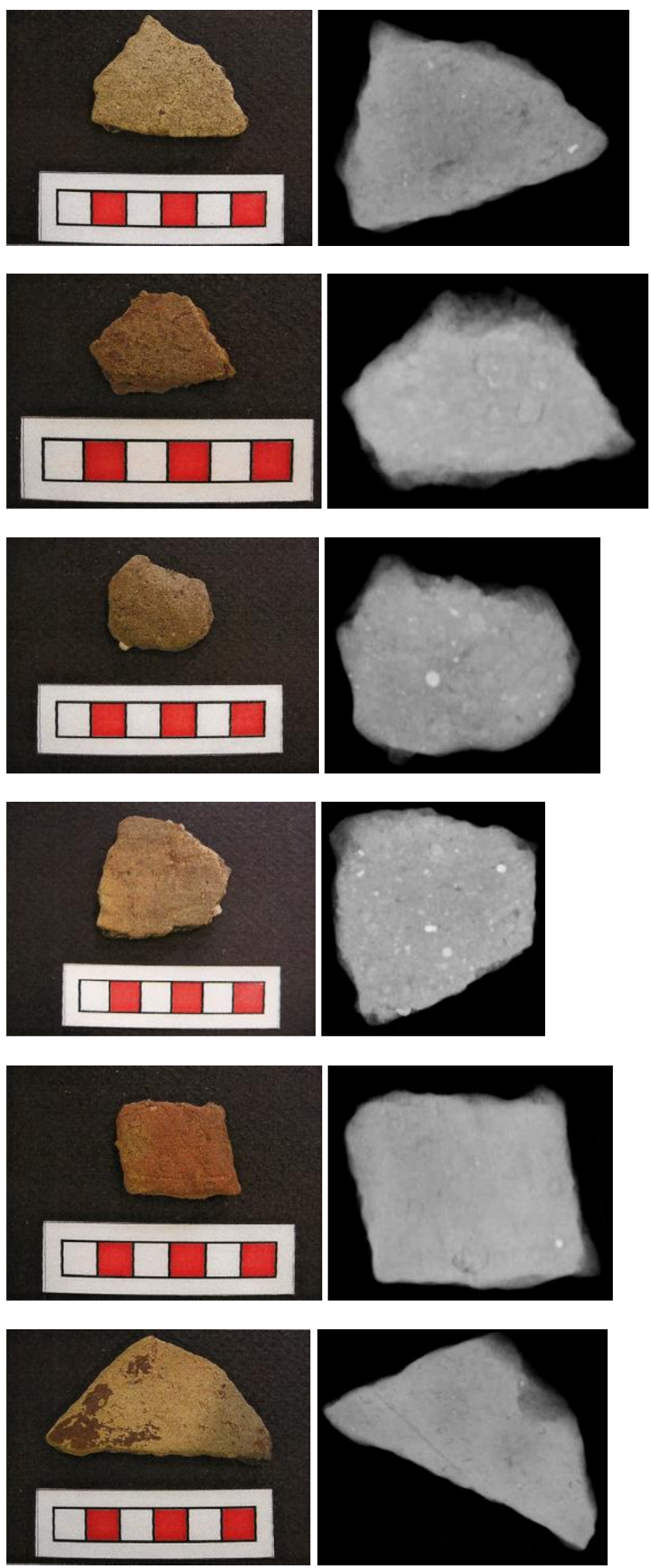
Peça MI6-80

Sítio MI6

Cultura Pantanal

Espessura $\quad 0,77 \mathrm{~cm}$

Medidas R-X; XRF; PIXE

Peça MI6-81

Sítio MI6

Cultura Pantanal

Espessura $\quad 0,77 \mathrm{~cm}$

Medidas R-X; XRF; PIXE

$\begin{array}{ll}\text { Peça } & \text { MI6-86 } \\ \text { Sítio } & \text { MI6 } \\ \text { Cultura } & \text { Guarani } \\ \text { Espessura } & 0,74 \mathrm{~cm} \\ \text { Medidas } & \text { R-X; XRF; PIXE }\end{array}$

Peça MI6-128

Sítio MI6

Cultura Guarani

Espessura $1,58 \mathrm{~cm}$

Medidas R-X; XRF; PIXE

$\begin{array}{ll}\text { Peça } & \text { MI6-132 } \\ \text { Sítio } & \text { MI6 } \\ \text { Cultura } & \text { Guarani } \\ \text { Espessura } & 0,78 \mathrm{~cm} \\ \text { Medidas } & \text { R-X; XRF; PIXE }\end{array}$

Peça MI6-139

Cultura Pantanal

Espessura $\quad 0,77 \mathrm{~cm}$

Medidas R-X; XRF; PIXE
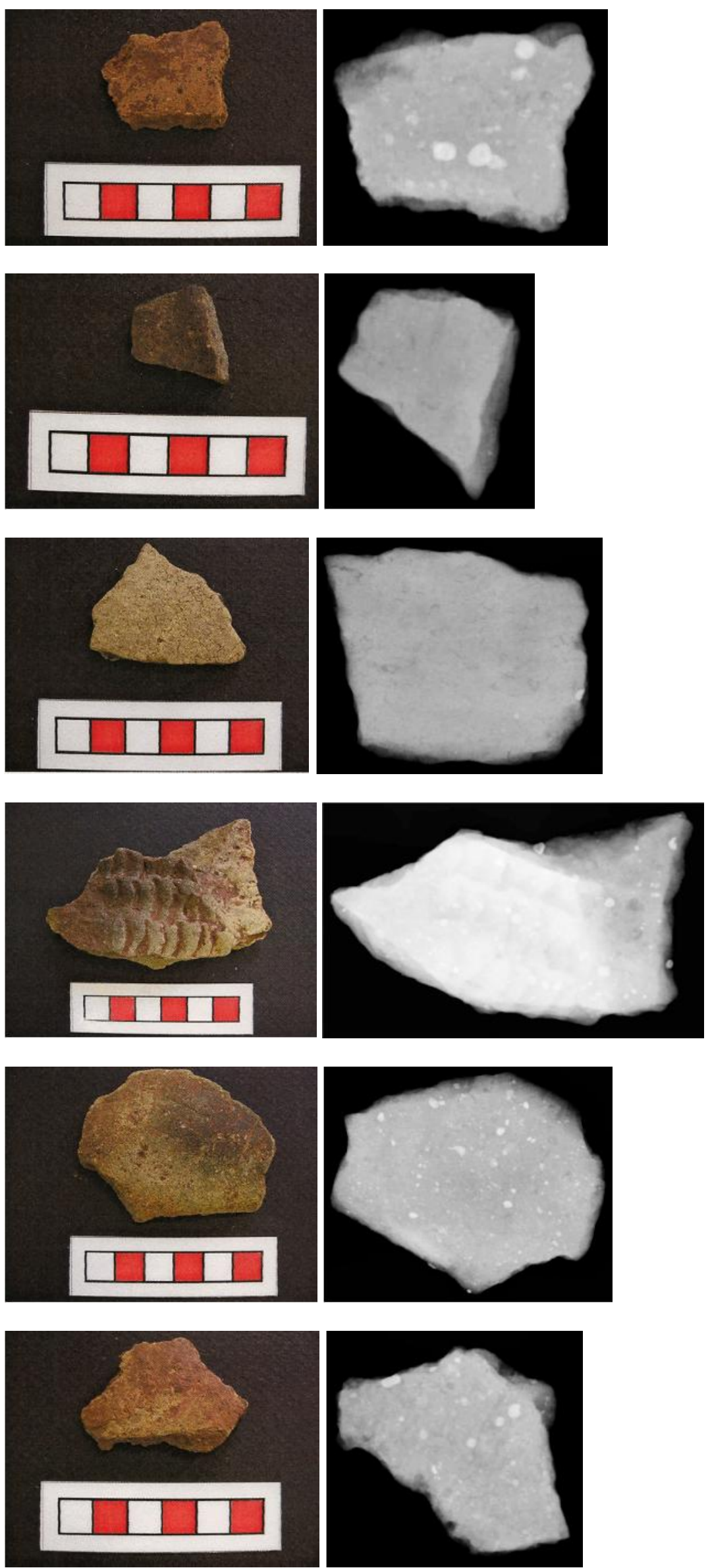
Peça MI6-149

Sítio MI6

Cultura Guarani

Espessura $\quad 0,68 \mathrm{~cm}$

Medidas $\mathrm{R}-\mathrm{X}$; XRF

Peça MI6-150

Sítio MI6

Cultura Guarani

Espessura $\quad 0,85 \mathrm{~cm}$

Medidas $\quad \mathrm{R}-\mathrm{X}$; XRF; PIXE

$\begin{array}{ll}\text { Peça } & \text { MI6-154 } \\ \text { Sítio } & \text { MI6 } \\ \text { Cultura } & \text { Guarani } \\ \text { Espessura } & 0,76 \mathrm{~cm} \\ \text { Medidas } & \text { R-X; XRF; PIXE }\end{array}$

Peça MI6-160

Sítio MI6

Cultura Guarani

Espessura $\quad 0,70 \mathrm{~cm}$

Medidas R-X; XRF; PIXE

$\begin{array}{ll}\text { Peça } & \text { MI6-167 } \\ \text { Sítio } & \text { MI6 } \\ \text { Cultura } & \text { Guarani } \\ \text { Espessura } & 0,57 \mathrm{~cm} \\ \text { Medidas } & \text { R-X; XRF; PIXE }\end{array}$

$\begin{array}{ll}\text { Peça } & \text { MI6-168 } \\ \text { Sítio } & \text { MI6 } \\ \text { Cultura } & \text { Guarani } \\ \text { Espessura } & 1,19 \mathrm{~cm} \\ \text { Medidas } & \text { R-X; XRF }\end{array}$
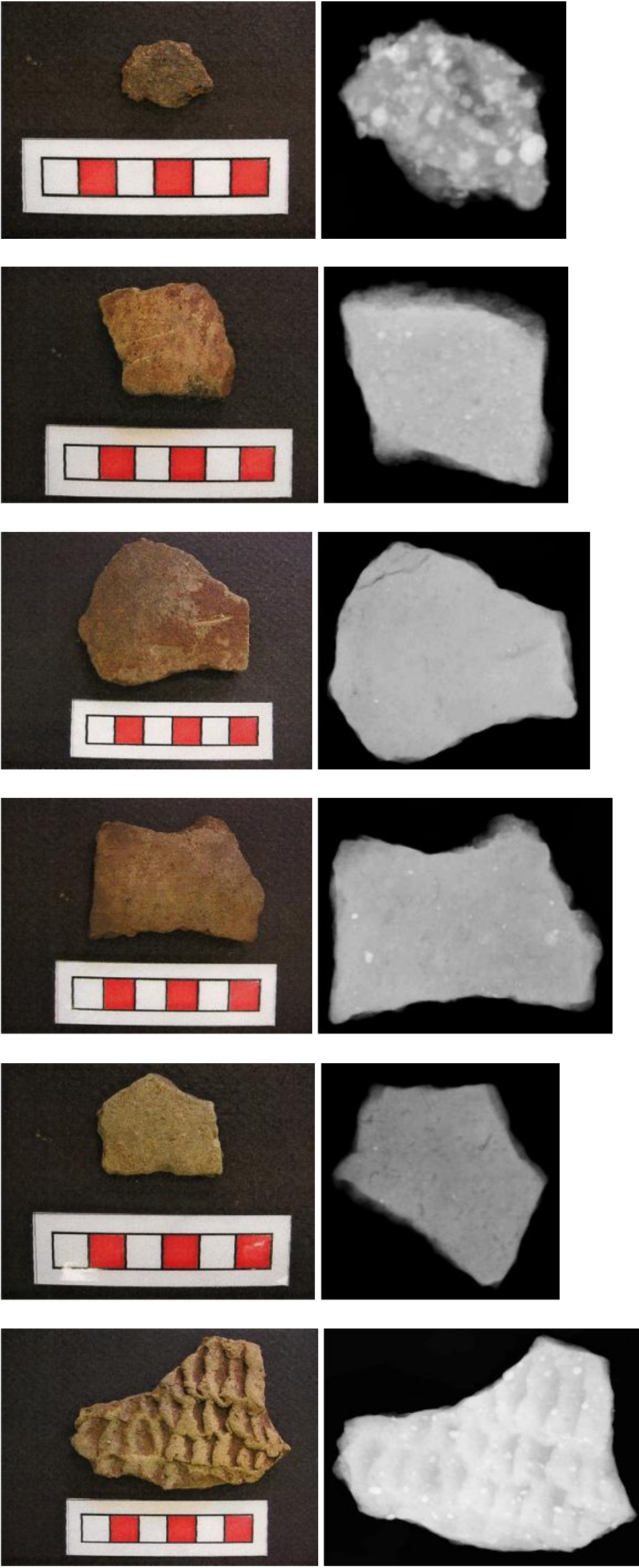


$\begin{array}{ll}\text { Peça } & \text { MI6-374 } \\ \text { Sítio } & \text { MI6 } \\ \text { Cultura } & \text { Pantanal } \\ \text { Espessura } & 0,52 \mathrm{~cm} \text {; PIXE } \\ \text { Medidas } & \text { R-X; XRF }\end{array}$

Peça MI6-389

Sítio MI6

Cultura Pantanal

Espessura $\quad 0,35 \mathrm{~cm}$

Medidas R-X; XRF; PIXE

$\begin{array}{ll}\text { Peça } & \text { MI6-390 } \\ \text { Sítio } & \text { MI6 } \\ \text { Cultura } & \text { Pantanal } \\ \text { Espessura } & 0,68 \mathrm{~cm} \\ \text { Medidas } & \text { R-X; XRF }\end{array}$

Peça MI6-391

Sítio MI6

Cultura Pantanal

Espessura $\quad 0,51 \mathrm{~cm}$

Medidas R-X; XRF

$\begin{array}{ll}\text { Peça } & \text { MI6-392 } \\ \text { Sítio } & \text { MI6 } \\ \text { Cultura } & \text { Pantanal } \\ \text { Espessura } & 0,43 \mathrm{~cm} \\ \text { Medidas } & \mathrm{R}-\mathrm{X} \text {; XRF }\end{array}$

$\begin{array}{ll}\text { Peça } & \text { MI6-393 } \\ \text { Sítio } & \text { MI6 } \\ \text { Cultura } & \text { Pantanal } \\ \text { Espessura } & 0,61 \mathrm{~cm} \\ \text { Medidas } & \mathrm{R}-\mathrm{X} ; \mathrm{XRF}\end{array}$
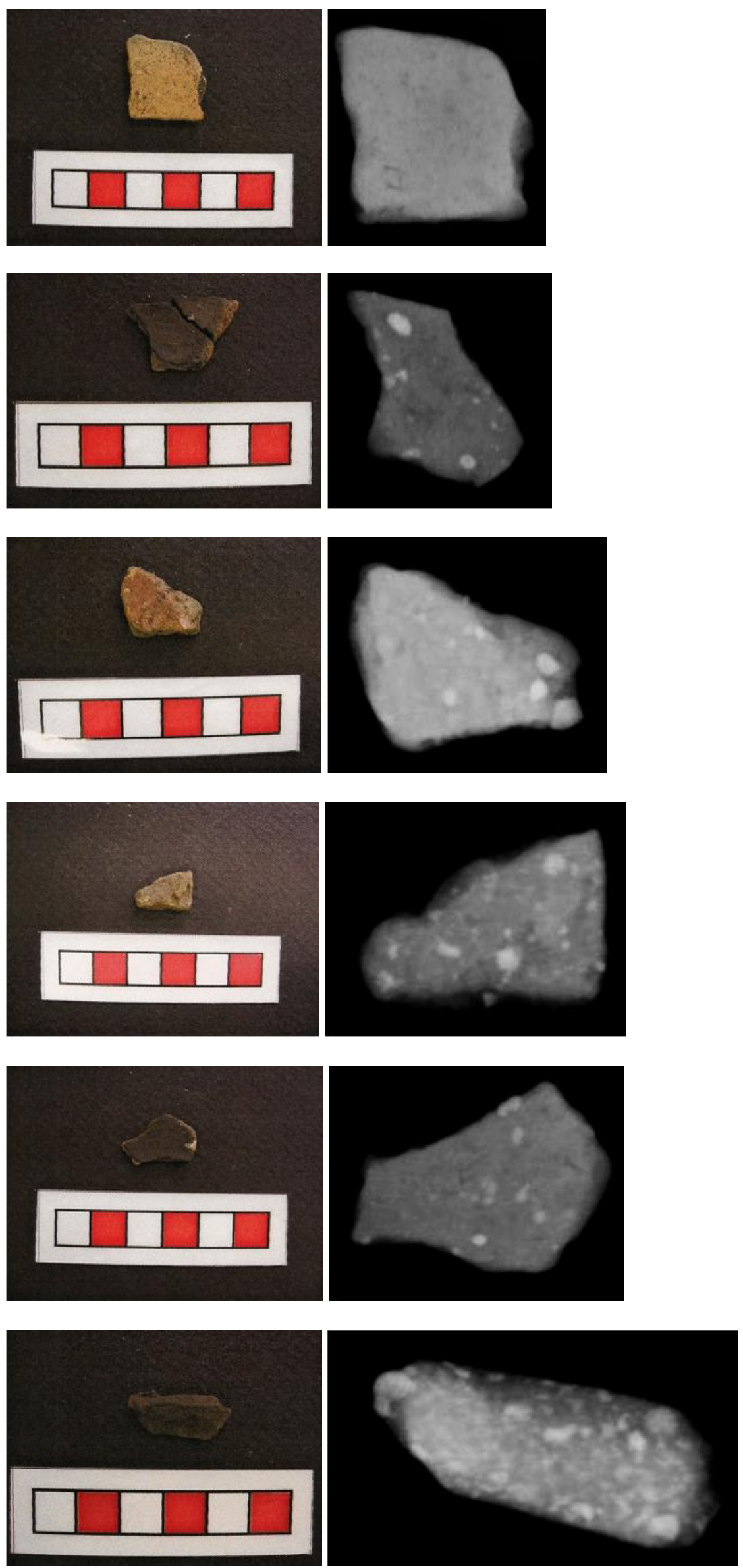


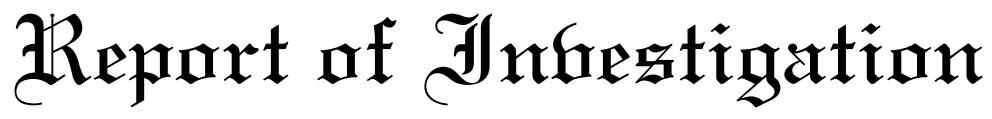 \\ Reference Material 8704
}

\author{
Buffalo River Sediment
}

This Reference Material (RM) is intended primarily for use in the analysis of sediments, soils, or materials of a similar matrix. A unit of RM 8704 consists of $50 \mathrm{~g}$ of freeze-dried, radiation-sterilized, homogenized, river sediment that is very similar in composition to SRM 2704, Buffalo River Sediment, having been collected at the same time and location (see "Source and Preparation of Material").

Reference Concentration Values: Reference values for concentrations of 25 elements are given in Table 1. Reference values are noncertified values that are the best estimate of the true value; however, the values do not meet the NIST criteria for certification and are provided with associated uncertainties that may not include all sources of uncertainty.

Information Concentration Value: An information value for arsenic is provided in Table 2. An information value is a noncertified value for which there is insufficient information to assign an uncertainty.

Expiration of Reference Values: The reference values of RM 8704 are valid, within the measurement uncertainties specified, until 01 December 2017, provided the RM is handled in accordance with instructions given in this report (see "Instructions for Use"). The reference values are nullified if the RM is contaminated or otherwise modified.

Maintenance of Reference Values: NIST will monitor this RM over the period of its validity. If substantive technical changes occur that affect the reference values before the expiration of this report, NIST will notify the purchaser. Registration (see attached sheet) will facilitate notification.

Statistical consultation was provided by W.F. Guthrie of the NIST Statistical Engineering Division.

The overall direction and coordination of the analyses were provided by G.C. Turk of the NIST Analytical Chemistry Division.

Spectrometric measurements were performed by A.P. Lindstrom, G.C. Turk, L.J. Wood, and L.L. Yu of the NIST Analytical Chemistry Division. Instrumental Neutron Activation Analysis was performed by R.R. Greenberg of the NIST Analytical Chemistry Division.

Support aspects involved in the issuance of this SRM were coordinated through the NIST Measurement Services Division.

Gaithersburg, MD 20899

Report Issue Date: 08 January 2008

See Report Revision History on Last Page
Stephen A. Wise, Chief Analytical Chemistry Division

Robert L. Watters, Jr., Chief Measurement Services Division 


\section{SOURCE, PREPARATION, AND ANALYSIS}

Source and Preparation of Material ${ }^{1}$ : The river sediment for SRM 2704 Buffalo River Sediment and RM 8704 Buffalo River Sediment was collected from the Buffalo River in the area of the Ohio Street Bridge, Buffalo, NY. The U.S. Army Corps of Engineers, under contract to NIST, collected and screened approximately $908 \mathrm{~kg}$ of river sediment and placed it in six 55-gallon, Teflon ${ }^{\circledR}$-lined drums. The drums were loaded onto a refrigerated truck and transported to the Technimed Corporation, Fort Lauderdale, FL for freeze-drying of the contents. The freeze-dried sediment was shipped to a laboratory contracted by NIST where it was screened and passed through a $150 \mu \mathrm{m}$ (100 mesh) sieve and retained on a $38 \mu \mathrm{m}$ (400 mesh) sieve. The SRM 2704 portion of the freeze-dried sediment was sieved and blended at NIST and subsequently radiation-sterilized, and bottled into $50 \mathrm{~g}$ units. The RM 8704 portion of the freeze-dried and sieved sediment was retained for approximately 6 years before being blended, radiation-sterilized, divided by a spinning riffler, and bottled into $50 \mathrm{~g}$ units.

\section{Methods of Analysis}

Spectrometric Comparison to SRM 2704: Samples weighing approximately $0.25 \mathrm{~g}$ were taken from each of 8 bottles of RM 8704 and 8 bottles of SRM 2704. The samples were put into solution using a lithium metaborate fusion procedure. The solutions of the two materials were spectrometrically compared using both inductively coupled plasma mass spectrometry (ICPMS) and inductively coupled plasma optical emission spectrometry (ICPOES). Mass fraction values for 18 elements in RM 8704 were calculated from the relative signal intensities (optical and/or mass spectrometric) of RM 8704 versus SRM 2704 and the certified mass fractions of SRM 2704. ICPMS measurements were made for arsenic, barium, calcium, cadmium, cobalt, chromium, copper, iron, magnesium, nickel, lead, titanium, thallium, uranium, vanadium, and zinc. For some elements ICPMS signals were measured at more that one mass, and the equally-weighted mean value was used as the ICPMS value. ICPOES measurements were made for aluminum, barium, calcium, cobalt, chromium, iron, potassium, magnesium, manganese, sodium, lead, titanium, uranium, vanadium, and zinc. For the elements for which both ICPMS and ICPOES measurements were made, the equally-weighted mean value was used.

Combustion Analysis: Carbon was determined in 8 bottles of RM 8704 and 8 bottles of SRM 2704 at LECO Corporation, Inc. using combustion analysis with infrared detection. In a manner analogous to the spectrometric comparison, the mass fraction of carbon was calculated from the relative carbon signals of RM 8704 versus SRM 2704 and the certified mass fraction of carbon in SRM 2704. The sample size was $0.25 \mathrm{~g}$.

Instrumental Neutron Activation Analysis (INAA): Samples weighing approximately $0.25 \mathrm{~g}$ were taken from each of 8 bottles of RM 8704 and 2 bottles of SRM 2704. Using standards prepared from dried filter papers onto which known amounts of the analytes of interest had been deposited, cerium, cobalt, chromium, cesium, europium, iron, hafnium, antimony, scandium, and thorium, were determined by INAA. SRM 2704 was analyzed as a quality control sample.

\section{INSTRUCTIONS FOR USE}

Use: A minimum sample weight of $0.25 \mathrm{~g}$ (dry weight - see "Instructions for Drying") should be used for analytical determinations relating to the reference values on this report of investigation.

Sample preparation procedures should be designed to effect complete dissolution. If volatile elements (i.e., mercury, arsenic, selenium) are to be determined, precautions should be taken in the dissolution of RM 8704 to avoid volatilization losses.

Instructions for Drying: When nonvolatile elements are to be determined, samples should be dried for 2 hours at $110^{\circ} \mathrm{C}$. Volatile elements (i.e., mercury, arsenic, selenium) should be determined on samples as received; separate samples should be dried as previously described to obtain a correction factor for moisture. Correction for moisture is to be made to the data for volatile elements before comparing to the reference values. This procedure, which was used for the determination of the volatile elements, ensures that these elements are not lost during drying. The approximate mass loss on drying has been found to be $0.8 \%$.

\footnotetext{
${ }^{1}$ Certain commercial equipment, instruments, or materials are identified in this report to adequately specify the experimental procedure. Such identification does not imply recommendation or endorsement by the NIST, nor does it imply that the materials or equipment identified are necessarily the best available for the purpose.
} 
Table 1. Reference Concentration Values for Selected Elements for RM 8704

\begin{tabular}{|c|c|c|c|}
\hline Element & \multicolumn{3}{|c|}{ Mass Fraction (\%) } \\
\hline Aluminum & 6.10 & \pm & 0.18 \\
\hline Calcium & 2.641 & \pm & 0.083 \\
\hline Carbon & 3.351 & \pm & 0.017 \\
\hline Iron & 3.97 & \pm & 0.10 \\
\hline Magnesium & 1.200 & \pm & 0.018 \\
\hline Potassium & 2.001 & \pm & 0.041 \\
\hline Sodium & 0.553 & \pm & 0.015 \\
\hline Titanium & 0.457 & \pm & 0.020 \\
\hline Element & \multicolumn{3}{|c|}{ Mass Fraction $(\mathrm{mg} / \mathrm{kg})$} \\
\hline Antimony & 3.07 & \pm & 0.32 \\
\hline Barium & 413 & \pm & 13 \\
\hline Cadmium & 2.94 & \pm & 0.29 \\
\hline Cerium & 66.5 & \pm & 2 \\
\hline Cesium & 5.83 & \pm & 0.12 \\
\hline Chromium & 121.9 & \pm & 3.8 \\
\hline Cobalt & 13.57 & \pm & 0.43 \\
\hline Europium & 1.31 & \pm & 0.038 \\
\hline Hafnium & 8.4 & \pm & 1.5 \\
\hline Lead & 150 & \pm & 17 \\
\hline Manganese & 544 & \pm & 21 \\
\hline Nickel & 42.9 & \pm & 3.7 \\
\hline Scandium & 11.26 & \pm & 0.19 \\
\hline Thorium & 9.07 & \pm & 0.16 \\
\hline Uranium & 3.09 & \pm & 0.13 \\
\hline Vanadium & 94.6 & \pm & 4.0 \\
\hline Zinc & 408 & \pm & 15 \\
\hline
\end{tabular}

Reference Value Uncertainties: The uncertainty in the reference values for aluminum, calcium, potassium, and sodium, derived from spectrometric comparison to SRM 2704 using ICPOES, is expressed as an expanded uncertainty, $U$, at the $95 \%$ level of confidence, and is calculated according to the ISO and NIST Guides [1]. The expanded uncertainty is calculated as $U=k u_{\mathrm{c}}$, where $u_{\mathrm{c}}$ is intended to represent, at the level of one standard deviation, the combined effects of the ICPOES measurement uncertainty and the uncertainty of the SRM 2704 certified value. The uncertainty for the SRM 2704 certified value has been recalculated from the original data according to ISO measurement uncertainty guidelines. The coverage factor, $k$, was obtained from the Student's $t$-distribution corresponding to the calculated effective degrees of freedom of $u_{\mathrm{c}}$ using a level of confidence of $95 \%$.

The uncertainty in the reference values for cadmium and nickel, derived from spectrometric comparison to SRM 2704 using ICPMS, is expressed as an expanded uncertainty, $U$, at the $95 \%$ level of confidence, and is calculated according to the ISO and NIST Guides [1]. The expanded uncertainty is calculated as $U=k u_{\mathrm{c}}$, where $u_{\mathrm{c}}$ is intended to represent, at the level of one standard deviation, the combined effects of the ICPMS measurement uncertainty and the uncertainty of the certified value of SRM 2704. The uncertainty for the certified value of SRM 2704 has been recalculated from the original data according to ISO measurement uncertainty guidelines. The coverage factor, $k$, was obtained from the Student's $t$-distribution corresponding to the calculated effective degrees of freedom of $u_{\mathrm{c}}$ using a level of confidence of $95 \%$.

The uncertainty in the reference values for magnesium, titanium, barium, manganese, lead, uranium, vanadium, and zinc, derived from spectrometric comparison to SRM 2704 using the equally weighted mean of ICPMS and ICPOES measurements, is expressed as an expanded uncertainty, $U$, at the $95 \%$ level of confidence, and is calculated according to the ISO and NIST Guides [1]. The expanded uncertainty is calculated as $U=k u_{\mathrm{c}}$, where $u_{\mathrm{c}}$ is intended to represent, at the level of one standard deviation, the combined effects of the ICPOES measurement uncertainty, the ICPMS measurement uncertainty, and the uncertainty of the SRM 2704 certified value. The uncertainty for the SRM 2704 certified value has been recalculated from the original data according to ISO 
measurement uncertainty guidelines. The coverage factor, $k$, was obtained from the Student's $t$-distribution corresponding to the calculated effective degrees of freedom of $u_{\mathrm{c}}$ using a level of confidence of $95 \%$.

The uncertainty in the reference values for iron, cobalt, and chromium, derived from the equally weighed mean of a spectrometric comparison to SRM 2704 (using both ICPMS and ICPOES) and an independent INAA analysis, is expressed as an expanded uncertainty, $U$, at the $95 \%$ level of confidence, and is calculated according to the ISO and NIST Guides [1]. The expanded uncertainty is calculated as $U=k u_{\mathrm{c}}$, where $u_{\mathrm{c}}$ is intended to represent, at the level of one standard deviation, the combined effects of the uncertainty in the spectrometric comparison (which includes ICPMS measurement uncertainty, ICPOES measurement uncertainty, and the uncertainty of the SRM 2704 certified value), the uncertainty of the INAA measurement, and the uncertainty of corrections for method biases [2]. The uncertainty for the SRM 2704 certified value has been recalculated from the original data according to ISO measurement uncertainty guidelines. The coverage factor, $k$, was obtained from the Student's $t$-distribution corresponding to the calculated effective degrees of freedom of $u_{\mathrm{c}}$ using a level of confidence of $95 \%$.

The uncertainty in the reference values of cerium, cesium, europium, hafnium, antimony, scandium, and thorium, derived from INAA analysis alone, is expressed as an expanded uncertainty, $U$, at the $95 \%$ level of confidence, and is calculated according to the ISO and NIST Guides [1]. The expanded uncertainty is calculated as $U=k u_{\mathrm{c}}$, where $u_{\mathrm{c}}$ is intended to represent, at the level of one standard deviation, the uncertainty of the INAA measurements. The coverage factor, $k$, was obtained from the Student's $t$-distribution corresponding to the calculated effective degrees of freedom of $u_{\mathrm{c}}$ using a level of confidence of $95 \%$.

The uncertainty in the reference value of carbon, derived from comparison to SRM 2704 using combustion analysis, is expressed as an expanded uncertainty, $U$, at the $95 \%$ level of confidence, and is calculated according to the ISO and NIST Guides [1]. The expanded uncertainty is calculated as $U=k u_{\mathrm{c}}$, where $u_{\mathrm{c}}$ is intended to represent, at the level of one standard deviation, the combined effects of the combustion analysis measurement uncertainty and the uncertainty of the SRM 2704 certified value. The uncertainty for the SRM 2704 certified value has been recalculated from the original data according to ISO measurement uncertainty guidelines. The coverage factor, $k$, was obtained from the Student's $t$-distribution corresponding to the calculated effective degrees of freedom of $u_{\mathrm{c}}$ using a level of confidence of $95 \%$.

Table 2. Information Concentration Value for Arsenic for RM 8704

Element Mass Fraction $(\mathrm{mg} / \mathrm{kg})$

Arsenic

17

Information Value for Arsenic: This information value was determined by spectrometric comparison to SRM 2704 using ICPMS after adjusting the certified value of arsenic in SRM 2704 downward by $6 \%$. The adjustment is based on measurements made at NIST since 1996, that indicate the certified value for SRM 2704 is no longer valid due to a loss of approximately $6 \%$ of the arsenic from SRM 2704. The arsenic value in RM 8704 is given for information only because there is insufficient information to assign an uncertainty.

\section{REFERENCES}

[1] ISO; Guide to the Expression of Uncertainty in Measurement; ISBN 92-67-10188-9, 1st ed., International Organization for Standardization: Geneva, Switzerland (1993); see also Taylor, B.N.; Kuyatt, C.E.; Guidelines for Evaluating and Expressing the Uncertainty of NIST Measurement Results; NIST Technical Note 1297, U.S. Government Printing Office: Washington, DC (1994); available at http://physics.nist.gov/Pubs/.

[2] Levenson, M.S.; et al, An ISO GUM Approach to Combining Results from Multiple Methods; unpublished manuscript.

Report Revision History: 08 January 2008 (Update of expiration date and editorial changes); 03 March 2000 (Original certificate date).

Users of this RM should ensure that the certificate in their possession is current. This can be accomplished by contacting the SRM Program at: telephone (301) 975-6776; fax (301) 926-4751; e-mail srminfo@nist.gov; or via the Internet at http://www.nist.gov/srm. 